\title{
Engineering Geology Applied to the Design and Operation of Underground Coal Mines
}

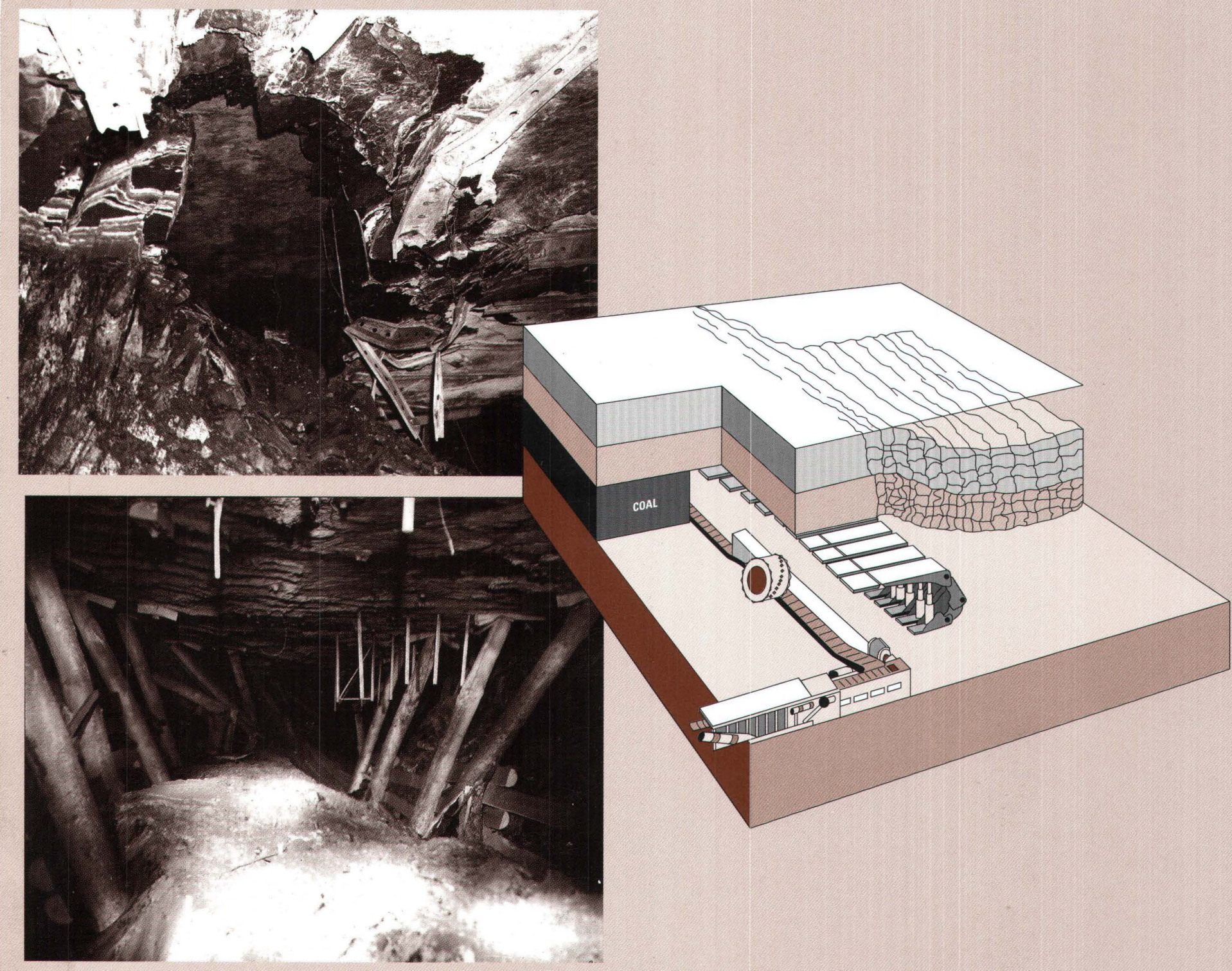

U.S. Geological Survey Bulletin 2147

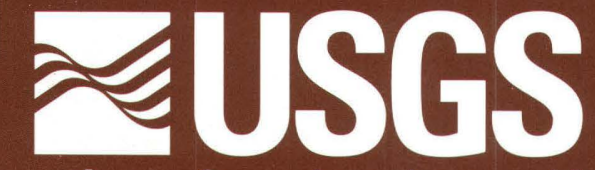


Cover. Long wall versus room-and-pillar mining: The uniform extraction and caving behind the shields of the longwall method (isometric illustration) help to reduce potential rock burst (bump) and squeeze conditions (top and bottom photographs, respectively) produced by the less uniform room-and-pillar mining method. 


\section{Engineering Geology Applied to the Design and Operation of Underground Coal Mines}

By C. Richard Dunrud 


\title{
U.S. DEPARTMENT OF THE INTERIOR BRUCE BABBITT, Secretary
}

\author{
U.S. GEOLOGICAL SURVEY
}

Thomas J. Casadevall, Acting Director

For sale by U.S. Geological Survey, Information Services

Box 25286, Federal Center

Denver, CO 80225

\author{
Any use of trade, product, or firm names in this publication is for descriptive purposes only and \\ does not imply endorsement by the U.S. Government \\ Library of Congress Cataloging-in-Publication Data \\ Dunrud, C. Richard. \\ Engineering geology applied to the design and operation of underground \\ coal mines / by C. Richard Dunrud. \\ p. cm.- (U.S. Geological Survey bulletin : 2147) \\ Includes bibliographical references and index. \\ Supt. of Docs. no.: I 19.3:2147 \\ 1. Coal mines and mining. 2. Engineering geology. 3. Coal-Geology. \\ 4. Ground control (Mining). I. Title. II. Series. \\ TN803.D88 1998 \\ $622^{\prime} .334-\mathrm{dc} 21$ \\ 98-2723 \\ CIP
}




\section{PREFACE}

The following course on engineering geology applied to underground coal mining is being published at the request of geologists and engineers in government and industry. It is an updated version of a 2-week course that was taught to geologists and engineers of State and Federal governments, mining companies, and consulting firms involved in designing, developing, and operating underground coal mines in Brazil. The course was given in September 1984, in São Paulo, S. P., Brazil, at the request of IPT (Instituto de Pesquisas Tecnologicas).

The course has been updated to include geologic and mining information obtained by the author on field visits to various coal mining areas of the Western United States, Yugoslavia, ${ }^{1}$ and Brazil and modified as a result of comments by two U.S. Geological Survey technical reviewers-Bion H. Kent and Mark A. Kirschbaum. Those parts pertaining to coal mining, subsidence, and mine site selection were given in a 2-day course to geologists and engineers of the Federal and State governments and to mining companies in April 1985, at Grand Junction, Colo. The outline was again modified as a result of comments from class participants.

The course discusses in detail how the disciplines of geology and geotechnology, herein called engineering geology, apply to exploration, design, and operation of underground coal mines. It incorporates results of 25 years of research studies on geology and coal mining by the author and also by many scientists in Federal and State governments, in educational institutions, and in the mining industry. ${ }^{2}$ It is intended for practicing scientists, engineering geologists, and engineers. The course material is presented in outline form to facilitate organization, retrieval, and presentation of all or any part of it for a specific use.

The basic goal of the course outline is to show how the disciplines of geology, geotechnology, and mining engineering can be integrated and used to make underground coal mining safer, more efficient, and more environmentally acceptable.

\footnotetext{
${ }^{1}$ The use of the terms Yugoslavia, Bosnia-Hertzegovina, and so on in this report reflects acceptable terminology of the mid-1980's.

${ }^{2}$ The original manuscript of this report was completed and submitted in 1985; the author retired from the U.S. Geological Survey in 1986. References and data have not been updated past 1987.
} 


\section{CONTENTS}

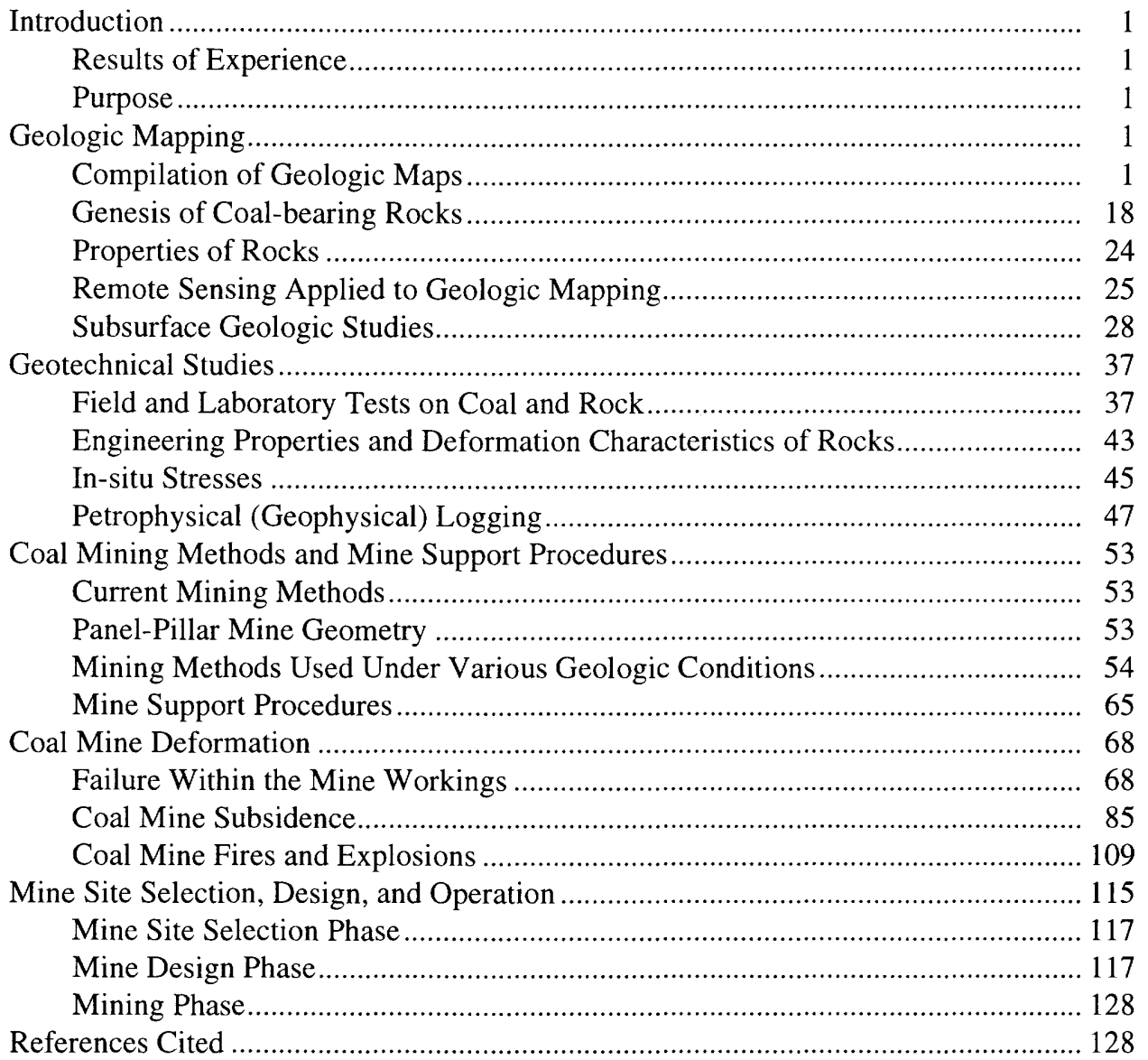

\section{FIGURES}

1. Field geologic map and vertical stereo aerial photographs of coal-bearing rocks in the Cedaredge area, Delta County, Colo.

2. Profiles showing general stratigraphic framework of the coal-bearing rocks of the Mesaverde Formation in the Paonia-Cedaredge area, Delta and Gunnison Counties, Colo.

3. Diagrams showing classification of faults caused by various stress conditions, based on the Mohr and Coulomb theories.

4. Rose diagrams showing the relation between the trends of cleat, joints at the outcrop, and lineaments

5. Profile showing structural relations between sedimentary rocks and laccoliths in the Paonia, Colo., area

6. Profile and logs showing effects of complex intrusive bodies on coal beds in the Eocene Ashford coal field, Pierce County, Wash.

7. Sketch map, cross section, and photograph showing landslides in the Somerset area, Delta County, Colo. ............ 17

8. Sketches and block diagram of models of various depositional environments ................................................... 20

9. Generalized stratigraphic column in Appalachian Basin relating lithology to ratio of rainfall-to-evapotranspiration 21

10. Diagram showing general relationships between peat-forming paleoenvironments and resulting coal quality in Central Appalachian Basin

11. Diagram showing classification of sedimentary rocks by lithology, grain size, and matrix. 
12. Diagram of transmission coefficients of electromagnetic (EM) radiation through the atmosphere as a function of wavelength

13. Diagrammatic profile showing a rotary drill bit, circulation of mud, and intrusion of mud into sides of drill hole. 28

14. Plan view showing reliability categories of outcrop and drill-hole data for classification of coal resources, based on distance from points of measurement.

15. Geologic logs showing lithology, relative resistance to weathering, grain size, and internal characteristics ........... 30

16. Semivariogram of coal thickness showing data points fitted to a spherical model .............................................

17. Map of Anderson coal deposit, Powder River Basin, Wyo., showing estimated thickness determined by Kriging

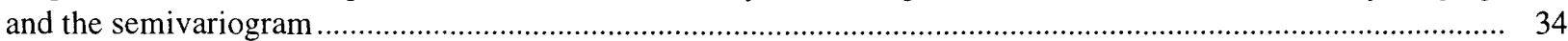

18. Map of Anderson coal deposit showing estimated Kriging variances.............................................................. 35

19. Tabulation of amount of coal in-place in the Anderson coal deposit, by township, in western Wyoming .............. 36

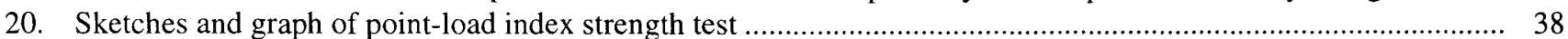

21. Graph to correct point-load index strength to standard core diameter of $50 \mathrm{~mm}$............................................... 39

22. Graph showing correlation between tests of point-load index strength and uniaxial compressive strength ............. 40

23. Geologic and geotechnical log of a core hole located north of Sheridan, Wyo...................................................

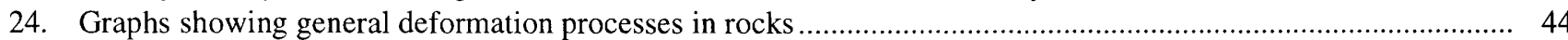

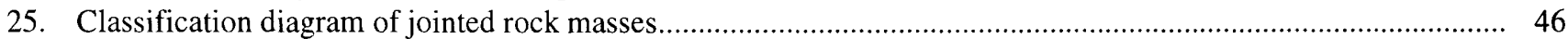

26. Graphs showing relation between vertical and horizontal stress with depth .................................................4

27. Sketch of zones around a mud-filled, rotary drill hole in a permeable sandstone .............................................. 49

28. Logs showing relation between lithology and petrophysical logs ................................................................ 50

29. Lithologic column and diagram showing relation between geologic and geotechnical properties of rocks from drill core and petrophysical logs, Somerset, Colo., area ................................................................................ 51

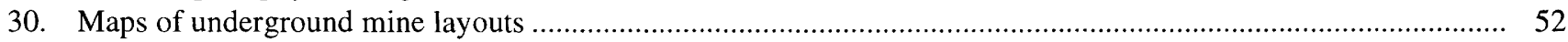

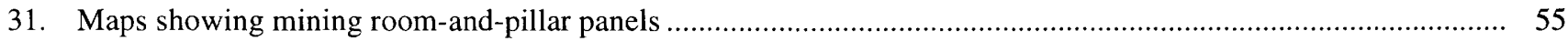

32. Mine sketch maps showing common room-and-pillar mining sequences ........................................................ 56

33. Block diagram showing a typical retreating longwall system ................................................................. 57

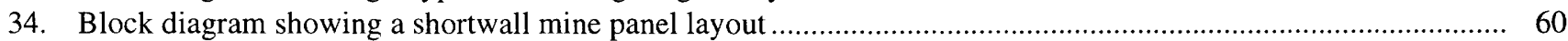

35. Sketch map and cross section showing mining thick coal beds by the double-lift longwall method near Breza, Bosnia-Hertzegovina, [former]Yugoslavia.

36. Sketch map and cross section showing mining thick coal beds by longwall with sublevel caving near Zenica, Bosnia-Hertzegovina, [former] Yugloslavia.

37. Plan and profiles showing a modified room-and-pillar mining method

38. Diagrammatic cross sections of mine openings showing how thick beams are more stable than thin beams .......... 66

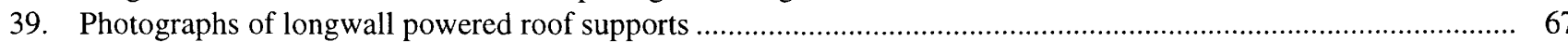

40. Photograph showing unstable mine roof in Somerset, Colo., area ................................................................... 69

41. Photographs and cross sections showing some causes and effects of mining hazards in Somerset, Colo., area ...... 70

42. Photographs and sketches showing structural features that caused severe roof-fall hazards in the Sunnyside coal

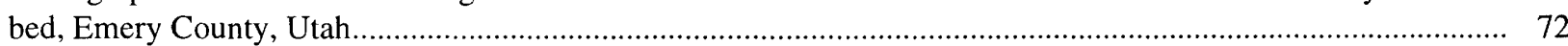

43. Photograph and sketch section showing effects of rock "spars" in the "B" coal bed, Somerset, Colo., area .......... 74

44. Sketch sections and photographs illustrating unstable mine openings caused by lateral tectonic and mine-induced stresses

45. Map and graph showing potential hazards from unstable roofs in southwestern Pennsylvania and northern West Virginia

46. Map and cross section showing conditions caused by rock bursts and bumps in Geneva mine area, Emery County, Utah

47. Map, cross section, and photographs showing damage caused by rock bursts and bumps, Geneva mine area, Emery County, Utah, Oct. 25, 1967.

48. Conceptual diagrams showing general relation of vertical stress to unmined coal and goaf areas in longwall and room-and-pillar extraction panels

49. Mine map location of an outburst in Redstone area, Pitkin County, Colo., 1969

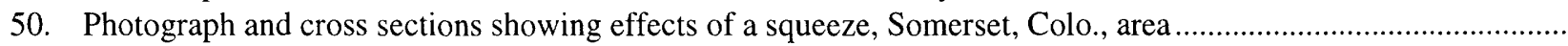

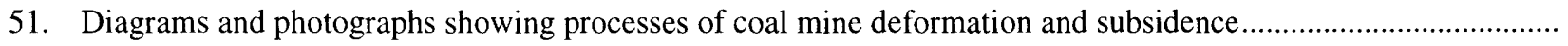

52. Photographs showing caving characteristics at the extraction limits in two room-and-pillar extraction panels .......

53. Graph showing maximum subsidence ratio for Western United States and the United Kingdom..........................

0

4

35

36

9

0

1

44

6

48

4

1

2

5

6

57
60


54. Conceptual subsidence maps and profiles

55. Profile showing laterally constrained plate undergoing downwarping

56. Coal mining and subsidence map and geologic cross section, Somerset area, Colorado........................................ 92

57. Coal mining and subsidence map and profiles, Huntington area, Utah ......................................................... 94

58. Subsidence graphs and map for predicting limit angle, displacement, tilt, and horizontal strain ......................... 98

59. Graph illustrating structural damage in relation to horizontal strain and length of structure.................................. 100

60. Cross sections and photograph showing how faults can control subsidence area ................................................. 101

61. Subsidence development curves for longwall and room-and-pillar extraction panels in Western United States and the United Kingdom

62. Cross sections of coal mine openings showing changes in stability with dip of a jointed roof .............................. 103

63. Sketches illustrating initial stages of stoping in thinly and thickly layered rocks............................................... 103

64. Sketches showing stoping limits controlled by topography, dip of coal, and local presence of strong rocks …....... 104

65. Photograph showing stoping process in the Sheridan area, Wyoming ............................................................ 105

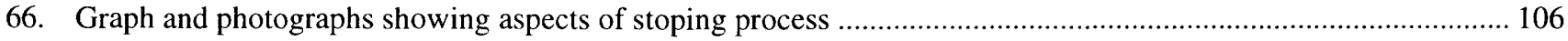

67. Photographs showing potentially hazardous sudden pit development ............................................................. 108

68. Maps, cross sections, and photographs showing block movement above underground coal mines in Colorado and Utah.

69. Maps showing sites of coal explosions in Colorado and [the former] Yugloslavia ................................................. 114

70. Flow diagram showing possible steps in mine site selection, mine design, and operation of underground coal mines

71. Maps showing thickness of the Pittsburgh coal bed and overburden thickness relative to the Pittsburgh coal bed in southwestern Pennsylvania and northern West Virginia.

72. Fence diagram of the Pittsburgh coal bed and overlying rocks, southwestern Pennsylvania and northern West Virginia.....

73. Mine map showing room-and-pillar extraction and longwall mine panels, Huntington area, Utah ........................ 122

74. Composite map showing mine workings and complex mine roof rocks northwest of Helper, Utah...................... 126

75. Maps showing contours of equal percentage of sand in the roofs of two mines in a lower and an upper coal bed, Huntington area, Utah.

\section{TABLE}

1. Maximum allowable subsidence deformations for various group classes of structures in [former] Yugoslavia, Poland, and the former Soviet Union

\section{METRIC CONVERSION TABLE}

Many of the measurements in this report are in feet, miles, and 2,000-pound tons. For some, metric equivalents are presented alongside. For others, conversion factors are as follows:

\begin{tabular}{lll}
\hline To convert & \multicolumn{1}{c}{ To } & Multiply by \\
\hline Feet $(\mathrm{ft})$ & Meters $(\mathrm{m})$ & 0.3048 \\
Miles $(\mathrm{mi})$ & Kilometers $(\mathrm{km})$ & 1.609 \\
$2,000-\mathrm{lb}$ tons & Metric tons $(\mathrm{t})$ & 0.91
\end{tabular}




\title{
Engineering Geology Applied to the Design and Operation of Underground Coal Mines
}

\author{
By C. Richard Dunrud ${ }^{3}$
}

\section{INTRODUCTION}

\section{RESULTS OF EXPERIENCE}

Experience in the United States and in other countries has repeatedly shown that proper pre-mine planning is important to a successful and efficient underground mining operation. The time and money spent in obtaining the necessary geologic and geotechnical information, in order to plan safe and efficient underground coal mines in advance of mining, are only a small fraction of the costs that are often incurred later to reduce hazards to life, property, or the environment after mining is well underway. Hazards such as coal mine bumps and rock bursts; underground fires, water infiltration, and flooding; and subsidence can cause costly redesign and rebuilding, or may even force abandonment of mines that were improperly planned initially. In addition, valuable coal resources may be lost in the process.

Following are some examples of mining hazards and environmental problems in the U.S.:

1. Coal resources and mining equipment have been lost and miners injured or killed in mines that were not designed to be compatible with the geologic and topographic setting; bumps, rock bursts, squeezes, roof falls, and floor heaves have caused premature abandonment of partially mined areas.

2. Many miners have been injured or killed by roof falls every year, particularly where the roofs are inherently weak or where geologic features such as channel deposits and slickensided surfaces weaken the roofs.

3. Many miners have been injured or killed each year in the U.S. by mine explosions and fires.

4. In many areas of the U.S., subsidence and fires in underground mines that were abandoned many years or decades ago are hazards, because many of the areas are becoming prime sites for residential and industrial growth. For example, expenditures by the U.S. Department of the Interior to mitigate emergency and high priority subsidence and fire problems, on lands that have been developed above

\footnotetext{
${ }^{3}$ U.S. Geological Survey, retired; volunteer (Scientist Emeritus).
}

abandoned underground coal mines, reached a total of $\$ 175.7$ million as of March 1985. This total does not include expenditures by other Federal and State agencies (Theodore Ifft, Office of Surface Mining, written commun., 1985).

\section{PURPOSE}

The primary goal of this report is to present, in a systematic outline format, information gained from studies and experience of many geologists, engineers, and miners in the U.S. and other countries in order to

1. Help geologists, engineers, and other mine planners design underground coal mines that are safer, more efficient, and compatible with the environment by incorporating the information presented herein.

2. Ensure that mine planners are more aware of some of the more important geologic and geotechnical factors that control or affect mining.

3. Show how geologic, geotechnical, and mining factors, commonly important to proper mine design, may be incorporated into the planning and design phase of the coal mining operations.

\section{GEOLOGIC MAPPING}

- Maps of geologic features are basic information sources which are useful tools in selecting the best mine sites and designing the safest and most efficient underground mines.

\section{COMPILATION OF GEOLOGIC MAPS}

- Involves gathering all needed information from (1) data searches of library and company files, (2) field geologic mapping, (3) drilling, logging, and on-site geophysics, (4) analysis of stratigraphic framework and genesis of coalbearing rocks, and (5) remote sensing. For best results these procedures commonly are done interactively and to some degree concurrently. 


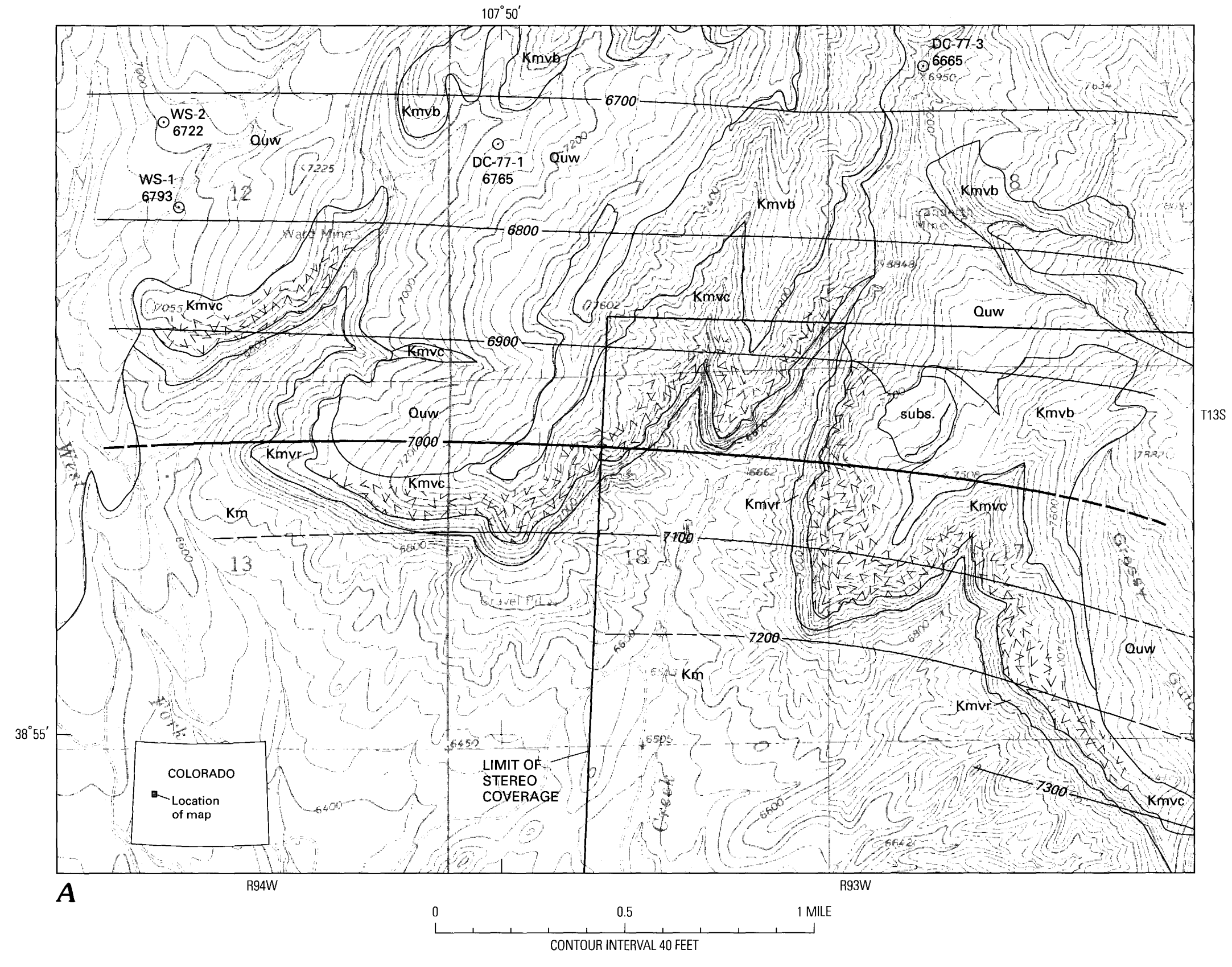




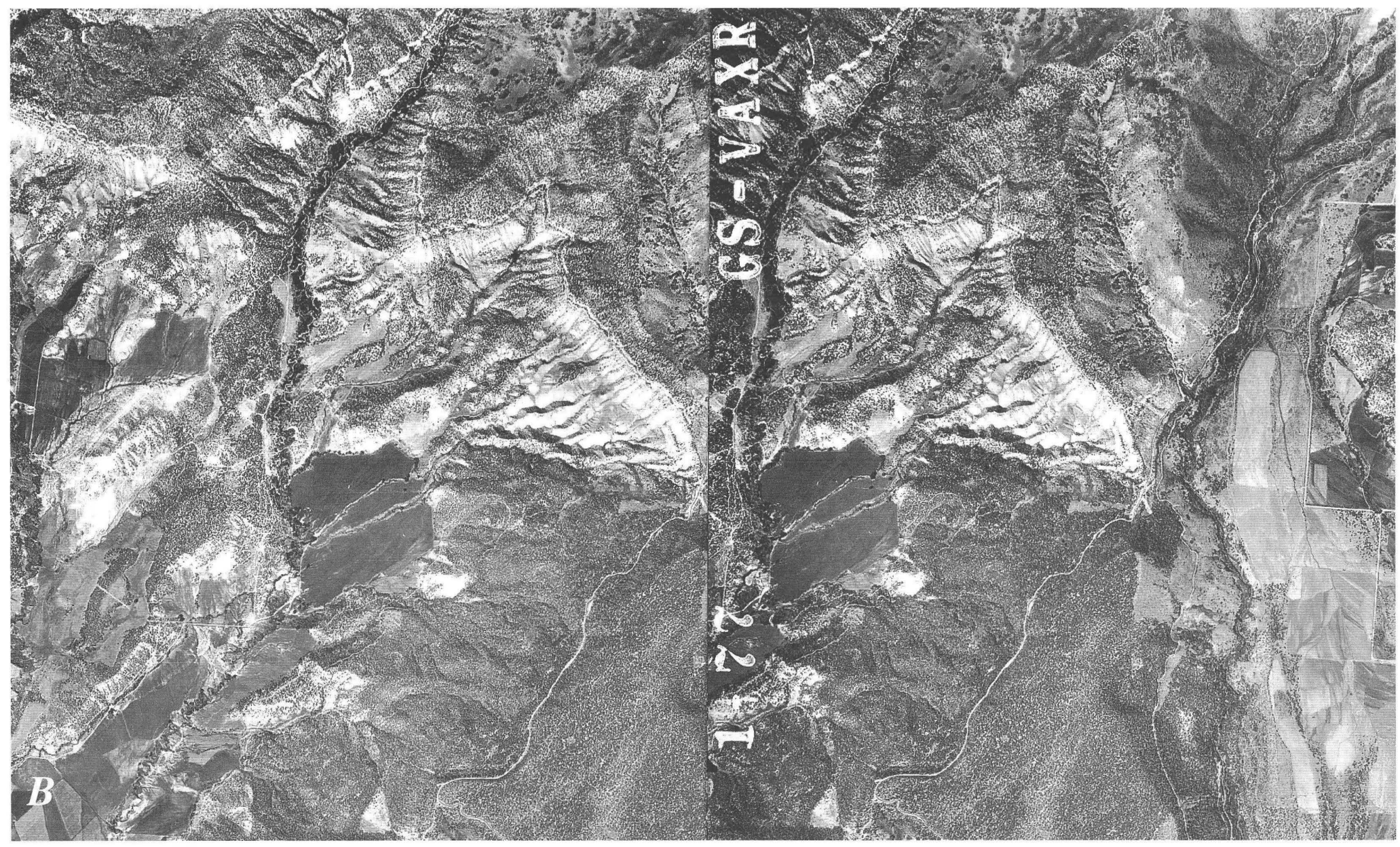

Figure 1. Field geologic map and vertical stereo aerial photographs of coal-bearing rocks in the Cedaredge area, Delta County, Colo. A, Quw, Quaternary unconsolidated deposits consisting primarily of clays of the Wasatch Formation and basalt boulders; Kmvb, barren member of the Upper Cretaceous Mesaverde Formation; Kmvc, coal-bearing member of the Mesaverde (baked and red-stained rocks from burning of coal beds indicated by v's); Kmvr, Rollins Sandstone Member of the Mesaverde; Km, Upper Cretaceous Mancos Shale. Structure contours on top of the Rollins Sandstone Member (in feet) are mapped along with exploratory drill holes (circled dots) and a subsidence area bounded by tension cracks (marked subs.) probably caused by mining and burning of coal beds (scale 1:24,000). $B$, Stereographic pair of vertical aerial photographs of the lower right part of the map area (bounded by black lines) that were used to help identify and locate geologic features. 


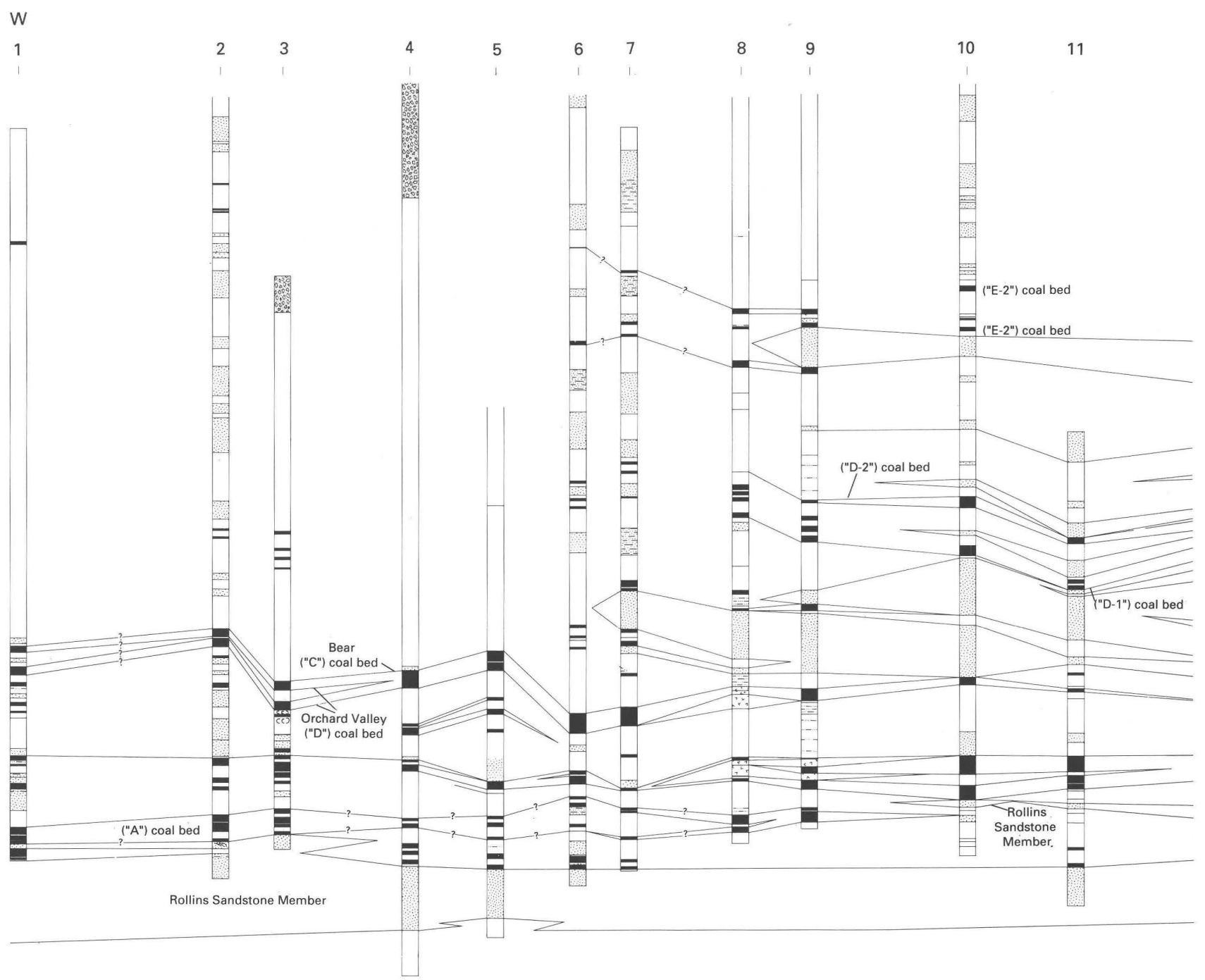

A-1. Paonia area, Delta and Gunnison Counties, Colorado; Section A (W-E): Oak Mesa to Anthracite Creek

\footnotetext{
${ }^{1}$ Coal-bed terminology from G.H. Horn and K.V. Cammack (unpub. mapping, 1945) and local mine terminology (proprietary data) as of 1981 .

${ }^{2}$ Coal-bed terminology from Collins (1976).

Distances between drill holes are to map scale unless otherwise indicated.
}

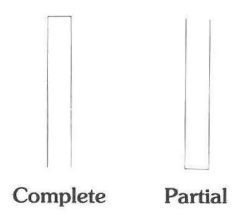

I. Data Searches

A. Reference libraries

1. Bibliographic indexes and cards in traditional libraries

2. Key words from computerized libraries, such as:

Coal resources

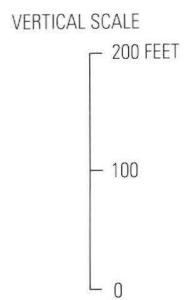

\section{EXPLANATION}

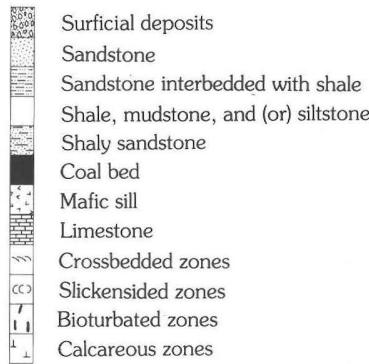

Coal mining

Coal geology

Structural geology

B. Drilling-log libraries

1. Stratigraphic and petrophysical strip logs of drill holes in the townships, ranges, and sections of interest 


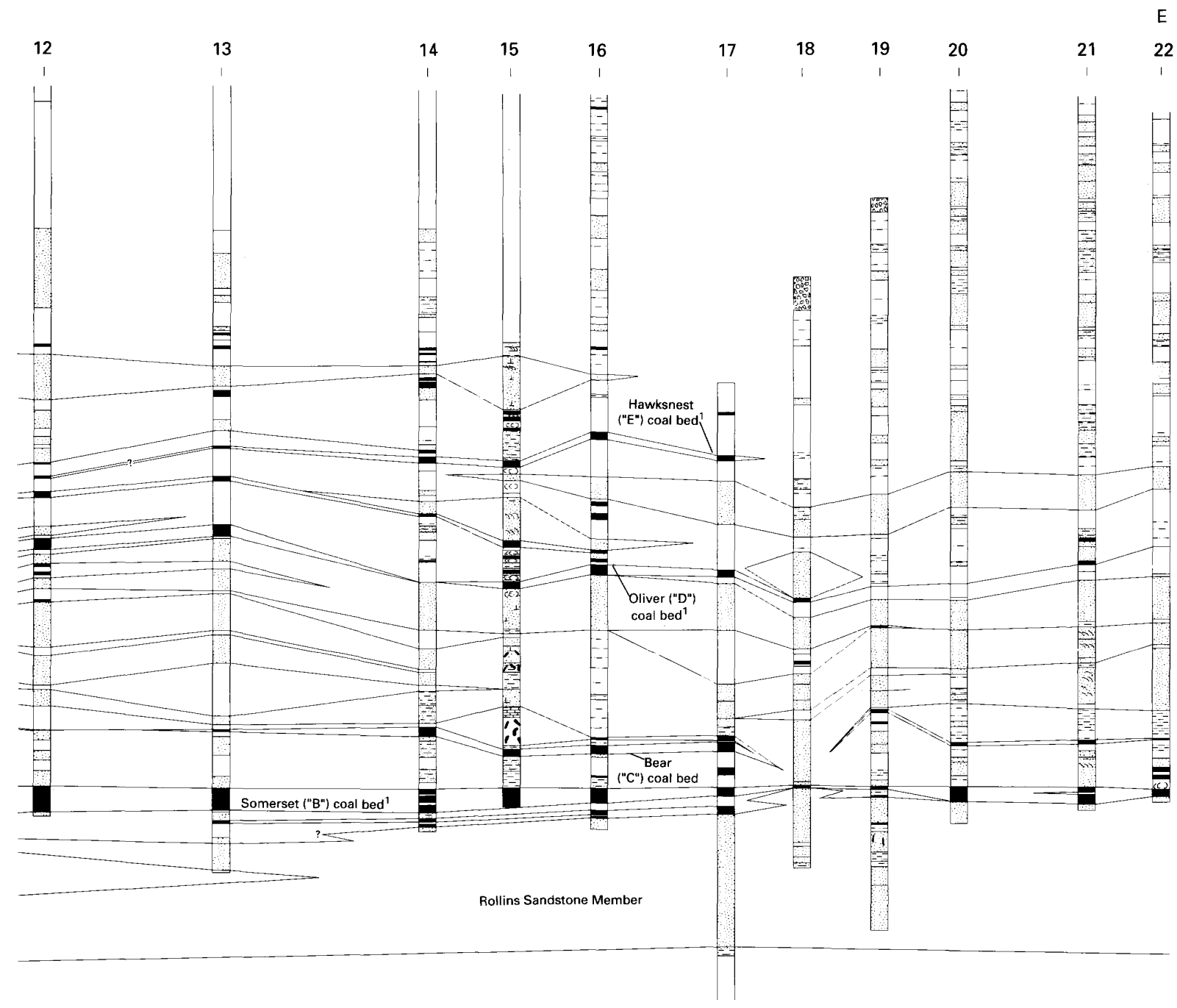

Figure 2 (above, facing page, following pages). Profiles showing the general stratigraphic framework of coal-bearing rocks of the Mesaverde Formation in the Paonia-Cedaredge area, Delta and Gunnison Counties, Colo. Drill hole information obtained from published data from Eager (1978 and 1979), and unpublished data from U.S. Steel Corp., Colorado Westmoreland Inc., and Grand Mesa Coal Co. A, East-west sections from the Rollins mine to Anthracite Creek. B, North-south sections from Dutch Creek mine to Wapiti Creek (headwaters of Coal Creek), Little Henderson Creek to Lick Creek, Currant Creek to Grand Mesa, and Lower Leroux Creek to Upper Leroux Creek. From Dunrud (1989a, b).

2. Stratigraphic and petrophysical logs of drill holes from computer databases of drilling$\log$ information services

II. Field Geologic Mapping (for example, Lahee, 1941, p. 395-558)

- Comprises a systematic examination, analysis, and plotting of coal, bedrock, and surficial deposits on a map or series of separate maps

- One can often effectively make a bedrock, surficial, and structural map concurrently in the field (example, fig. 1)

- For best results compile the geology (lithology, structure, and stratigraphic sections) on a topographic base map in the field
- Portable microcomputers with capabilities to plot stratigraphic sections can be useful during field compilation

- Mapping methods depend on such factors as detail required, accuracy needed, and time available

A. Reconnaissance mapping-may be used where preliminary information is needed to plan a detailed study or where requirements for detail and compilation accuracy are minimal, and time is short; geologic features are located and transferred to a base map:

1. By pace (or odometer), compass, and altimeter traverses (a method that has been used for decades) 


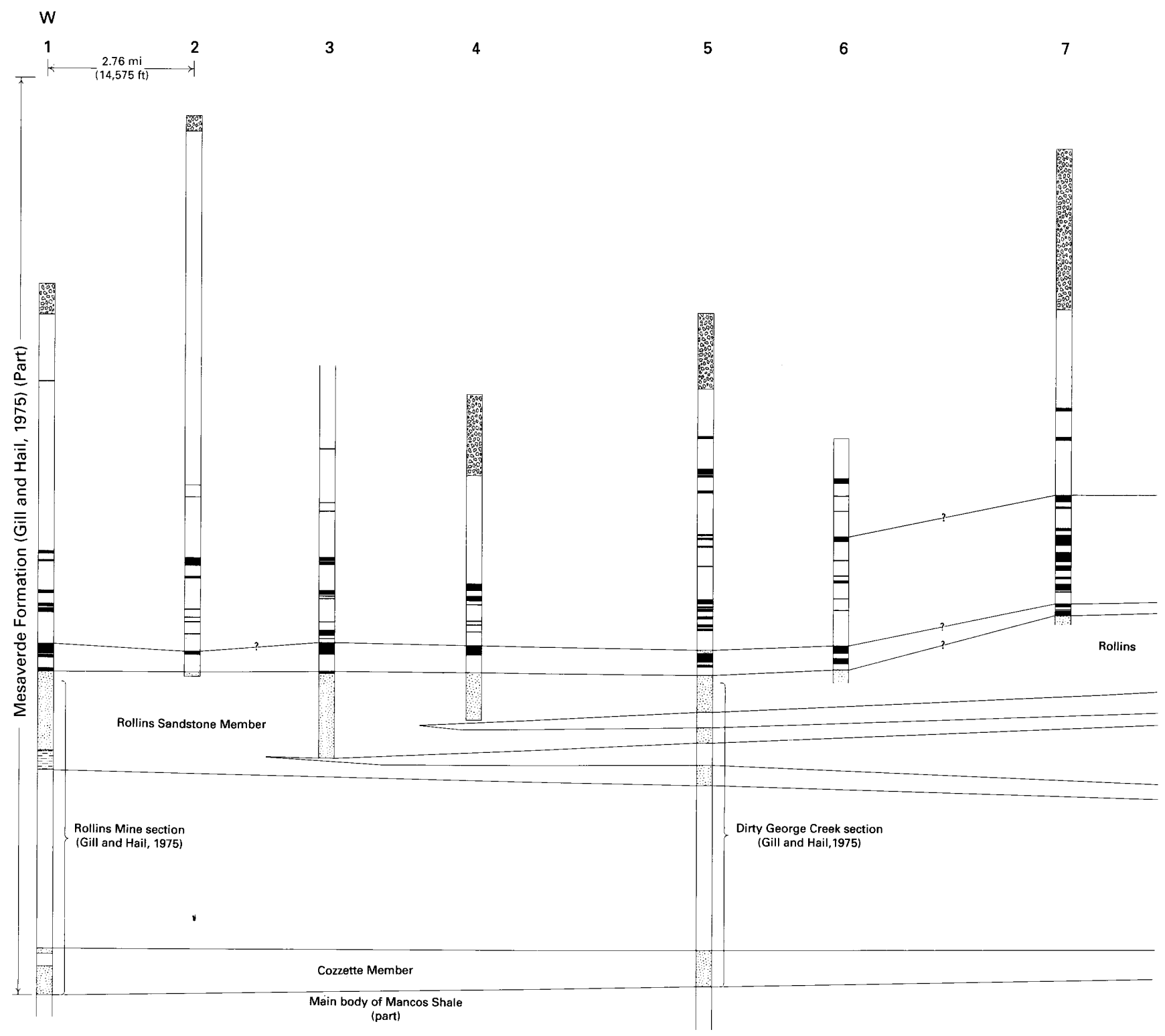

A-2. Cedaredge area, Delta County, Colorado; Section A (E-W): Rollins Mine to Oak Mesa

Figure 2 (above and facing page)-Continued. Profiles showing the general stratigraphic framework of coal-bearing rocks of the Mesaverde Formation in the Paonia-Cedaredge area, Delta and Gunnison Counties, Colo.

2. By viewing stereographic pairs of aerial photographs in the field or with the aid of precision photogrammetric plotters (modern method)

B. Detailed mapping (for example, Hayes and Sanchez, 1979; Dunrud and Barnes, 1972)

1. Map stratigraphic units, bedding attitude, coal beds, lineaments, faults, and joints on a topographic base map by:

a. Plane table and stadia rod using intersection or triangulation (for example,
Lahee, 1941, p. 506-526) or successive iteration without the use of a stadia rod

b. Using the stereoscope and stereographic pairs of aerial photos, landforms, distribution of bedrock and surficial units, and cultural features can be located by inspection in the field and can be accurately transferred to the topographic base map; where outcrops of various lithologies are extensive, this method commonly is accurate and efficient for geologists who (1) can see three 


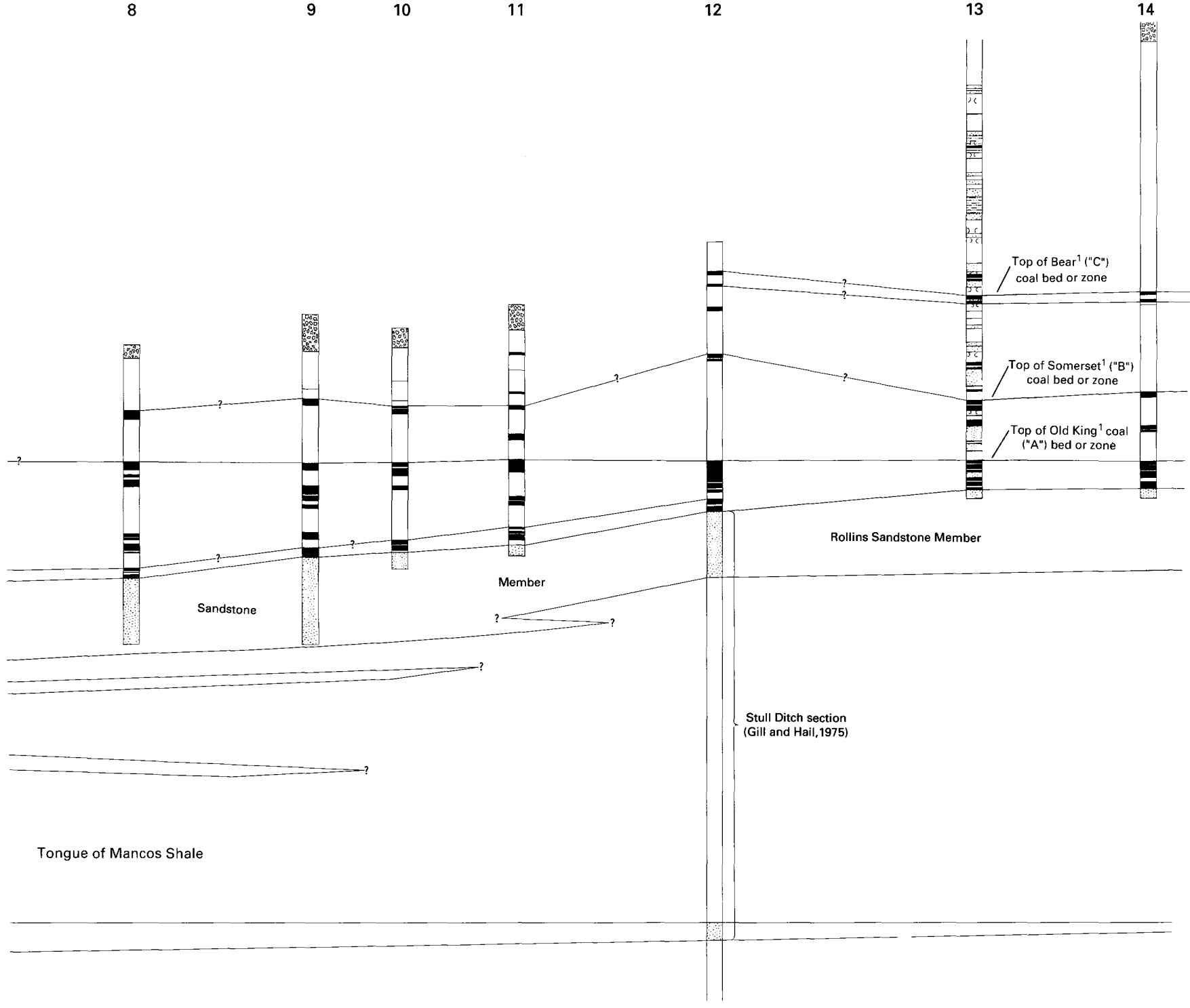

dimensions in stereographic projection and evaluate landforms and (2) have experience with fitting landforms seen in stereographic projection to topographic maps

c. Plotting geologic contacts and other geologic information on topographic base maps from stereographic pairs of aerial photos set up on a precision plotter; these are useful techniques where necessary (contacts, however, may not fit on map accurately if topographic map was made from photographs of a different scale than are being used to plot the geology). (For more detail see, for example, M'Gonigle,
1983, p. 1805-1808; Molnia, 1983, p. 1808-1812)

2. Compile geologic information on orthophotographs that have been rectified to the topography of the image

a. Contacts and other information can be plotted in true position and elevation by inspection if photos and contours are accurately registered

C. Selection of geologic features and information to be mapped and described

1. Locate, map, measure, and describe characteristics of coal beds

a. Measure-coal thickness at the outcrop where possible 


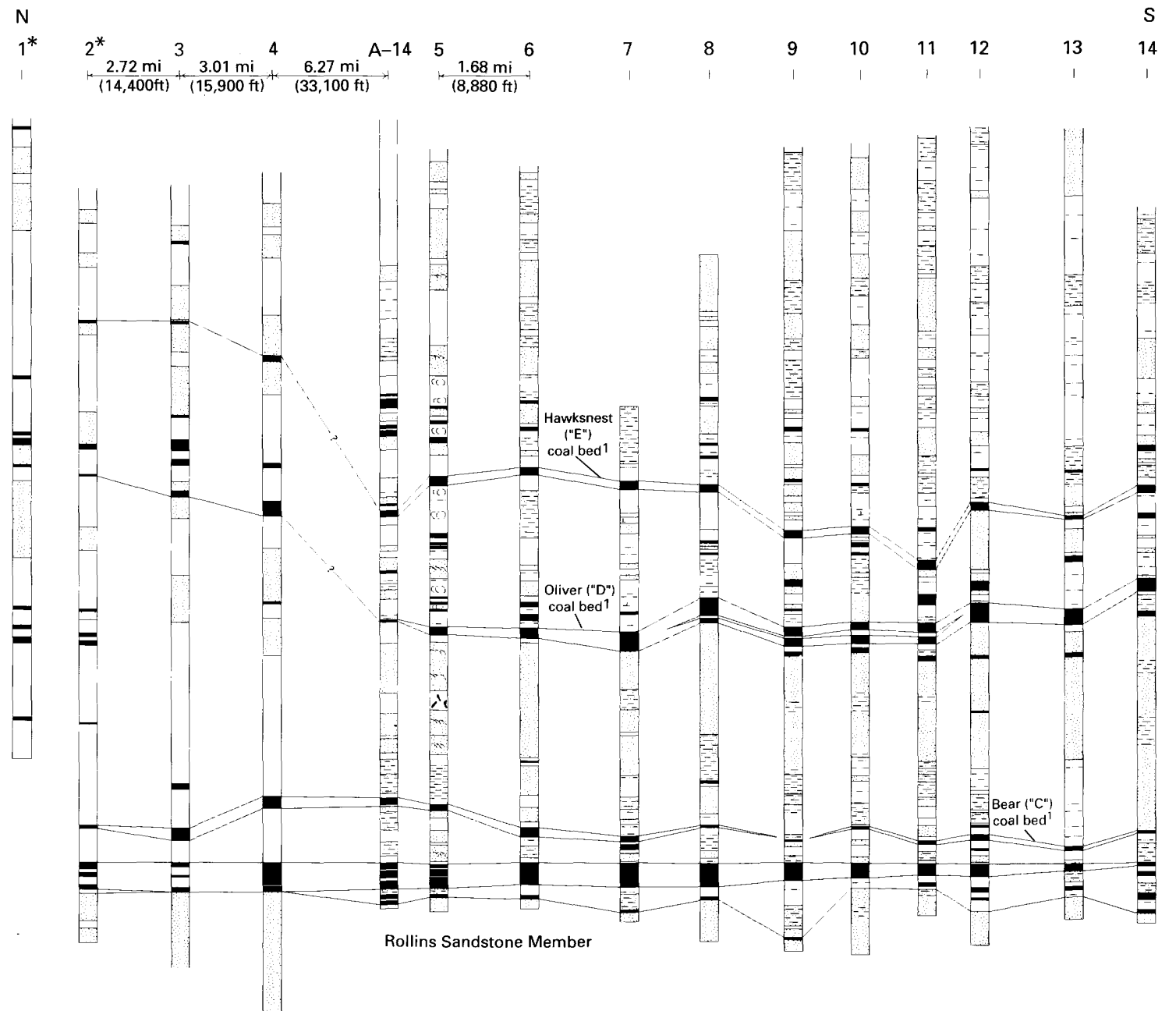

Section D (N-S): Little Henderson Creek to Lick Creek

B-1. General stratigraphic framework in the Paonia-Cedaredge area, Delta and Gunnison Counties, Colorado

${ }^{1}$ Coal- bed terminology from G.H. Horn and K.V Cammack (unpub. mapping, 1945) and local mine terminology (proprietary data) as of 1981

* Means that logs were determined from petrophysical logs

Distances between drill holes are to map scale uniess otherwise indicated

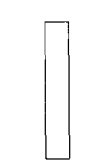

Complete

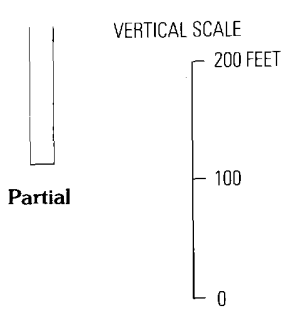

b. Describe and measure structure (spacing of layers, cleats, joints)

c. Measure coal quality and ash content of coal in the laboratory; describe coal and rock partings in the following format as follows (Carol Connor, written commun., 1984):
I- Description of coal bed(s)

a- Banded

Bright matrix

Dull matrix

b- Nonbanded

Bright

Dull 


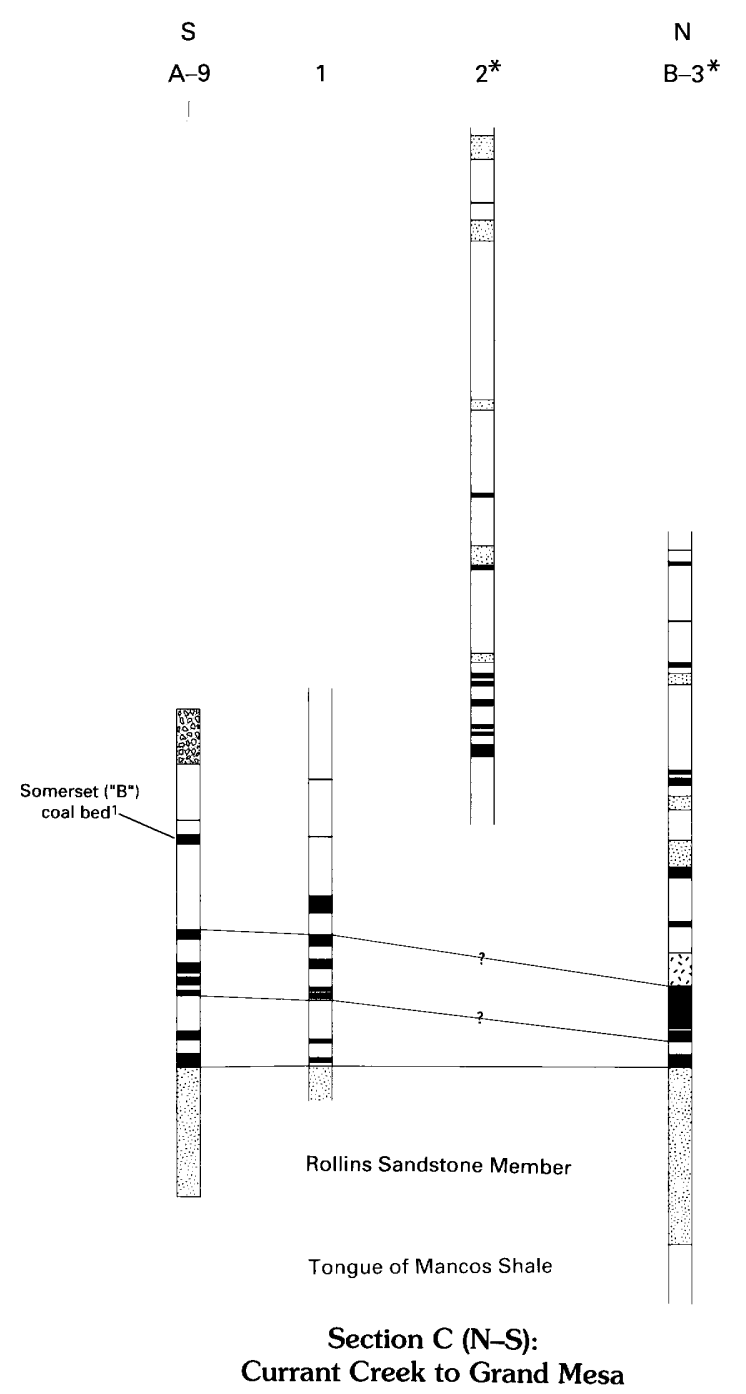

NE

A-12 $\quad 1$ 2*

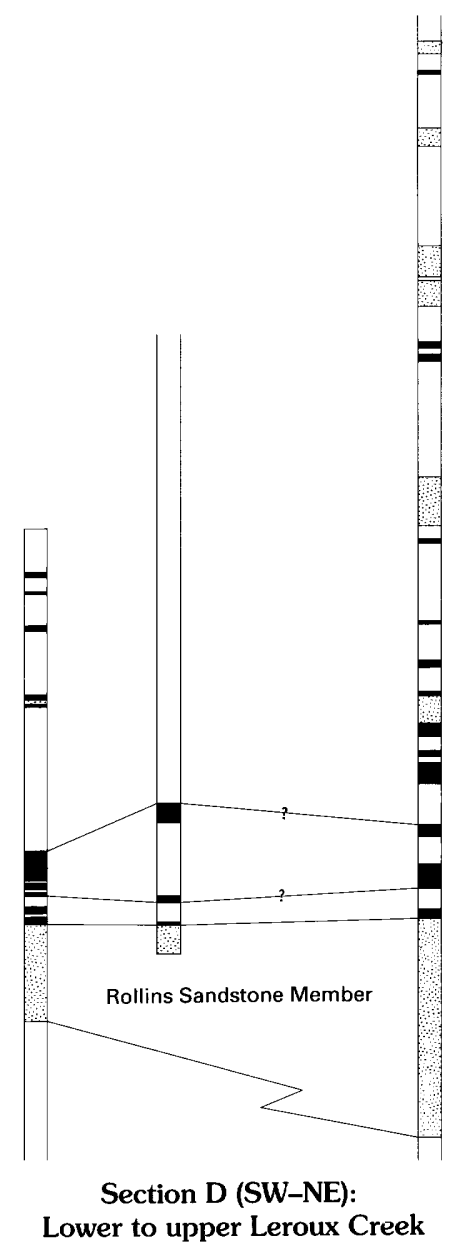

Figure 2 (above and facing page) - Continued. Profiles showing the general stratigraphic framework of coalbearing rocks of the Mesaverde Formation in the Paonia-Cedaredge area, Delta and Gunnison Counties, Colo.

\section{2- Rock partings \\ a- Thickness \\ b- Lithology}

2. Map important sedimentary rock units on the topographic base (for example, Roehler, 1979; Sanchez and Hayes, 1979; Dunrud and Barnes, 1972) to help determine:

a. Structure

b. Overburden thickness

c. Lithology of rocks above and below coal beds

d. Depositional environment(s) and dominant geotechnical properties of the coal beds and coal-bearing rocks

3. Determine stratigraphic framework of coalbearing rocks; this commonly involves: a. Compiling coal sections (fig. 2) and fence diagrams of the coal-bearing rocks from geologic and geophysical drill-hole data and measured sections of bedrock at a vertical scale large enough to evaluate the individual coal beds (commonly $1: 600$ to $1: 50,000$ )

b. Correlating coal beds or coal zones between drill holes and measured sections

c. Determining where extra control points from drilling or measured sections are needed for reliable correlations; the reliability of coal correlations and resource calculation depends on an understanding of the depositional environment of the 


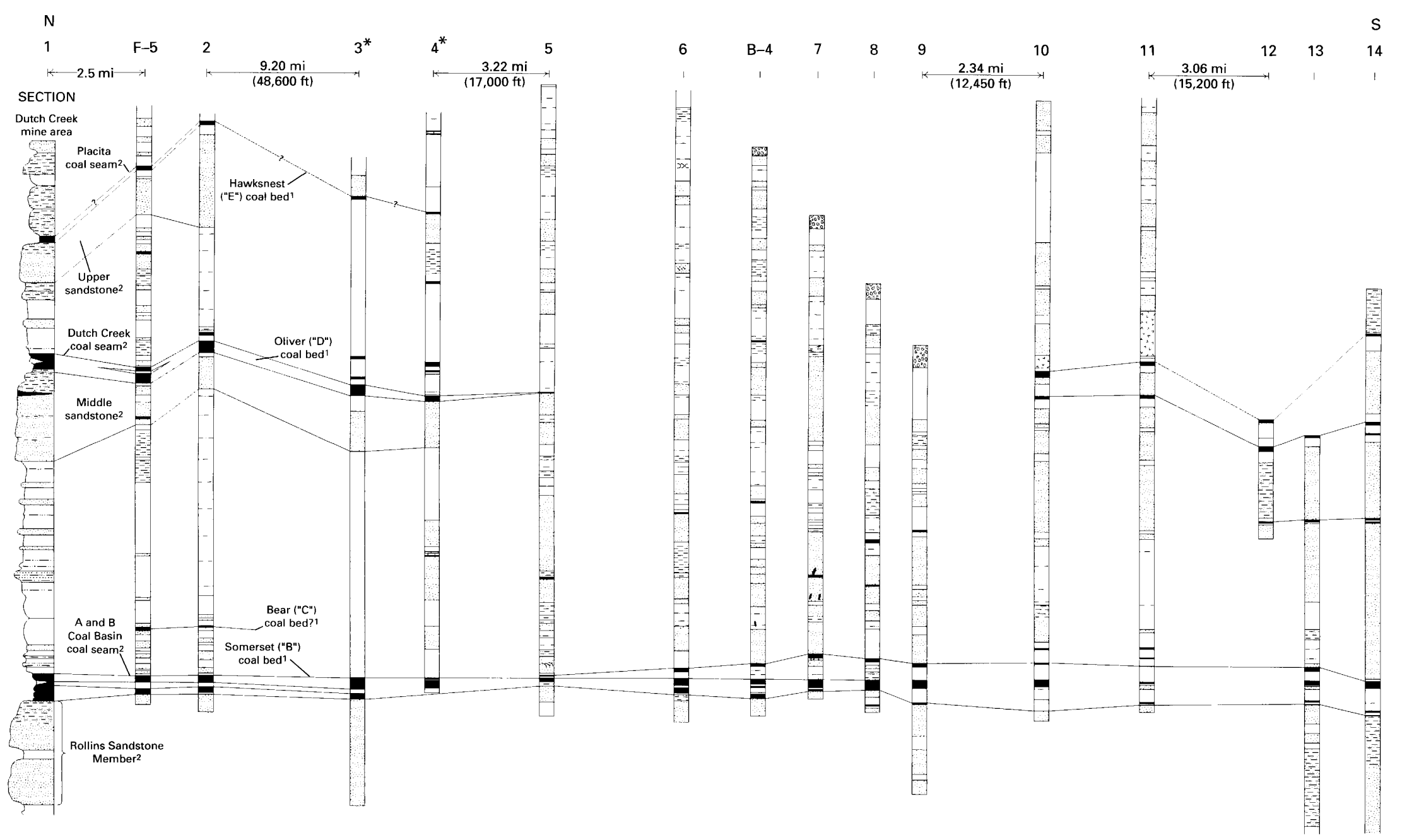

B-2. Paonia area, Delta and Gunnison Counties, Colorado; Section E (N-S): Dutch Creek Mine to Wapiti Creek

${ }^{2}$ Coal-bed terminology from Collins (1976).

Figure 2-Continued. Profiles showing the general stratigraphic framework of coal-bearing rocks of the Mesaverde Formation in the Paonia-Cedaredge area, Delta and Gunnison Counties, Colo. 

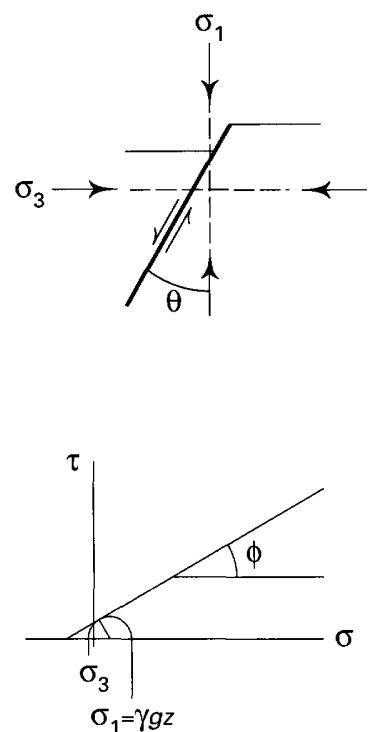

$\theta=25^{\circ}-30^{\circ}$

NORMAL
CROSS SECTIONS OF FAULTS
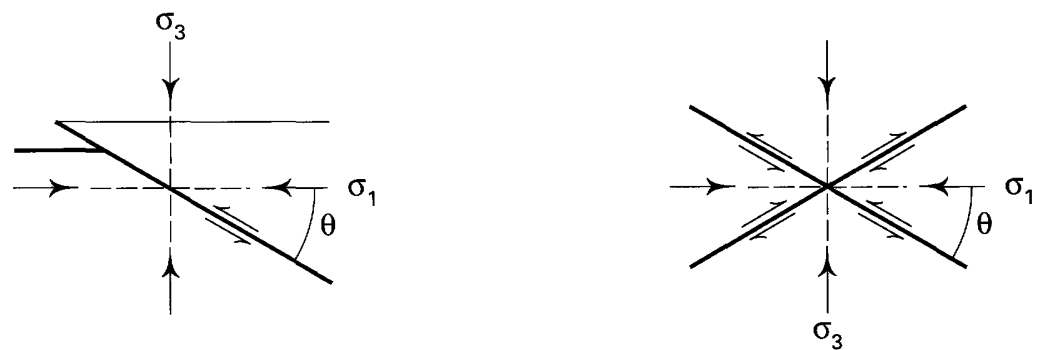

MOHR-COULOMB STATE OF STRESS AT FAILURE

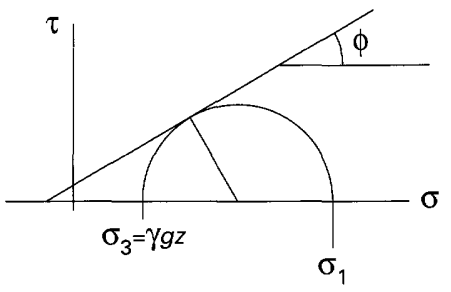

$\theta=20^{\circ}-25^{\circ}$

REVERSE

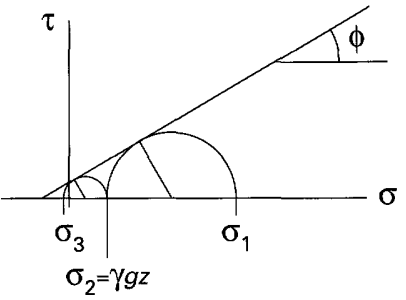

$\theta \simeq 30^{\circ}$

STRIKE SLIP

Figure 3. Classification of faults caused by various stress conditions, based on Mohr and Coulomb theories. Modified from Jaeger and Cook (1979, p. 425-428); reproduced with permission of Chapman and Hall. $\gamma$, average overburden density; $g$, gravitational acceleration; $z$, overburden depth. $\sigma$, normal stress; $\tau$, shear stress.

coal and associated rocks, the location of marker rock units, and distance between data points; for example (fig. 2):

1 - The Somerset " $\mathrm{B}$ " coal bed, which is the thickest coal zone in the Somerset (Colorado) area, can be accurately correlated where drill holes are spaced about $4,000-8000 \mathrm{ft}$ apart, because the extensive, regressive, marine Rollins Sandstone Member of the Mesaverde Formation provided a depositional environment conducive to extensive coal deposition and also contains a marker horizon to correlate the coal beds

2- The Hawksnest "E" coal bed (Somerset area), however, can be correlated with reasonable accuracy only where drill holes are spaced less than about 2,000 ft apart, because it is located in a deltaic sequence that has no extensive marker horizon to help correlate the coal beds

4. Map the faults-they are related to regional stresses (fig. 3)
- They commonly control the layout of mining panels and entries, and also control the location and orientation of longwall panels

- Analysis of the type(s) of faulting in an area can help predict the relative magnitudes and directions of principal stresses that may be found during mining (Jaeger and Cook, 1979 , p. 425-444)

a. Types of faults (fig. 3):

I- Normal-maximum principal stress is vertical and is approximately equal to $\gamma g z$ (average overburden density $(\gamma)$ times gravitational acceleration $(g)$ times the coal depth $(z)$ at time of formation); the horizontal compressive stress is small

2- Reverse-maximum principal stress is horizontal and greater than $\gamma g z$

3- Strike slip-maximum principal stress is horizontal and greater than $\gamma g z ;$ intermediate principal stress is vertical and is about equal to $\gamma g z$

5. Map the joints-fractures without displacement-they commonly are related to sedimentation, compaction (depth of burial), lithification, and tectonic stresses 

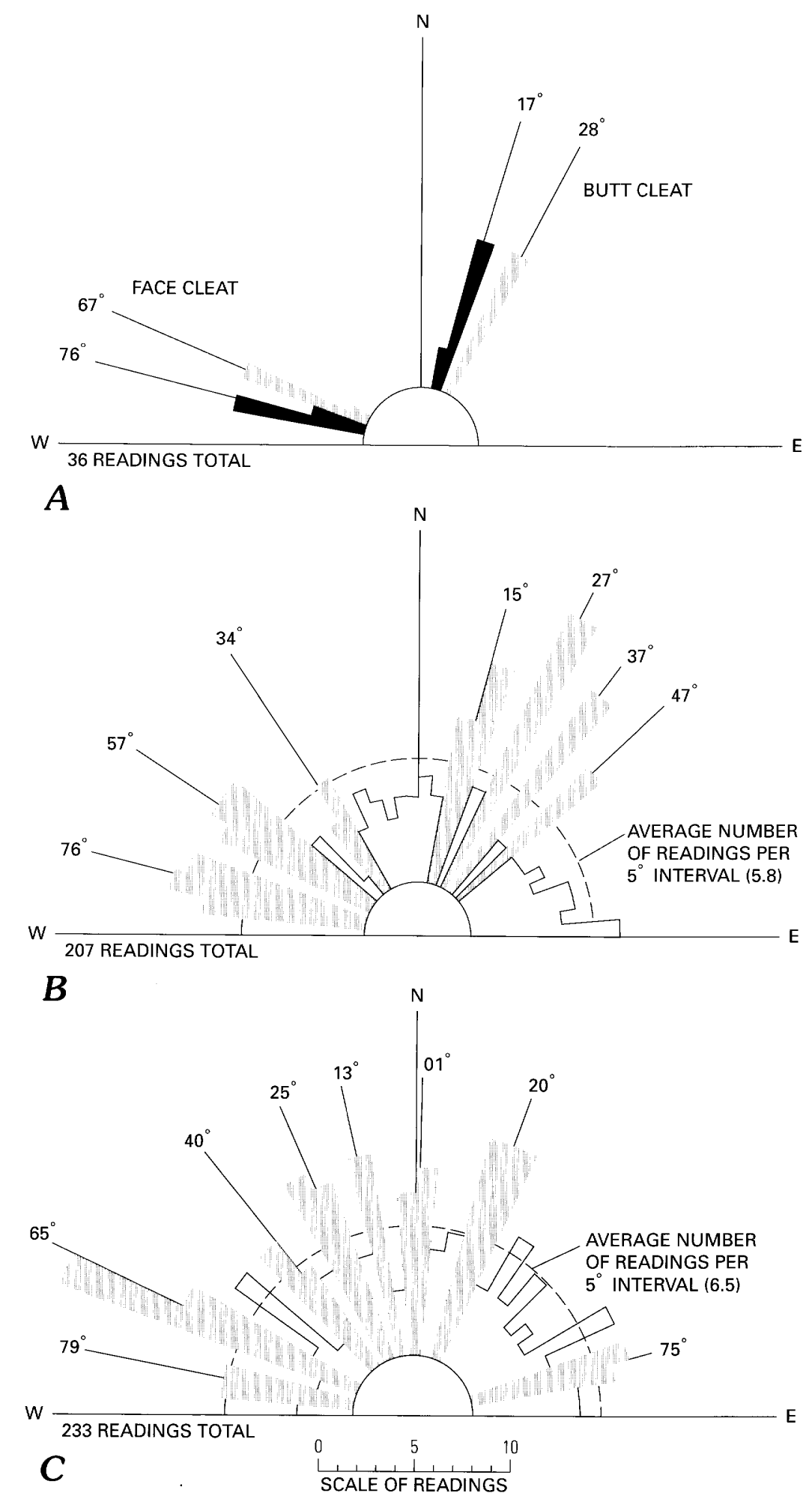

Figure 4. Rose diagrams showing the relation between the trends of $A$, cleat; $B$, joints at the outcrop; and $C$, lineaments in southwestern Pennsylvania and northwestern West Virginia. From McCulloch and others (1975, p. 28, 39, 44). 
Figure 4-Continued.

Rose diagrams. $D$, Orientation of cleat in various stratigraphic positions in six coal beds in West Virginia. From McCulloch and others (1976, p. 14).

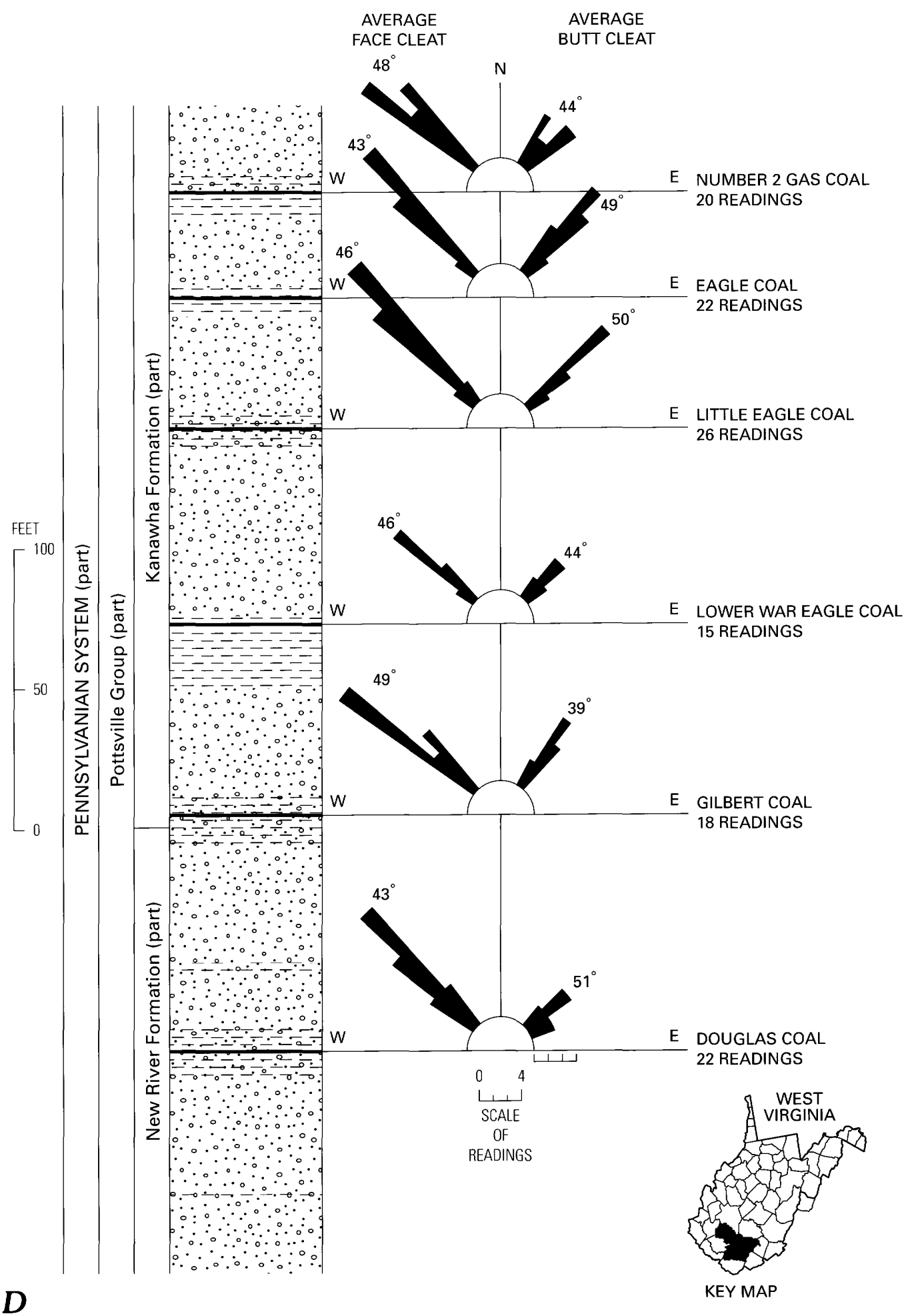


a. Steeply dipping to vertical joints

1- Commonly are oriented subparallel to the strike and dip of bedrock in local areas of the Western U.S.

2- Spacing, continuity, and definition commonly are functions of lithology and grain size, tectonic history, and topography

a- Joints commonly are more widely spaced and more extensive in sandstones than in shales, probably because the sandstone units commonly are thicker and coarser grained than the shales

$b$ - Joints in a given lithology commonly are more closely spaced together near drainages than elsewhere, because horizontal confining stresses are reduced near drainages

$c$ - Inclined joints locally occur as conjugate joint sets in the Paonia, Colo., area and appear to be related to a later tectonic activity than the activity controlling the vertical joints

b. Trends of joints can be measured by direct observation with compass in the field where bedrock crops out, or by methods such as surface resistivity surveys where bedrock is not exposed (for example, Leonard-Mayer, 1984)

6. Cleat in coal-cleats commonly occur in coal as two sets that dip steeply to vertically; nearly perpendicular fracture systems are called face cleats and butt cleats (McCulloch and others, 1974; McCulloch and others, 1976)

a. The face cleats commonly are linear, continuous, and extensive (may be many feet in length); they may cut across bedding planes and other structural features; face cleats commonly are about perpendicular to the fold axes of anticlines and synclines

b. The butt cleats often are less linear, less planar, less continuous, and less extensive than the face cleats

c. Before mining was mechanized, the orientation of the cleats often controlled the direction of mining, because it was easier to mine perpendicular to the face cleats than at an angle to them

d. The orientation and distribution of cleats are still important in mining because they provide avenues for methane and water to flow through the coal beds

7. Lineaments-types

a. Parallel to valleys and ridges: this type appears to be related to dominant joint trends in local areas of western Colorado

b. Crosscut valleys and ridges: locally parallel to faults and to fracture zones parallel to faults in western Colorado

8. Relationships among structural features

a. Steeply dipping joints, cleats and linear features were found to be oriented subparallel to one another in southern Pennsylvania and northern West Virginia (fig. $4 A-C$ )

b. Cleat orientation in deeper coal beds may also be similar to cleat orientation in overlying coal beds, where principal stresses were similar at the time of formation (fig. 4D; McCulloch and others, 1976)

c. Relationships are shown by equal-area plots, such as poles to faults and joints (Hoek and Brown, 1980, p. 61-86) and rose diagrams (McCulloch and others, 1975, p. 27-53)

1- Facilitate statistical analysis of their orientation in different structural domains

2- Can be used to help determine principal stress directions at the time of formation

9. Intrusive rocks-knowledge of location, geometry, and structure can be very important in designing proper mine layout and mining method

- Intrusive rocks, such as laccoliths, stocks, dikes, sills, and complex intrusions, can change attitude and quality of coal deposits and affect methane concentrations

a. Laccoliths-vertical and lateral intrusions which can split the coal strata; they commonly change:

1- The attitude of coal above and below a laccolith (fig. 5)

2- The coal rank and quality (coal rank and quality may differ above and below the laccolith because of different heat and chemical effects)

3- Coal rank and quality laterally and vertically along lateral parts of the intrusion

b. Stocks-predominantly vertical intrusions-commonly 


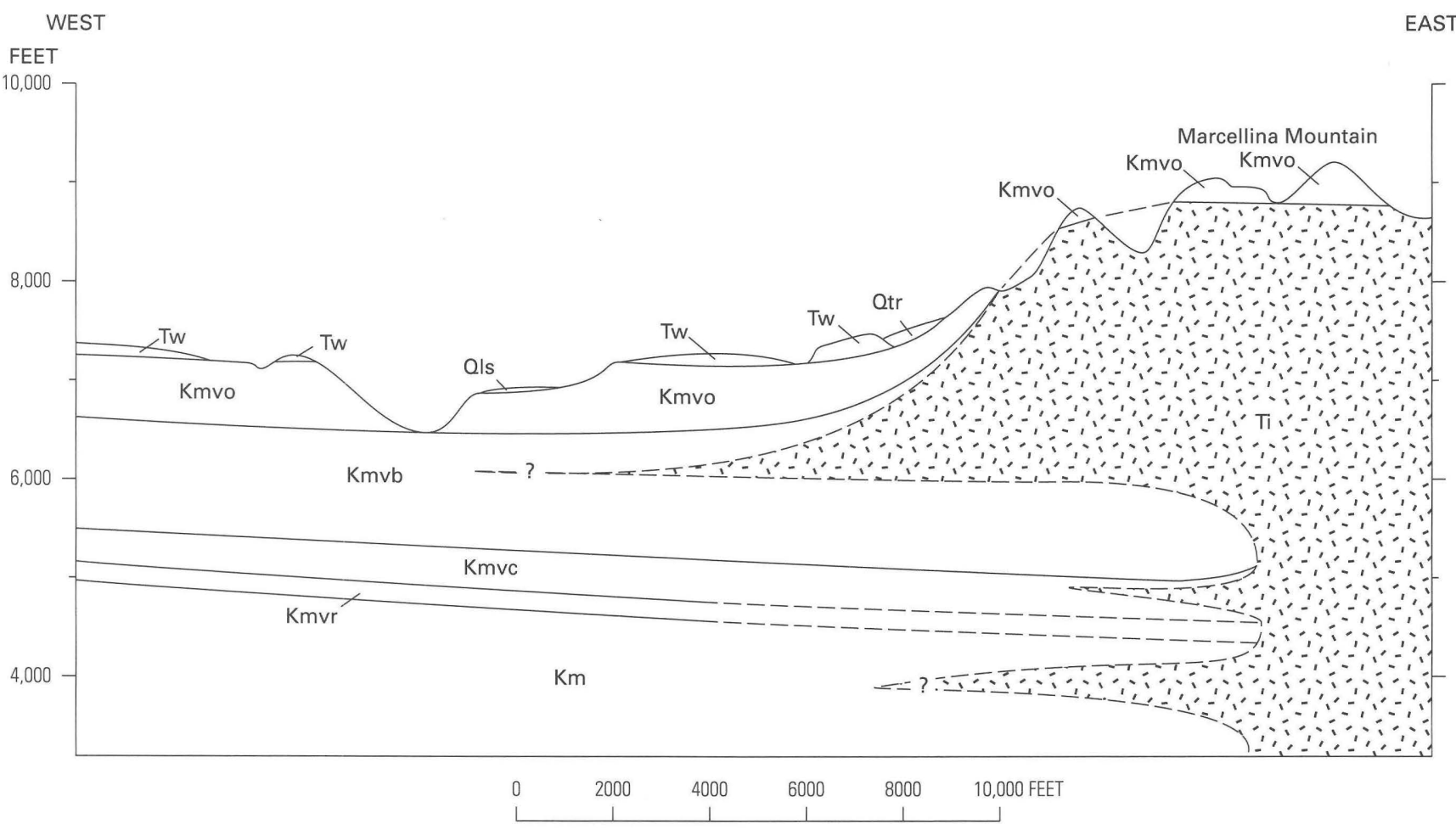

Figure 5. Profile showing structural relations between sedimentary rocks and laccoliths in the Paonia, Colo., area. Tongue of granodiorite laterally intrudes the barren member of the Mesaverde Formation, which causes rocks above tongue to dip steeply off flank of Marcellina Mountain, whereas rocks and coal beds beneath the tongue dip gently beneath lateral extension of laccolith. Qtr, Quaternary talus and rock glacier deposits; Qls, Quaternary landslide deposits; Ti, Tertiary (Eocene) intrusive rocks composed primarily of granodiorites; Tw, Eocene Wasatch Formation; Kmvo, Ohio Creek member of the Upper Cretaceous Mesaverde Formation; Kmvb, barren member of the Mesaverde Formation; Kmvc, coal-bearing member of the Mesaverde Formation; Kmvr, Rollins Sandstone Member of the Mesaverde Formation; Km, Upper Cretaceous Mancos Shale. From Dunrud (1989a).

1- Deform all strata near intrusive

2- Affect coal and rock more extensively in a vertical direction than do laccoliths

c. Dikes-commonly crosscut coal and associated rocks

1- Coal and rock may be deformed, thermally altered, and otherwise changed in rank and quality

2- Mining hazards, such as roof falls, bumps, and outbursts, may be more common near dikes than elsewhere because they transect and fracture the rocks of the roof and floor

d. Sills, which are parallel to attitudes of coal beds and associated rocks, commonly deform and thermally alter the coal over large areas, where intrusion occurs within or near coal beds

e. Complex intrusions are irregular bodies that thicken and thin, crosscut, and are parallel to bedrock in short distances (fig. 6)

1- Coal rank and quality can be affected in highly variable ways, depending on their thickness, temperature, chemistry, and proximity to intrusive rocks

10. Extrusive rocks

a. Flows

1- Basalt flows and andesite sheets can obscure coal deposits, particularly where flows are extensive

b. Ash fall deposits (tonsteins, bentonites)

1- Are useful in correlating coal beds because they provide an independent time datum where they are preserved near or within coal beds

2- Commonly weather to montmorillonite (smectite)

3- May be identified on gamma-ray logs (natural gamma) if thick enough, because they often are more radioactive than the host rocks 

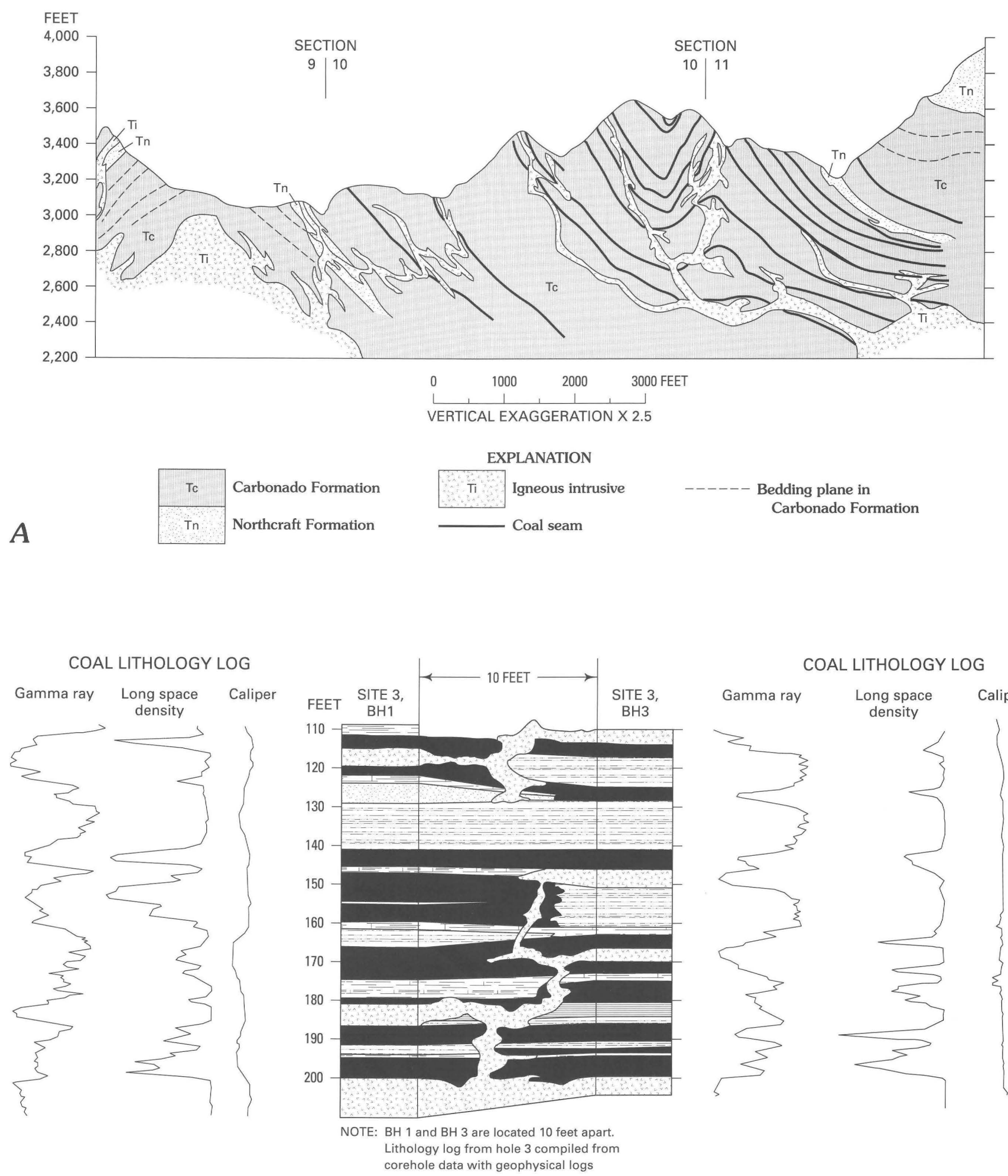

COAL LITHOLOGY LOG

EXPLANATION 
Figure 6 (facing page). Profile and logs showing effects of complex intrusive bodies on coal beds in the Eocene Ashford coal field, Pierce County, Wash. A, Diagrammatic profile through sections 9 to 11 , T. 15 N., R. 6 E., Pierce County, Wash. (approximately $3 \mathrm{mi}$ north of Ashford). B, Lithologic and petrophysical logs showing changes in coal and rock between two drill holes $10 \mathrm{ft}$ apart. Modified from Beeson (1980, p. 89-91).

11. Surficial deposits-should be mapped where they may affect coal exploration, mine development, personnel, mining equipment, and surface structures (entries, shafts, loading facilities, access roads); types of deposits:

a. Alluvium, colluvium, slope wash deposits

b. Talus, rock glaciers, rock-fall areas

c. Landslides and other types of massgravity movements-need to locate, understand process, and describe state of activity (active, dormant, quasi-stable) prior to design of mine facilities, utilities, and roads (for details on landslide processes, see Wieczorek, 1984, p. 337-342; Varnes, 1978, p. 11-33; fig. 7)

1- Excavation for roads and buildings during exploration and mining can reduce lateral support and cause unstable conditions

2- Wetting, caused by changes in ground- and surface-water flow, and vibrations from construction or mining activities may trigger failure in potentially unstable ground

3- Active movements include falls, topples, slides, lateral spreads, flows, rock creep, and complex combinations of these (Varnes, 1978, p. 11)

a- Differential movement can cause tensile and shear failure near boundaries (slip surfaces) of slide, which can pull apart or offset mine structures or utilities

$b$ - Scarps toward the head of the slide and bulging toes near boundary in lower part of slide (fig. 7A) can cause serious damage to mine structures and utilities

d. Extent of burned-coal areas near outcrop should be evaluated

1- Lateral and vertical extent of naturally burned areas in the subcrop can provide information on lost reserves and can outline areas where drilling will not be productive

2- Large movements, such as collapse and landslides, involving rotation, toppling, slumping, sliding, and flowing of bedrock and surficial material, may be triggered where subsidence occurs above burn zones near the coal outcrop (fig. $7 B$ )

$a$ - Slumping of the rotated block may occur where the rocks are flat to gently dipping
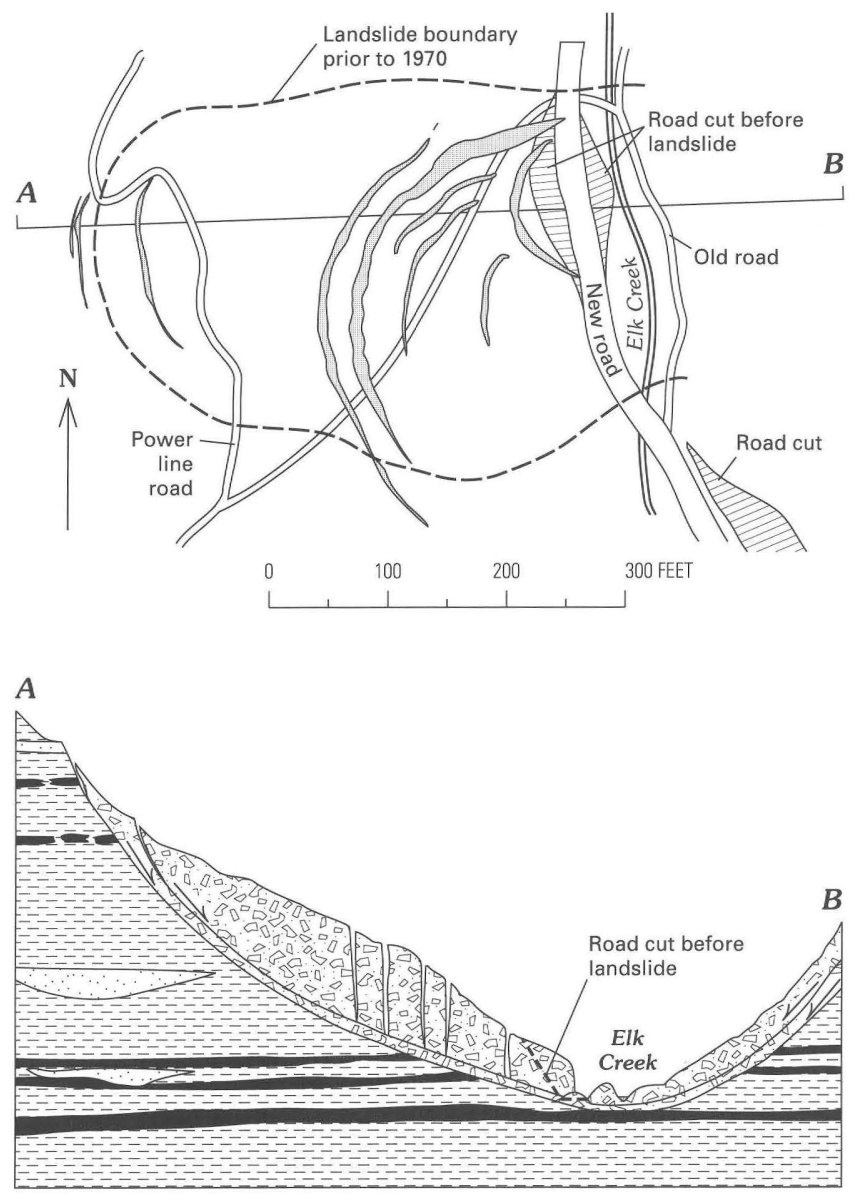

A

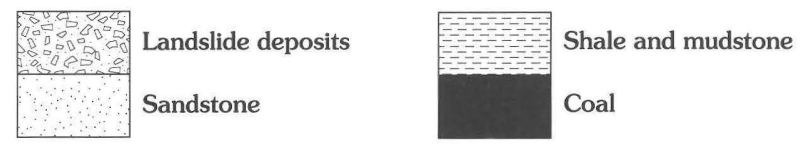

Figure 7 (above and following page). Landslides in the Somerset area, Delta County, Colo. A, Map and cross section showing landslide caused by excavation of a mine access road in the 1970's. Horizontal and vertical scales approximately equal. $B$, Photograph, looking southward, showing landslide scarps that may have been triggered by subsidence above naturally burning coal beds, which are located near the base of the oversteepened slopes. 


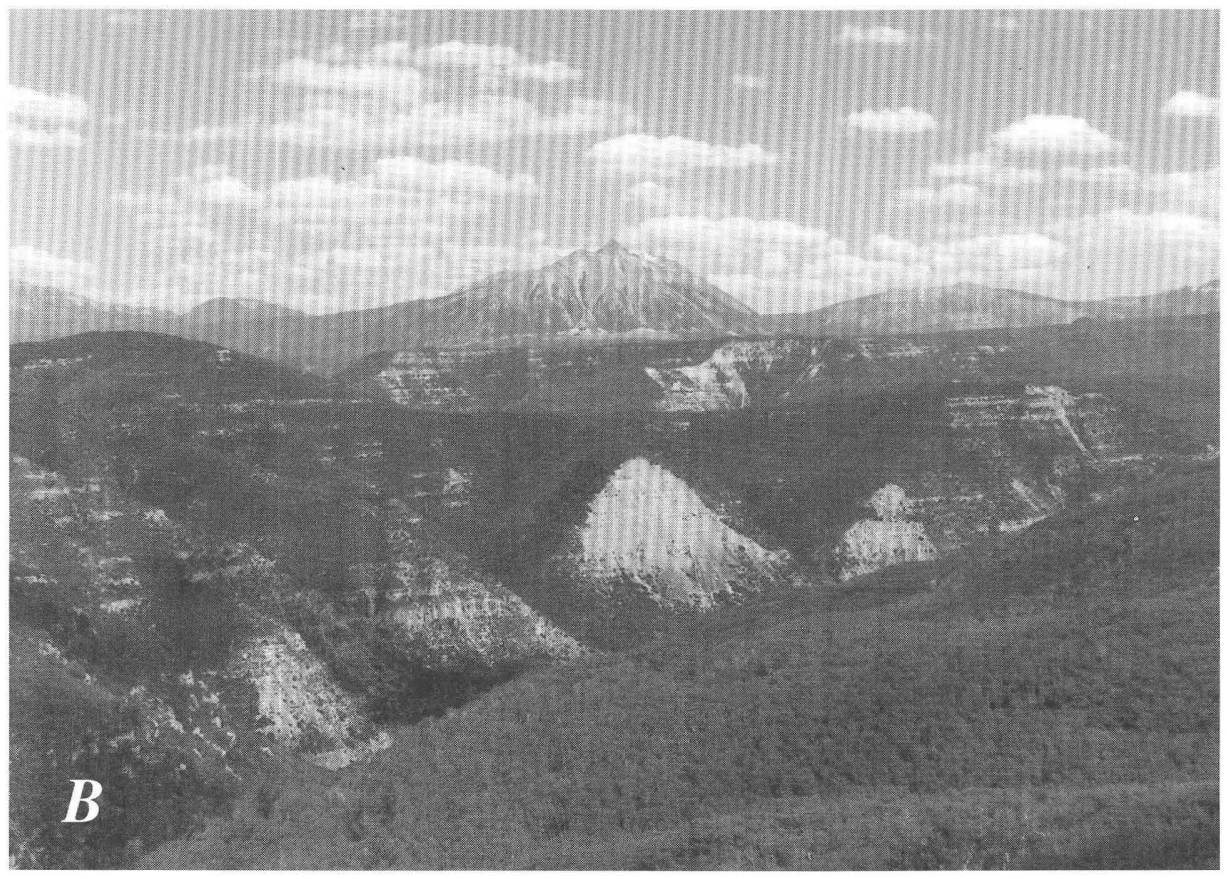

Figure 7-Continued. Landslide scarps (B), Somerset area, Colorado, that may have been triggered by subsidence above naturally burning coal beds.

$b$ - Bedding-plane slides of the rotated block may occur where the bedrock dips moderately to steeply toward the outcrop

D. Selection of mapping scales

- Overview maps, detailed geologic and engineering geologic maps, and derivative maps that systematically portray coal resources (coal thickness and quality), geology (lithology and structure), and geotechnical properties (stress, strength, slake durability) should be compiled so that safe, efficient, and environmentally compatible mines can be developed

1. Minimum thickness of mappable units is related to map scale - compare, for example, Williams and Hackman, 1971 (1:250,000); Hayes and Sanchez, 1979 (1:24,000); Dunrud and Barnes, 1972 (1:6,000); rock units commonly are mapped that are thicker than about $100 \mathrm{ft}(30 \mathrm{~m})$ at a scale of 1:50,000, 50 $\mathrm{ft}(15 \mathrm{~m})$ at a scale of $1: 25,000,5-10 \mathrm{ft}$ $(1.5-3 \mathrm{~m})$ at a scale of $1: 2,500$

2. Map scale is governed by degree of detail needed

a. Overview maps (for general mine site selection): scale range is about 1:50,000 to $1: 250,000$

b. Detailed maps of selected areas (after obtaining overview maps) are most useful for detailed engineering geologic evaluation and mine design: scale range is about $1: 2,500$ to $1: 25,000$ c. Derivative maps (for general and detailed use): scale should be the same as the overview and detailed maps

III. Drilling-commonly necessary to locate and analyze coal and key rock units

A. Use outcrop and subcrop data and burned areas delineated on geologic map(s) to locate drill holes and correlate map units

B. Use drill core to determine coal thickness and quality and lithology, sedimentary structures, and geotechnical properties of rocks above and below the coal bed(s)

C. Drill-hole data, such as location, lithology, structure, and geotechnical properties, can be stored in a computer system, which facilitates the use of data at different scales and for different purposes

\section{GENESIS OF COAL-BEARING ROCKS}

- Involves determining (1) depositional environment, (2) paleotectonic environment, (3) coal-forming environment, (4) paleoclimate, (5) processes of coal formation, and (6) genetic types of coal

- Knowledge of genesis is useful in predicting conditions before mining, such as stress and deformation in the coal, roofs, and floors; potential for roof falls, bumps, and squeezes; and type and extent of roof support required

- Can be used to correlate coal and lithologic units using profiles of coal bed(s) and associated rocks in drill holes (fig. 2) and measured sections to compile coal- and rock-thickness 
maps (derivative maps); and to make mathematical-statistical analyses (such as Kriging) to determine coal thickness with horizontal position

\section{Depositional Environment}

A. Fluvial (river) deposits-as described, for example, by Flores (1980); Leeder (1982, p. 142-154); Friedman and Sanders (1978, p. 199-251)

1. Channels range from straight with lateral bars, to braided with channel bars, to sinuous with point bars, to distributive with interdistributary bars (fig. $8 \mathrm{~A}$ )

2. Meandering channels with levees can provide conditions for accumulation of peat in backswamps

a. The thick coal beds and coal zones in the Paleocene Tongue River Member of the Fort Union Formation in the Powder River Basin, for example, may have formed in floodbasin swamps near meandering streams, which were isolated by changes in the courses of stream channels (avulsions), and where the swamps were free of overbank and crevasse splay deposits (Flores, 1980, p. 92)

3. Channel and sheet deposits (sand to silt and clay) caused by breaches in levees (crevasse channels and crevasse splays) can

a. Cause mine roof control problems during and after mining

b. Affect mining efficiency by partially cutting out the coal

c. Form partings in the coal

d. Cause changes in mine roof lithology in short distances (as implied by fig. 8C; Flores and others, 1982)

B. Lacustrine (lake) deposits-numerous varieties, depending on climate, water depth, clastic sediment, and solute input

1. Oil shale and trona were deposited in vast amounts in the Eocene Green River Formation in Colorado and Wyoming

2. Thin coal beds, interbedded with carbonaceous shale, can occur in swamps near lake shorelines (for example, Flores, 1980, p. 93)

C. Deltaic deposits-type depends on dominant control (fig. $8 B$ )

1. The sediment-laden water, where interacting with relatively still bodies of water, can be subject to (for example, Leeder, 1982, p. 191):

a. Deceleration caused by diffusion and turbulence

b. Bed friction

c. Buoyancy forces d. Wave-induced currents

e. Tide-induced currents

2. Delta systems commonly are river, wave, and (or) tide dominated

a. River dominated (for example, the Mississippi delta)—delta plain is dominated by many large and small, rapidly changing distributaries, interdistributary bays, local lakes, and numerous channel changes (avulsions) as the delta progrades and gradient changes occur

b. Tide and wave dominated, for example, the Niger (Allen, 1970) and Guadalupe (Texas Gulf Coast) deltas (Donaldson and others, 1970; Dickinson and others, 1972) - the Niger is characterized by major coastal barrier islands and tidal inlets that cause the Niger to divide into many small channels, which are dominated by tides; the bed load is redistributed by severe wave action. The Guadalupe delta is reported to have features similar to those of Upper Cretaceous rocks of the Rocky Mountains and Pennsylvanian rocks of northern West Virginia

3. Coarsening-upward deposits on delta fronts may be cut by fining-upward, distributarychannel sands of the delta plain or by tidalchannel deposits of the delta front

4. Peat deposits commonly are located in backswamps at the top of progradational deltaic sequences, where the water is clear and sediment deposition is minimal

D. Coastal deposits

- Stratigraphic sequences produced by barrier island processes are different for regressive and transgressive phases (for example, Leeder, 1982, p. 195-201; Dickinson and others, 1972; Flores and others, 1982); for example:

1. Regressive barrier deposits may grade upward from (a) bioturbated shoreface mudstones, to (b) planar- and cross-stratified to trough cross-stratified deposits of the backshore-foreshore facies, to (c) cross-stratified sandstones of the wind-dune deposits

2. Transgressive barriers formed by sea transgressions may grade upward from (a) bioturbated lagoonal mudstones, to (b) trough cross-stratified flood tidal delta deposits, to (c) bioturbated deposits with planar and trough cross stratification, roots, and coal beds in the tidal flat and marsh-washover and washover facies, to (d) cross-stratified backshore dune sandstones 

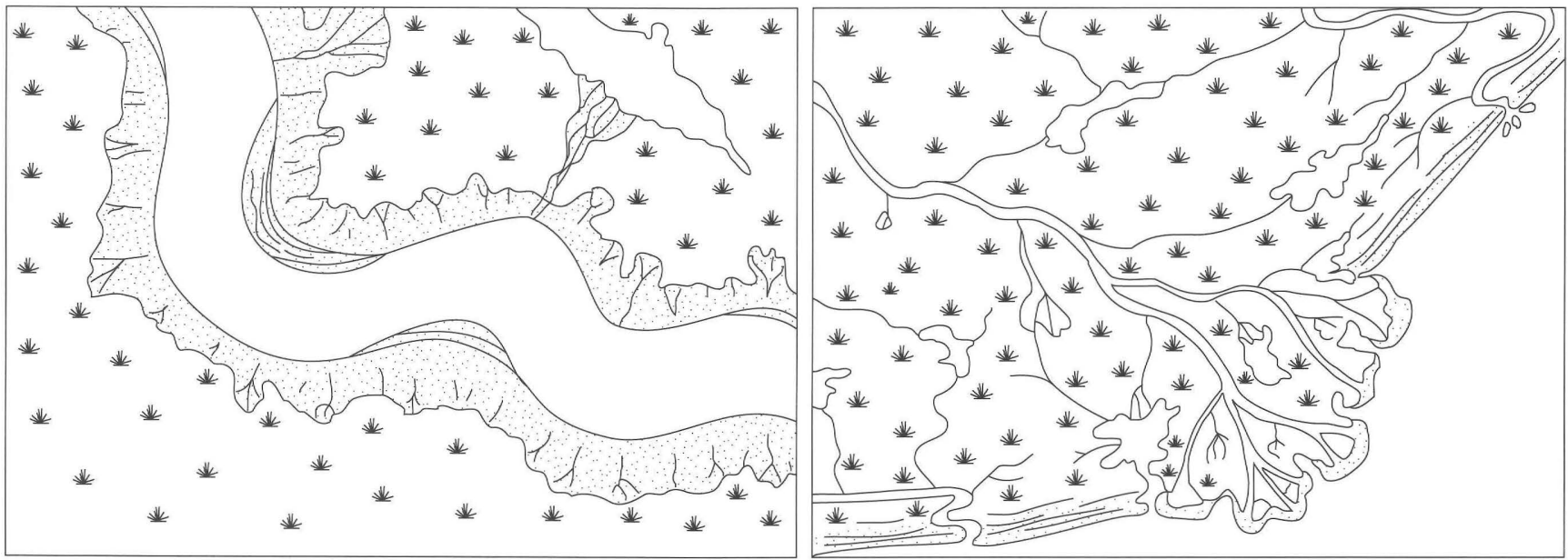

A

Fluvial (alluvial) model

$B$ Fluvial-influenced delta and strandplain model
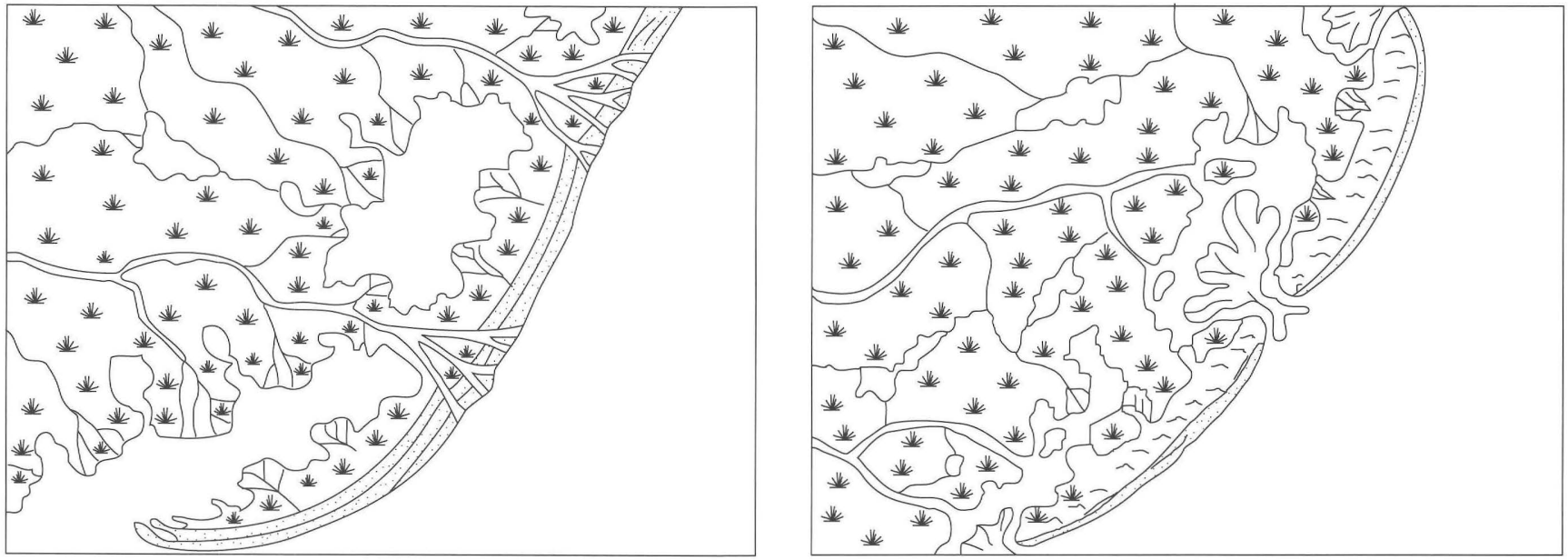

B

B

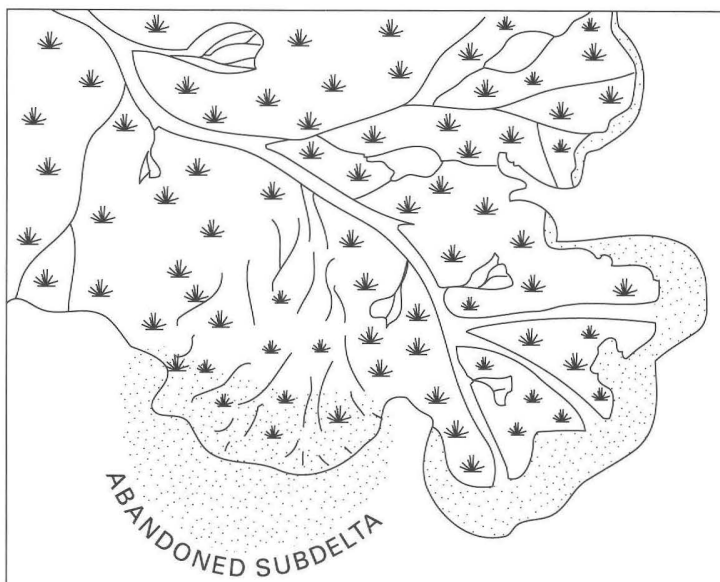

B

Fluvial-dominated delta model

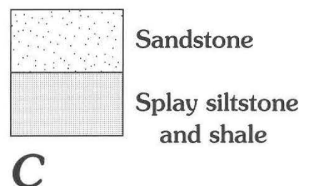

LEVEE DISTRIBUTARY CHANNEL

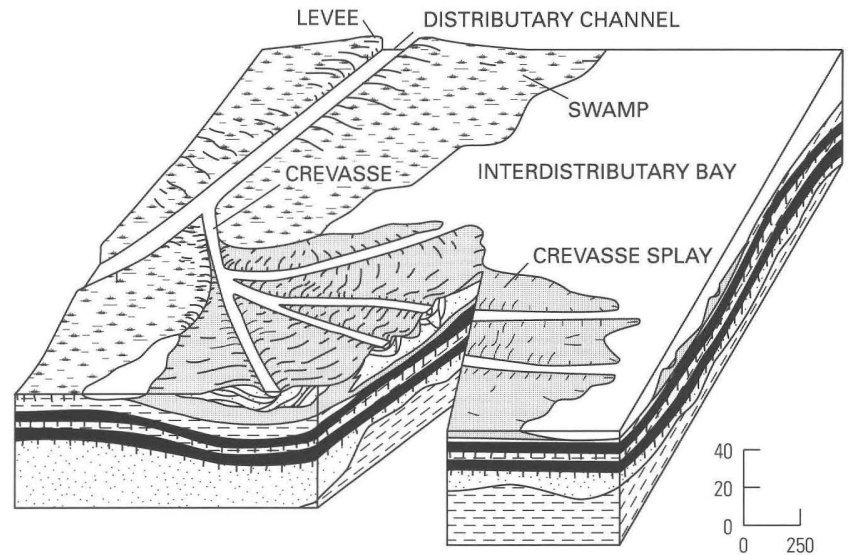

EXPLANATION

Figure 8. Models of various depositional environments. A, Fluvial model. $B$, Marine and fluvial models for wave- and fluvial-dominated deltas and barrier-island deposits. From Flores (1980, p. 18). $A$ and $B$, no scale. $C$, Crevasse splay deposits from the stratigraphic record in Kentucky. From Horne and others (1977, p. 92). 
Figure 9. Generalized stratigraphic column in Appalachian Basin relating lithology to the ratio of rainfall-to-evapotranspiration. The data are interpreted from coal quality and lithologic information. From C.B. Cecil and others (written commun., 1984).
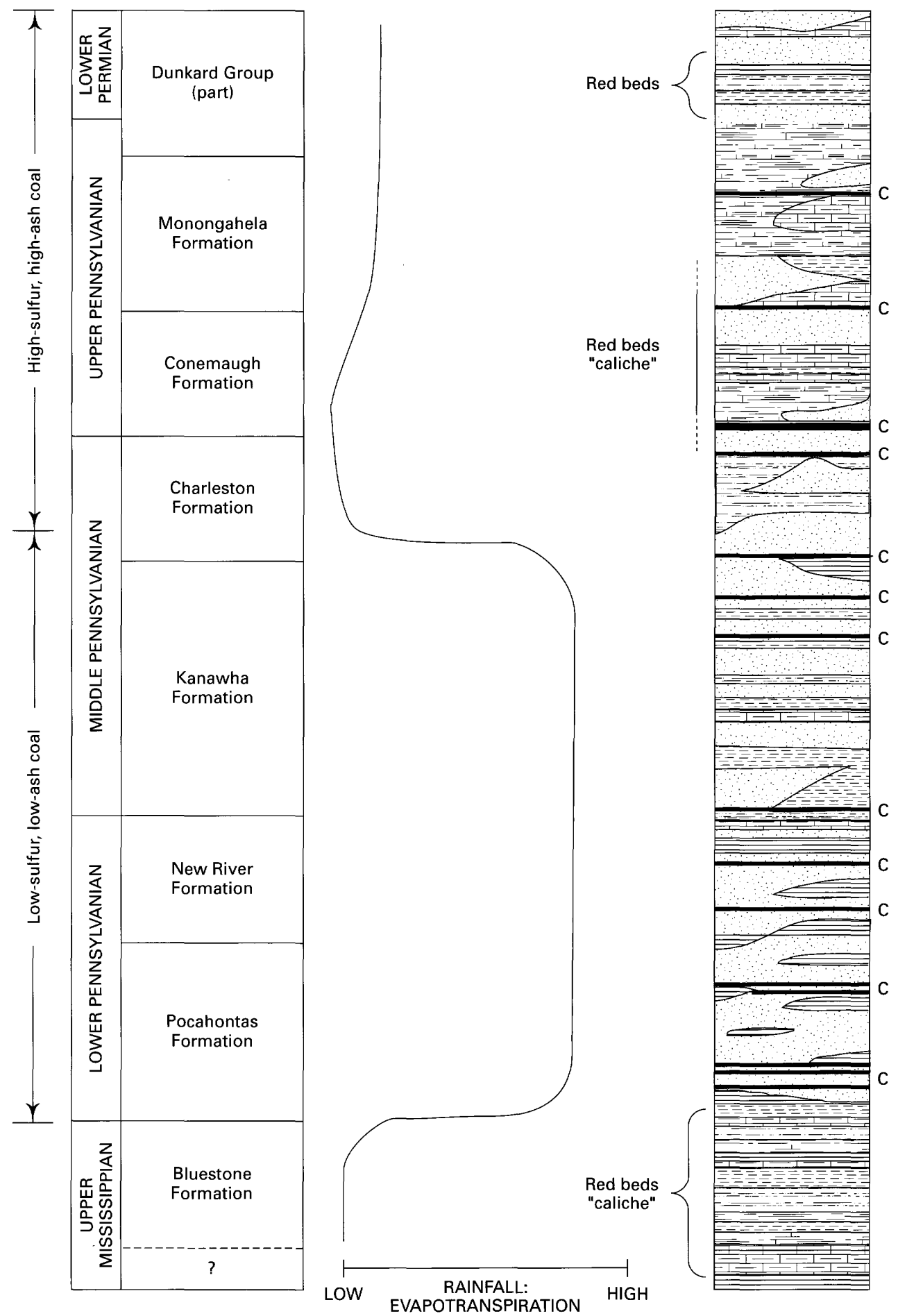

EXPLANATION

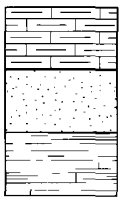

Limestone

Sandstone

Calcareous shale
Shale

Mudstone

Siltstone 
3. Barrier inlet deposits-commonly have a major effect on barrier deposits and are intimately related to both transgressive and regressive deposits; may contain fewer bioturbated deposits and deposits with root zones and coal zones and more cross-stratified and trough cross-stratified deposits than do deposits from prograding and transgressive barrier processes

4. Preservation of coastal deposits (including peat) during sea transgressions depends on (a) rate of rise in sea level, or (b) rate of subsidence (Leeder, 1982, p. 199) and (or) sediment supply; there may be:

a. Total preservation, where transgression is rapid

b. Partial preservation, where transgression is moderate

c. Complete loss, where transgression is slow

II. Paleotectonic Environment

- Must be favorable for continued peat accumulation (for example, Stach and others, 1975, p. 5-58)

A. Gradual and continual subsidence or rise in ground-water levels that keeps pace with accumulation of organic matter

B. Tectonic movements that reduce stream gradients and create environments favorable for the formation of peat

C. For thick coal beds to form (perhaps thicker than about $10 \mathrm{ft}$ ), tectonic lowering of the surface must keep pace with peat accumulation; tectonic activity also controls the position and trends of rivers, lakes, deltas, and shorelines

1. River and lake systems may be parallel to the axes of sedimentary basins; the axes of thick coals may also be parallel to the basin axes; tributaries may be at large angles to basin axes

2. Lagoonal coal deposits may be roughly perpendicular to river systems and may be parallel to the structures governing the shorelines

3. Delta coal deposits may be at various angles to the river and shoreline and basin axes

III. Coal-forming Environments-factors affecting coal thickness and quality

A. Depositional environment favorable for the formation of peat (Friedman and Sanders, 1978, p. 199-302; Fairbridge and Bourgeois, 1978, p. 165-167)

1. Flora must be available to form residual organic matter
2. Conditions must be favorable for the accumulation of organic material

a. Water must be poorly aerated (low oxygen levels) and acidic (Graf, 1980) as well as clear and stagnant with a constant high water table (Stach and others, 1975, p. 10) to prevent oxidation of the peat that has already formed

b. Sediment supply must be limited in areas where peat is accumulating, or else a bony coal or an organic shale or mudstone may result

3. Coal, particularly dull coals (clarites and durites) and sapropelic coals, can form from detrital organic matter (gyttja; see Fairbridge and Bourgeois, 1978, p. 394 for definition), that accumulates from the remains of floating plants, algae, pollen, and spores in lakes (Stach and others, 1975, p. 25-26)

4. The Permian Gondwanaland coals of South Africa and Brazil are believed to have formed in swamps between moraine deposits and retreating ice sheets, or on fluvialglacial fans (Stach and others, 1975, p. 16)

\begin{tabular}{|c|c|c|}
\hline & \multicolumn{2}{|c|}{ PEAT-FORMING ENVIRONMENT } \\
\hline Nutrient content & $\begin{array}{l}\text { Oligotrophic } \\
\text { (low nutrients) }\end{array}$ & $\begin{array}{l}\text { Eutrophic to mesotrophic } \\
\text { (moderate to high nutrients) }\end{array}$ \\
\hline Physiography & $\begin{array}{l}\text { high moor } \\
\text { (ombrogenous), } \\
\text { or low moor }\end{array}$ & low moor \\
\hline Water source & rain dominant & $\begin{array}{l}\text { surface and ground } \\
\text { dominant }\end{array}$ \\
\hline Geochemistry & $\begin{array}{l}\text { highly acidic }(\mathrm{pH}<4) \\
\text { phenol rich, antiseptic; } \\
\text { oxygen rich }\end{array}$ & $\begin{array}{l}\text { mildly acidic to nearly } \\
\text { neutral }(\mathrm{pH}>4) \\
\text { septic; oxygen poor }\end{array}$ \\
\hline Plants & $\begin{array}{l}\text { low diversity; } \\
\text { xeromorphic; } \\
\text { stunted }\end{array}$ & $\begin{array}{l}\text { high diversity; } \\
\text { luxuriant }\end{array}$ \\
\hline Degradation & $\begin{array}{l}\text { dominantly chemical; } \\
\text { cellulose preserved }\end{array}$ & $\begin{array}{l}\text { dominantly biological; } \\
\text { cellulose degraded }\end{array}$ \\
\hline $\begin{array}{l}\text { Corresponding coal } \\
\text { quality }\end{array}$ & $\begin{array}{l}\text { low ash (<10 percent); } \\
\text { low sulfur (<1 percent) }\end{array}$ & $\begin{array}{l}\text { high ash (>10 percent); } \\
\text { high sulfur (>1 percent) }\end{array}$ \\
\hline $\begin{array}{l}\text { Major stable minerals } \\
\text { in coal }\end{array}$ & kaolinite, quartz & $\begin{array}{l}\text { kaolinite, illite, quartz, } \\
\text { pyrite, calcite }\end{array}$ \\
\hline $\begin{array}{l}\text { Primary associated } \\
\text { lithologies }\end{array}$ & $\begin{array}{l}\text { sandstones, siltstones, } \\
\text { shales }\end{array}$ & $\begin{array}{l}\text { shales, siltstones, } \\
\text { sandstones, limestones, } \\
\text { calcareous paleosols }\end{array}$ \\
\hline $\begin{array}{l}\text { Central Appalachian Basin } \\
\text { formations (Series) }\end{array}$ & $\begin{array}{l}\text { Charleston Sandstone, } \\
\text { Kanawha Formation, } \\
\text { New River Formation, } \\
\text { Pocahontas Formation } \\
\text { (Lower to Middle } \\
\text { Pennsylvanian) } \\
\end{array}$ & $\begin{array}{l}\text { Dunkard Group, } \\
\text { Monongahela Formation, } \\
\text { Conemaugh Formation, } \\
\text { Allegheny Formation } \\
\text { (Middle Pennsylvanian } \\
\text { to Lower Permian) }\end{array}$ \\
\hline Paleoclimate & tropical; ever wet & tropical; monsoonal \\
\hline
\end{tabular}

Figure 10. General relationships between peat-forming paleoenvironments and resulting coal quality in the Central Appalachian Basin. From C.B. Cecil and others (written commun., 1984). 
IV. Paleoclimate

- In order to form low-sulfur, low-ash coals, the following is considered necessary (C.B. Cecil, written commun., 1984):

A. Ever-wet climate (Stach and others, 1975, p. 9); a climatic change from ever-wet to monsoonal probably occurred where sulfur and ash content increases (fig. 9)

B. Raised peat bogs - such as those found in Sumatra and Indonesia today - may also be a way to form low-sulfur, low-ash coals (example-Pocohontas No. 3; C.B. Cecil, oral commun., 1984)

1. Peat domes, which commonly have the shape of an inverted saucer, may be an example of how coals of low ash content are formed

2. Peat domes can form on any surface at any elevation relative to surface or ground water where the ever-wet annual precipitation exceeds about 24 in. $(700 \mathrm{~mm})$ (Stach and others, 1975, p. 9)

C. A necessary condition to form low-sulfur, lowash coals may be that the peat develops from:

1. Plants that grow in an acidic environment where water source is only from rainfall (oligotrophic environment)

2. Plants that are producers of few limbs with crowns, bulbous roots, and many spores (xeromorphic plants) (fig. 10)

V. Processes of Coal Formation (from organic material to coal) are thought to involve:

A. Volume reduction (compaction) of organic matter to form peat (peatification) (average ratio of about 5:1) (Stach and others, 1975, p. 33-34)

B. Compaction of peat to form coal (coalification)-based on percentage change in water content; Fairbridge and Bourgeois (1978, p. 169) and Stach and others (1975,p. 17-18) suggest the following ratios: (1) $2: 1$ for lignite, (2) $3: 1$ for subbituminous B coal, (3) 7:1 for high volatile bituminous $\mathrm{C}$ coal

C. The amount of compaction necessary for a given rank of coal depends somewhat on the type of plants involved, in addition to effective stress

1. Forest-type plants compress less than reed peats or gyttja

a. Pteridosperm peats must have compacted about $7: 1$ to reach the coking coal stage

b. For durites of Carboniferous age formed from gyttja, compaction may amount to as much as 20:1 (Stach and others, 1975, p. 18)

D. Two systems may be considered in coalification 1. Closed system (volatiles remain in system)
2. Open system (volatiles are squeezed out during compaction; probably the more common under many geologic conditions)

E. Time required to form coals from peat in a pressure cell at about $100^{\circ} \mathrm{C}$ ranges from 10 to 50 years (C.B. Cecil, oral commun., 1984)

VI. Genetic Types of Coal (coal facies)(Stach and others, 1975, p. 18-26)

A. Related to the components of the coal (macerals) and minerals

B. There are two types of coals

1. Autochthonous (peat formed in place)most minable coals are of this type

2. Allochthonous (plant detritus was transported considerable distances from where plants grew) - these coals are usually high in mineral matter

C. Macerals are divided into three groups, which in turn are divided into different types (for example, Stach and others, 1975, p. 55-108)

1. Vitrinite (woody parts of plants)

a. Telinite-macerals with cellular structures from tree trunks, branches, stems

b. Collinite-macerals of a gel-like consistency

c. Vitrodetrinite-translucent plant detritus

2. Exinite

a. Sporinite-the exterior walls (skins) of spores and pollen

b. Cutinite-remains of leaves, cuticles, stems

c. Resinite-natural resins produced by metabolism of plants

d. Alginite-remains of algae (boghead coals)

e. Liptodetrinite-fine detrital plant remains

3. Inertinite (highly decomposed humus, charcoal)-macerals do not soften like vitrinite and exinite groups during carbonization (coking) process-commonly consists of six basically different macerals (for details see Stach and others, 1975, p. 95-108)

a. Fusinite-from charcoal; forms fusain layers

b. Semifusinite-from partly charred plant tissues

c. Macrinite-amorphous, nongranular ground mass

d. Inertodetrinite-fine fragments or remains of fusinite, semifusinite, macrinite, or sclerotinite 
e. Micrinite-very small (approx. $1 \mu \mathrm{m}$ (micrometer)) grains, apparently formed from plant cells

f. Sclerotinite-hard, brittle remains of fungus, spores, and bacteria (for details see Stach and others, 1975, p. 95-108)

\section{PROPERTIES OF ROCKS}

\section{Physical Properties}

- Are a function of density, rock strength, hardness, and behavior during mining and commonly control the stability of mine openings; strength and hardness are controlled by rock texture, grain mineralogy, and type of matrix

A. Density-can be determined in the laboratory or by geophysical logging methods

B. Texture-determine with hand lens or binocular microscope

1. Grain size — phi scale—silty $\left(<2^{-4} \mathrm{~mm}\right)$, very fine $\left(2^{-3}\right.$ to $\left.2^{-4} \mathrm{~mm}\right)$, fine $\left(2^{-2}\right.$ to $\left.2^{-3} \mathrm{~mm}\right)$, medium ( $2^{-1}$ to $\left.2^{-2} \mathrm{~mm}\right)$, coarse $\left(2^{-0}\right.$ to $2^{-1}$ $\mathrm{mm}$ ), very coarse ( $2^{-0}$ to $2^{1} \mathrm{~mm}$ ) (for example, Leeder, 1982, p. 35)

2. Grain shape-angular, subangular, subrounded, rounded (influences packing framework)

3. Grain form-elongate to equidimensional (influences packing framework)

4. Arrangement-packing framework (along with grain size, shape, form and matrix or cement controls porosity and permeability)

C. Grain mineralogy-quartz, feldspar, mica, others

D. Matrix or cement-clay matrix; cement may consist of carbonates, silica, others (cementation may occur by diagenetic processes after sedimentation)

II. Sedimentary Characteristics (see, for example, Leeder, 1982, p. 85-116; Klein, 1977; Lahee, 1941, p. 80-89)

A. Bedding, laminations

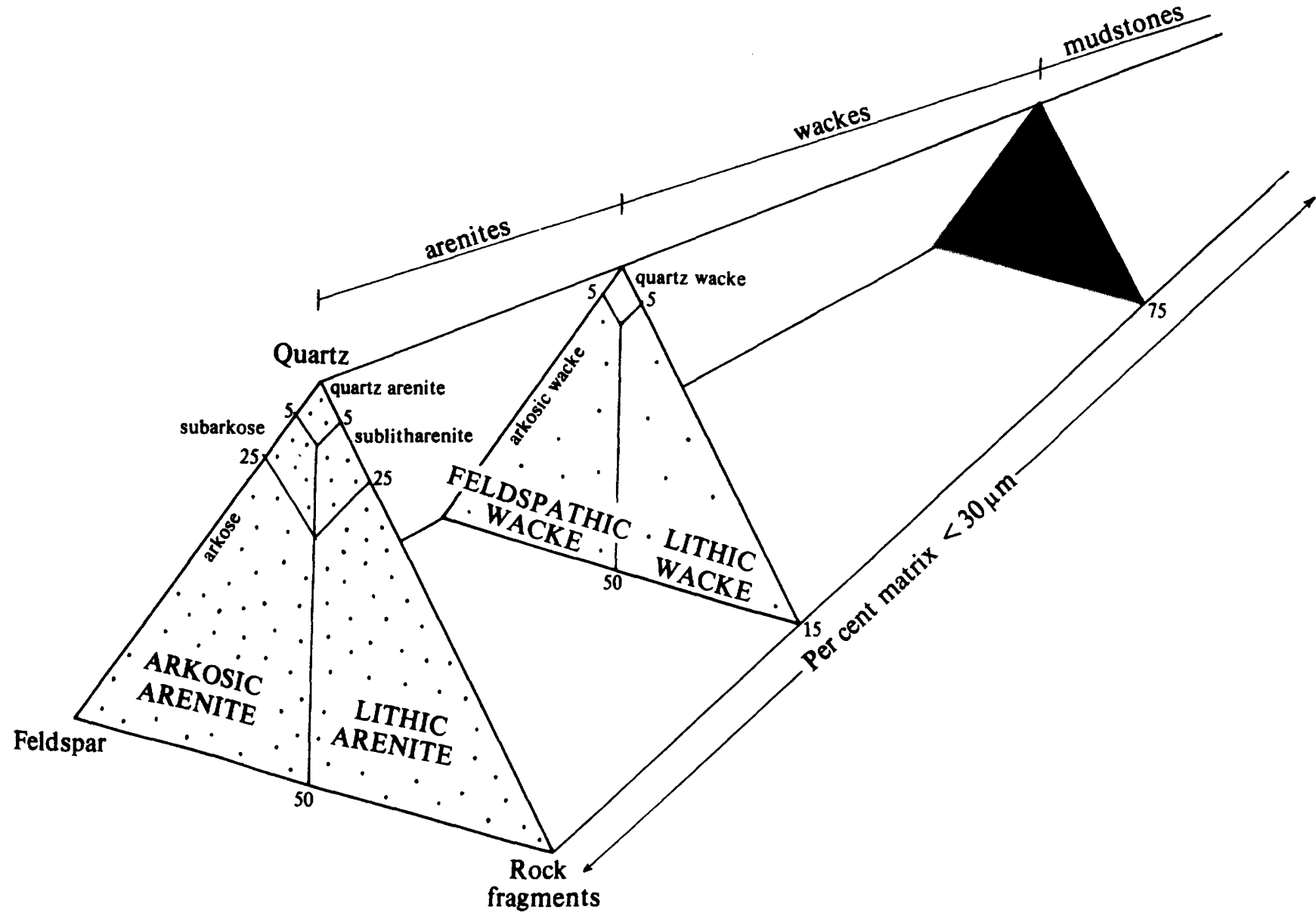

Figure 11. Classification of sedimentary rocks by lithology, grain size, and matrix. From Dott, 1964, and Pettijohn and others, 1972 (in Leeder, 1982, p. 283). Reproduced with concurrence of SEPM (Society for Sedimentary Geology). 
B. Crossbedding, graded bedding, cross laminations

C. Change in grain size with stratigraphic position

1. Fining upward

2. Coarsening upward

D. Biogenic structures

1. Sediment sources primarily animal remains, such as reefs and stromatolites

2. Sediments reworked by animals

a. Bioturbated rocks-animals can rework sediments faster than water and wind in some environments, such as Mugu Lagoon in California (John Warme, oral commun., 1984)

E. Index fossils (for example, Howard, 1972, p. 215-225; Hantzschel, 1975)

1. Certain animals are restricted to particular environments

2. Depositional environments and stratigraphic correlations often can be determined by using index fossils (Gill and Hail, 1975)

F. Soft sediment structures (have very important bearing on the stability of mine openings because they commonly cause planes or zones of weakness in their lithified components) (see, for example, LeBlanc, 1975; Klein, 1975, p. 78; Leeder, 1982, p. 113)

1. Liquifaction and water-escape structures

2. Rotational slides, slumps, growth faults

3. Dewatering pipes

4. Mud and sand volcanoes

5. Turbidity flow, debris flow

6. Differential-loading, compaction, and diapir structures

G. Diagenesis (lithification) (Leeder, 1982, p. 270-302) transforms:

1. Mud to mudstone

2. Sand to sandstone

3. Carbonate material to limestone, dolomite, others

III. Classification of Sediments

- Based on composition of components (primarily quartz, feldspar, rock fragments), texture, and matrix (size fraction less than $30 \mu \mathrm{m}$ (micrometers) in diameter) (fig. 11)
A. Arenites-less than 15 percent matrix
B. Wackes-15 to 75 percent matrix
C. Mudstones-greater than 75 percent matrix

IV. Bulk Properties of Grain Aggregates (see, for example, Lahee, 1941, p. 90-96)

A. Porosity - the percentage of space occupied by particle interstices per unit bulk volume of material (ratio of void volume to total volume)

1. Commonly increases with rate of deposition for a given lithology
B. Permeability - a measure of the relative ease of fluid flow through a material when subjected to differential pressure

1. Increases with increasing interconnection between pores

2. Decreases with increasing differential pressure

V. Microscopic Properties (see, for example, Stach and others, 1975)

A. Coal composition-components are macerals

B. Thermal maturation-vitrinite reflectance

1. Rank of coal can be determined by vitrinite reflectance on polished surfaces (Stach and others, 1975, p. 239-284)

C. Composition of coke-determined on polished specimens (Stach and others, 1975, p. 298-309)

D. Composition, texture, and structure of rocks near coal beds

VI. Geotechnical Properties (strength, engineering properties, and so on, discussed in geotechnical studies section)

\section{REMOTE SENSING APPLIED TO GEOLOGIC MAPPING}

I. Basic concepts (see, for example, Siegal and Gillespie, 1980; Green, 1983, for more detail)

A. Electromagnetic (EM) radiation from the sun is reflected and re-emitted from the ground surface into the air and outer space, where it can be detected by cameras, scanners, or other recording equipment aboard spacecraft, satellites, or aircraft

B. Quantum mechanics principles predict that absorption and emission of radiation spectra from the material will correspond to discrete energy levels present in the molecules and atoms of earth materials

C. The wavelength of the maximum spectral emission often is inversely proportional to the absolute temperature

D. The atmosphere attenuates EM radiation as a function of wavelength; the atmosphere is opaque to EM radiation at wavelengths of about $1.4,2.0,2.7-2.9,4.2-4.3,5.2-7.5 \mu \mathrm{m}$, and more than $13.9 \mu \mathrm{m}$, whereas the atmosphere transmits EM radiation at wavelengths of about $0-1.3$, 1.6-1.9, 2.1-2.6, 3.0-4.1, 4.4-5.1, and 7.6-13.8 $\mu \mathrm{m}$ (spectral windows) (fig. 12)

1. EM radiation detectors are designed to receive radiation through these wavelength windows

E. The frequency and amplitude of radiation emitted from the target area depend on the molecular 


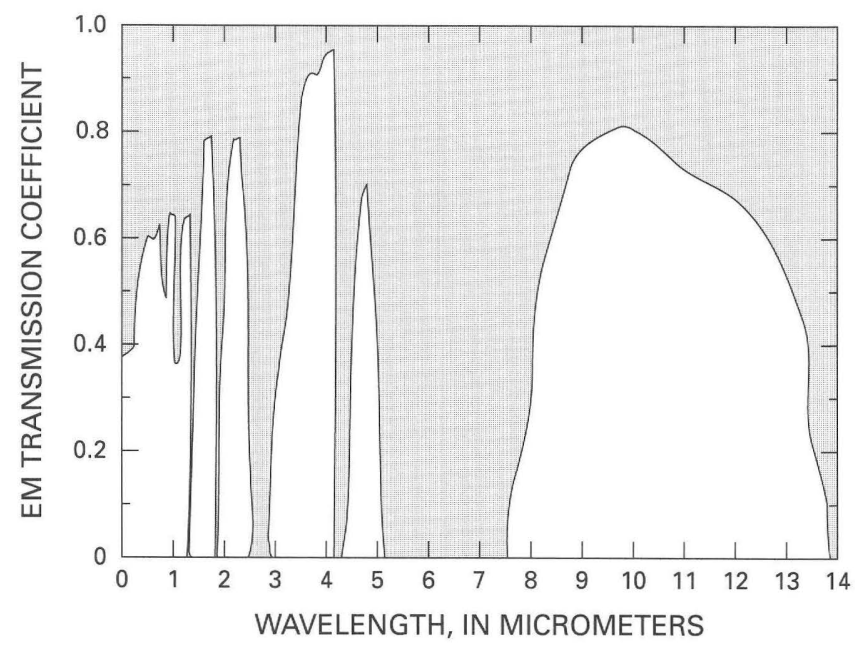

Figure 12. Typical transmission coefficients of electromagnetic (EM) radiation through the atmosphere $1.6 \mathrm{~km}$ thick as a function of wavelength. Atmosphere is opaque (shaded areas) at wavelengths of about $1.4,2.0,2.7-2.9,4.2-4.3$, and 5.2-7.5 $\mu \mathrm{m}$. Spectral windows (white areas between shaded areas) are the wavelengths that can be used to monitor and record electromagnetic radiation through the atmosphere from spacecraft and aircraft. Modified from Siegal and Gillespie (1980, p. 49).

and electronic transitions within the material in the target area

1. Important because, as a consequence, the wavelength and intensity will vary with the composition of the material in the target area

2. Spectral signatures can accurately characterize some substances and discriminate among others

a. For example, the gray scales of the Landsat multispectral scanner (MSS) images of clear water are different from images of water with suspended sediment

b. Therefore, water bodies with different amounts of suspended material can be identified

3. Spectral signatures from material composed of many substances, such as rock, soil, and vegetation, are less clear than spectral signatures of individual substances because of interaction between reflected and re-emitted radiation from the different molecules or atoms comprising the material

F. Wavelength and intensity of EM radiation reflected or absorbed and re-emitted from the material are detected and transmitted from spacecraft to Earth stations for recording and processing, or are detected by cameras in aircraft for direct processing

II. Image Enhancement
- Commonly is done optically or digitally to help analyze and determine rock units, rock properties, and geologic features (faults, landslides); results are field checked for accuracy

III. Basic Techniques to Distinguish between Reflectance and Emission Spectra of Elements of a Scene Involve:

A. Determining resistant versus nonresistant rock units (Siegal and Gillespie, 1980)

1. Gray scales may differ for reflected versus emitted EM radiation from different types of material and lithologies in different spectral bands

B. Changes in type and growth character of vegetation on rock units and features with various properties

1. Reflection and emission spectra of different types of vegetation may show different grayscale intensities

C. Manipulation of the gray scale of black and white images optically or digitally by

1. Expanding the gray-scale range or density values (contrast stretching)

2. Taking ratios of images in various spectral bands (image ratioing)

3. Enhancing the boundaries of various elements of a scene (edge enhancement)

D. False color images, made from filtered black and white images, that distinguish geologic attributes more clearly and more completely than the black and white images because the eye can distinguish many more colors than grayscale intensities

1. Different colors are produced in accordance with gray-scale differences in the various spectral bands

E. Digital classification of Landsat multispectral satellite data, in which vegetation patterns highlight geologic attributes. See for example Pettinger (1982, p. 30-32), including table of correspondences of image color with vegetation type

IV. Digital Image Processing (Enhancement)

A. A numerical representation of spectral radiance or other aspects, such as gravity, magnetic field, topographic relief, and thermal inertia

B. Spectral radiance identified by an array of numbers that represents radiance values, or data numbers (DN of Gillespie (1980, p. 139-226)), at each sample point on the image

1. The values can be stored on magnetic tape or disk, corrected for distortion, and enhanced by digital computer for use in geologic mapping 
C. Image enhancement that cannot be done optically can be done digitally; for example:

1. Various types of nonlinear transformations can enhance images far beyond the capabilities of optical techniques (see, for example, Gillespie, 1980, p. 139-226); two transformations particularly useful in geology are

a. Principal component transformation-creates new images whose probability density functions have orthogonal (independent) axes (see, for example, Gillespie, 1980, p. 195-202 for details)

b. Canonical analysis-a multiple discriminant analysis, which produces a transformation that maximizes the separation of the elements of a scene and geometrically produces a set of mutually orthogonal (independent) axes; the axes are fitted to the image information by rotation, translation, and scaling in such a way that the first new axis created yields the greatest amount of spectral variance (greatest amount of information) (see, for example, Abrams and Siegal, 1980, p. 408-409)

V. Applications to Geologic Analysis and Mapping

A. Aerial photographs-recorded on black-andwhite or color film

1. Used primarily in compiling geology in the field (field stereoscope) or the office using precision plotters (see Molnia, 1983, p. 1809 , for details) at scales of 1:5,000 to $1: 100,000$

-2. Coal beds, rocks associated with the coal beds, and surficial material can be mapped in detail on appropriate topographic maps using stereo models, stereoscopes, and precision stereographic plotters (for example, M'Gonigle, 1983, p. 1805-1807)
3. Color photos and color infrared photos are most valuable to distinguish coal beds, clinker (burn zones in coal areas), and other rock and surficial units in the Western United States (for example, Molnia, 1983, p. 1808)

B. Images from Earth-orbiting satellites, such as Landsat, are the most important source for Earth resource mapping at scales of $1: 100,000$ to $1: 5,000,000$ or more and where cloud cover and haze are not a continual problem

1. Many geologic features and types of vegetation can be distinguished by enhancing imagery by such methods as contrast stretching, image ratioing, principal component transformation, canonical analysis, and by making false color composites of the enhanced images at scales ranging from about 1:50,000 to $1: 5,000,000$ (see Blodget and Brown, 1982; Pettinger, 1982; Lang and others, 1987; and Sultan and others, 1987, for details)

2. Ratioing of images from the multispectral scanner (MSS) and thematic mapper (TM) can yield valuable information about geology, vegetation, and culture over large, inaccessible areas

3. Enhanced images may be overlaid or composited to topographic maps of appropriate scale

C. Landsat D has a TM with a ground resolution of about $100 \mathrm{ft}(30 \mathrm{~m})$; the MSS has a ground resolution of about $240 \mathrm{ft}(80 \mathrm{~m})$ except the thermal infrared wavelength, which has a ground resolution of about $360 \mathrm{ft}(120 \mathrm{~m})$

D. The following wavelengths and principal applications, which are related to the various atmospheric spectral windows (fig. 12), apply to the thematic mapper (Freden and Gordon, 1983, p. 548-549):

\begin{tabular}{ccll}
\hline Band & $\begin{array}{c}\text { Wavelength range } \\
\text { (micrometers) }\end{array}$ & Color & \multicolumn{1}{c}{ Principal applications } \\
\hline 1 & $0.45-0.52$ & Blue & Differences between soil and vegetation, coniferous and deciduous trees. \\
2 & $0.52-0.60$ & Green & Green reflectance of healthy vegetation. \\
3 & $0.63-0.69$ & Red & Absorption of chlorophyll for various plant species \\
4 & $0.76-0.90$ & Infrared & Delineates water bodies and biomass. \\
5 & $1.55-1.75$ & Infrared & Measures vegetation moisture; delineates snow and clouds. \\
6 & $10.4-12.5$ & Therm.IR & Thermal mapping; plant-stress mapping; estimating soil moisture. \\
7 & $2.08-2.35$ & Infrared & Mapping hydrothermally altered rocks. \\
\hline
\end{tabular}


VI. Automatic Classification of Features on the Surface of Earth and other Planets (Thematic Mapping)

A. A data analysis technique using algorithms that define image classes on the scene with similar spectral density (see, for example, Abrams and Siegal, 1980, p. 409-412)

B. Manipulation of selected color properties (hue, saturation, and intensity) of a digital image by coordinate transformation to enhance various aspects (geology, vegetation, water turbidity) of the target area (Green, 1983, p. 107-111)

1. Image classes may or may not be mutually exclusive

C. Two procedures for image classification

1. Supervised-image classes are determined by an operator using on-site knowledge of terrain (ground truth)

2. Unsupervised-image classes are determined using selected mathematical algorithms

\section{SUBSURFACE GEOLOGIC STUDIES}

- Basic concepts involve use of geologic maps made from outcrop studies, thematic maps from Landsat imagery combined with drilling, petrophysical logging, and seismic profiling to determine the (1) elevation, attitude, and thickness of coal beds or zones; (2) thickness of rocks above, between, and below coal beds or zones; and (3) physical and chemical properties of coal and associated rocks that are important to mine development

\section{Geologic and Thematic Maps}

- Use to design the location and spacing of drill holes and to select drilling procedures (core drilling, rotary drilling)

II. From Available Surface Map and Drilling and Logging Information Make Derivative Maps, such as:

A. Structural-contour maps of coal beds and other key horizons

B. Thickness maps of the coal beds

C. Overburden-thickness maps of strata above the coal beds

D. Lithologic maps of rocks above, between, and below coal beds

\section{Rotary Drilling Systems}

- Rotary drilling systems generally consist of (1) a mast or tower, (2) drill rods and a hardened steel or diamond bit and (or) core system, (3) rotary power system, and (4) circulation system such as a mud pump and tank; the system commonly is truck-mounted for portability (Cumming and Wicklund, 1975; Moore, 1974; and Lahee, 1941, p. 559-573)
- Using a normal circulation pattern, clean mud is circulated down the drill stem; mud and rock chips are brought up in the annulus between drill stem and drill hole (fig. 13)

A. Conventional system

1. Core is collected in core barrel located between end of drill stem and drill bit

2. All drill pipe must be removed from the borehole each time core container (core barrel) is full

B. Wire-line system

1. Consists of (1) an outer core barrel connected to thin-walled drill rods, (2) an inner core barrel that can be pulled through the drill rods, and (3) a catching, retrieving, and

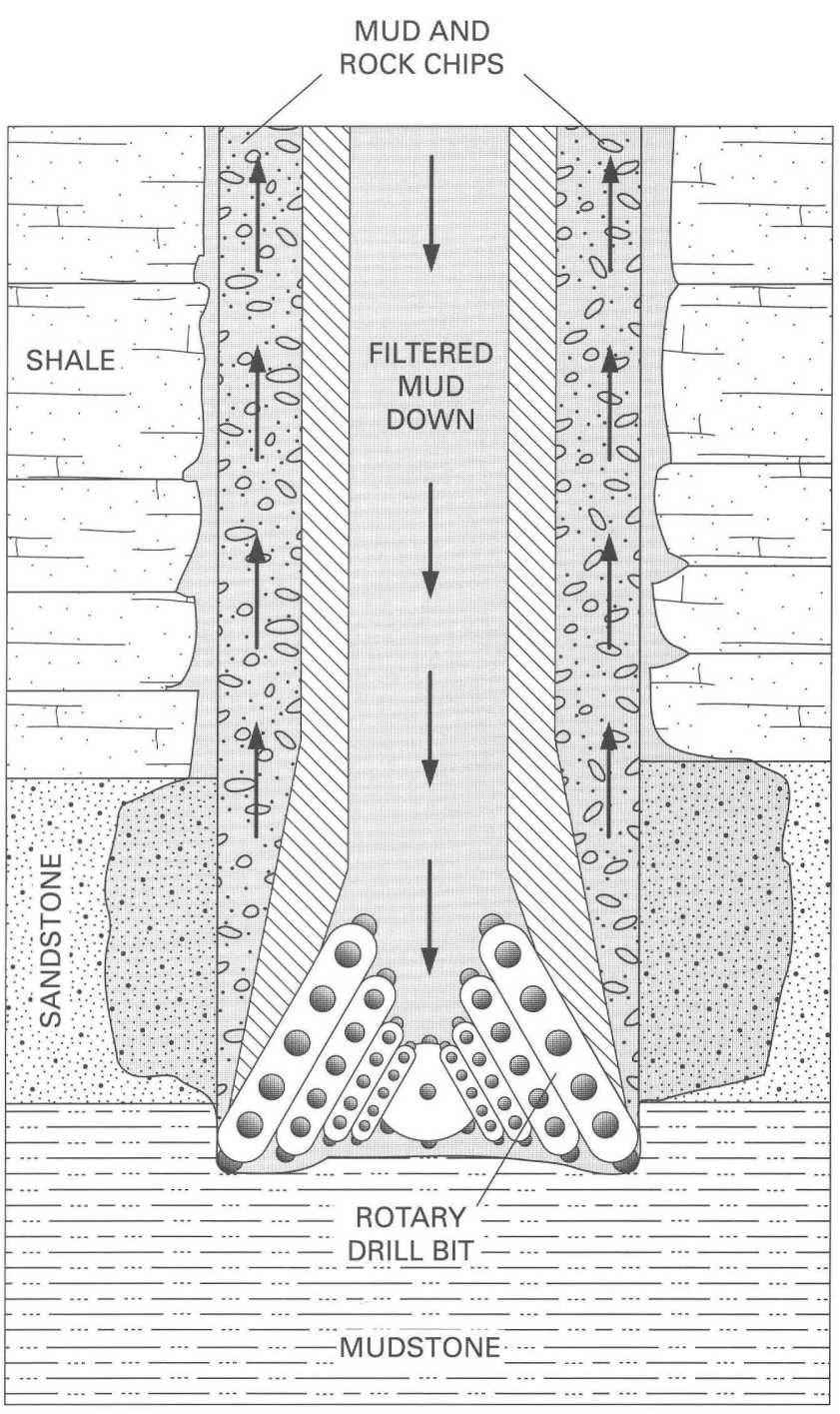

Figure 13. Diagrammatic profile showing a rotary drill bit, circulation of mud, and intrusion of mud into the sides of a drill hole. Drilling mud intrudes further into more permeable sandstones than into less permeable shale and mudstone. Shown at about $1 / 2$ scale. Modified from Friedman and Sanders (1978, p. 417).Used with permission. 


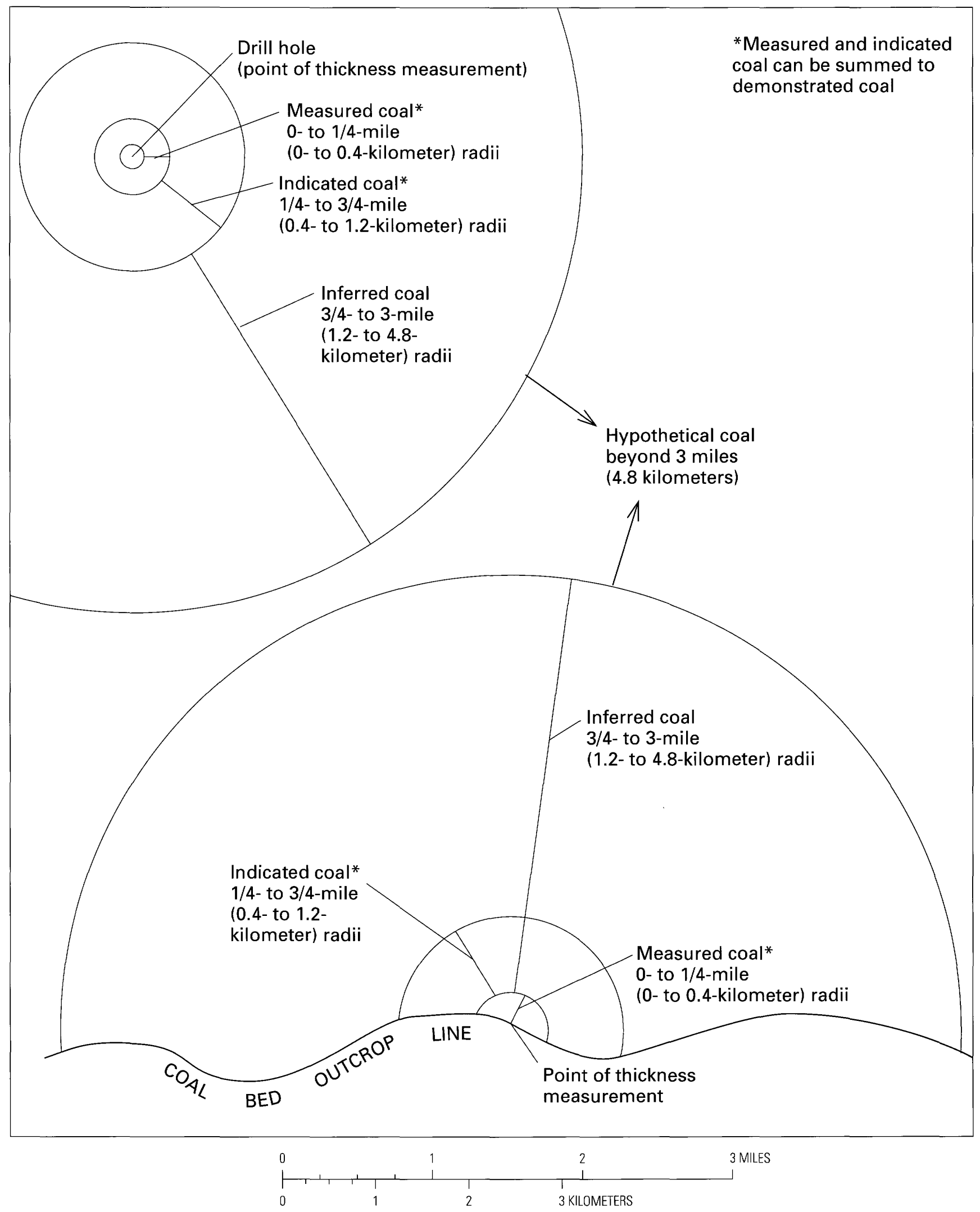

Figure 14. Plan view showing reliability categories of outcrop and drill-hole data for classification of coal resources, based on distance from points of measurement. From Wood and others, 1983, p. 11. 
hoisting assembly that pulls the inner core barrel when full

2. This system saves time and money compared to the conventional coring system at depths of more than about $400 \mathrm{ft}$ according to Cumming and Wicklund (1975, p. 64), but applicable depth may be about $300 \mathrm{ft}$ in some cases

3. Core barrel is removed from inside drill pipe by small steel cable (wire line) without removing drill rods from hole

4. Core quality depends on maintaining proper rotation speed, bit pressure and circulation, not overfilling core barrel, and not dropping and redrilling core

C. Rotary drilling (drilling without taking core)

1. Drilling is continuous except to insert another length of drill rod or to change the bit

2. Circulation medium is air, foam, or mud

3. Fresh-water or salt-water mud usually is put in hole prior to petrophysical logging, where mud is not used in drilling

a. Drilling muds also can be used to protect against blowouts: use a mud that has a density great enough such that the hydrostatic pressure of the mud is

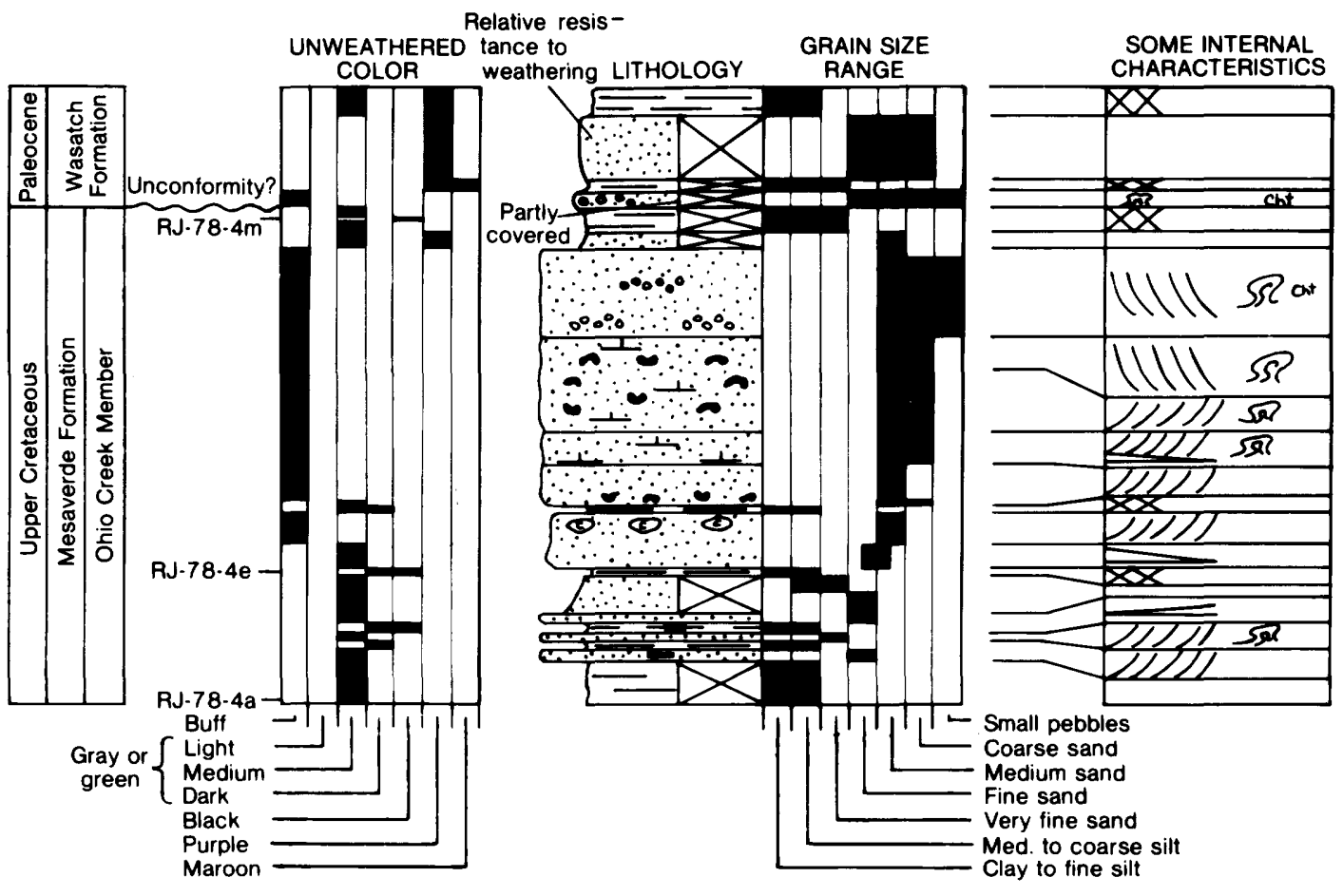

EXPLANATION
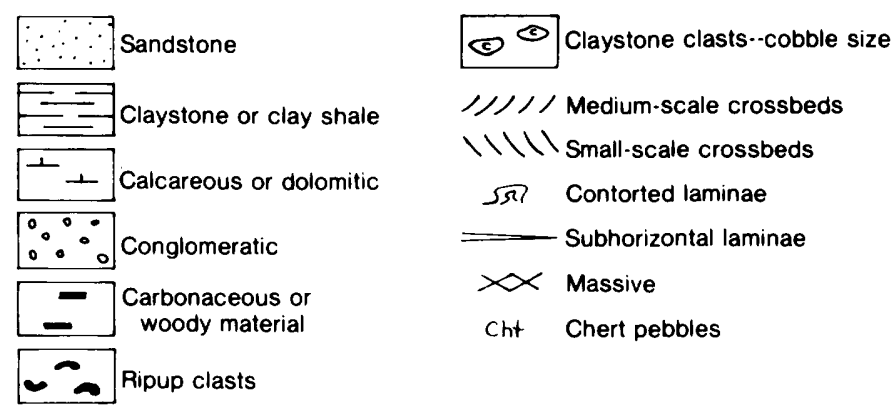

\section{A}

Figure 15 (above and facing page). Geologic logs showing lithology, relative resistance to weathering, grain size, and internal characteristics. $A$, Sample $\log ; B$, Log of the Upper Cretaceous Hunter Canyon Formation including the Ohio Creek Member in western Colorado. From Johnson and May (1980, p. 7-9). 

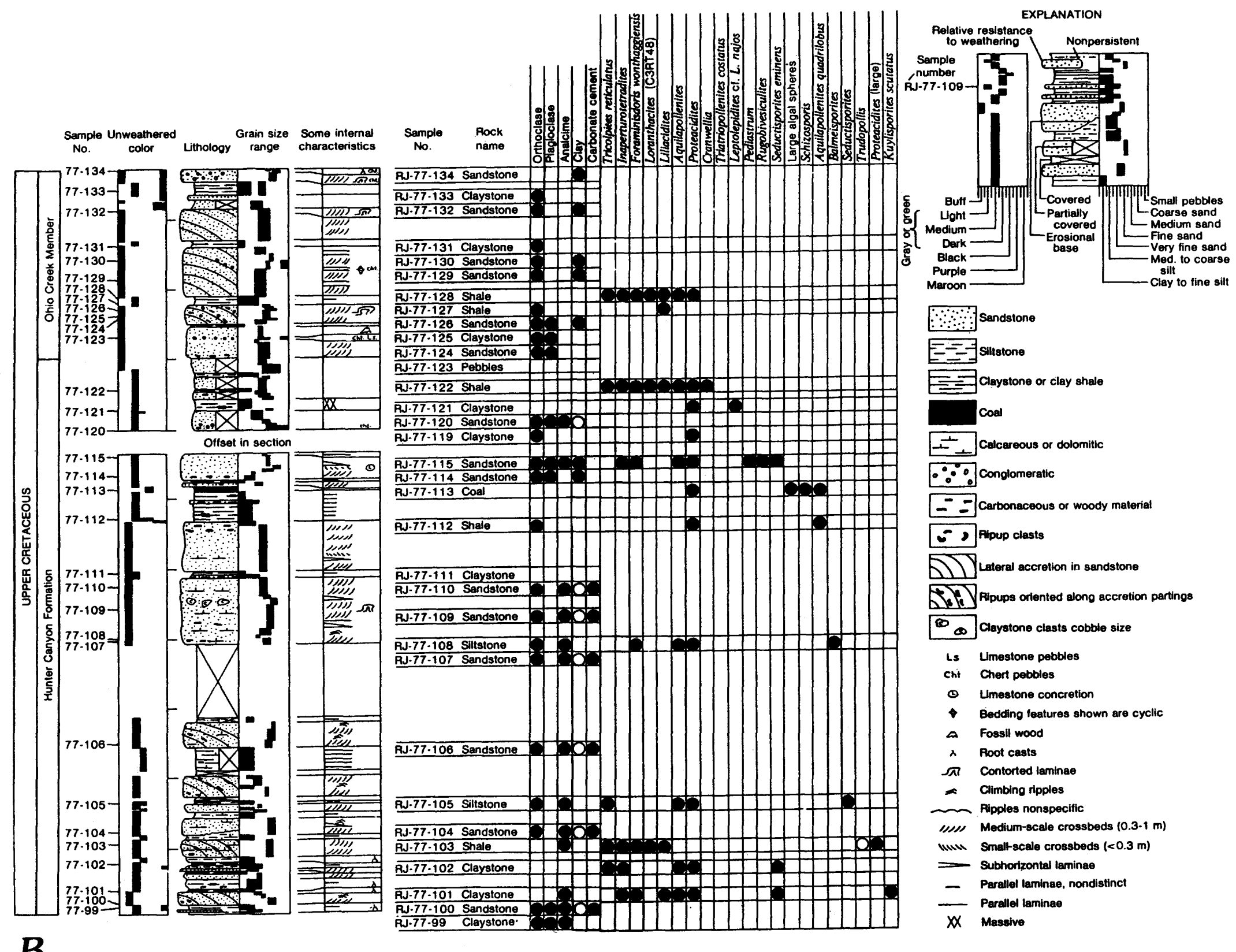
greater than the pressure of the formation

D. Twin-hole drilling commonly involves

1. Core drilling an index hole for lithologic and geotechnical control

2. Rotary drilling a hole near the core hole to produce a straight hole of uniform diameter in order to obtain better petrophysical logs

IV. Locating Drill Sites

A. Use available information on structure and thickness of the coal bed(s) from geologic maps for best results

1. Select drill sites as needed to supplement and augment outcrop information

2. Required spacing of drill holes for accurate correlation of coal beds varies with depositional environment of the coal-bearing rocks, but, as stated, may range from 2,000 to $8,000 \mathrm{ft}$ (fig. 2)

3. Reliability categories for classification of coal resources on the basis of distance between data points have been standardized by the USGS (U.S. Geological Survey) in the following manner (fig. 14; Wood and others, 1983, p. 2-11):

a. Measured -0 to $1 / 4 \mathrm{mi}$ from data point

b. Indicated-1/4 to $3 / 4 \mathrm{mi}$ from data point

c. Inferred-3/4 to $3 \mathrm{mi}$ from data point

d. Hypothetical-more than $3 \mathrm{mi}$

B. Locate position of drill site accurately with respect to section, township, and range, latitudelongitude coordinates $(\mathrm{x}, \mathrm{y})$, and elevation above sea level $(\mathrm{z})$

1. Survey location to within a few centimeters of horizontal and vertical position using, for example,

a. Precision theodolite (about 1 second accuracy) and distance measuring device for establishing primary triangulation stations to within an accuracy of a few centimeters

b. Theodolite and distance measuring device and level or laser for locating drill-hole sites with an accuracy of a few decimeters (about $1 \mathrm{ft}$ )

\section{Geologic logging}

- Logging of drill core and drill holes commonly involves obtaining lithologic, geotechnical, and petrophysical logs (geotechnical and petrophysical logging is discussed in the section "Geotechnical Studies"); geologic and geotechnical logging should be done concurrently to save time and money

1. Logging involves examining washed and (or) split core to determine lithology, primary and secondary structure, and texture on a foot-byfoot basis (fig. 15)

a. Lithology-can be determined by hand lens or binocular microscope and noted on $\log$ in writing or graphically

b. Primary sedimentary structures-such as bedding, crossbedding, soft sediment structures, biogenic structures-can be observed with the naked eye, hand lens, or binocular microscope and noted on $\log$ in writing or graphically; secondary structures-such as joints, cleat, fractures, and faults-can be observed and noted on log in writing or graphically

c. Texture-size, shape, and arrangement of grains and matrix - can be observed with binocular microscope or hand lens for coarser grained rocks and logged descriptively or graphically

V. Methods of Determining Coal Resources (Wood and others, 1983)

- Definition of resource- "naturally occurring concentrations or deposits of coal in the Earth's crust, in such forms and amounts that economic extraction is currently or potentially feasible" (Wood and others, 1983, p. 19); the resource may be hypothetical (undiscovered) or identified

- Reserve is differentiated from resource by being those parts of an identified resource "that meet specified minimum physical and chemical criteria related to current mining and production practices, including those for quality, depth, thickness, rank, and distances from point of measurement" (Wood and others, 1983, p. 18-19) and which are economically extractible under existing environmental, legal, and technological constraints

- Coal-bed thickness, quality (sulfur, ash, energy content (in $\mathrm{Btu} / \mathrm{lb}$ or $\mathrm{cal} / \mathrm{g}$ )), rank, structure, and overburden thickness can all be measured, analyzed, and mapped at the same time

A. Maps are usually made during drilling and exploration, mine site evaluation, or early mine design phases; map products should therefore include

1. Thickness map(s) of the coal bed(s), including use of reliability categories (fig. 14; see, for example, Wood and others, 1983; Roehler, 1979)

2. Data on coal quality (calorific values, sulfur, ash, moisture content)

3. Structure contour map(s) of the base or top of the coal bed(s) of the area of interest from measured sections, drilling, and logging; contours commonly are constructed by hand 


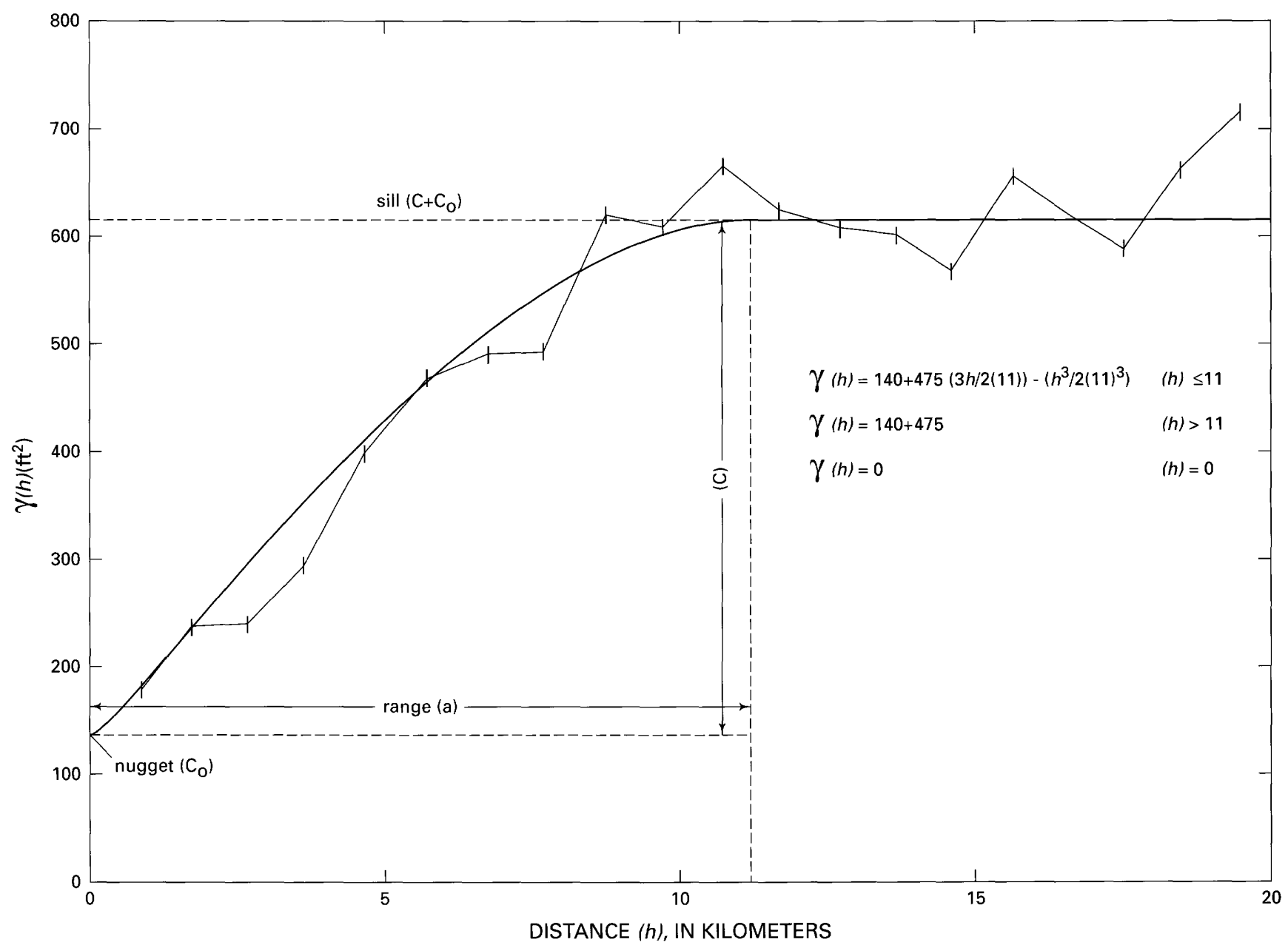

Figure 16. Semivariogram of coal thickness showing data points that have been fitted to a spherical model; a, range, horizontal distance at which curve becomes flat; C, sill, point at which curve becomes flat. Modified from Pierce and others (1982, p. 265).

or computer from drill-hole and outcrop measurements

4. Thickness of the rocks between coal beds (interburden maps) where more than one coal bed is present

5. Overburden thickness map(s)

6. Thickness and geotechnical properties of rocks beneath the coal

B. Coal-bed thickness commonly varies with direction for coal deposits; thickness may often be most uniform parallel to the axes of deposition and least uniform at right angles to this trend

1. Thickness maps of small areas commonly are compiled by hand-drafting methods, using stratigraphic framework data to help determine the distribution of the thickness, rank, and coal quality data in relation to depositional environment

2. Mathematical-statistical methods can be used to help provide the most reliable estimate values, such as elevation of coal bed(s), thickness, rank, sulfur, ash, moisture content, calorific value between data points

a. Using these methods usually requires that the values of the data points be entered into a computerized data base that has the flexibility and power to efficiently process the information of interest by various geologic, mathematical, and statistical methods at various scales

C. Mathematical-statistical methods, such as Kriging, have been used to obtain regional estimates of coal thickness and quality between data points

1. The Kriging method takes into account location and spacing of data points and variance of data with a minimum of error variance (figs. 16-18; Clark, 1979; F.W. Pierce and others, written commun., 1983; Pierce and others, 1982; Mousset-Jones, 1980; Rendu, 1982) 


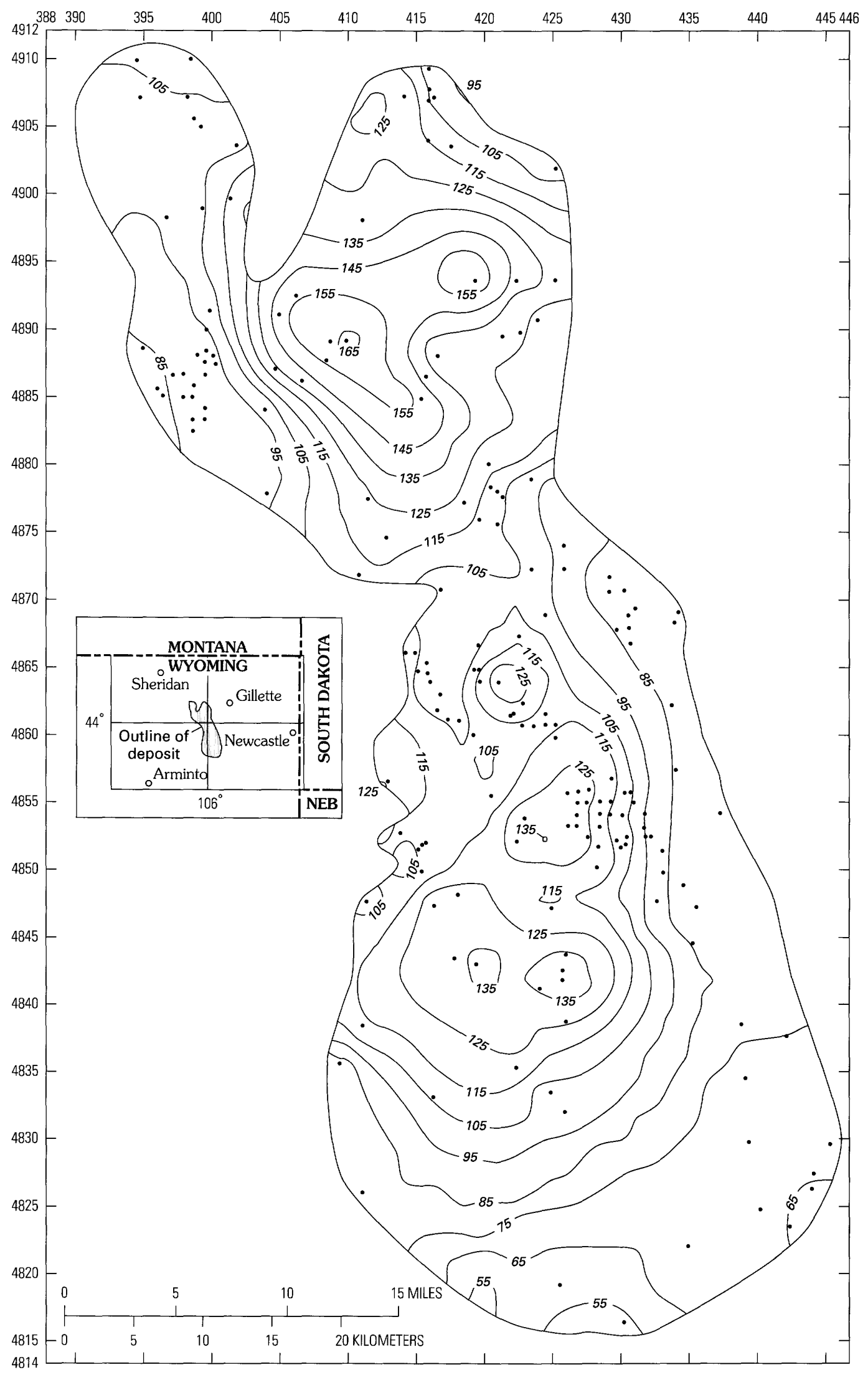

Figure 17. Map of Anderson coal deposit, Powder River Basin, Wyoming, showing estimated thickness determined by Kriging and the semivariogram (fig. 16). Contour interval $10 \mathrm{ft}$. Marginal scale divisions are UTM grid, zone 13, in kilometers. From Pierce and others (1982, p. 266). 
Figure 18. Map of Anderson coal deposit showing estimated Kriging variances. Contour interval is $75 \mathrm{ft}^{2}$; marginal scale divisions are UTM grid, zone 13 , in kilometers. From Pierce and others (1982, p. 266).

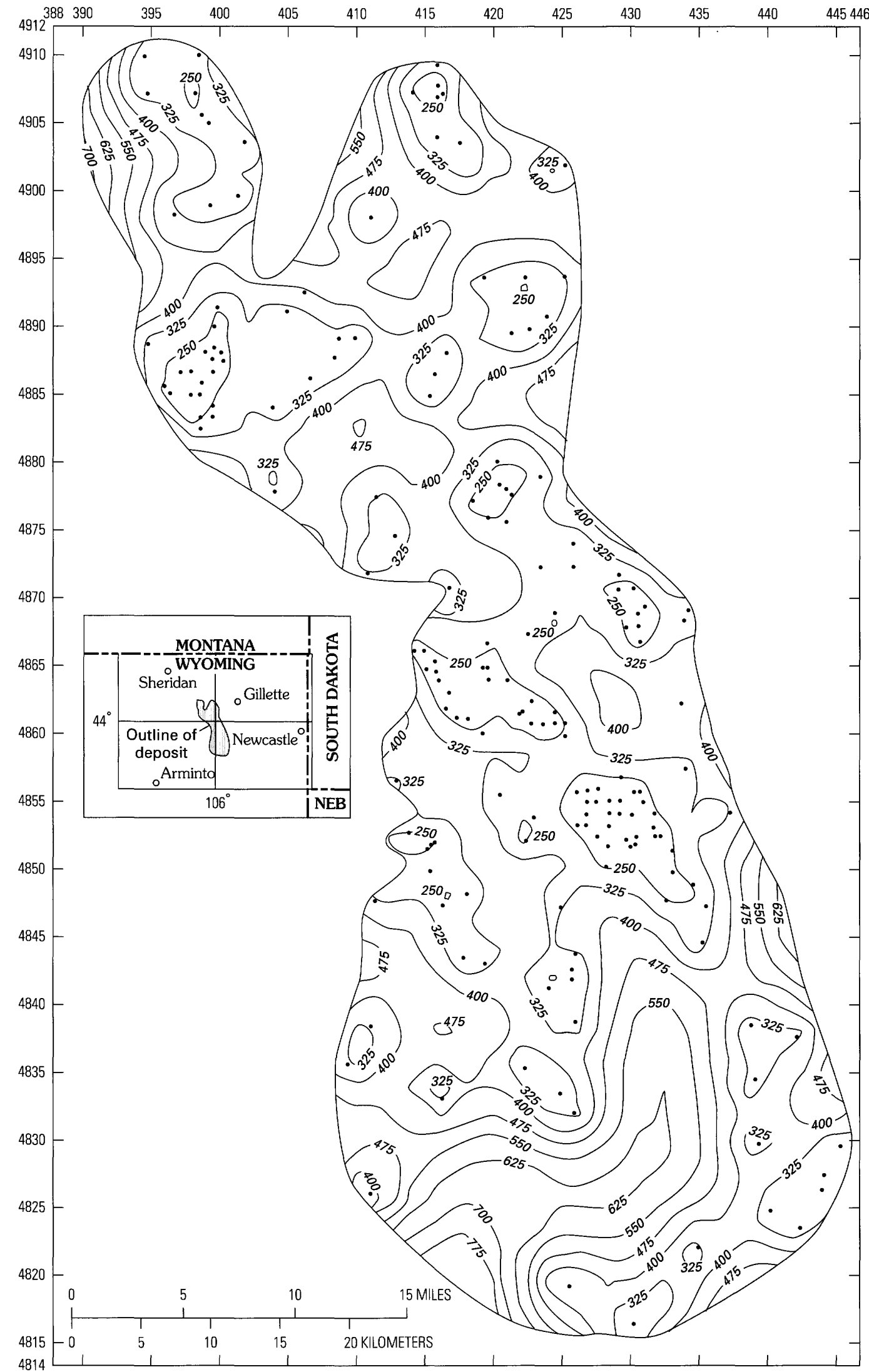


2. Values such as thickness, Btu, sulfur, moisture, and ash content commonly have some degree of regional or areal continuity, and must be separated into homogeneous groups or subsets, or regionalized by (1) coal bed or zone, (2) depositional environment, or (3) burned, weathered, or slumped areas

3. Estimate the value of a regionalized variable at a point (called point Kriging) or over an area (block Kriging)

a. Calculate statistical weights for the data points

1- The estimates are obtained by summing the products of the sample

\begin{tabular}{|c|c|c|c|c|c|}
\hline $\begin{array}{c}\text { Township } \\
\mathrm{N} .\end{array}$ & $\begin{array}{c}\text { Range } \\
\text { W. }\end{array}$ & $\begin{array}{c}\text { Area } \\
(\text { acres })^{1}\end{array}$ & $\begin{array}{c}\text { Kriged } \\
\text { thickness } \\
(\text { feet })^{1}\end{array}$ & $\begin{array}{c}\text { In-place } \\
\text { coal } \\
\text { (megatons) }\end{array}$ & $\begin{array}{c}0.95 \text { error } \\
\text { limits } \\
\text { (percent) }\end{array}$ \\
\hline 50 & 79 & 12,084 & 101.5 & 2,172 & \pm 19 \\
\hline 50 & 78 & 9,507 & 104.9 & 1,766 & \pm 11 \\
\hline 50 & 77 & 10,018 & 123.3 & 2,185 & \pm 15 \\
\hline 50 & 76 & 7,767 & 105.0 & 1,444 & \pm 14 \\
\hline 49 & 79 & 8,669 & 98.9 & 1,518 & \pm 26 \\
\hline 49 & 78 & 16,669 & 109.7 & 3,237 & \pm 13 \\
\hline 49 & 77 & 21,056 & 135.1 & 5,035 & \pm 14 \\
\hline 49 & 76 & 23,020 & 135.7 & 5,530 & \pm 12 \\
\hline 49 & 75 & 273 & 130.8 & 63 & \pm 18 \\
\hline 48 & 79 & 5,051 & 87.8 & 785 & \pm 17 \\
\hline 48 & 78 & 23,041 & 106.7 & 4,353 & \pm 7 \\
\hline 48 & 77 & 23,189 & 148.9 & 6,113 & \pm 9 \\
\hline 48 & 76 & 21,703 & 125.6 & 4,826 & \pm 12 \\
\hline 47 & 78 & 8,912 & 92.9 & 1,466 & \pm 20 \\
\hline 47 & 77 & 22,489 & 121.1 & 4,821 & \pm 12 \\
\hline 47 & 76 & 21,614 & 110.5 & 4,228 & \pm 8 \\
\hline 47 & 75 & 3,103 & 87.6 & 481 & \pm 23 \\
\hline 46 & 77 & 4,607 & 105.4 & 860 & \pm 10 \\
\hline 46 & 76 & 22,617 & 105.8 & 4,235 & \pm 9 \\
\hline 46 & 75 & 19,416 & 88.1 & 3,026 & \pm 12 \\
\hline 45 & 77 & 7,486 & 116.5 & 1,543 & \pm 15 \\
\hline 45 & 76 & 23,344 & 113.7 & 4,698 & \pm 9 \\
\hline 45 & 75 & 22,610 & 101.2 & 4,052 & \pm 10 \\
\hline 45 & 74 & 2,953 & 80.2 & 419 & \pm 24 \\
\hline 44 & 77 & 10,323 & 115.7 & 2,114 & \pm 14 \\
\hline 44 & 76 & 22,545 & 126.5 & 5,046 & \pm 10 \\
\hline 44 & 75 & 23,639 & 104.5 & 4,374 & \pm 10 \\
\hline 44 & 74 & 11,556 & 82.4 & 1,686 & \pm 29 \\
\hline 43 & 77 & 15,833 & 107.8 & 3,020 & \pm 16 \\
\hline 43 & 76 & 23,675 & 122.8 & 5,148 & \pm 12 \\
\hline 43 & 75 & 23,667 & 104.4 & 4,375 & \pm 22 \\
\hline 43 & 74 & 11,551 & 77.4 & 1,583 & \pm 20 \\
\hline 42 & 77 & 13,818 & 87.2 & 2,132 & \pm 26 \\
\hline 42 & 76 & 23,706 & 93.5 & 3,923 & \pm 27 \\
\hline 42 & 75 & 23,567 & 82.0 & 3,422 & \pm 31 \\
\hline 42 & 74 & 22,091 & 70.7 & 2,765 & \pm 18 \\
\hline 42 & 73 & 410 & 72.0 & 52 & \pm 30 \\
\hline 41 & 77 & 535 & 82.5 & 78 & \pm 50 \\
\hline 41 & 76 & 12,697 & 72.4 & 1,627 & \pm 38 \\
\hline 41 & 75 & 16,328 & 64.8 & 1,874 & \pm 24 \\
\hline 41 & 74 & 4,903 & 71.1 & 617 & \pm 35 \\
\hline \multicolumn{2}{|c|}{ TOTAL (or average) } & 602,042 & $2(105.7)$ & $112,700 \pm 4 \%$ & \\
\hline
\end{tabular}

${ }^{1}$ Values rounded for inclusion in table, but not for calculations.

${ }^{2}$ Average thickness value for deposit. values and their respective weighting factors

2- The resulting weights have a minimum error variance and are unbiased

b. Probabilistic confidence limits of the variable estimates can be derived from the error variance (for general information on the Kriging technique, for example, see Mousset-Jones, 1980, chap. 1-4)

4. Select the model that best fits the spatial correlations of the values by using such functions as the semivariogram

a. The semivariogram is "a graph that gives one-half of the mean squared difference of point values separated by any distance $h$ " (F.W. Pierce and others, written commun., 1983) (fig. 16)

b. The validity of the semivariogram model can be tested by cross validation procedure, whereby a data point is removed from the data set, its value is estimated from the model using the remaining data points, the point is put back in the data set, and another point is removed and checked until the variance of all points has been estimated

c. The experimentally and mathematically fitted semivariograms for an area are compared (fig. 16)

1- Kriging of a particular block of coal land can be done after an acceptable model has been chosen

2- Estimates of the average value of such aspects as coal thickness, sulfur content, or Btu values can be made (fig. 17)

Figure 19. Tabulation of coal in-place in the Anderson coal deposit by township in western Wyoming. Values in millions of short tons ( 1 short ton equals 0.907 metric ton); coal is assumed to weigh 1,770 short tons per acre-foot. From Pierce and others (1982, p. 263). 
3- Kriging variance of selected values, such as coal thickness or rank, can also be estimated for the block or for a particular point or points of interest (fig. 18)

4- Estimates of coal tonnages can be tabulated and statistical error limits determined from tables (fig. 19) without using intermediate isopach maps that can be a source of error and that provide no statistical error limits

d. Point Kriging can also be used, for example, to make contour maps of the top, bottom, or thickness of a coal bed, or of sulfur, ash, moisture, Btu values at one or more points; the method can be used to:

1- Produce a regularly spaced grid of the estimated values

2- Evaluate the precision of the Kriged estimate; maps can then be made that show where need for additional data is greatest (fig. 18)

a- Drill holes can be hypothetically added in the Kriging process and new error variance maps made until the error variance is at an acceptable level before any more drilling is done

D. Surface modeling programs for microcomputers and minicomputers can be used to make contour maps from point data, such as drill holes, observation points on outcrops, or Kriged data

- The basic concept involves making various two-dimensional maps and three-dimensional perspective diagrams from drill-hole and outcrop data

- This procedure facilitates analysis and plotting of geologic data and virtually eliminates need for drafting

- The general procedures are as follows (Gardner and Carter, 1986):

1. Create a uniform grid from the data, such as $x, y$ coordinates and elevation of tops and bottoms of coal beds and other important lithologies

a. Use a digitizing tablet and mouse to enter $\mathrm{x}$ and $\mathrm{y}$ coordinates and elevations of the ground surface and values of interest at points on a working map

b. Calculate uniform grids of surfaces comprising the ground surface and of tops and bottoms of units of interest from the scattered data files
2. Construct the necessary annotation files, such as faults, polygon data (lease tracts, land nets, others), planimetric data (roads, towns, and other types of boundaries), and necessary text information

3. Plot maps, cross sections, fence diagrams, and perspective diagrams by combining the necessary files for the product needed; name the plot file, and transmit the file to plotter

\section{GEOTECHNICAL STUDIES}

- Involve the study and analysis of the strength, slake durability, engineering properties, and deformation characteristics of the coal and associated rocks by field and laboratory testing and by petrophysical methods

- These are important to mine design (for more details see, for example, Peng, 1978, p. 43-51; Bell, 1975, p. 25-39)

\section{FIELD AND LABORATORY TESTS ON COAL AND ROCK}

I. Field Index Tests

A. Point-load strength test-a simple, inexpensive strength test that can be done on coal and rock in the field before the core is altered or disturbed (for details see Reichmuth, 1962, p. 49-52; Broch and Franklin, 1972; Hassani and others, 1980, p. 543-558; and Stimpson and RossBrown, 1979)

1. A rapid field testing procedure for estimating tensile and compressive strength (fig. 20)

2. Test involves hydraulically loading the coal or rock to be tested by hardened steel points with a 5-mm radius of curvature, recording the gage pressure at failure, and converting to the standard point-load index strength relative to the standard $50-\mathrm{mm}$ core diameter (fig. 21)

3. Tests can be run on each core sample diametrally and axially in a few minutes, in sequence with drilling operations, before rocks become altered from atmospheric effects such as wetting or drying; tests can also be performed on non-core rock samples

a. Core length must be equal to diameter or greater for the test to be valid

b. Point-load index strength $\left(I_{\mathrm{S}}\right)$ is calculated by:

$$
I_{\mathrm{S}}=P / D^{2}
$$

where: $P=$ gage pressure in $\mathrm{MPa}$ and $D=$ core diameter or distance between platens in $\mathrm{mm}$ 
c. Correct the point-load index strength obtained on the core to a standard 50$\mathrm{mm}$ core diameter $\left(I_{S(50)}\right)$ (fig. 21$)$

4. Uniaxial compressive strength of the core tested can be estimated by multiplying the standard index strength $\left(I_{S(50)}\right)$, by 15 to 35 , based on results of tests by D'Andrea and others $(1965$, p. 7) or by 22 to 35 , with an average of 25 or 28 , based on results of many tests by many investigators (Hassani and others, 1980, p. 553) (fig. 22)

5. Anisotropic index-the ratio of axial to diametral point-load strength for a given rock sample-helps estimate behavior of bedded roof rocks during mining; rocks that are highly anisotropic commonly are thinly layered or slabby and may require resin bolts for adequate roof support

B. Slake durability test

- This is a rapid, inexpensive, standard index test to simulate the accelerated behavior of rocks when subjected to wetting and drying, to estimate the resistance of shales, mudstones, and other clay-bearing rocks to weathering processes, and to evaluate slaking of mine roofs in response to circulation of air with varying humidity levels (fig. 23; see, for example, Franklin and Chandra, 1972, for more details)

1. The slake durability index test $\left(I_{d}\right)$ is performed as follows:

a. Insert about 10 oven-dried lumps, which weigh about $50 \mathrm{~g}$ each, into the slake durability drum of standard sieve mesh that is immersed in a distilled water bath at a level of $2 \mathrm{~cm}$ from the drum axle

b. Rotate the drum at $20 \mathrm{rpm}$ for $10 \mathrm{~min}$

c. Oven dry the material retained in the drum sieve at a temperature of $105^{\circ} \mathrm{C}$

d. Determine the percentage of the ratio of the oven-dried weight before the slake durability test to the oven-dried weight after the slake durability test

2. A second-cycle slake can be obtained by repeating the procedure on the same sample a second time

3. Slake durability index values (in percent) are:

1 st cycle $-I_{\mathrm{d} 1}=\left(W_{\mathrm{a} 1} / W_{\mathrm{b} 1}\right) \times 100$,

2nd cycle $-I_{\mathrm{d} 2}=\left(W_{\mathrm{a} 2} / W_{\mathrm{b} 2}\right) \times 100$,

where $W_{\mathrm{b}}=$ oven-dried weight before drum rotation

and $W_{\mathrm{a}}=$ oven-dried weight after drum rotation

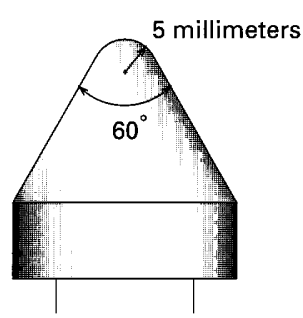

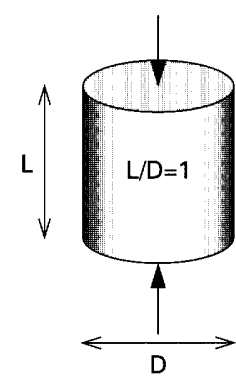

Axial test

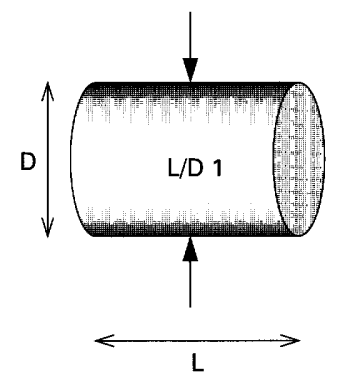

Diametral test

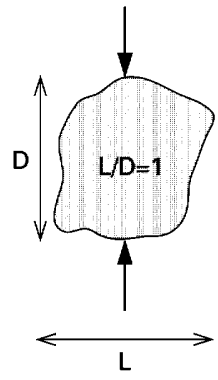

Irregular shape test
A

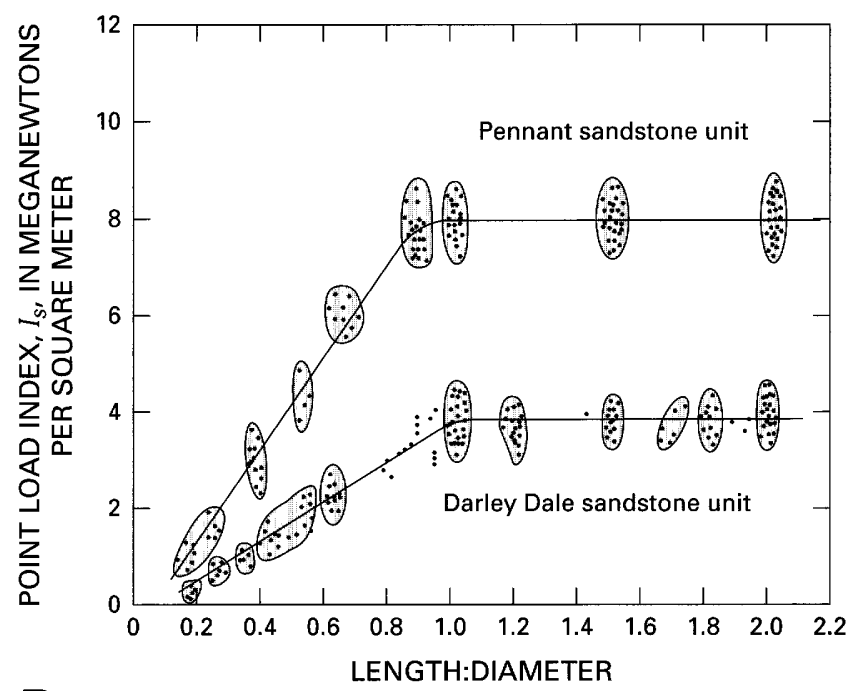

B

Figure 20. The point-load index strength test. $A$, Point-load platen, directions of loading, and necessary dimensions of rock in relation to core and irregular lumps. $B$, Variation of the point-load index strength versus the ratio of core length to core diameter. Modified from Hassani and others (1980, p. 550).

Figure 21 (facing page). Graph to correct point-load index strength to the standard core diameter of $50 \mathrm{~mm}$. For example, the index strength of a $75-\mathrm{mm}$ core with a gage pressure of $1.8 \mathrm{MPa}$ is converted along curved line to the standard diameter to $2.3 \mathrm{MPa}$; an index strength of $3.9 \mathrm{MPa}$ for a $35-\mathrm{mm}$ core is converted to 2.8 $\mathrm{MPa}$ along curved line. Modified from Hassani and others (1980, p. 552). 


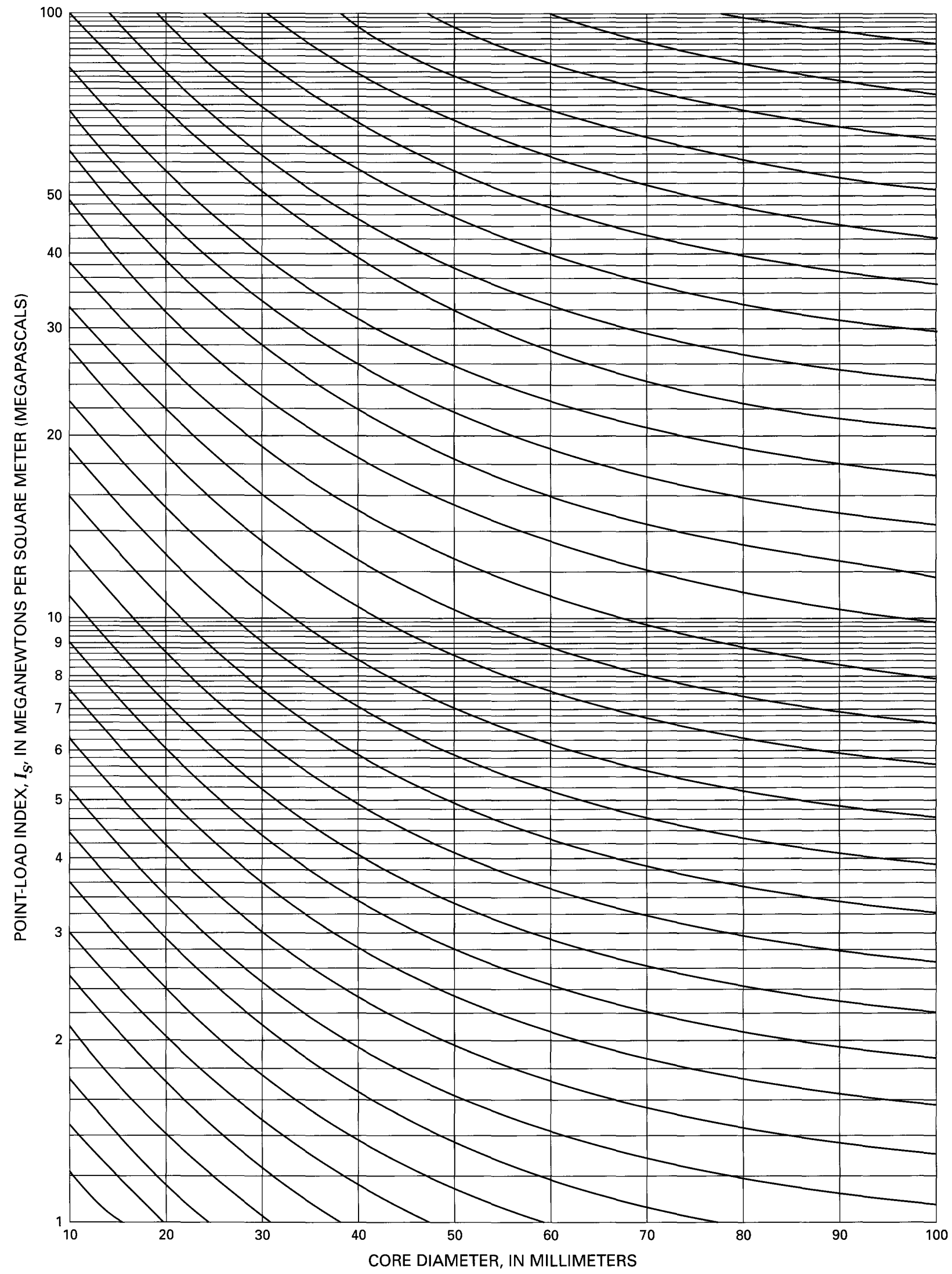




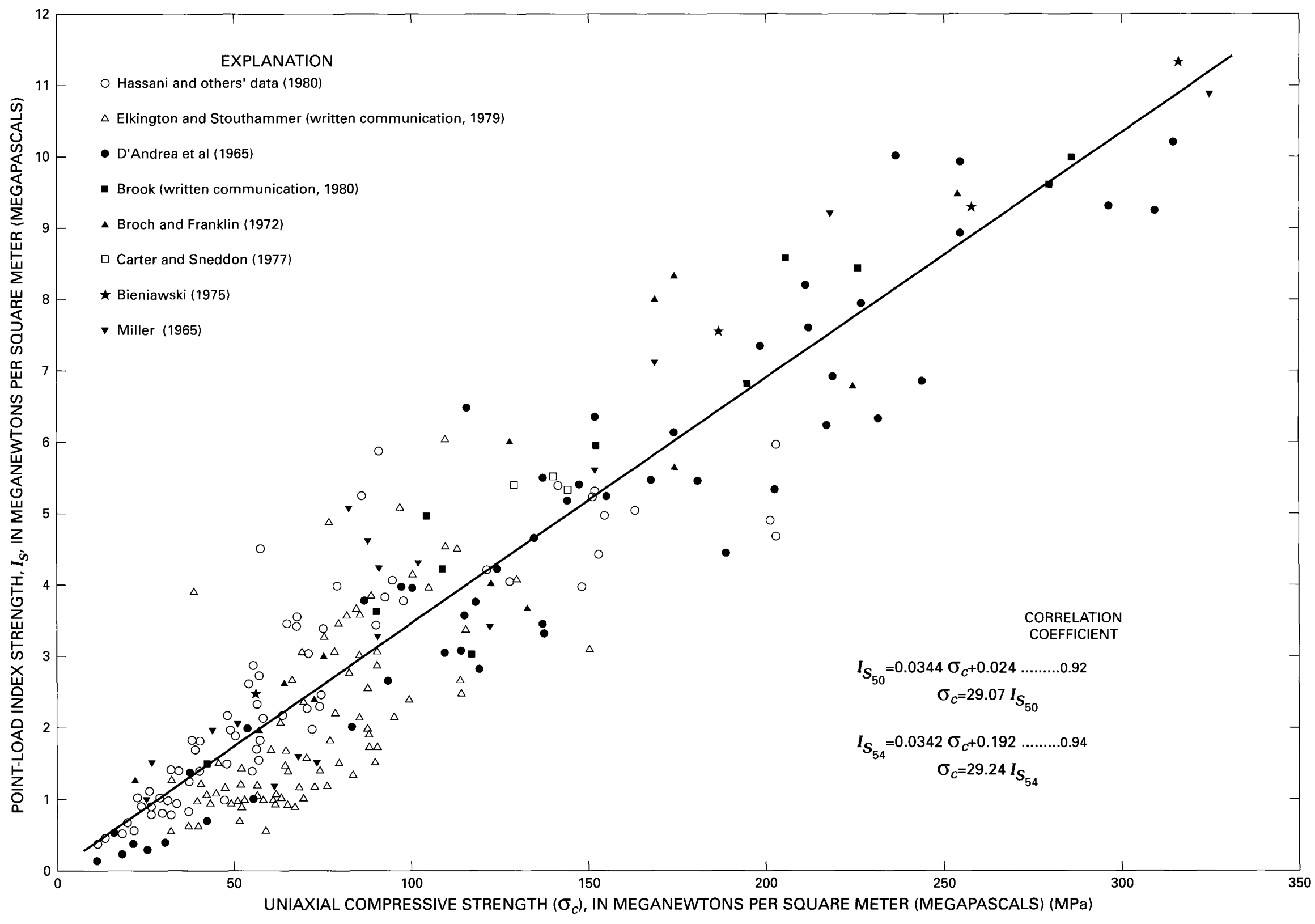

Figure 22. Graph showing correlation between tests of point-load index strength and uniaxial compressive strength. Modified from Hassani and others (1980, p. 553). 


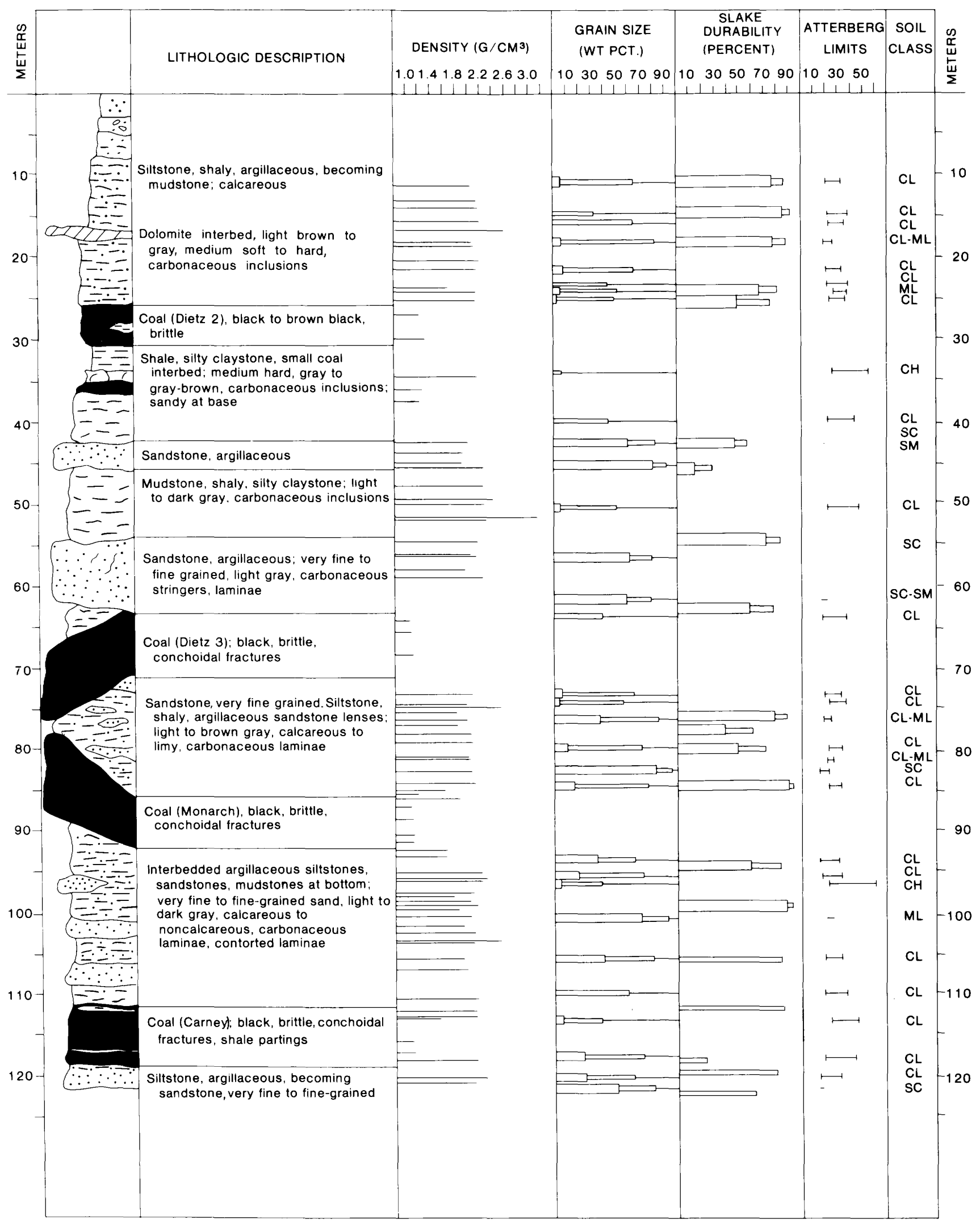

A

Figure 23 (above and overleaf). Log properties of a core hole located $7 \mathrm{mi}$ north of Sheridan, Wyo. $A$, geologic properties; $B$, geotechnical properties. From Dunrud and Osterwald (1980, p. 10-11). 


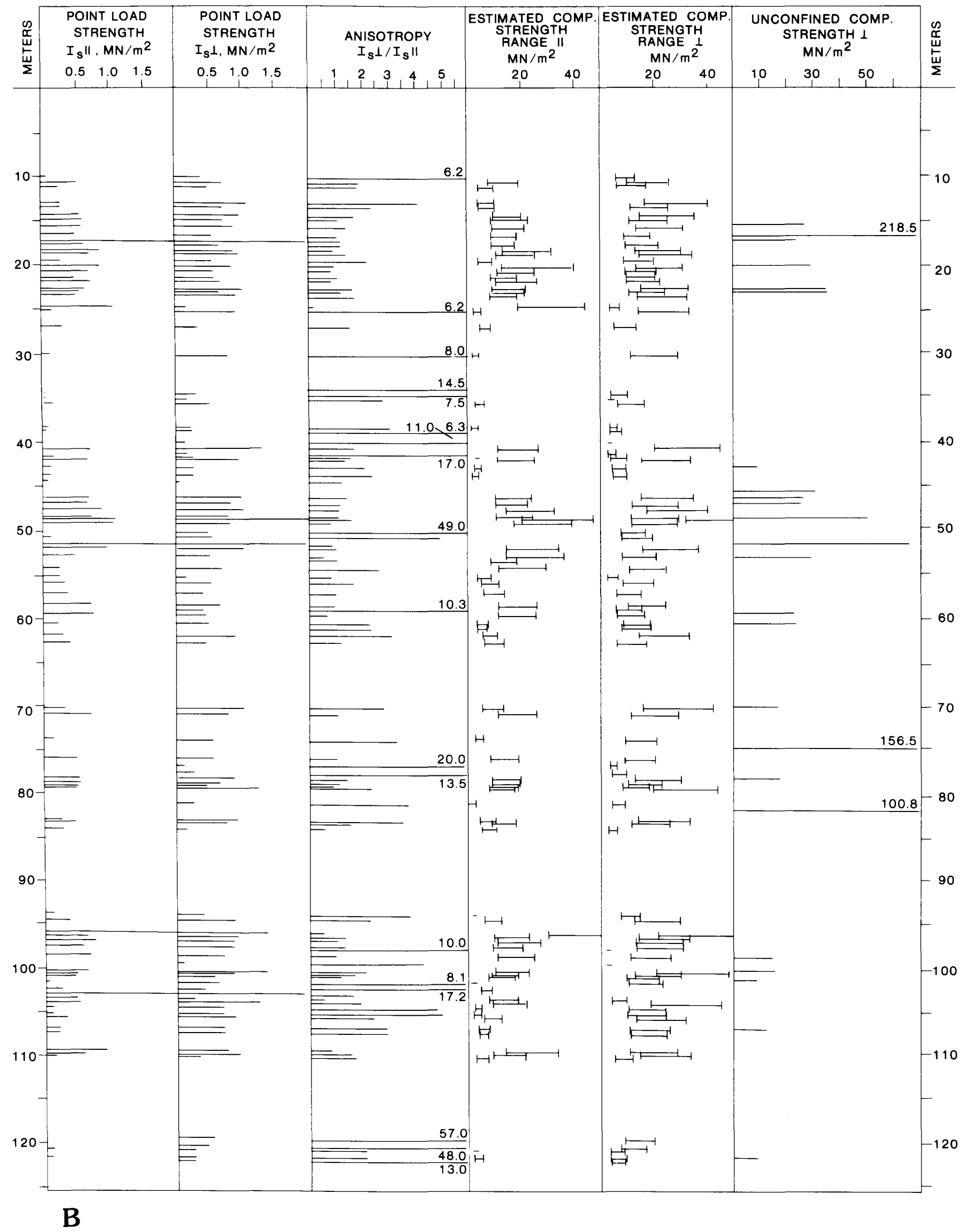

Figure 23-Continued. Log properties of a core hole located 7 mi north of Sheridan, Wyo. $B$, geotechnical properties. From Dunrud and Osterwald (1980, p. 10-11). 


\section{Laboratory Tests}

- Include the following (see, for example, Bell, 1975, p. 32-39, and also appropriate American Society for Testing and Materials (ASTM) procedure manuals for details):

A. Tensile strength

1. Brazilian test

2. Pull-apart (direct-tensile) test

3. Point-load index test

B. Compressive strength

1. Uniaxial-most common compressive strength test

2. Triaxial

C. Shear strength

1. Direct shear

2. Determine from Mohr envelope-of-confined-compressive-strength test

D. Porosity-permeability

E. Atterberg limits on crushed rock or soil

F. Coal hardness and strength tests (see Stach and others, 1975, p. 285-292, for details) (important values to know in order to select proper mining equipment)

1. Vickers' hardness test for microstrength (attachment to microscope)

2. Mechanical strength index tests

a. Vickers' macrostrength test (test over larger area than microstrength)

b. Compressive-strength test on cubes 3 $\mathrm{cm}$ in edge length or on cylinders

c. Ball-mill-grindability test (ASTM standard test)

d. Hardgrove grindability test (ASTM standard test) (index commonly increases (coal easier to grind) with decreasing percentage of volatile matter; for example, Kent and Arndt, 1980, p. 40)

e. The Russian Protod'yakono hardness "F", which is approximately equal to 1 percent of the uniaxial compressive strength (Kent and Arndt, 1980, p. 55-58); the uniaxial compressive strength often decreases with increasing sample size, with decreasing cleat spacing, and with increasing percentage of volatiles

I- Friability is related to size stability by ASTM shatter and tumbler tests

2- ASTM drop shatter test (D440-49) - results are in percent of size fractions remaining
3- ASTM tumble test (D441-45)—used to determine the relative stability of 1.0 - to 1.5-in. size fraction after tumbling for $1 \mathrm{hr}$-friability (in percent) equals 100 minus the percent breakage

f. Brabender structure test (tests done on crushed samples)

\section{ENGINEERING PROPERTIES AND DEFORMATION CHARACTERISTICS OF ROCKS}

- Obtain from field and laboratory strength tests and (or) downhole geophysical logging (see, for example, Cook and Hood, 1978)

\section{Elastic Moduli}

- Ratio of stress to corresponding strain within the proportional limit (deforms according to Hooke's law; segment $\mathrm{O}-\mathrm{B}$ in fig. 24A)
A. Young's modulus
B. Bulk modulus
C. Shear modulus
D. Poisson's ratio-the ratio of horizontal to verti- cal unit strain where vertical stress is applied

II. Deformation (Macrostrain) Characteristics (see, for example, Jaeger and Cook, 1979, p. 78-86; Peng, 1978, p. 52-56)

A. Elastic deformation (fig. 24A)

1. Strain of laboratory specimen increases in proportion to increasing stress in the region $\mathrm{O}-\mathrm{B}$

2. Failure may occur suddenly with a release of strain energy where stresses suddenly exceed the strength of the material

B. Ductile deformation-occurs in the pre-peakstrength region $(\mathrm{B}-\mathrm{C})$ where the rock sustains permanent deformation without losing its ability to resist load

C. Brittle deformation or failure occurs in the postpeak-strength region (C-D) where the rock undergoes permanent deformation with a decreasing ability to support stress

III. Rock Strength

- Ability to sustain increased stress load while undergoing deformation commonly decreases with:
A. Decreasing confining pressure (fig. 24B)
B. Increasing pore-water pressure
C. Increasing temperature (Jaeger and Cook, 1979, p. 89)

IV. Time-dependent Deformation (creep) (see, for example, Jaeger and Cook, 1979, p. 308-325) 

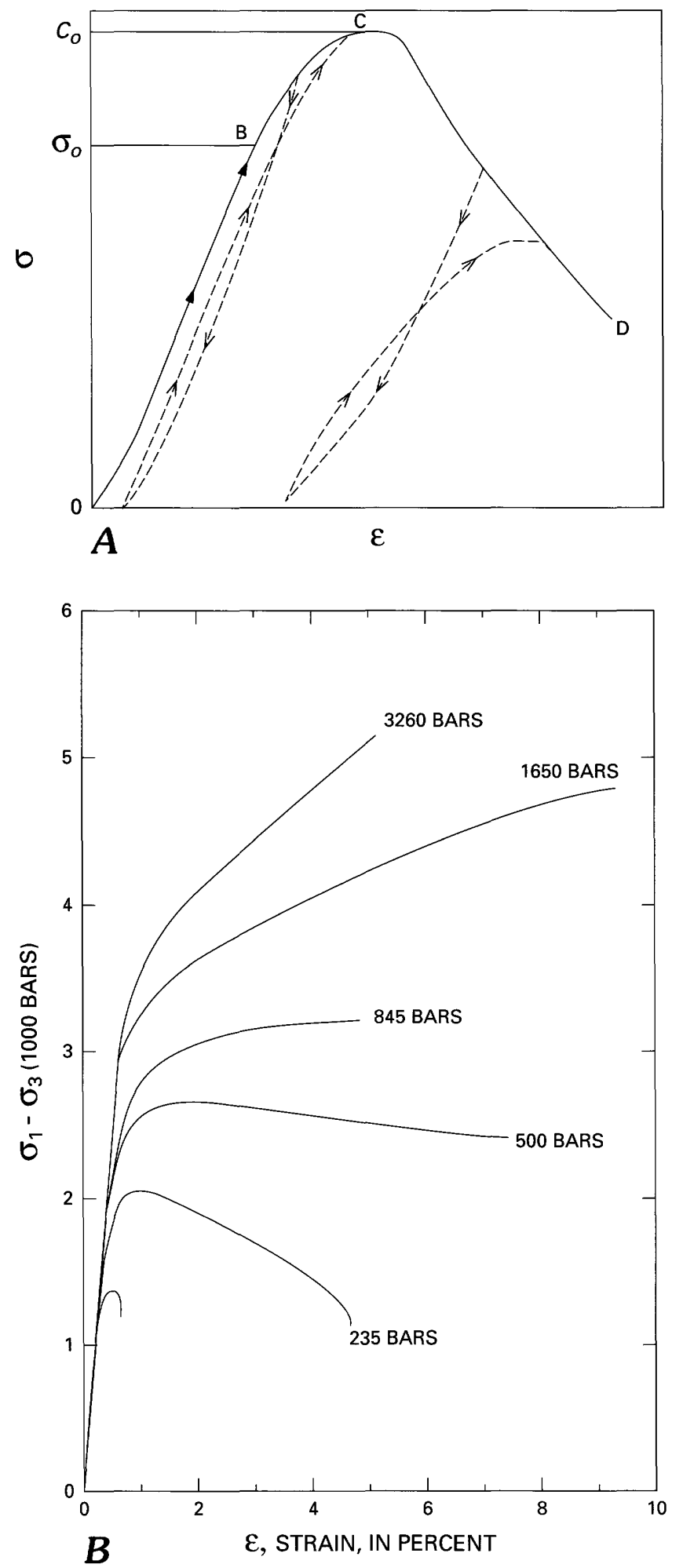

Figure 24. Graphs showing general deformation processes in rocks. $A$, Normal stress $(\sigma)$ in relation to strain $(\varepsilon)$ in the proportional (linearly elastic) region $(\mathrm{O}-\mathrm{B})$, ductile strain region $(\mathrm{B}-\mathrm{C})$, and post-peak, brittle and failure region (C-D). Dashed lines show loci of stress-strain points as stress is reduced and increased in the direction of arrows. $B$, Stress difference $\left(\sigma_{1}-\sigma_{3}\right)$ curves in relation to strain $(\varepsilon)$ showing rock strength as a function of confining pressure for Carrara marble. All numbers on curves are confining pressure in bars. Modified from Jaeger and Cook (1979, p. 79, 89); reproduced with permission of Chapman and Hall.

- Rocks commonly undergo the following stages of timedependent deformation under constant stress:

A. Transient creep (strain rate decreases with time)

1. No permanent deformation can occur if the rock is in the transient-creep stage

B. Steady-state creep (strain rate is roughly constant with time)

1. Permanent deformation can occur if the rock is in the steady-state-creep stage

C. Tertiary creep (strain rate increases with time)

D. Time-dependent deformation of the rock mass may be different than time-dependent strain of samples because the type, number, and orientation of discontinuities increase with the size of most rocks

V. Engineering Classification of Rocks (Hoek and Brown, 1980)

A. Deere's rock quality designation (RQD)

1. $\mathrm{RQD}=100 \times$ length of NX core recovered $(>10 \mathrm{~cm}) /$ length of core obtained in interval (length of core may range from (1) length of core run, to (2) length of core in lithologic interval, to length of borehole)

\begin{tabular}{ll}
\hline RQD & Rock quality \\
\hline$<25$ percent & very poor \\
$25-50$ percent & poor \\
$50-75$ percent & fair \\
$75-90$ percent & good \\
$90-100$ percent & very good \\
\hline
\end{tabular}


B. Deere and Miller's classification of intact rock strength (Hoek and Brown, 1980, p. 25):

\begin{tabular}{lcccl}
\hline \multicolumn{1}{c}{ Description } & \multicolumn{2}{c}{ Uniaxial compressive strength } & Examples of rocks \\
\cline { 5 - 5 } & & & & \\
& & & & \\
Very low strength & $150-3,500$ & $10-250$ & $1-25$ & Chalk, claystone. \\
Low strength & $3,500-7,500$ & $250-500$ & $25-50$ & Coal, siltstone, schist. \\
Medium strength & $7,500-15,000$ & $500-1,000$ & $50-100$ & Sandstone, hard schist, slate. \\
High strength & $15,000-30,000$ & $1,000-2,000$ & $100-200$ & Granite, gneiss. \\
Very high strength & $>30,000$ & $>2,000$ & $>200$ & Quartzite, dolomite, gabbro, basalt. \\
\hline
\end{tabular}

C. Deere's classification of jointed rocks (for example, Hoek and Brown, 1980, p. 25):

\begin{tabular}{lrll}
\hline Description & \multicolumn{2}{c}{ Joint spacing } & Condition of rock mass \\
\hline Very wide & $>3 \mathrm{~m}$ & $(>10 \mathrm{ft})$ & Solid. \\
Wide & $1-3 \mathrm{~m}$ & $(3-10 \mathrm{ft})$ & Massive. \\
Moderately close & $0.3-1 \mathrm{~m}$ & $(1-3 \mathrm{ft})$ & Blocky. \\
Close & $50-300 \mathrm{~mm}$ & $(2$ in. to $1 \mathrm{ft})$ & Fractured. \\
Very close & $<50 \mathrm{~mm}$ & $(<2$ in. $)$ & Highly fractured. \\
\hline
\end{tabular}

D. CSIR geomechanics classification of jointed rock masses:

1. Combines the more important aspects of many classification methods into one classification (fig. 25A)

E. NGI tunnelling quality index

1. Adds more information on properties of discontinuities than CSIR classification (Hoek and Brown, 1980, p. 27-34)

F. Unified rock classification system (URCS) of Williamson (1984) uses field-investigative methods for estimating degree of weathering, rock strength, permeability caused by joints and other discontinuities, and density (fig. 25B)

\section{IN-SITU STRESSES}

- Stress at a point within the rock mass (for example, Jaeger and Cook, 1979, p. 371-383; Corlett and Emery, 1959; Hoek and Brown, 1980, p. 93-101); primarily involves (1) vertical stresses and (2) horizontal stresses as modified by (a) Poisson's ratio effect, (b) sedimentation processes (loading, compaction, cementation, diagenesis), (c) tectonic stresses, (d) time-dependent deformation of rocks under elevated stress and temperature at depth, and (e) recent, rapid erosion that may cause unloading

- The state of stress in coal and associated rocks commonly can reflect their total loading history (Corlett and Emery, 1959 , p. 375-377)

I. The vertical stress commonly is approximately equal to the weight of the overburden (gravitational loading) $(24 \mathrm{MPa} / \mathrm{km}, 1 \mathrm{psi} / \mathrm{ft}, 24 \mathrm{kPa} / \mathrm{m}$, where the average rock density equals $2.4 \mathrm{~g} / \mathrm{cm}^{3}\left(2,400 \mathrm{~kg} / \mathrm{m}^{3}\right)$ (fig. 26A)

II. The horizontal stresses may range from about 0.3 to 5.5 times the vertical stress at depths ranging from 100 to $1,000 \mathrm{~m}$ below the surface (fig. $26 B$; Hoek and Brown, 1980, p. 95-101); they may be caused or influenced by a combination of:

A. Gravitational loading and the effect of Poisson's ratio, which increases with depth at slightly 


\begin{tabular}{|c|c|c|c|c|c|c|c|c|c|}
\hline \multirow{2}{*}{\multicolumn{3}{|c|}{ ATTRIBUTES OF ROCK MASS }} & \multicolumn{7}{|c|}{ RANGES OF ROCK STRENGTHS } \\
\hline & & & \multirow{2}{*}{$\begin{array}{l}\text { Very high } \\
>8 \mathrm{Mpa}\end{array}$} & \multirow{2}{*}{ 4-8 Mpa } & \multirow{2}{*}{$\begin{array}{l}\text { Medium } \\
\text { 2-4 Mpa }\end{array}$} & Low & \multicolumn{3}{|c|}{ Very low } \\
\hline \multirow{3}{*}{1} & \multirow{2}{*}{$\begin{array}{c}\text { Strength of } \\
\text { intact rock } \\
\text { material }\end{array}$} & \multirow{2}{*}{$\begin{array}{c}\begin{array}{c}\text { Point-load } \\
\text { strength index }\end{array} \\
\begin{array}{c}\text { Uniaxial } \\
\text { compressive } \\
\text { strength }\end{array}\end{array}$} & & & & 1-2 Мpa & \multicolumn{3}{|c|}{$\begin{array}{l}\text { For this low range } \\
\text { uniaxial compressive } \\
\text { test is preferred }\end{array}$} \\
\hline & & & $>200 \mathrm{Mpa}$ & $100-200 \mathrm{Mpa}$ & $50-100 \mathrm{Mpa}$ & 25-50 Mpa & $\begin{array}{l}10-25 \\
\mathrm{Mpa}\end{array}$ & $\begin{array}{l}\text { 3-10 } \\
\text { Mpa }\end{array}$ & $\begin{array}{c}1-3 \\
\mathrm{Mpa}\end{array}$ \\
\hline & \multicolumn{2}{|r|}{ Rating } & 15 & 12 & 7 & 4 & 2 & 1 & 0 \\
\hline \multirow{2}{*}{2} & \multicolumn{2}{|c|}{ Drill core quality, $\mathrm{RQD}_{1}^{2} \mathrm{pct}$} & $90-100$ & $75-90$ & $50-75$ & $25-50$ & \multicolumn{3}{|c|}{$<25$} \\
\hline & \multicolumn{2}{|r|}{ Rating } & 20 & 17 & 13 & 8 & \multicolumn{3}{|c|}{3} \\
\hline \multirow{2}{*}{3} & \multicolumn{2}{|c|}{ Spacing of joints } & $>3$ meters & $1-3$ meters & 0.3-1 meters & 50-300 millimeters & \multicolumn{3}{|c|}{$<50$ millimeters } \\
\hline & \multicolumn{2}{|r|}{ Rating } & 30 & 25 & 20 & 10 & \multicolumn{3}{|c|}{5} \\
\hline \multirow[t]{2}{*}{4} & \multicolumn{2}{|c|}{ Condition of joints } & $\begin{array}{l}\text { Very rough surfaces } \\
\text { Not continuous } \\
\text { No separation } \\
\text { Hard joint wall rock }\end{array}$ & $\begin{array}{l}\text { Slightly rough surfaces } \\
\text { Separation }<1 \mathrm{~mm} \\
\text { Hard joint wall rock }\end{array}$ & $\begin{array}{l}\text { Slightly rough surfaces } \\
\text { Separation <1mm } \\
\text { Soft joint wall rock }\end{array}$ & $\begin{array}{c}\text { Slickensided surfaces } \\
\text { or } \\
\text { Gouge }<5 \mathrm{~mm} \text { thick } \\
\text { or } \\
\text { Joints open } 1-5 \mathrm{~mm} \\
\text { Continuous joints }\end{array}$ & \multicolumn{3}{|c|}{$\begin{array}{c}\text { Soft gouge }>5 \mathrm{~mm} \text { thick } \\
\text { or } \\
\text { Joints open }>5 \mathrm{~mm} \\
\text { Continuous joints }\end{array}$} \\
\hline & \multicolumn{2}{|r|}{ Rating } & 25 & 20 & 12 & 6 & \multicolumn{3}{|c|}{0} \\
\hline \multirow{4}{*}{5} & \multirow{3}{*}{$\begin{array}{l}\text { Ground } \\
\text { water }\end{array}$} & $\begin{array}{l}\text { Inflow per } \\
10 \text { meters of } \\
\text { tunnel length }\end{array}$ & \multicolumn{2}{|c|}{ None } & $<25$ liters/minute & 25-125 liters/minute & \multicolumn{3}{|c|}{$>125$ liters/minute } \\
\hline & & \begin{tabular}{|c|} 
Ratio \\
$\begin{array}{c}\text { Joint water } \\
\text { pressure }\end{array}$ \\
$\begin{array}{c}\text { Major principal } \\
\text { stress }\end{array}$ \\
\end{tabular} & & & $0.0-0.2$ & $0.2-0.5$ & & $>0.5$ & \\
\hline & & $\begin{array}{l}\text { General } \\
\text { conditions }\end{array}$ & Comp & tely dry & $\begin{array}{c}\text { Moist only } \\
\text { (interstitial water) }\end{array}$ & $\begin{array}{l}\text { Water under } \\
\text { moderate pressure }\end{array}$ & & $\begin{array}{l}\text { vere wa } \\
\text { roblem }\end{array}$ & \\
\hline & & Rating & & 0 & 7 & 4 & & 0 & \\
\hline
\end{tabular}

${ }^{1}$ Strength in Megapascals (Meganewtons per square meter).

${ }^{2}$ Rock Quality Designation.

A

Figure 25 (above and facing page). Classification tables of geotechnical properties in jointed rock masses. A, Classification based on part A of the classification of the South African Council for Scientific and Industrial Research (CSIR). Modified from Hoek and Brown (1980, p. 25-26). B, The unified rock classification system (URCS). The classification systems are based on degree of weathering, estimated strength, discontinuities, and unit weight (density). Modified from Williamson (1984, p. 347).

more than one-half the rate of the vertical stress $(10 \mathrm{MPa} / \mathrm{km} ; 0.45 \mathrm{psi} / \mathrm{ft} ; 10 \mathrm{kPa} / \mathrm{m}$ where Poisson's ratio equals 0.3 and the average density equals $2.4 \mathrm{~g} / \mathrm{cm}^{3}$ )

B. Stresses caused by intergranular adjustments of grains during sedimentation, compaction (Capper and Cassie, 1963, p. 99-100), and diagenesis

C. Tectonic stresses causing folding and faulting (fig. 3; Jeremić, 1981b)

D. Time-dependent deformation, which may increase with increasing confining stress and temperature, can cause the vertical and horizontal components of stress to eventually become nearly equal (Heim, 1912, in Hoek and Brown, 1980, p. 95-96)

E. Recent, rapid erosion that forms steep cliffs, deep canyons, and ridges may:

1. Cause a reduction in vertical stress but retain high horizontal stresses beneath canyons

2. Cause a reduction in horizontal stress in cliff and canyon walls but retain high vertical stress beneath ridges and mesas 


\begin{tabular}{|c|c|c|c|c|c|c|}
\hline \multicolumn{7}{|c|}{ DEGREE OF WEATHERING } \\
\hline \multirow{2}{*}{\multicolumn{2}{|c|}{ REPRESENTATIVE }} & \multirow{2}{*}{ ALTERED } & \multicolumn{4}{|c|}{ WEATHERED } \\
\hline & & & \multicolumn{2}{|c|}{$>$ GRAVEL SIZE } & \multicolumn{2}{|c|}{$<$ SAND SIZE } \\
\hline $\begin{array}{l}\text { Micro fresh state } \\
\text { (MFS) }\end{array}$ & $\begin{array}{l}\text { Visually fresh state } \\
\text { (VFS) }\end{array}$ & $\begin{array}{l}\text { Stained state } \\
\quad \text { (STS) }\end{array}$ & \multicolumn{2}{|c|}{$\begin{array}{l}\text { Partly decomposed state } \\
\text { (PDS) }\end{array}$} & \multicolumn{2}{|c|}{$\begin{array}{l}\text { Completely decomposed state } \\
\text { (CDS) }\end{array}$} \\
\hline A & $\mathrm{B}$ & $\mathrm{C}$ & \multicolumn{2}{|c|}{ D } & \multicolumn{2}{|c|}{$E$} \\
\hline \multicolumn{2}{|c|}{$\begin{array}{c}\text { UNIT WEIGHT } \\
\text { RELATIVE ABSORPTION }\end{array}$} & $\begin{array}{l}\text { COMPARE TO } \\
\text { FRESH STATE }\end{array}$ & NON-PLASTIC & PLASTIC & NON-PLASTIC & PLASTIC \\
\hline
\end{tabular}

\begin{tabular}{|c|c|c|c|c|}
\hline \multicolumn{5}{|c|}{ ESTIMATED STRENGTH } \\
\hline \multicolumn{4}{|c|}{ REACTION TO IMPACT OF ONE POUND BALLPEEN HAMMER } & \multirow{3}{*}{ 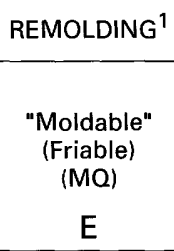 } \\
\hline $\begin{array}{l}\text { "Rebounds" } \\
\text { (Elastic) } \\
\text { (RQ) }\end{array}$ & $\begin{array}{c}\text { "Pits" } \\
\text { (Tensional) } \\
\text { (PQ) }\end{array}$ & $\begin{array}{c}\text { "Dents" } \\
\text { (Compression) } \\
\text { (DQ) }\end{array}$ & $\begin{array}{l}\text { "Craters" } \\
\text { (Shears) } \\
\text { (CO) }\end{array}$ & \\
\hline A & $\mathrm{B}$ & C & D & \\
\hline $\begin{array}{c}>15,000 \mathrm{psi}^{2} \\
>103 \mathrm{MPa}\end{array}$ & $\begin{array}{c}8,000-15,000 \mathrm{psi}^{2} \\
55-103 \mathrm{MPa}\end{array}$ & $\begin{array}{c}3,000-8,000 \mathrm{psi}^{2} \\
21-55 \mathrm{MPa}\end{array}$ & $\begin{array}{c}1,000-3,000 \mathrm{psi}^{2} \\
7-21 \mathrm{MPa}\end{array}$ & $\begin{array}{l}<1,000 \mathrm{psi}^{2} \\
<7 \mathrm{MPa}\end{array}$ \\
\hline
\end{tabular}

${ }^{1}$ Strength estimated by soil mechanics technology.

${ }^{2}$ Approximate unconfined compressive strength.

\begin{tabular}{|c|c|c|c|c|}
\hline \multicolumn{5}{|c|}{ DISCONTINUITIES } \\
\hline \multicolumn{3}{|c|}{ VERY LOW PERMEABILITY } & \multicolumn{2}{|c|}{ MAY TRANSMIT WATER } \\
\hline $\begin{array}{c}\text { Solid } \\
\text { (Random breakage) } \\
\text { (SRB) }\end{array}$ & $\begin{array}{c}\text { Solid } \\
\text { (Preferred breakage) } \\
\text { (SPB) }\end{array}$ & $\begin{array}{c}\text { Solid } \\
\text { (Latent planes } \\
\text { of separation) } \\
\text { (LPS) }\end{array}$ & $\begin{array}{c}\text { Nonintersecting } \\
\text { open planes } \\
\text { (2-D) } \\
\text { D } \\
\end{array}$ & $\begin{array}{c}\text { Intersecting } \\
\text { open planes } \\
\text { (3-D) } \\
\text { E }\end{array}$ \\
\hline$A$ & B & $\mathrm{C}$ & ATTITUDE & INTERLOCK \\
\hline
\end{tabular}

\begin{tabular}{|c|c|c|c|c|}
\hline \multicolumn{5}{|c|}{ UNIT WEIGHT } \\
\hline Greater than & & & & Less than \\
$160 \mathrm{lb} / \mathrm{ft}^{3}$ & $150-160 \mathrm{lb} / \mathrm{ft}^{3}$ & $140-150 \mathrm{lb} / \mathrm{ft}^{3}$ & $130-140 \mathrm{lb} / \mathrm{ft}^{3}$ & $130 \mathrm{lb} / \mathrm{ft}^{3}$ \\
$2.55 \mathrm{~g} / \mathrm{cm}^{3}$ & $2.40-2.55 \mathrm{~g} / \mathrm{cm}^{3}$ & $2.25-2.40 \mathrm{~g} / \mathrm{cm}^{3}$ & $2.10-2.25 \mathrm{~g} / \mathrm{cm}^{3}$ & $2.10 \mathrm{~g} / \mathrm{cm}^{3}$ \\
A & B & $C$ & $D$ & $E$ \\
\hline
\end{tabular}

B

\section{PETROPHYSICAL (GEOPHYSICAL) LOGGING}

- Very important to mine-site selection and mine design

- Involves drilling, downhole logging, measurement of strength, and other physical properties previously mentioned in the field and laboratory testing of representative core samples of coal and rocks of key lithologies, particularly near the coal beds

- Results of geotechnical testing of small samples, however, may not be representative of the bedded, faulted, and jointed rock mass that they were taken from; the geomechanics classification previously discussed (for example, Hoek and Brown, 1980, p. 25-26) helps to take this into account 


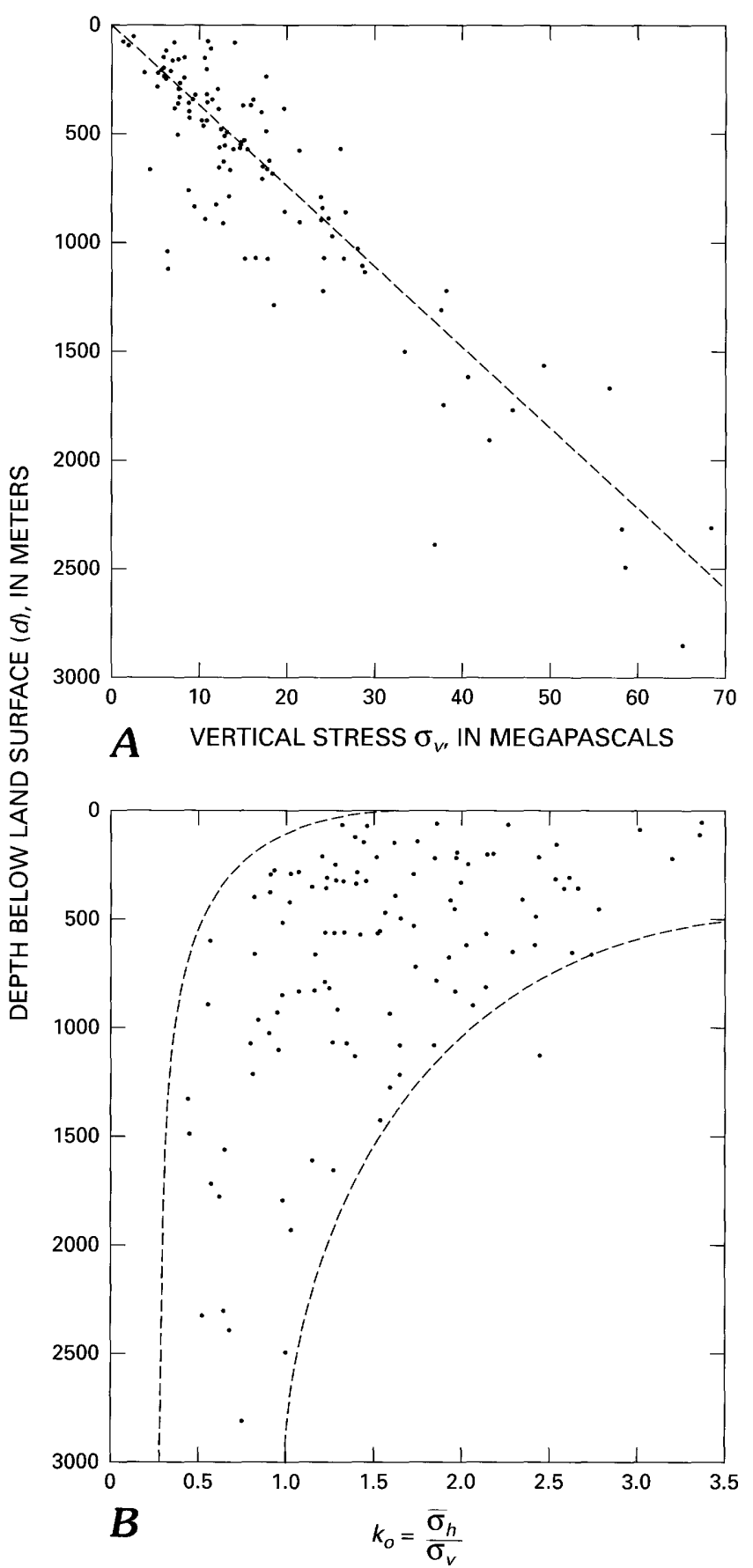

Figure 26. Relation between measured vertical and horizontal stress with depth. $A$, Vertical stress as a function of depth. Straight line, approximate median. $B$, Ratio of average horizontal stress to vertical stress with depth. Measurements are from Australia (47 points), United States (17 points), South Africa (17 points) Scandinavia (15 points), Canada (13 points), and other areas (4 points). Dashed envelope encloses points. Modified from Hoek and Brown (1980, p. 99-100).
- Results and operation of geotechnical logging and testing can be computerized

\section{Petrophysical Well-log Analysis}

- For example, see Asquith, 1982, for details; although the book is petroleum oriented, its techniques can help determine lithology and ground-water resources

- Can often estimate or determine lithology and physical properties of rocks penetrated by drill holes and determine the location and thickness of coal beds and other rock units

A. Rock properties, such as porosity, water saturation or hydrocarbon saturation, formation temperature, and lithology can be determined or estimated down an uncased, mud-filled, rotary drill hole by analysis of standardized electric logs, gamma-ray, gamma-density, sonic, neutron, caliper, and temperature logs (fig. 27)

1. Determine porosity from sonic, density, and neutron-density logs

2. Determine necessary parameters for water saturation as follows (see, for example, Asquith, 1982, p. 104-105):

a. Formation factor $(F)$ from sonic-porosity, density-porosity, and (or) neutronporosity logs

b. Resistivity of the formation water $\left(R_{w}\right)$ from the corrected spontaneous potential (SP) $\log$ or by other methods

c. Resistivity of the formation beyond the zone influenced by the mud $\left(R_{t}\right)$ from the deep, alternating current, induction $\log \left(R_{i l d}\right)$ or the deep, direct current laterolog $\left(R_{l l d}\right)$

d. Determine bulk volume water $(B V W)$ by the equation:

$$
B V W=S_{w} \times \phi, \text { where: }
$$

$S_{w}=$ formation water saturation

$\phi=$ formation porosity (Asquith, 1982,

$$
\text { p. 98, 104-105) }
$$

e. Estimate formation temperature by measuring the temperature at the drill collar and at the bottom of the hole and assuming a linear temperature gradient between the two

B. Depth and thickness of coal beds can be accurately determined from resistivity, conductivity, 


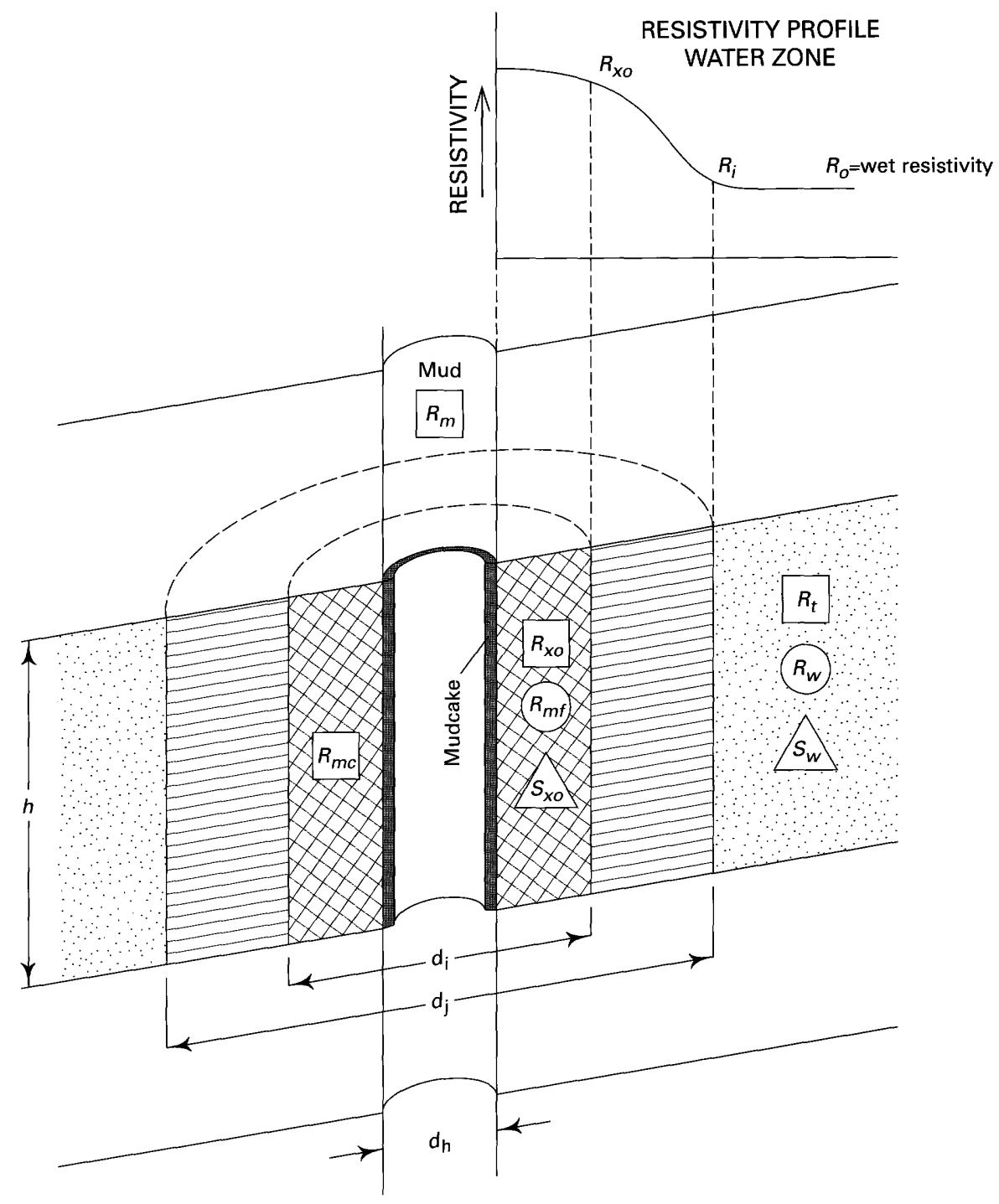

EXPLANATION

Resistivity of the zone

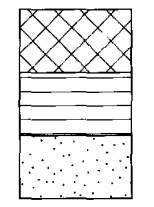

Flushed zone

Zone of transition or annulus (invaded zone)

Resistivity of the water in the zone

Water saturation in the zone

Uninvaded zone

Figure 27. Zones around a mud-filled, rotary drill hole in a permeable sandstone. Mud filtrate $(\mathrm{mf})$ occurs in flushed zone inward from mudcake $(\mathrm{mc})$ on walls of hole. Resistivity of freshwater mud in flushed zone $\left(R_{x o}\right)$ is high because fresh water is the mud medium; resistivity of the invaded (transition) zone $\left(R_{i}\right)$ decreases to the true resistivity of porous, water-filled sandstone $\left(R_{o}\right.$ or $\left.R_{t}\right)$. $d_{i}$, diameter of flushed zone (+hole); $d_{j}$, diameter of flushed zone + invaded zone $(+$ hole); $d_{h}$ diameter of drill hole. Modified from Asquith (1982, p. 7, 10). 


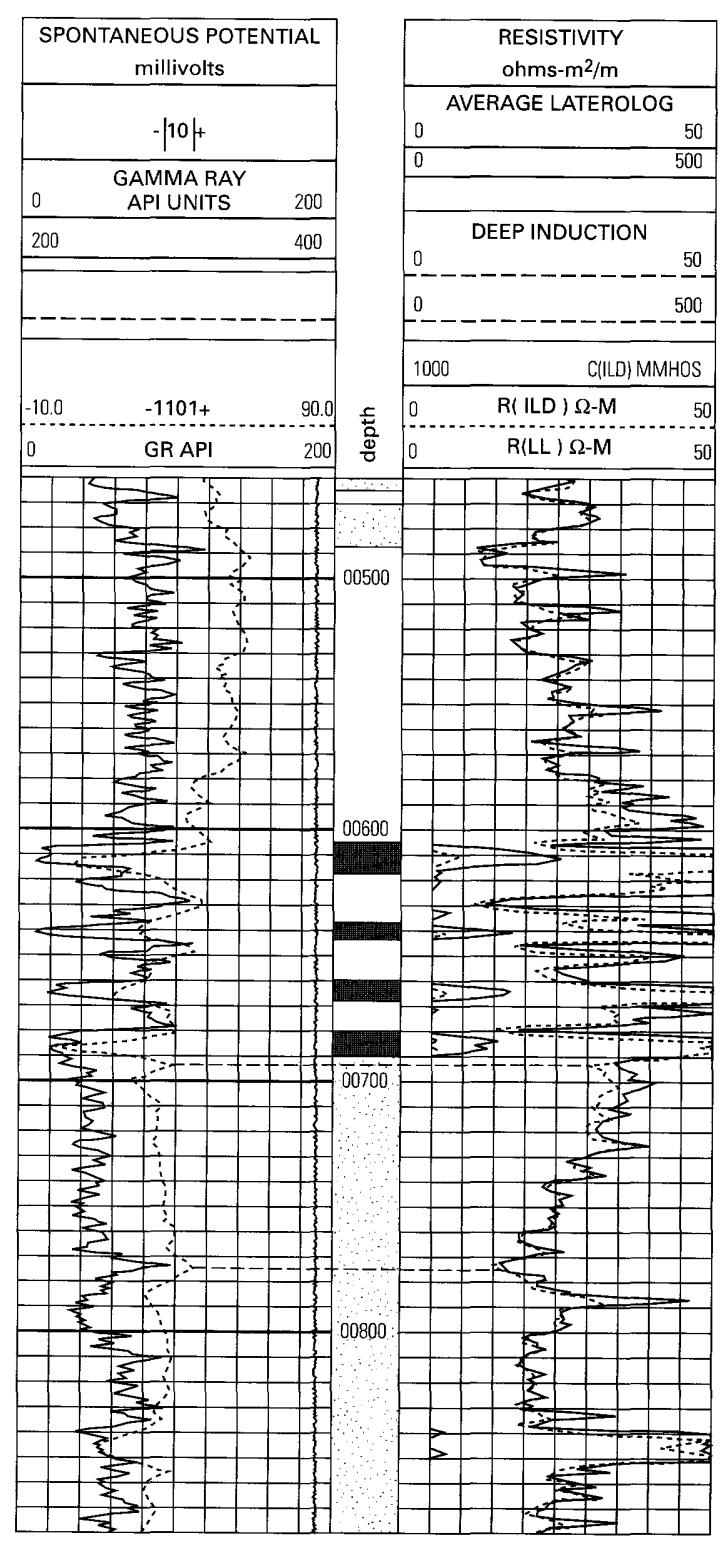

A
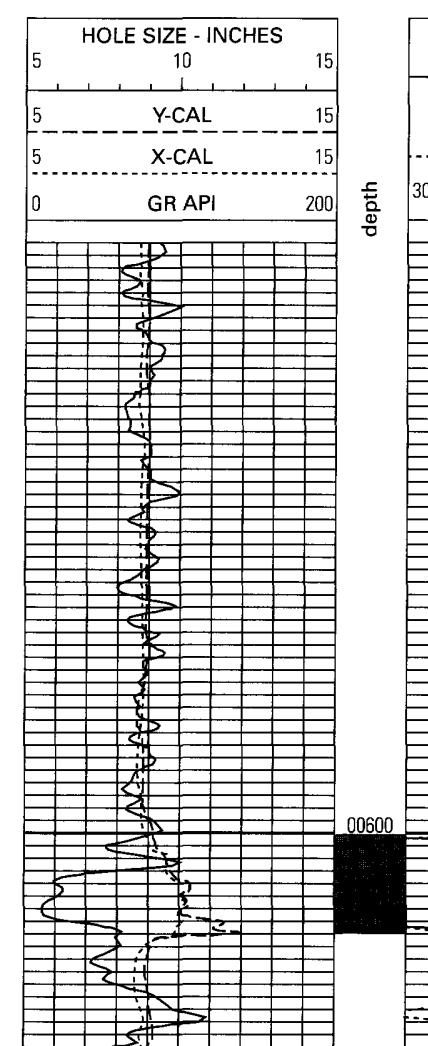

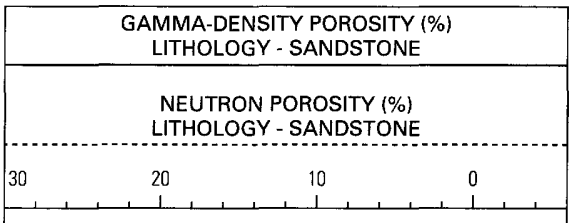

응
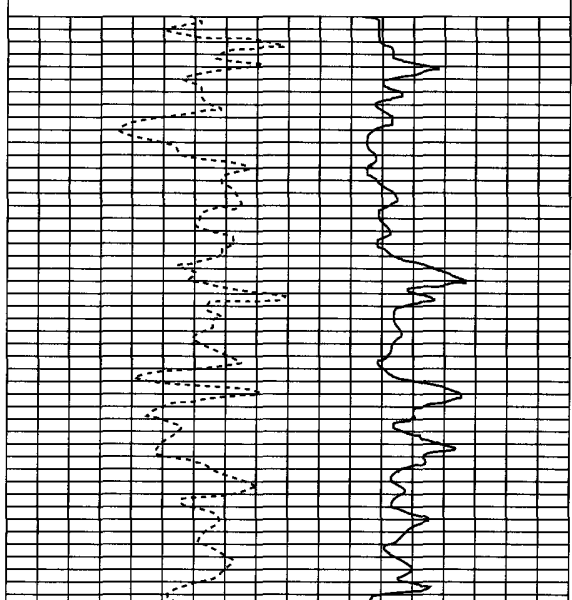

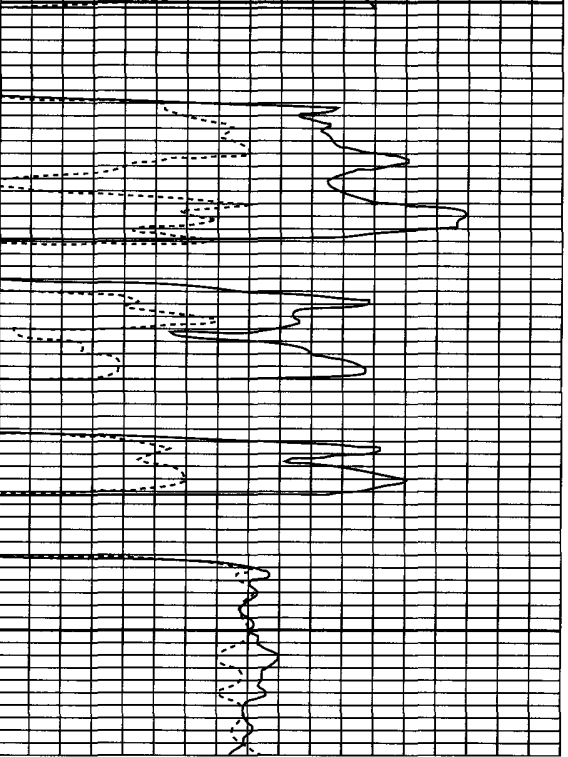

B

Figure 28. Relation between lithology and petrophysical logs. A, Spontaneous-potential (SP), gamma-ray, resistivity logs showing sandstones (stippled), shales and mudstones (unpatterned), and coal (black) for an oil well test hole in the Somerset, Colo., area. $B$, Neutronporosity, gamma-density porosity, gamma-ray (GR), and caliper (CAL) logs showing detail of coal beds shown in $A$. Note that, in $A$ and (or) $B$, coal beds have diagnostic traces on gamma-ray, resistivity, and porosity logs.

natural-gamma, gamma-density, and sonic logs because of large differences of these properties between coal and other rocks (fig. 28A, B)

1. Coal beds have high resistivity, but low conductivity, natural-gamma radiation, density, density porosity, and neutron porosity

C. Lithologic logging can be done from a calibrated set of petrophysical logs (Asquith, 1982, p.135-137
1. Rock types may be determined by cross-plot methods:

a. Cross plot of formation resistivity $\left(R_{t}\right)$ versus sonic or neutron porosity or density and gamma-ray logs (Daniels and Scott, 1982)

b. Lithology may also be accurately determined by statistical analysis (such as Bayes decision rule) or multivariate 


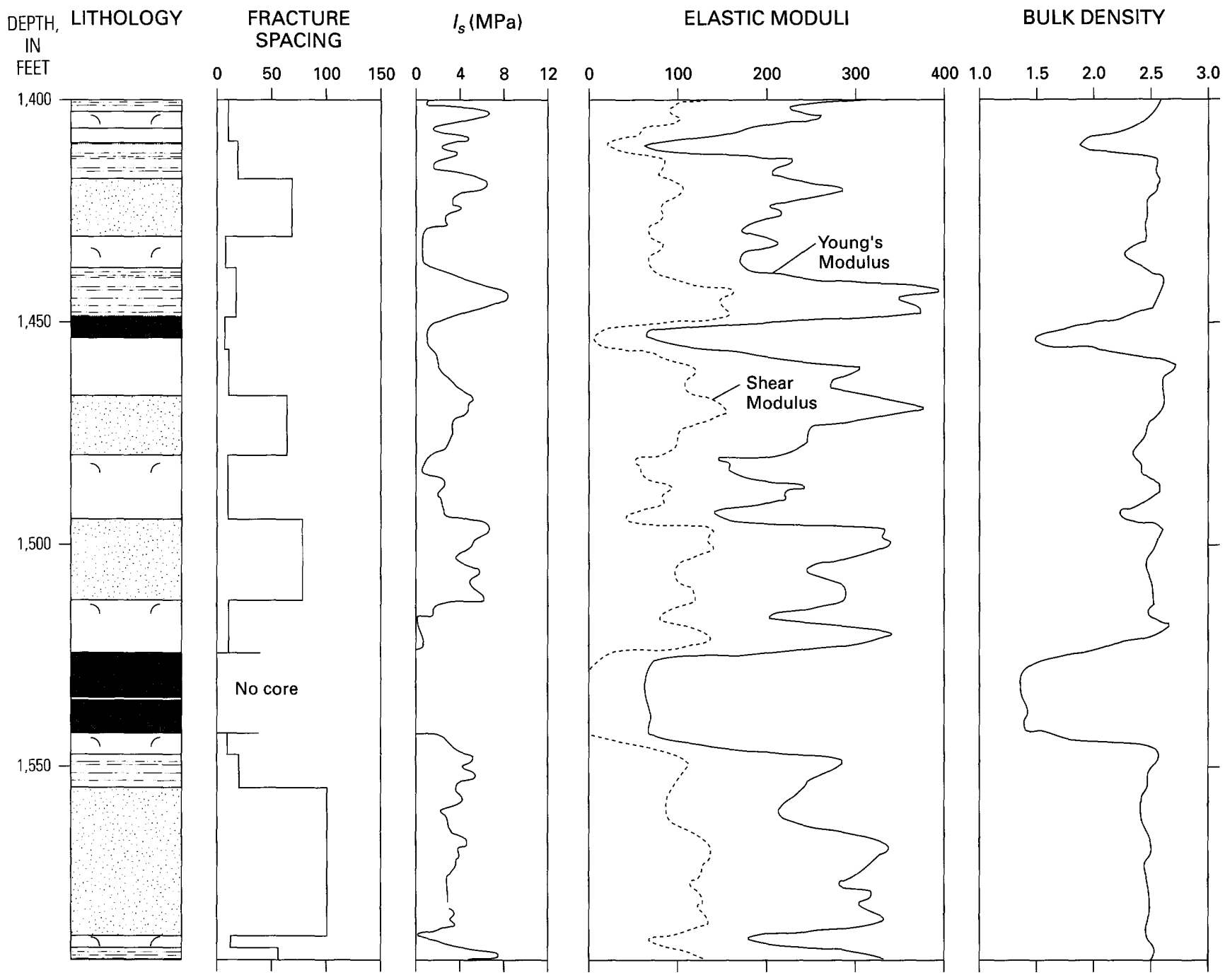

EXPLANATION

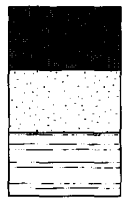

Coal

Sandstone

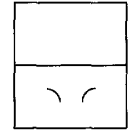

Shale and mudstone

Siltstone

Figure 29. Relation between geologic and geotechnical properties of rocks from drill core and petrophysical logs in the Somerset, Colo., area. Lithology of drill core is plotted along with fracture spacing (in centimeters), point-load index strength (Is, in MegaPascals), elastic moduli (in kilobars), and bulk density (in grams per cubic centimeter).

analysis (such as principal component cross plots) of digitized petrophysical logs (see, for example, Delfiner, 1984; Widdicombe and others, 1984)

c. Lithologic control can be obtained from core cuttings, mud logs, or from core from wells in the area

D. Lithology, fracture spacing (related to RQD), point-load strength, slake durability, bulk modulus, and shear modulus from geologic, geotechnical, and petrophysical logging were all found to be correlatable in the Paonia area, Delta and Gunnison Counties, Colo. (fig. 29)

1. Therefore, physical and engineering properties may often be accurately determined from high-resolution, calibrated petrophysical logs where baseline core logs are available for comparison 


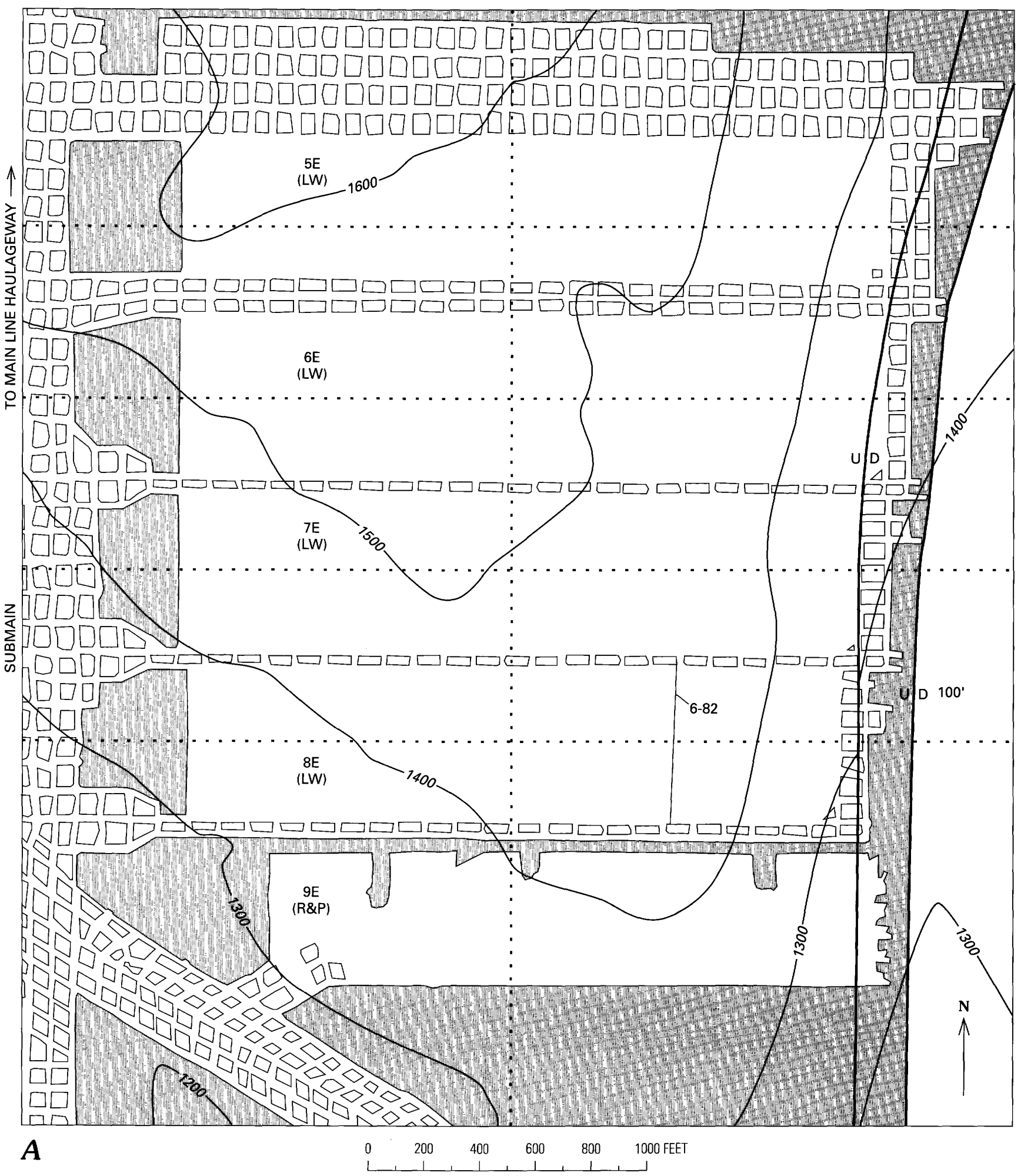

Figure 30 (above and facing page). Underground mine layouts contrasting geometry between two methods of mining. A, Typical longwall mine layout in Carbon County, Utah. Heavy line, fault; U, upthrown side; D, downthrown side. $8 \mathrm{E}$ (LW) means 8 East longwall extraction panel, 9E (R\&P) means 9 East room-and-pillar extraction panel, and so forth. Each dot of the dotted lines, that are longitudinal to longwall panels, and the one perpendicular to panels represents a subsidence measuring station. $B$, Room-and-pillar mine layout in Gunnison County, Colo. Heavy lines, rock spars; dashed where approximately located. Diagonal line pattern, mined-out areas as of dates shown. 1,000 ft grid. 


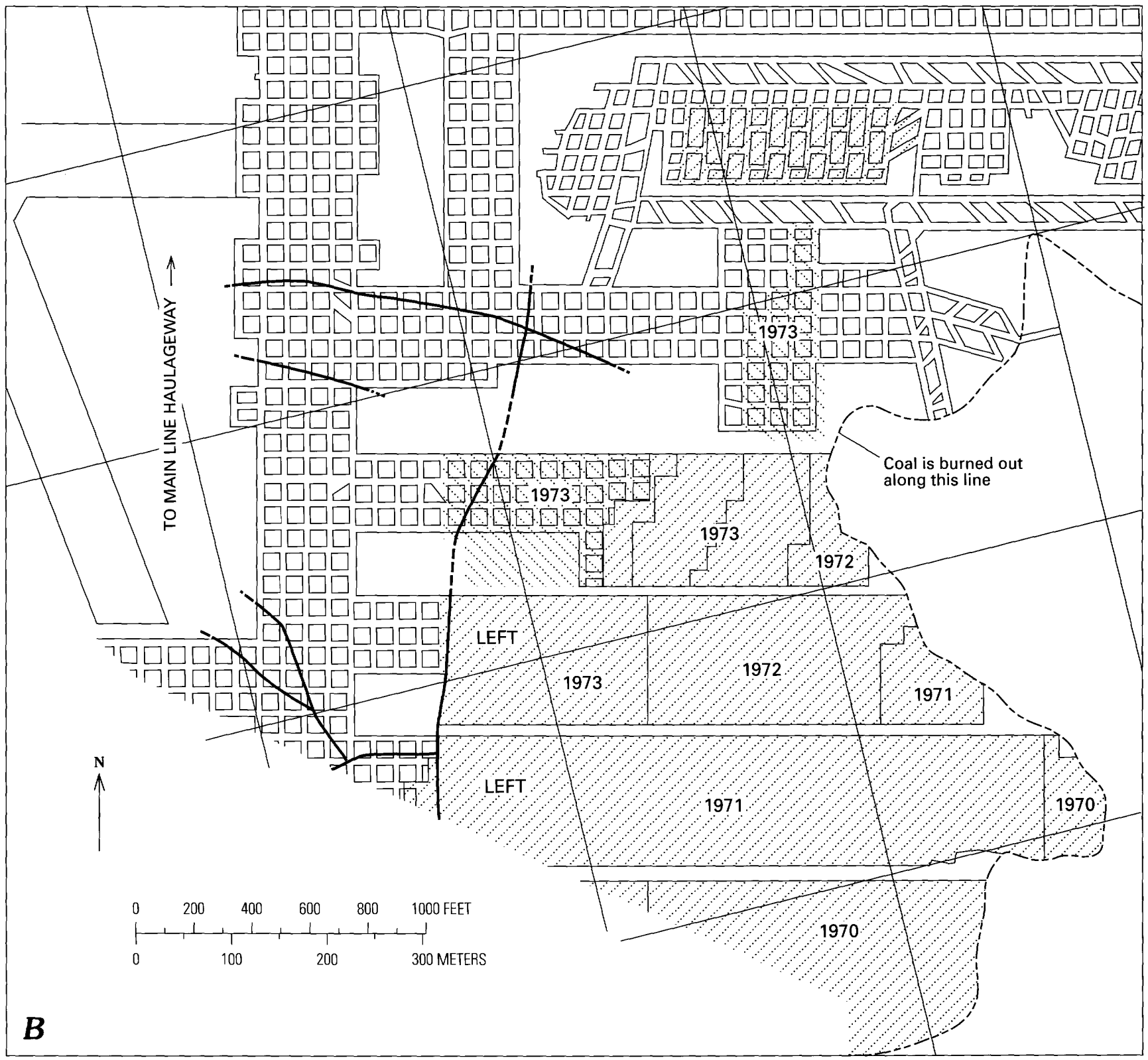

\section{COAL MINING METHODS AND MINE SUPPORT PROCEDURES}

\section{CURRENT MINING METHODS}

I. Room-and-Pillar-probably the most extensively used method in the United States

II. Longwall-becoming more extensively used in the United States

III. Shortwall-currently used only locally, if at all

IV. Hydraulic-used only locally where geologic, hydrologic, and topographic conditions are favorable

\section{PANEL-PILLAR MINE GEOMETRY}

I. Typical Layout of a Large Mine (fig. 30)

- Where the dip of the mined coal bed is equal to or greater than about $5^{\circ}$; layout consists of:

A. Main-line haulageway(s) from mine portals or shafts, which provide access, ventilation, and haulage for much or all of the mine; they usually are subparallel to the strike of the coal bed being mined

B. Submains (often called slopes or raises), which are driven off mainline haulageways to the active mining areas to provide access, ventilation, and haulage from the panel entries to the 
main-line haulageway; they commonly are subparallel to the dip of the coal bed being mined (fig. 30B)

C. Panel entries, which commonly are driven on the downdip sides of the mining panels for access, ventilation, and haulage from room-and-pillar, longwall, or other active mining areas to the submains; these entries usually are subparallel to the strike of the mine coal bed and consist of two- or three-entry systems

II. Smaller mines may not have any main-line haulageways connecting to slopes or raises; rather, the slopes and raises may provide access, ventilation, and haulage from portals or shafts directly to the panel entries

\section{MINING METHODS USED UNDER VARIOUS GEOLOGIC CONDITIONS}

I. Room-and-Pillar Mining Methods (see, for example, Kauffman and others, 1981) (fig. 31)

A. Commonly are used effectively where:

1. The coal is lenticular or extremely variable in thickness, or cut by rock channels (wants)

2. The current economic value of the coal reserves does not warrant the capital investment costs of longwall mining machinery (see, for example, Katell and others, 1976, for capital investment and costs of operating room-and-pillar mines)

3. The roof rocks are strong, relatively uniform, and have few slickensides and other fractures, and the rock does not slake readily when exposed to humid or alternately humid and dry ventilation air

4. The dip of the coal bed is less than about $15^{\circ}$ (in the days before mechanization, coal commonly was mined by room-and-pillar methods in beds dipping from $45^{\circ}$ to nearly vertically)

B. Of the four basic methods of extracting the coal by the room-and-pillar method, two involve pillar extraction on the retreat, and two involve advance and retreat mining (Kauffman and others, 1981, p. 1-25)

C. Rooms and crosscuts are driven and pillars extracted on the retreat from a set of panel entries (usually three) driven on the advance to the panel limit to establish haulage and ventilation (fig. 31A)
1. This is the most common method used in coal mines in the Western United States where pillars (formed when rooms and crosscuts are driven) are extracted

2. It has the following advantages:

a. The roof in the panel areas does not need to be supported for a long time, a major factor in mine safety

b. Recovery of reserves is maximized

c. Mining is done near (within the distance of a few rooms of) solid coal that minimizes the possibility of a squeeze

d. The section is easy to ventilate

3. The method is reported (Kauffman and others, 1981) to have certain disadvantages in some mining operations

a. Tonnage extracted per belt move may be low

b. Average haul distance may be long

D. Rooms and crosscuts are driven on the advance for the length of the panel; then the panel is completely extracted on the retreat (fig. 31B)

1. The method has the following advantages:

a. Tonnage extracted per belt move may be high

b. Average haul distance may be short

c. Easy to ventilate; maximum recovery of reserves obtained unless a squeeze occurs

2. The method also has disadvantages:

a. Roofs must be maintained over the life of the panel; this may create severe roof control problems, particularly in extraction areas

b. A squeeze may occur unless the pillars are designed to adequately withstand mine-induced stresses, and unless the rock above and beneath the coal can accommodate these stresses (see, for example, Babcock and others, 1981, and Wilson, 1981, for information on stable pillar width)

1- Squeezes have forced miners to abandon panels mined by this method in Colorado and Utah, for example, where abutment stresses exceeded the strength of the pillars

E. Rooms and crosscuts are driven and pillars are extracted on one side of the panel on the advance; then rooms and crosscuts are driven 


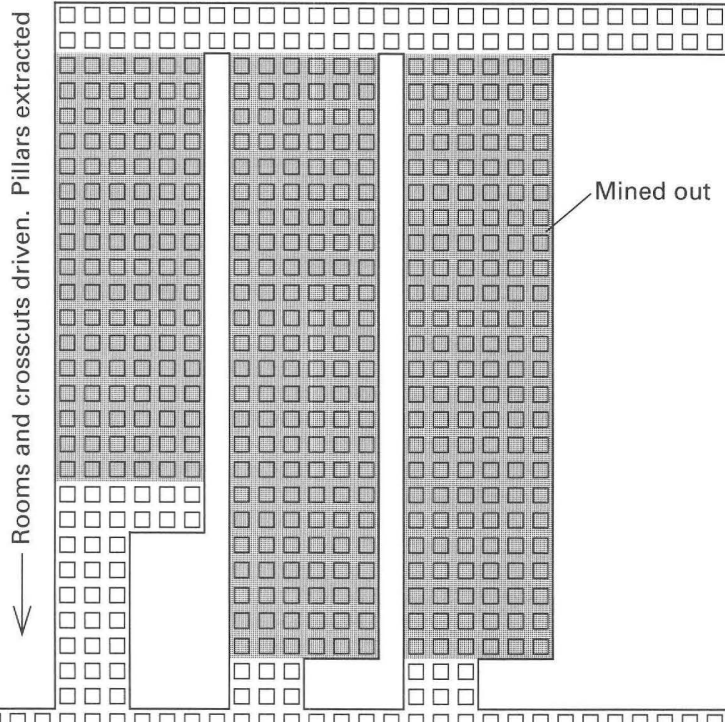

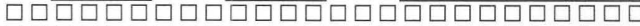

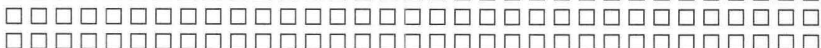

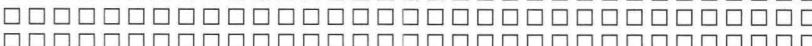

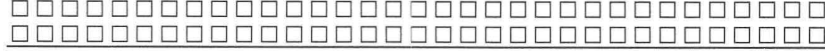

A

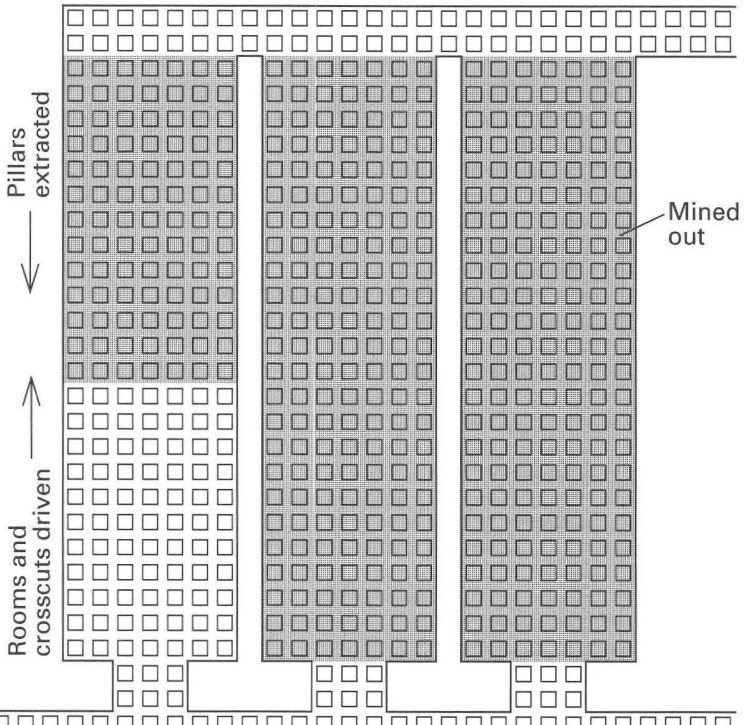

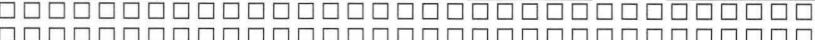

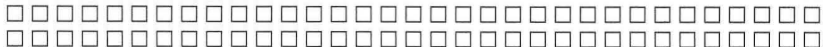
ㅁำ

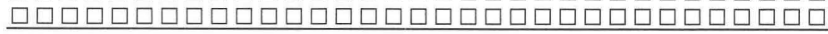

\section{B}

Figure 31. Diagrammatic maps showing different room-and-pillar mine geometrics. $A$, Rooms and crosscuts are driven and pillars are extracted on the retreat. $B$, Rooms and crosscuts are driven on the advance; pillars are completely extracted in panel on the retreat. $C$, Rooms and crosscuts are driven and pillars are extracted on the advance on one side of the panel, then rooms and crosscuts are driven and pillars are extracted on the other side of the panel on the retreat. $D$, Rooms and crosscuts are driven only on the advance to establish ventilation and haulage, rooms are driven to panel boundaries on the retreat on either side of haulageway and airway(s). Area is shaded where pillars have been extracted. Arrows beside mining panels indicate direction(s) of driving rooms and extracting pillars. From Kauffman and others $(1981$, p. 13-16).

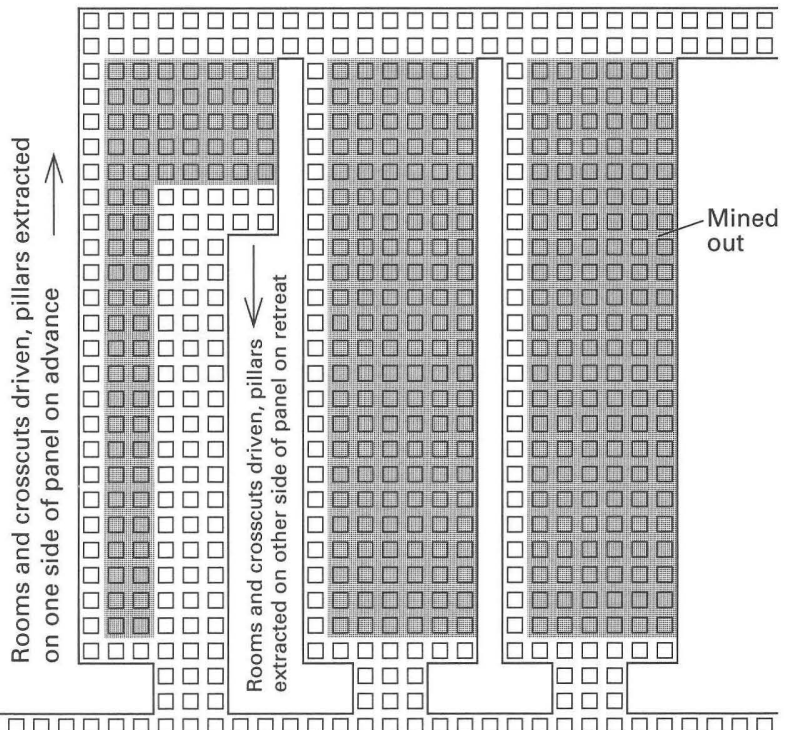

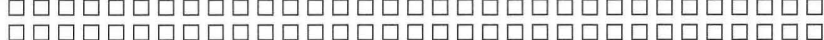

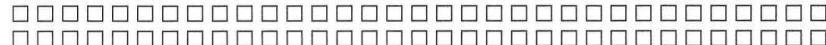

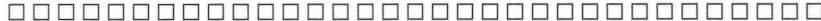

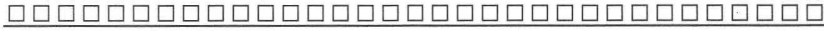

C

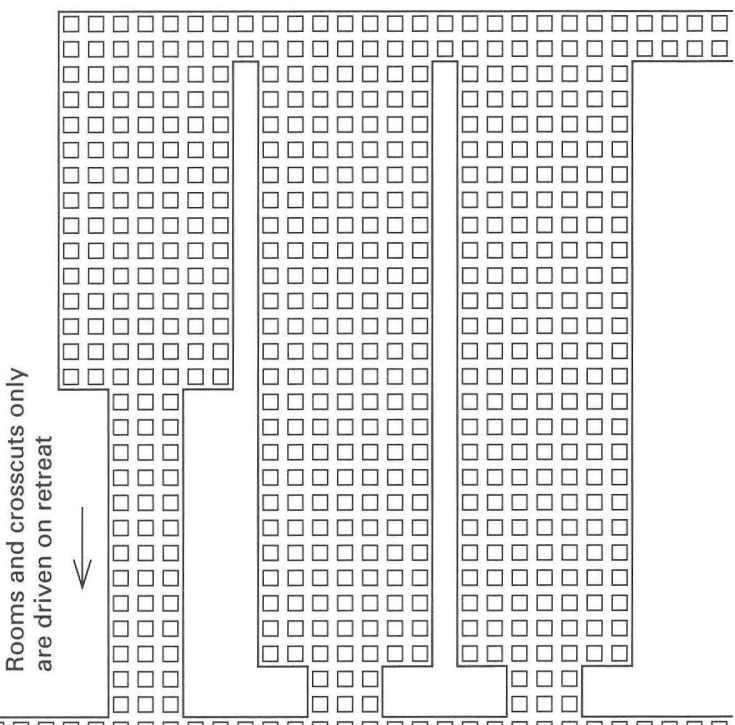

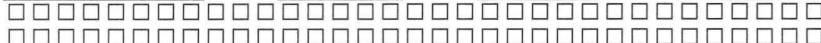

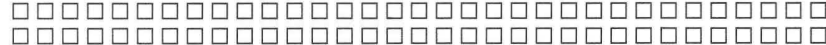

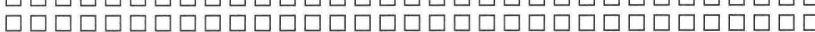

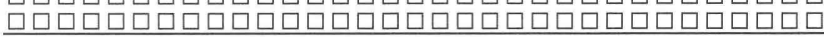

D 
and pillars are extracted on the other side of the panel on the retreat (fig. 31C)

1. This method of mining has not been observed by the writer

2. Reported advantages (Kauffman and others, 1981, p. 17) are:

a. The roof needs to be maintained only for a short time

b. Active mining areas are concentrated

c. Maximum recovery of reserves is obtained (unless roof falls, bumps, or squeezes occur)

3. Reported disadvantages are:

a. Active mining areas must be maintained near a caved area

b. Solid coal is not on one side of panel entry set

c. Tonnage per belt move is low

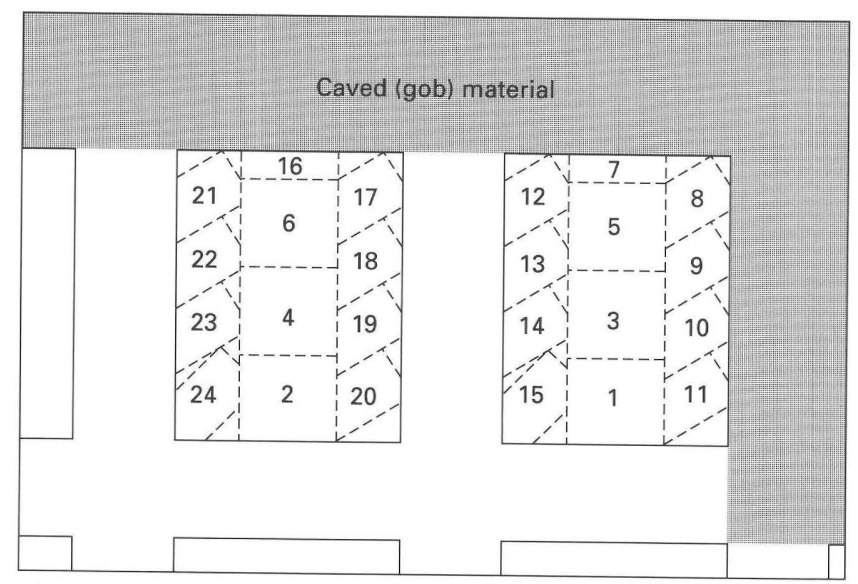

A

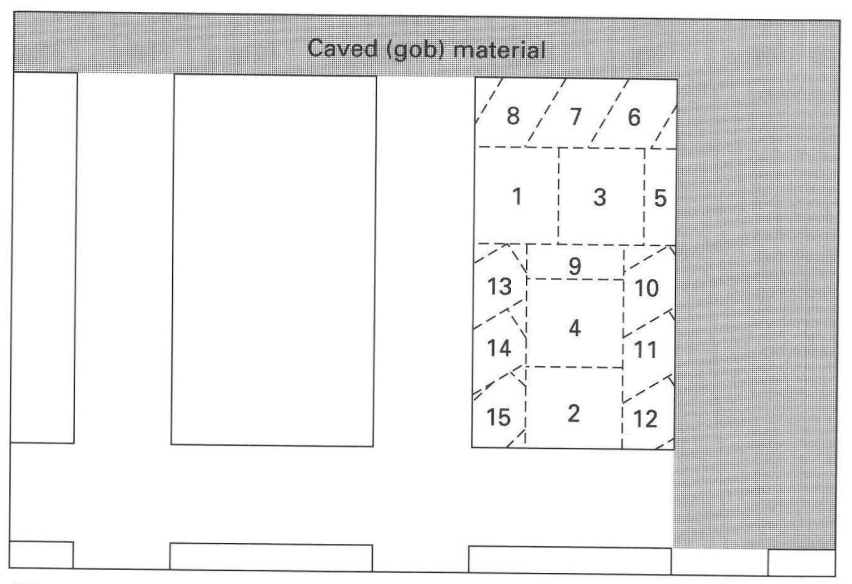

B d. Average haul distance is long

e. Panel is difficult to ventilate and bleed

F. Rooms and crosscuts are driven only on either side of initial panel entries (usually three for haulage and ventilation) on the retreat; no pillars are extracted (fig. $31 D$ )

1. May be used where subsidence is to be prevented or reduced, or where weak roofs and floors prohibit pillar extraction and longwall mining is not economical (for details in design of stable pillars, see Babcock and others, 1981; Bieniawski, 1981; Rockaway and Stephenson, 1982; Pariseau, 1980; Wilson, 1981)

2. Advantages (in addition to minimizing subsidence) are:

a. Active mining areas are not near any caved areas

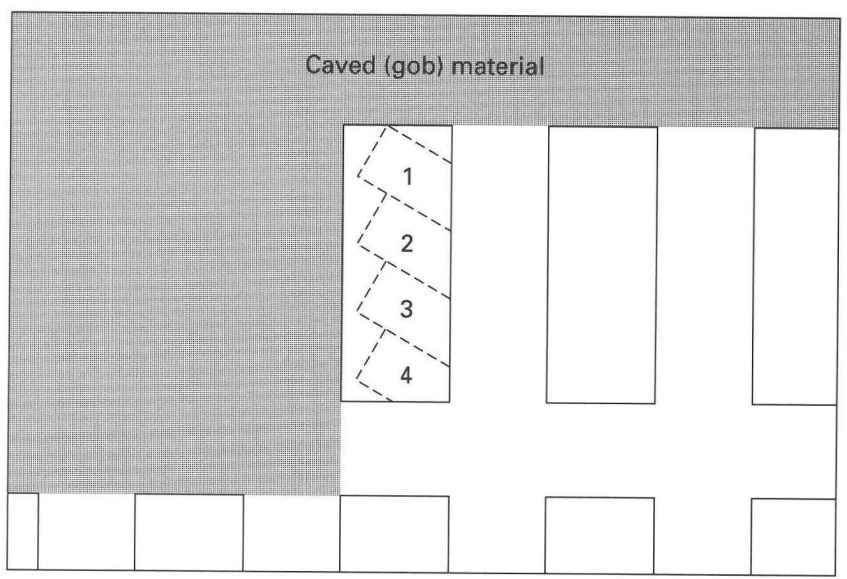

C

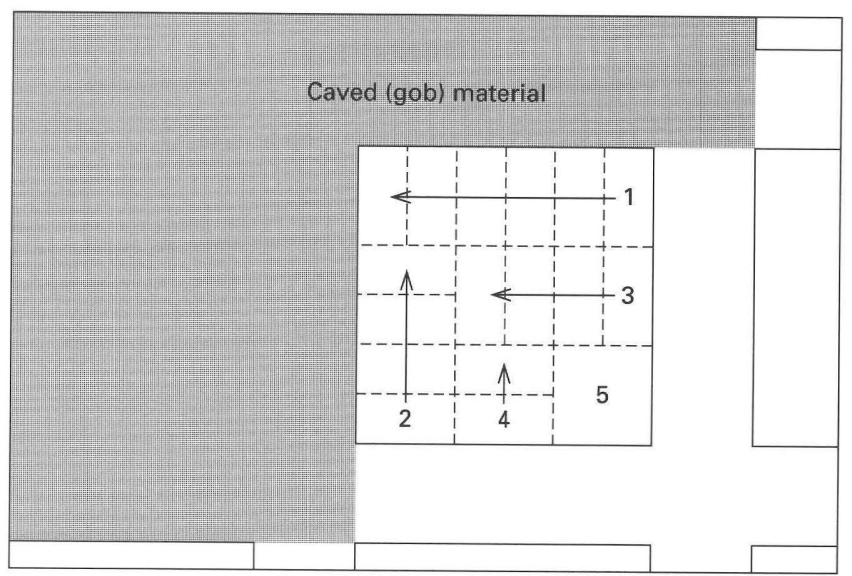

D

Figure 32. Common room-and-pillar mining sequences. Numbers indicate the sequence in which the coal is removed. $A$, split-and-fender; $B$, pocket-and-wing; $C$, outside lift; $D$, open-ending. From Kauffman and others (1981, p. 3-6). 


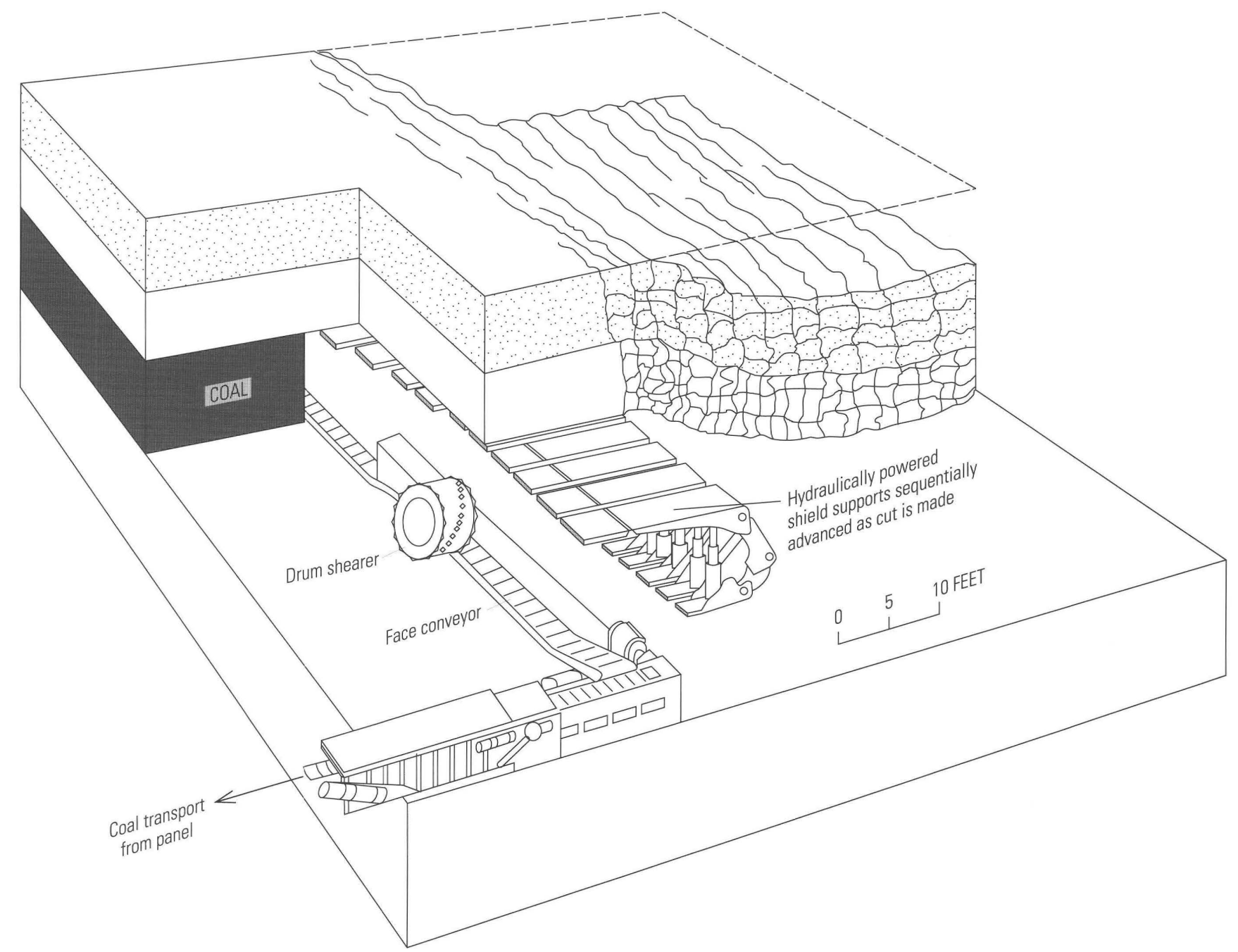

Figure 33. Block diagram showing a typical retreating longwall system. Coal is cut by drum shearer, deposited on face conveyor (conveyor parallel to mining face), and transported to the surface. The roof caves behind the hydraulically powered shield supports, creating the goaf (gob).

b. The active mining area is near solid coal

c. Roof needs to be maintained only for a short time

d. Work places are concentrated in a small area

e. Panel is easy to ventilate and bleed

3. Disadvantages are:

a. Low extraction ratio (about 50 percent or less)

b. Tonnage extracted per belt move may be low

c. Average haul distance may be long

d. Pillars may eventually fail or catch fire due to fluctuating water tables, failure of seals, and for other reasons (see section, "Coal Mine Fires and Explosions" for details)
G. Common room-and-pillar mining sequences (fig. 32; Kauffman and others, 1981)

1. Split-and-fender (also called split-and-wing and split-and-pillar) (fig. 32A)

a. The most widely used method in the United States

b. Can be used to extract small pillars (single split) or large pillars (multiple splits)

c. Generally involves mining at least two pillars simultaneously

2. Pocket-and-wing (fig. $32 B$ )

a. Used primarily for extracting large pillars

b. Two areas are mined in an alternating sequence on one pillar

3. Outside lift; used with success by a few mines (fig. 32C) 
a. Suitable for small pillars

b. Suitable for long slender pillars

4. Open-ending (fig. 32D)

a. Commonly used in conventional mining sections where drilling, blasting, loading, and bolting are practiced

b. May often be hazardous to miners and mining machinery because active mining areas are located near actively caving, or caved areas

II. Longwall Mining Method (see, for example, Olson and Tandanand, 1977; Oitto, 1979; Poad and others, 1977; Kuti, 1979)

A. The method is being more extensively used in areas of the Western United States where roof control problems are encountered by room-andpillar retreat mining

B. A long, straight face of coal (longwall) is cut by a drum shearer or a plow; the coal falls on a moving conveyor and is transported to the haulageway, where another conveyor or other equipment transports the coal to the surface (fig. 33)

1. The roof is supported by powered hydraulic frame, chock, or shield supports in most modern mines of the United States and other countries

2. The roof caves behind the supports

C. The longwall method is used almost exclusively in many countries

1. An example is in the Ruhr, Aachen, and Saar-Lorraine districts of Germany, where beds dip as much as $45^{\circ}$, the overburden thickness averages $2,700 \mathrm{ft}(825 \mathrm{~m})$, and the roof rocks are soft and weak because they are filled with cavities and cut by numerous faults (Curth, 1974a)

D. Advantages of longwall mining are:

1. Extraction efficiency and overall percentage of reserves extracted commonly are greater by longwall than by the room-and-pillar method

2. Productivity and yield are higher; tons of coal per mining panel and per individual shift usually are much higher than in roomand-pillar mining panels

a. Mines supplying powerplants, for example, must meet tonnage requirements and guarantee production; the longwall method may be required because it commonly is not subject to losses in production caused by bumps, outbursts, or roof falls that may be associated with the room-and-pillar method

3. Longwall mining panels commonly provide safer working environments for miners a. In the Bosnia-Hertzegovina region of Yugoslavia (as it existed in the 1980's), for example, fire and explosion hazards and hazards from rock bursts and bumps (discussed later) have been less for longwall mining panels than for room-andpillar extraction panels under similar conditions (Muris Osmanagić, written commun., 1984)

4. The longwall method, as discussed later, can be used to mine coal in beds too thick or too thin to mine by the room-and-pillar method

5. Beds can be more safely and efficiently mined at greater depths or in multiple, vertically superimposed sequences by longwall methods than by the room-and-pillar method

6. The longwall method can be used in steeply dipping coal beds (perhaps as steep as $45^{\circ}$ ); however, conventional methods of driving entries in the United States cannot keep up with longwall rates of movement in coal beds dipping more than about $15^{\circ}(25$ percent grade)

7. Longwall methods commonly work well beneath weak, slickensided roofs, which commonly are a severe hazard to miners and equipment when the room-and-pillar method is used

E. Disadvantages of the longwall method:

1. Capital investment costs for equipment may be four to five times greater than for the room-and-pillar method, based on recent conversations with mine management in the Western United States (four times greater for 10 -ft faces, five times greater for 15 - $\mathrm{ft}$ faces)

2. The method may not be efficient or economical where coal beds thicken and thin or split in short distances, or are faulted

a. The method requires intensive geologic and geotechnical studies in areas where the coal beds are cut by numerous faults

b. In the southern part of Brazil, near Criciuma, Santa Catarina, for example, where all known Brazilian coal reserves occur (1987), one reserve has a high percentage of coal and a low percentage of rock (in many other areas the coal beds consist of about equal amounts of coal and rock)

1- An extensive longwall mine is planned for this area of Brazil for efficiency and safety

2- Mine management is concerned that the area may contain a number of faults that cannot be mapped at the 
surface and projected to the coal zone because of extensive surficial deposits that obscure the bedrock geology

3- The location and displacement of any faults must be known at the mine design stage in order to lay out the mine in such a manner that will extract this prime coal reserve most efficiently and safely

3. The longwall method would not be economical where the potential value of reserves does not warrant the high initial capital investment costs of the longwall system

F. Longwall mining layouts currently being used (Olson and Tandanand, 1977, p. 17-18) are:

1. Full retreat (fig. 30A)

a. Used almost exclusively in the United States where the profit motive is the determining factor (that is, where the system is not subsidized by a government agency for research and development)

b. Two or three entries commonly are driven to the panel boundary to be mined on 400to $600-\mathrm{ft}(\approx 120-180 \mathrm{~m})$ spacings

c. Longwall mining equipment (shearer, conveyor, hydraulic roof supports) is installed

d. Coal is then extracted on the retreat toward the main (or submain) haulageway

e. Advantages:

1- Conditions of coal, roof, and floors, which may be variable, can be precisely determined during the entrydriving phase (geologic and drilling analyses in advance of mining would have given predicted conditions)

2- Hazards from stress concentrations, fires, and explosions are reduced, compared to advancing longwall, because the goaf is behind the active working, access, haulage, and ventilation areas

3- Entries providing access, haulage, and incoming air ventilation to the longwall operation are protected by solid coal

4- Rate of face movement commonly is not controlled by entry drivage rate

f. Disadvantages:

1- High production does not occur as soon as in advancing longwall section or room-and-pillar operations, because of equipment set-up time

2. Alternating retreat layout (for example, see Olson and Tandanand, 1977, p. 7)

a. Involves the longwall system that retreats toward submains from another submain located at the other end of the panel

3. Advancing longwall

a. Face usually is advanced from a barrier near the main entries

b. Pack (entry support) walls are constructed in sequence with face advance

c. May locally work better than retreat longwall where the dip of the coal exceeds about $15^{\circ}$, because entry development on retreat longwall may not be able to keep up with the rate of longwall retreat mining in beds dipping more than $15^{\circ}$

d. An advantage is that high production usually occurs sooner than on retreat longwall, because the panel is driven from a barrier near the submain without the necessity of driving development entries

e. Disadvantages:

1- Access, haulage, and ventilation must be beside the goaf

2- Stress concentrations may be too high for the packwalls, causing a squeeze that could close off access haulage and ventilation and threaten life and property

3- Fires and explosions from methane in the goaf may be a severe threat to life and property

4. Advance and retreat longwall (Olson and Tandanand, 1977, p. 17-18)

a. A combination of advancing and retreating layouts

b. This method reportedly was planned in the Redstone, Colo., area in the late 1970's or early 1980's; however, the high gas and dust content of this coal reportedly prevented completion of the project

III. Shortwall Mining (Peng, 1978, p. 20-23)

A. This is a hybrid concept that uses methods from both the room-and-pillar and the longwall methods (fig. 34)

1. The coal is mined on the retreat using a continuous mining machine

2. The coal is transported by shuttle car to a conveyor or mine car load point 


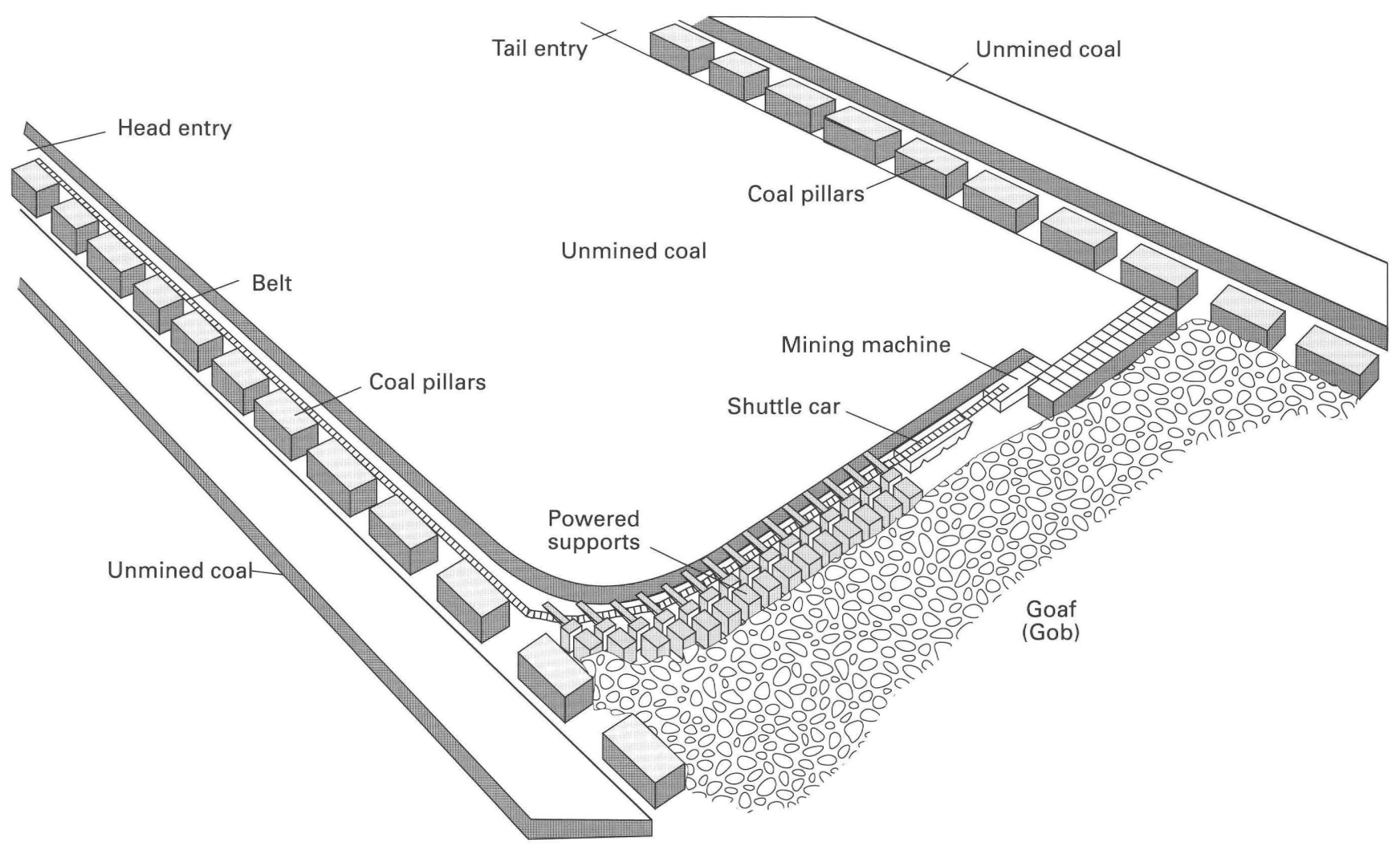

Figure 34. Block diagram showing a shortwall mine panel layout. Two-entry system portrayed is becoming popular in Western United States in longwall sections because bumps, roof falls, and spontaneous combustion (probably caused by stress-generated heating) reportedly are reduced, compared with three-entry system. Modified from Peng (1978, p. 21).

3. The roof is temporarily supported by powered supports with specially designed, extendable canopies that support an area along the face that is wide enough for a continuous miner and shuttle car

B. Layout of panel is similar to longwall, but the panel width commonly is less (ranging between about 100 and $200 \mathrm{ft}$ ) and each cut is wider (ranging between about 6 and $11 \mathrm{ft}$ )

C. Only a few shortwall systems have operated in the United States; few, if any, advantages over the longwall retreat method have been reported

IV. Special Mining Methods for Thick or Multiple Beds

- These methods may be a viable alternative to current mining practices in many areas of the United States where the coal is thicker than about $10-12 \mathrm{ft}$ or where the coal is minable by standard methods (individual $10-12 \mathrm{ft}$ thick or less) but occurs in multiple beds separated by rock intervals ranging from a foot or so to as much as $30 \mathrm{ft}$ thick

A. High-face longwall-this method currently is being used in local areas of the United States (such as Hanna, Wyo.) and in other countries to mine coal as much as $15 \mathrm{ft}$ thick in one lift with powered shield supports
1. As much as $14 \mathrm{ft}$ of coal is cut in the Hanna, Wyo., area in panels $400-600 \mathrm{ft}$ wide and 2,200-8,300 ft long

a. The coal dips from $6^{\circ}$ to $15^{\circ}$ beneath overburden ranging from 200 to $500 \mathrm{ft}$ thick

b. Yield from a panel averages about 30 short tons/manshift (total production/ number of miners underground)

c. Productivity from a panel averages about 3,000 short tons/shift (J. Strid, oral commun., 1985)

2. High-face longwall proved to be most efficient in the Breza area, located $25 \mathrm{~km}$ northwest of Sarajevo in Bosnia-Hertzegovina, Yugoslavia (as it existed in the 1980's), based on analyses of profit ratio (percent of money made/money spent), work safety (injuries/1,000 tons), productivity (tons/ day), yield (tons/individual shift), capital investment (money/ton capacity of mine), and extraction ratio (percentage of tons of coal mined/tons of coal available) 
3. High-face longwall panels in [former] Yugoslavia were begun in 1979 in the Breza area in coal beds dipping $18^{\circ}-30^{\circ}$ in panels about $300 \mathrm{ft}$ wide, beneath overburden as much as $1,150 \mathrm{ft}$ thick

a. Since the advent of modern, high capacity longwall mining machine powered shield supports (total bearing capacity of
$420 \mathrm{MPa}$ ) and double-drum shearers with a maximum cutting height of $15.7 \mathrm{ft}$, yield from the panels has averaged about $37 \mathrm{t}$ (metric tons) per individual shift

4. High-face longwall methods also are used at Zenica, Bosnia-Hertzegovina, [former] Yugoslavia, to mine a coal bed about 14-16 $\mathrm{ft}$ thick, which dips as much as $30^{\circ}$ and is

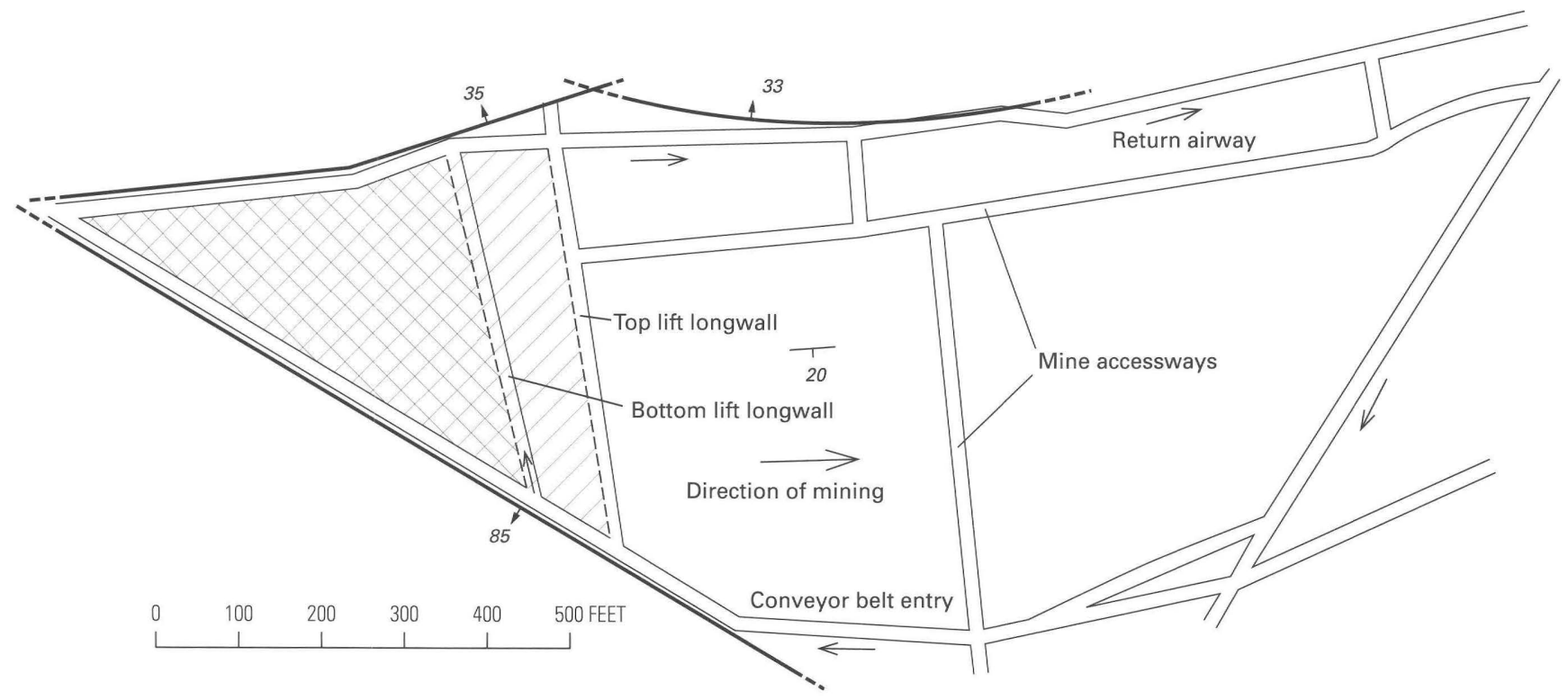

A

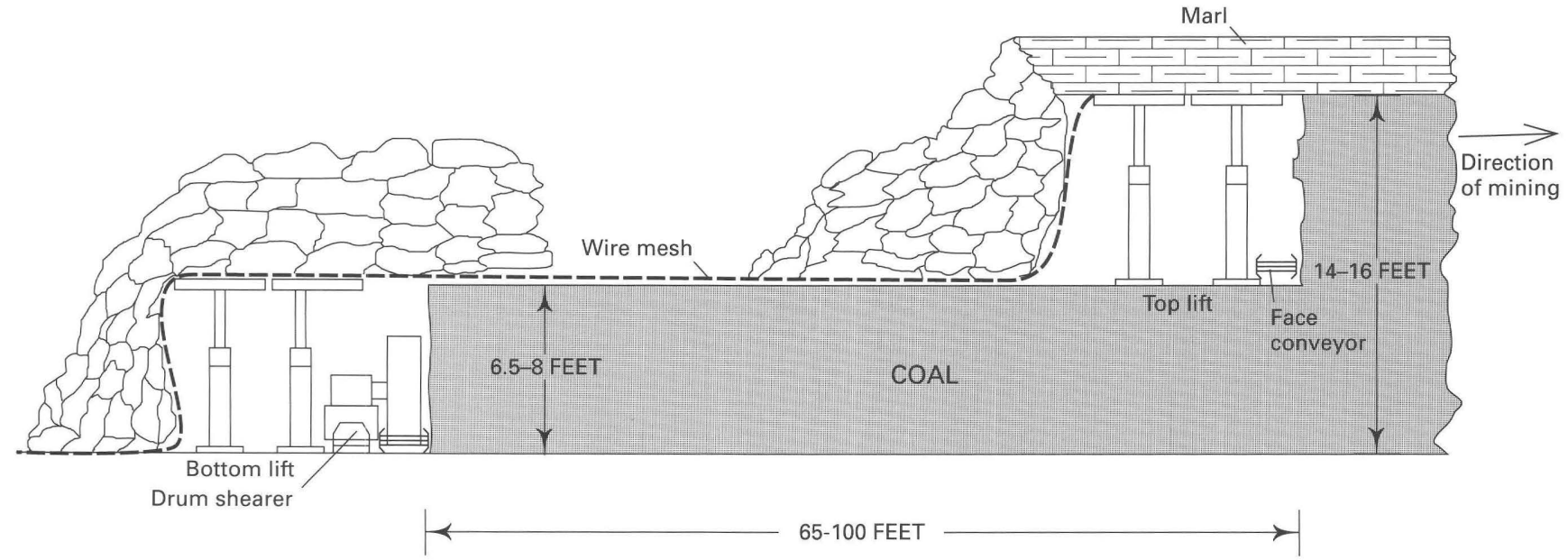

$B$

Figure 35. Mining thick coal beds by the double-lift longwall method near Breza in Bosnia-Hertzegovina, [former] Yugoslavia. A, Map of a longwall panel in a coal bed 14-16 ft thick (strike and dip shown), surrounded by gently to steeply dipping faults (heavy lines, dashed where approximate). The top lift (diagonal line pattern) is about $100 \mathrm{ft}$ ahead of the bottom lift (cross hatching). B, Cross section showing detail of the double-lift longwall system. Top lift cuts a face from 6.5 to $8 \mathrm{ft}$ high $65-100 \mathrm{ft}$ ahead of bottom lift. Wire mesh placed above the roof support on the top lift is used to help restrain rock fragments from falling into the trailing bottom lift. Modified from M. Osmanagić (written commun., 1984). 
located at depths of as much as $1,150 \mathrm{ft}$ beneath the surface

B. Double-lift longwall has been used in the 1970's and 1980's to mine brown coal beds as much as $15-20 \mathrm{ft}$ thick near the town of Breza in BosniaHertzegovina, [ former] Yugoslavia (fig. 35A, B)

1. Coal has been mined in beds dipping as much as $20^{\circ}$, beneath overburden as much as $1,150 \mathrm{ft}$ thick

2. The top lift cuts $6.5-8 \mathrm{ft}$ of coal along a face $300-500 \mathrm{ft}$ long (fig. 35B)

3. The bottom lift cuts a similar face height 65-100 ft behind the face of the top lift

4. The conveyor belt entry serves both the top and bottom lifts

5. Stresses on the bottom lift are small if this spacing is maintained

6. Stresses increase greatly on the bottom lift, and are accompanied by bottom heaving of soft shale floors in the entries, if the lift spacing becomes more than $100 \mathrm{ft}$

7. Productivity of the top lift averages 14 tons/ individual shift; the bottom lift averages 8 tons/individual shift

8. This method may also be used where two minable coal beds are separated by rock partings as thick as about $30 \mathrm{ft}$

C. Single-lift longwall with sublevel caving has recently been used in the Zenica area of BosniaHertzegovina, [former] Yugoslavia (fig. 36A, $B$ )

1. The coal bed being mined ranges from 43 to $48 \mathrm{ft}$ thick, dips as much as $11^{\circ}$, and is mined as deep as $1,800 \mathrm{ft}$

2. Multilift, sublevel caving has replaced the earlier, double-lift longwall method, which mined two 10-ft lifts, but lost about 50 percent of the coal in the middle of the bed

3. During the last 5 years of continuous operation (to 1984), the method yielded an average of $25 \mathrm{t}$ (metric tons) per individual shift from panels about $400 \mathrm{ft}$ wide; the extraction ratio is as much as 80 percent

D. Multilift, longwall mining with sublevel caving has been used in the mines near Valenje, Slovenia, [former] Yugoslavia, where a lignite as much as $250 \mathrm{ft}$ thick has been mined since 1885

1. The lignite currently (mid-1980's) is mined in $33-\mathrm{ft}(10-\mathrm{m})$ lifts
2. The latest method involves cutting a longwall face about $10 \mathrm{ft}$ high with a drum shearer using powered shield supports

3. The lignite above the support is caved onto a goaf-side conveyor or is caved through a trap door in the shield and is removed by the face conveyor; this latter procedure also is reportedly used in some Hungarian mines (B. Lutzens, U.S. Bureau of Mines, oral commun., 1985)

a. At Valenje, the coal commonly is blasted to induce caving, particularly where trap-door shield supports are used

E. Modified room-and-pillar mining with block caving and backfilling

1. Brown coal from about 50 to $65 \mathrm{ft}$ thick has been mined beneath a village near the town of Mostar in Bosnia-Hertzegovina, [former] Yugoslavia, where the coal dips as much as $15^{\circ}$ and occurs at depths between 400 and $800 \mathrm{ft}$ beneath the surface (fig. 37)

a. The rooms are about $330 \mathrm{ft}$ long and are separated by unmined coal (fig. 37A, B)

b. In profile, the rooms are inverted trapezoids about $65 \mathrm{ft}$ wide at the top and 16 $\mathrm{ft}$ wide at the bottom, separated by pillars which are upright trapezoids with widths similar to the rooms (fig. 37C)

c. Three rooms are linked by chain conveyor in the mining cycle

1- While the first room is being mined, the mined-out area is being hydraulically backfilled with marl to reduce fire and explosion hazards and subsidence in this urban area of [former] Yugoslavia

$a$ - Subsidence is only about 2 percent of the mining thickness where hydraulic backfilling is done

2- The second room is mined (by a modified block-caving method) (fig. 37B)

$a$ - The coal falls to the chain conveyor as it is drilled and blasted

3- The third room is prepared for mining

a- A ventilation entry is driven at the roof; the roof is bolted 


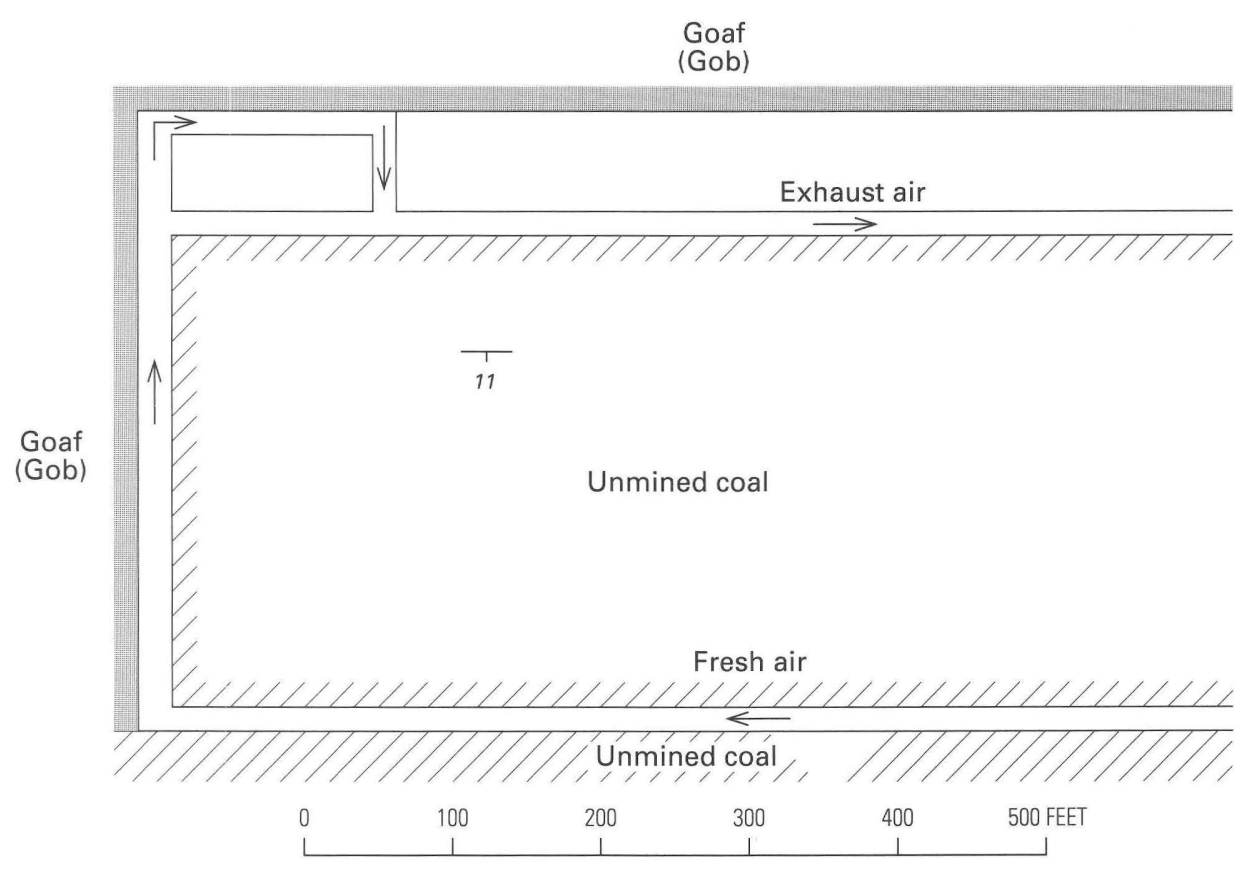

\section{A}

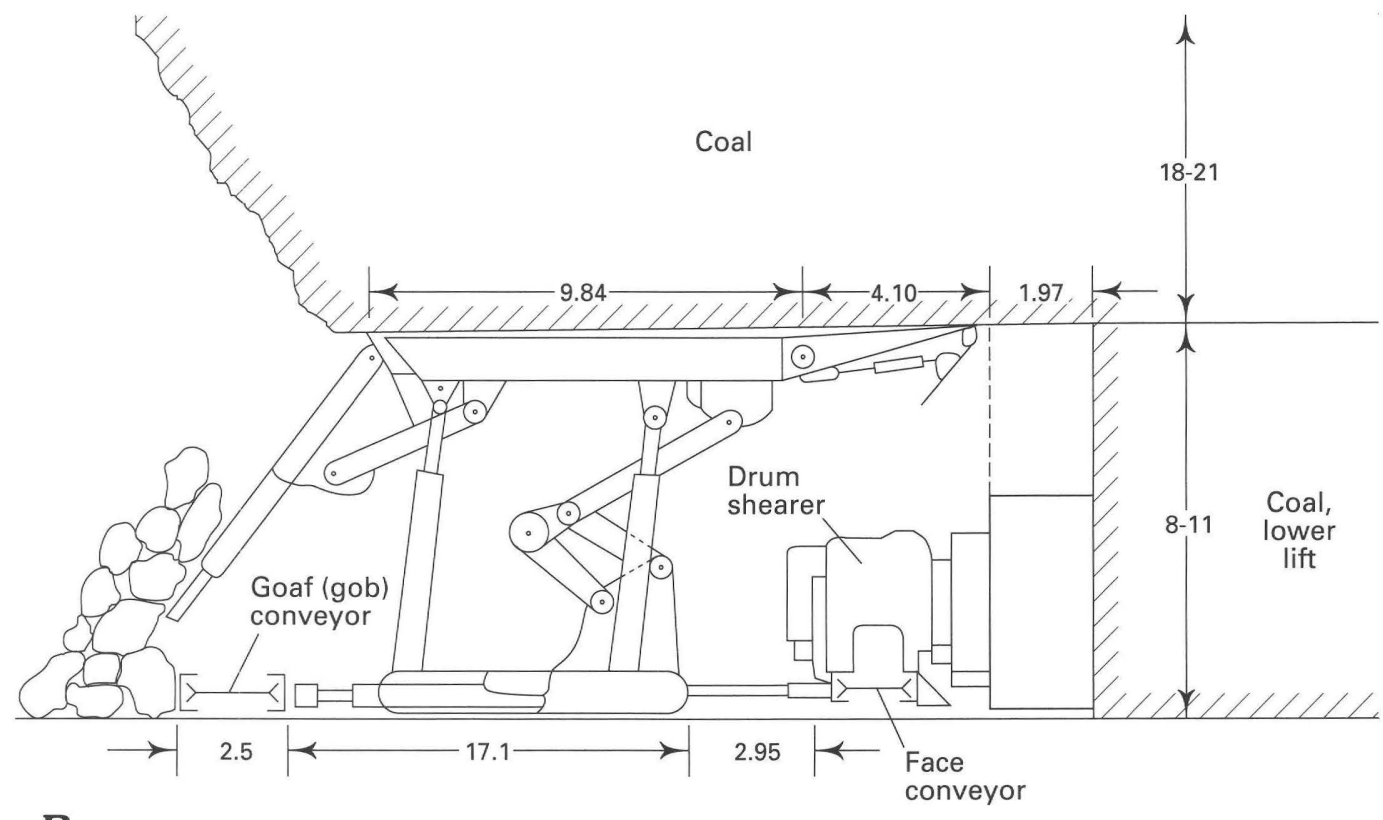

$B$

Figure 36. Mining thick coal beds by longwall with sublevel caving near Zenica, Bosnia-Hertzegovina, [former] Yugoslavia. A, Map showing a typical panel to be mined in a coal bed 43-48 ft thick which dips $11^{\circ}$. A top lift $10-15 \mathrm{ft}$ thick is mined on the advance. Arrows indicate flow of ventilation air. $B$, A bottom lift $8-11$ $\mathrm{ft}$ thick is mined on the retreat and the middle lift $18-21 \mathrm{ft}$ thick is mined by sublevel caving. The face and goaf conveyors transport coal from face and goaf sides, respectively. Modified from M. Osmanagić (written commun., 1984). Measurements shown in feet; $1 \mathrm{ft}=0.3048 \mathrm{~m}$. 

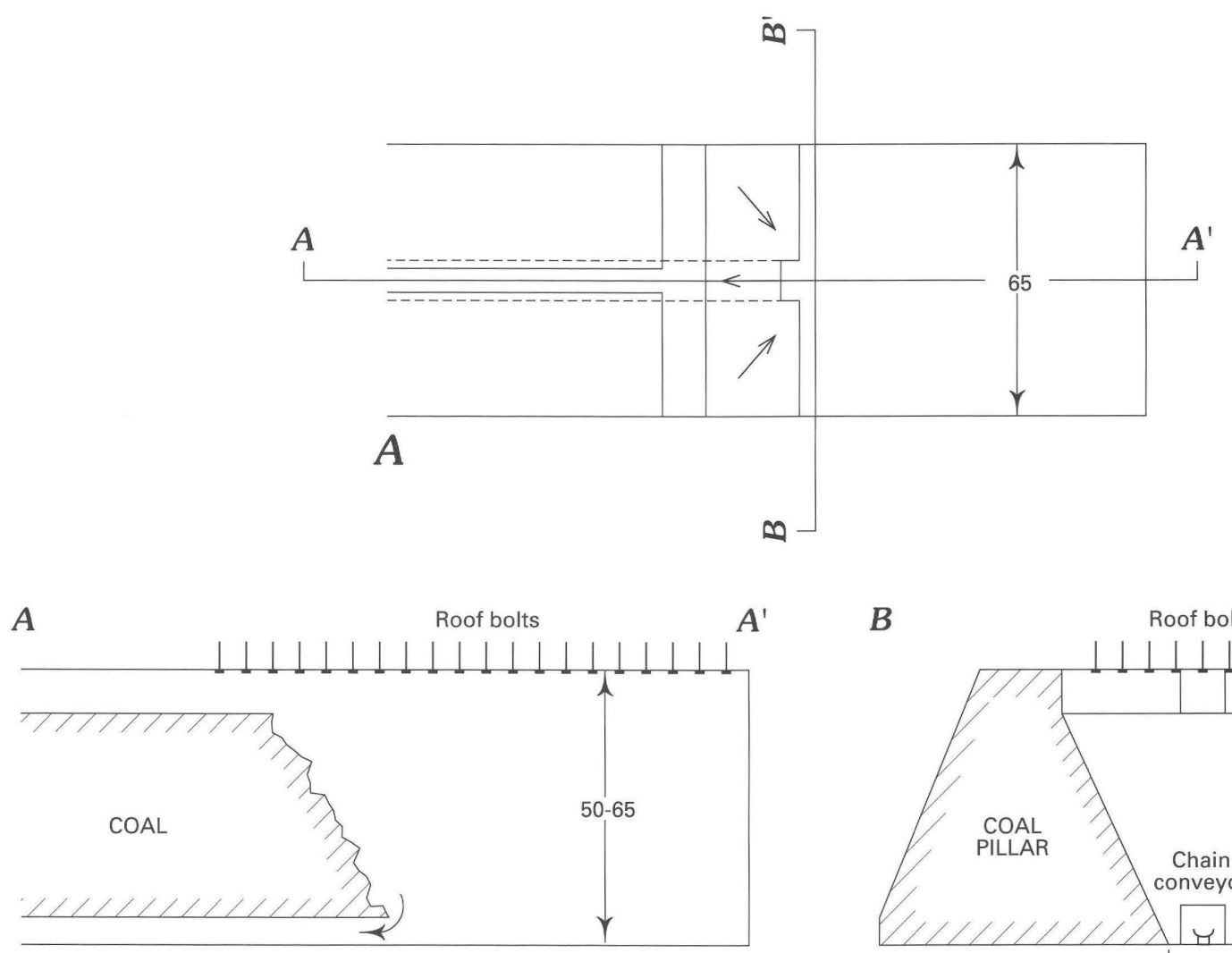

B

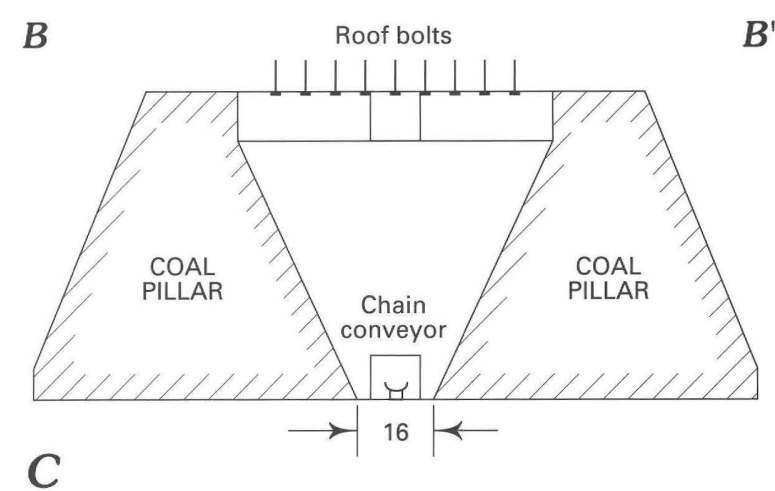

Figure 37. Plan and profiles showing a modified room-and-pillar mining method. The method has been used in sequence with hydraulic backfilling near Mostar in Bosnia-Hertzegovina, [former] Yugoslavia, to mine thick coal beds in one pass. A, plan view. Dashed lines in $A$, Entry beneath coal. $B$, longitudinal profile; $C$, transverse profile. Modified from M. Osmanagić (written commun., 1984). Measurements in feet.

$b$ - A haulage entry is driven at the floor for the chain conveyor

4- Production averages 500 tons/day from a room, with an average yield of about $40 \mathrm{t}$ (metric tons) per individual/shift

5- Extraction efficiency is about 50 percent

F. Hydraulic mining (Cooley, 1975; Kent and Arndt, 1980); basic concepts:

1. Monitor jets, with water pressures greater than about $5,000 \mathrm{lb} / \mathrm{in}^{2}{ }^{2}\left(350 \mathrm{~kg} / \mathrm{cm}^{2}\right)$ or water cannons with pulsed water jets, with peak pressures of 40,000-100,000 lb/in. ${ }^{2}$ are used to cut the coal from the face

a. The coal is cut and broken by processes such as granular hydrobreaking (under shear and tensile failure) and granular erosion (for example, Cooley, 1975)
2. Coal is transported from the face to the surface by flumes or slurry pipelines, or by shuttle cars, conveyor belts, or mine cars (Cooley, 1975)

3. According to Cooley (1975), hydraulic mining may be an efficient alternative to other mining methods in areas where

a. Coal beds are 6-50 ft thick, are of high cash value (such as coking quality coal), and dip at angles greater than about $5^{\circ}$

b. The floor rock is strong and not softened by water

c. Faults and sudden changes in dip (rolls) rarely occur, particularly where flumes are to be used

d. The coal is friable and easily broken by water jets (friability commonly decreases with increasing coal hardness and compressive strength (see section, "Geotechnical Studies")) 
e. The overburden thickness is less than about 2,000 ft (610 m)

f. Supply of water and electric power is adequate

g. The sulfur content of the coal is low; this prevents acid water problems in mine drainage

h. There is an adequate way to dispose of the coal slimes in lagoons or elsewhere without causing environmental problems

1- At Page, Ariz., where coal is supplied by slurry pipeline from the surface mine at Black Mesa, the operators burn the dried slimes in the powerplant, and thus solve the slime problem and gain some additional energy

i. There are solutions for problems of high humidity, temperature, and low visibility at mining faces

4. Hydraulic mining methods are under consideration in some areas of the Western United States where dips are too steep for entries to be driven by continuous miners

a. For example, hydraulic mining and slurry transport methods were considered in the 1970's in the Carbon River area of Washington, where highly folded coking coal beds are located (Cooley, 1975, p. 9-13)

\section{MINE SUPPORT PROCEDURES}

\section{The Type or Types of Roof Support Used}

- Depends primarily on the type of openings to be supported (haulageways, manways, aircourses), method of mining used (room-and-pillar, longwall), the length of time to be supported, and the geologic and geotechnical properties of the roof and floor rocks

\section{Roof Bolts}

- Very useful to make thinly layered rock sequences behave as a thicker and stronger beam by bolting them together (fig. 38; Panek, 1974, p. 92-96; Evans, 1941)

A. An integral support structure is therefore made from the roof material, which reduces material haulage, expense, and reduces roof fall hazards

B. Bolts are used throughout most mines in the Western United States, but are particularly useful in haulageways, airways, and rooms where unobstructed openings are needed for the movement of mining equipment
C. Bolts should be long enough to anchor in firm rock (for load relations on preloaded rock bolts, see Osen and others, 1965)

D. Bolts commonly are installed in a rectangular grid pattern on about 4- to 6-ft centers; steel mats and steel mesh are often installed during the bolting process, particularly in weak roofs that may fail between the bolts

E. Expansive shell, friction-anchored bolts commonly are used where strong, uniform roof rocks occur or where there are no rapid changes in roof lithology and structure, and where rocks are not subject to air slaking (for example, Parsons and Osen, 1968)

1. The anchor point is only at the top end of the bolt; tensioned, point anchor bolts may outperform non-tensioned, full-column, resingrouted bolts in strong, slake-resistant rocks where resistance to shear is important (Bortels and Pappas, 1985)

F. Epoxy-resin bolts are used most extensively in recent times where the roof is weak, slickensided, prone to slake, and (or) fractured; they are also useful where channel deposits occur (for example, Radcliffe and Stateham, 1980)

1. This type of bolt forms a more or less continuous anchor throughout its length because the epoxy resin fills much of the hole; tensioned, full-column, resin-grouted bolts perform best in medium- to low-strength, thinbedded rocks (soft sandstone, shale, and mudstone)

2. Although more expensive than the expansive shell bolt, this type of bolt is used exclusively in some room-and-pillar mines of the Western United States with weak, slickensided roofs, because it significantly reduces roof-fall hazards to life and property and promotes greater extraction efficiency

III. Other Methods of Supporting the Roof in Entries and Rooms

A. Props (individual vertical supports) - used to support the roof in mine openings where large open areas are not needed for mining equipment or where breaker timbers are used to induce caving at the pillar line (fig. 52)

1. Props can provide much support where the roof consists of thinly layered rocks that tend to buckle if there is no support, but tend to be stable if some minimal support is provided (Parker, 1973) 
B. Cribs-used where high stresses are a problem, such as in entries where no mining equipment is moving or where there is no haulage (as in longwall tailgate entries)

1. Cribs also were used in a retreating longwall section in the Sunnyside, Utah, area to support the center of a single-entry system; fireresistant panels divide the entry into two entries to provide more stable access, ventilation, and haulage (Poad and others, 1977)

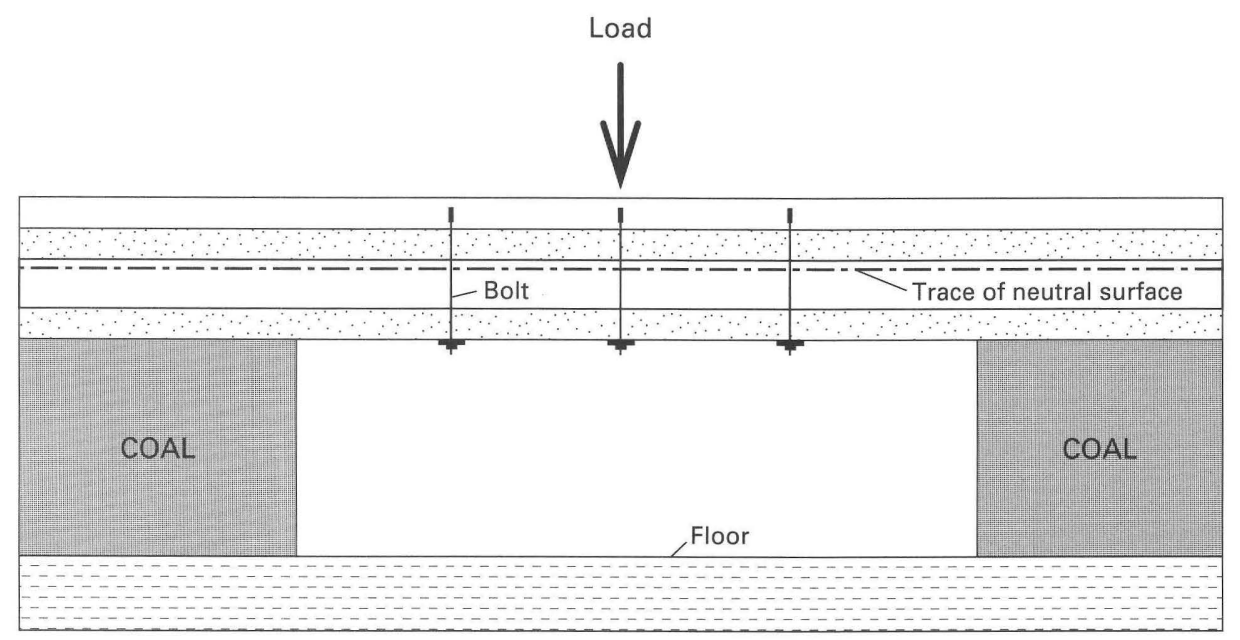

A

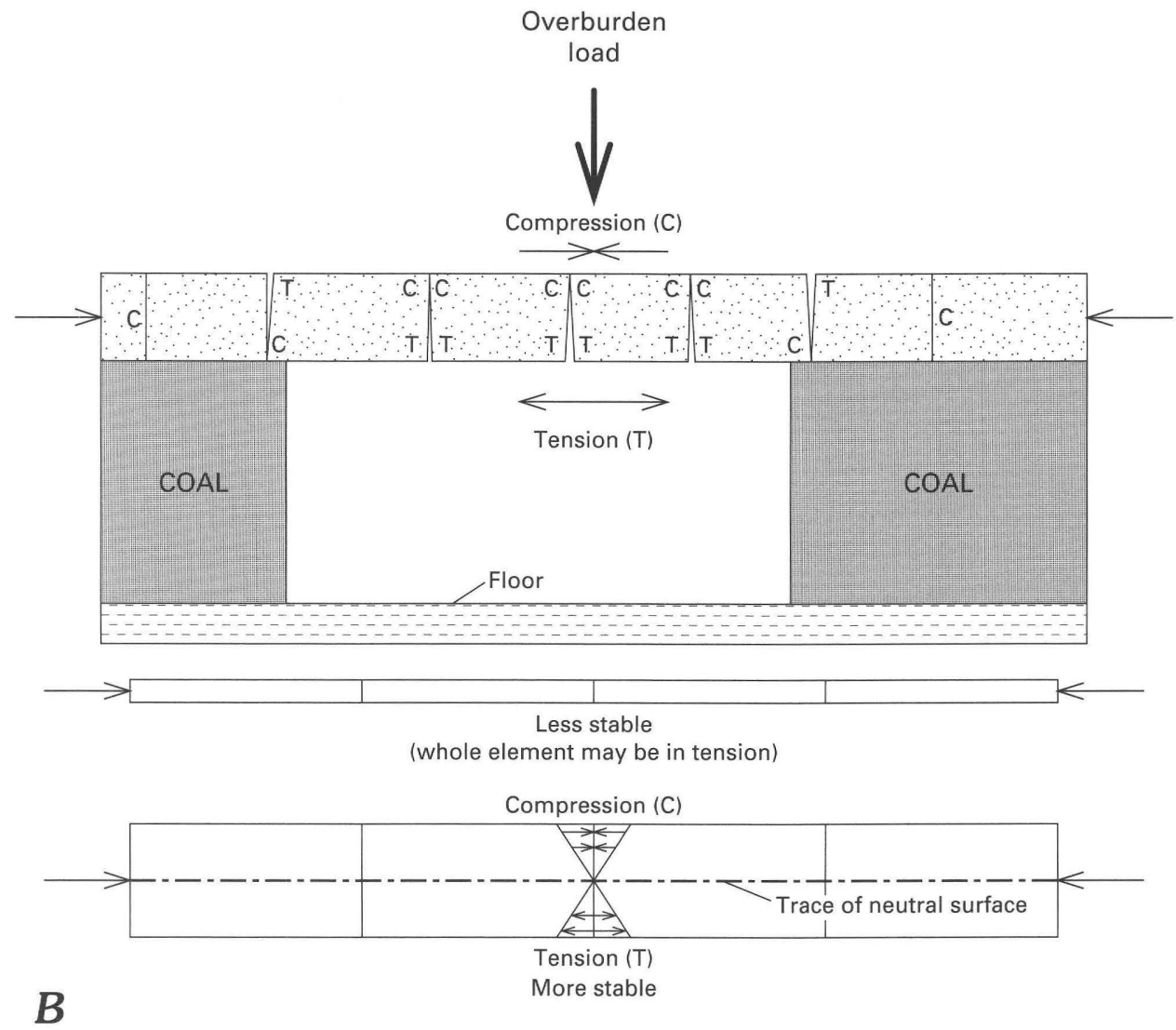

C. Steel arches-commonly used in important entries, such as haulageways, where high stress concentrations could cause severe roof and rib failures, which may be a hazard to life and property and cause losses in production

1. The basic concept is that the arches form a support that is strong, yet yieldable, in order to restrain roof rocks and promote transfer of vertical stresses from the roof to the ribs

IV. Support for the Longwall Mining Operation
Figure 38. Diagrammatic cross sections of mine openings showing how thick beams are more stable than thin beams. A, Thin rock units are bolted together and made into one thick beam. Modified from Panek (1974, p. 93). B, Jointed sandstone that is more stable because of its thickness. Modified from Parker (1973). Neutral surface is where there is neither compression nor tension. 

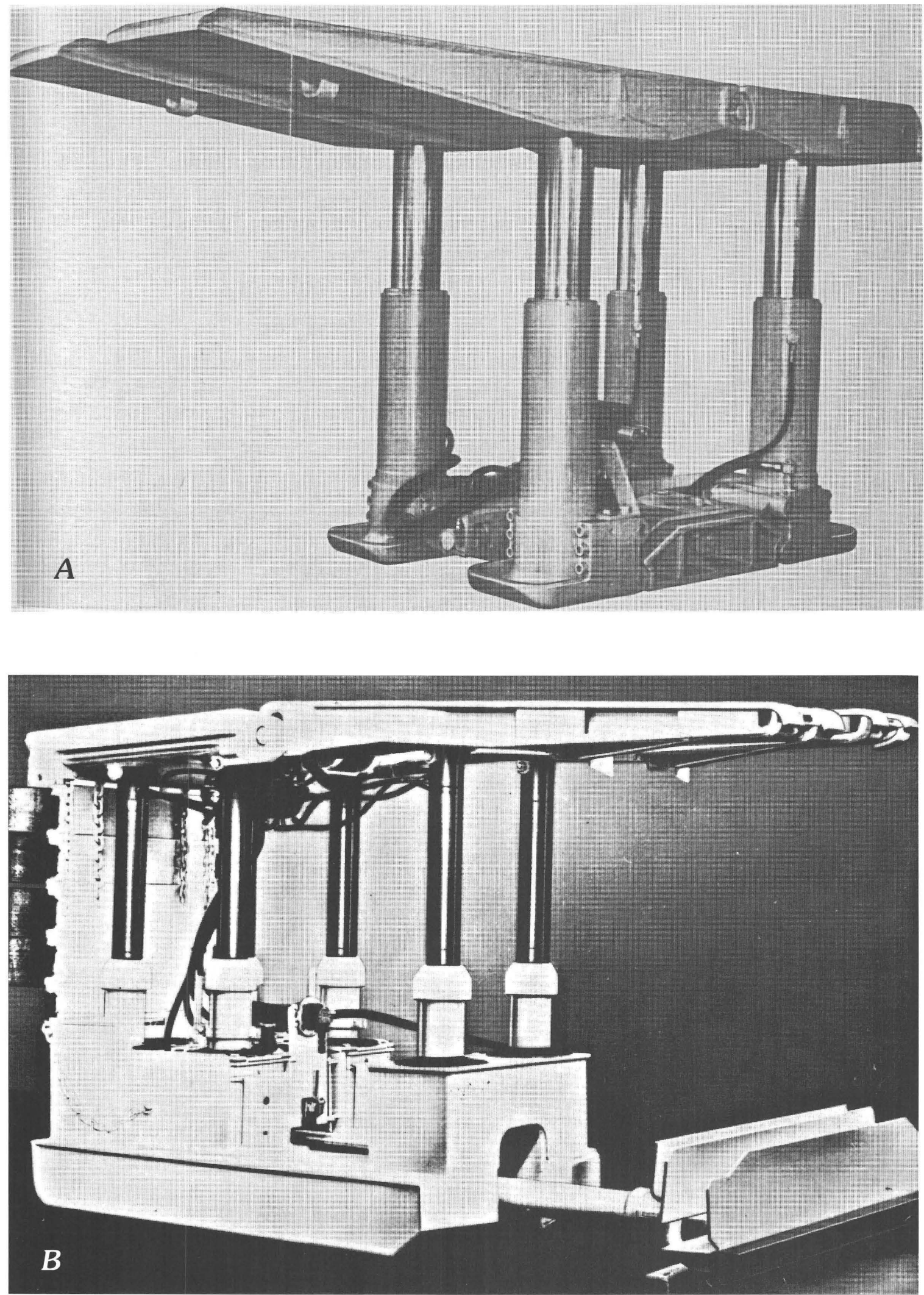

Figure 39 (above and overleaf). Longwall powered roof supports. $A$, frame-type; $B$, chock-type; $C$, shield-type. From Olson and Tandanand (1977, p. 37, 39, and 41). 


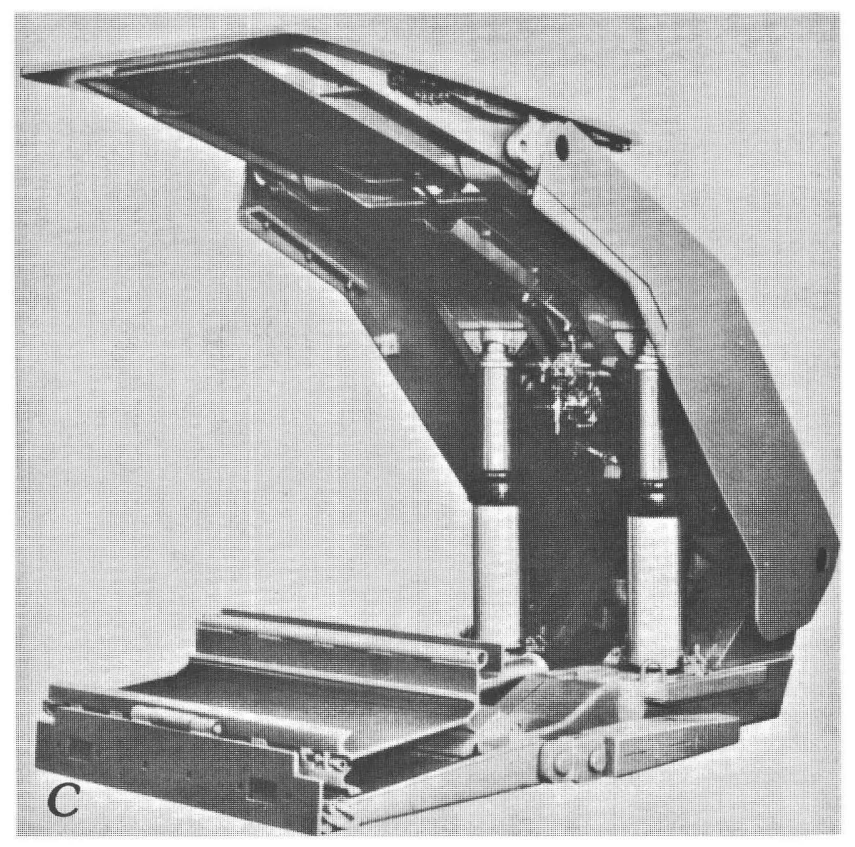

- Commonly there are three basic types: (a) the frame, (b) the chock, and (c) the shield (Olson and Tandanand, 1977, p. 35-56; Curth, 1974b, p. 101-114)

- Simple, in-mine strength tests in the roof and floor rocks, together with geotechnical properties' testing procedures discussed in the section, "Geotechnical Studies," can provide information on the type of power supports needed, so that they will not punch into the roofs and floors during mining (Barry and Nair, 1970)

A. Frame-type supports consist of two pairs of hydraulic props that are mounted on separate bases and connected to two parallel frames (fig. 39A)

1. Supports are not attached to the conveyor but are advanced hydraulically

2. The support bases are designed to be wide enough to have sufficient bearing area to prevent penetration into the floor; this bearing area may vary greatly, depending on the strength of the floor rocks

B. Chock-type supports consist of three to six hydraulic props that are assembled into a single, rigid unit (fig. 39B)

1. The chock is attached to the conveyor

2. A hydraulic ram forces the chock and conveyor to slide along the mine floor

C. Shield-type supports typically provide the most stable support, and consist of a base frame, a roof shield, and a caving shield (fig. 39 C)
1. This type of support, although relatively more expensive, is used more often in deeper mines, particularly where the coal is thicker than about $8 \mathrm{ft}$ and stability of the goaf becomes more important

2. Chock shields combine the unitized construction of the chock support with the shielding advantages of the shield support

\section{COAL MINE DEFORMATION}

- Involves failure within the mine workings, subsidence, and fires and explosions

\section{FAILURE WITHIN THE MINE WORKINGS}

- Consists primarily of (1) roof falls (caving, slabbing, stoping, en-masse failure), (2) explosive failure of mine roofs, ribs, and floors (rock bursts, bumps, and gas outbursts), (3) rock flow (squeezes, floor heave), and (4) inflows of water and methane

\section{Roof Falls}

- Failure is caused by gravity, tectonic stresses, and (or) mine-induced stresses (for example, Peng, 1978, p. 28-40, 71-86; 1980, p. 44-66)

A. Roof falls cause more than 50 percent of all underground fatalities (Peng, 1978, p. 29)

1. Most roof-fall fatalities occur within $5-25 \mathrm{ft}$ of the mining face, particularly where slickensided fractures and slickensided features such as channel cutouts (horsebacks) and conical or elliptical surfaces (pots, caldron bottoms, bells) are located (fig. 40; Peng, 1978, p. 29-32)

2. The time and money spent in damage and lost production commonly increase in direct proportion to the volume of falls and their proximity to active mining and transport areas (for example, Peng, 1978, p. 37-39)

B. Geologic conditions, mine geometry, and mine extraction and support methods are the main factors controlling the location and type of failure (successive failure or slabbing, caving and en-masse failure)

1. Slabbing and en-masse roof failure: slabbing is the term used where failure occurs in thinly layered or bedded rocks; en-masse failure occurs in more thickly layered or massive rocks; these types of failure are more likely to occur: 
a. Near lenticular deposits and channel deposits (fig. 41A-D; for further details, see Nelson, 1983; Krausse and others, 1979; Moebs, 1977; Moebs and Ellenberger, 1982; McCulloch and others, 1975; Overbey and others, 1973; Iannancchione and Puglio, 1979)

1- Slickensided and highly polished fractures are common failure surfaces near channel deposits (Moebs, 1977, p. 17; figs. $40,41 C, D$ )

2- Pots, horsebacks, and slickensided surfaces (slips) are common in mudstone and shale near channel deposits or near other highly stressed areas where differential compaction has occurred

b. Beneath deep canyons where unloading stress may cause rebound and fracturing (for example, Overbey and others, 1973, p. 8; Kent, 1974) c. Near linear features (for example, Overbey and others, 1973, p. 10-11; McCulloch and others, 1975, p. 37-50)

d. Near mine boundaries or barrier pillars in mines above or below the mine

2. Slabbing also commonly occurs in thinly layered or cross-layered strata or in shales in mines that have not been adequately rock bolted or in shales and mudstones that have a low slake-durability index and are prone to slake from humidity and temperature changes (fig. $42 A, B, D$ )

a. Areas of potential roof failure by slabbing can often be detected by the drumlike sound when the roof is tapped, rather than the solid, ringing sound emitted by a stable roof; however, the roof may have a solid sound, even where enmasse failure is imminent (Peng, 1978, p. 36-37)

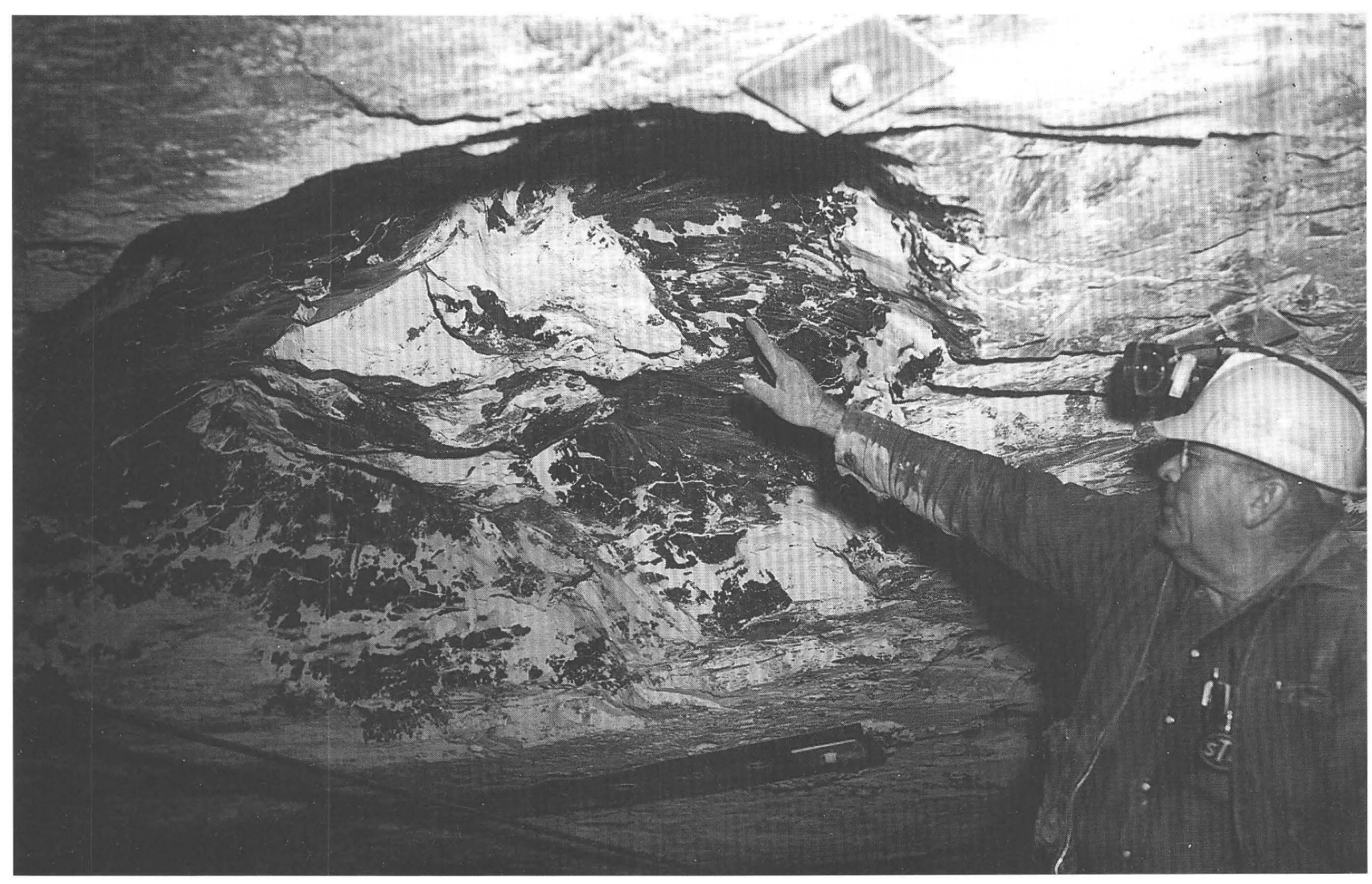

Figure 40. Photograph illustrating unstable mine roof in the Somerset, Colo., area. Parabolic to irregularly curved surfaces in a shale roof in the Bear coal bed cause severe roof-fall hazards to life and property. These features are called pots, bells, or caldron bottoms by miners, and may be caused by localized stresses around features present in the coal-forming material such as tree stumps and roots. Photograph by the author, 1972 . 
3. En-masse failure can also be caused by structural features and mine-induced stresses such as:

a. Rock spars, joints, faults, biogenic structures (such as those made by burrowing organisms), and cross stratification (figs. 42, 43)

b. Arching failure where horizontal stresses are greater than vertical stresses (fig. 44A; also see Parker, 1973, p. 77; Aggson, 1979)

4. Tectonic or mine-induced lateral stresses can cause buckling, flowage, and en-masse failure (fig. 44A, $B, C$ )

C. Hazards to life and mining equipment commonly are most severe where unstable roof conditions (caused by weak, slickensided, or highly fractured rocks), unloading or rebound in stream valleys, and lineaments are superimposed in the same area (fig. 45)

\section{Rock Bursts and Bumps}

- Sudden and explosive releases of energy accompanied by air blasts, flying coal, rock, and dust, and occasional explosive releases of methane occur in highly stressed areas where large amounts of strain energy have been stored (for example, Peng, 1978, p. 343-359)

A. The term rock burst commonly refers to explosive releases of energy that occur in rock above or beneath the mine workings; bumps are those releases occurring in or near the mine workings (although both really are rock bursts because coal is a rock by definition)

B. Flying coal, rock, fine dust, and air blasts commonly produced by rock bursts and bumps can be a severe hazard to life and property in the mine, and the resulting earth tremors (earthquakes) can cause damage to mine workings and nearby structures at the surface

C. Bumps are most likely to occur where:

1. The roof and (or) floor rocks are strong and therefore may store large amounts of energy

2. Overburden thickness is greater than about $1,000 \mathrm{ft}$, or $500 \mathrm{ft}$ in rugged topography (Rice, 1935), which commonly causes high differential vertical and lateral stresses

3. The coal is also strong and hard, and can absorb large amounts of strain energy

4. The pillars are within a certain critical size range (commonly where the height-to-width ratios of the pillars range between about 1:4 and 1:10)

5. The ratio of accumulated elastic strain energy to permanent strain energy is large
6. Strain energy accumulates parallel to the long sides of rectangular pillars (Kauffman and others, 1981, p. 132-133; Peng, 1978, p. 343-347; this report, fig. 46)

D. Rock bursts and bumps may be predicted by drilling ahead and testing for highly stressed areas (jammed drill bits, flying coal from drill hole, and knocking sounds from hole may
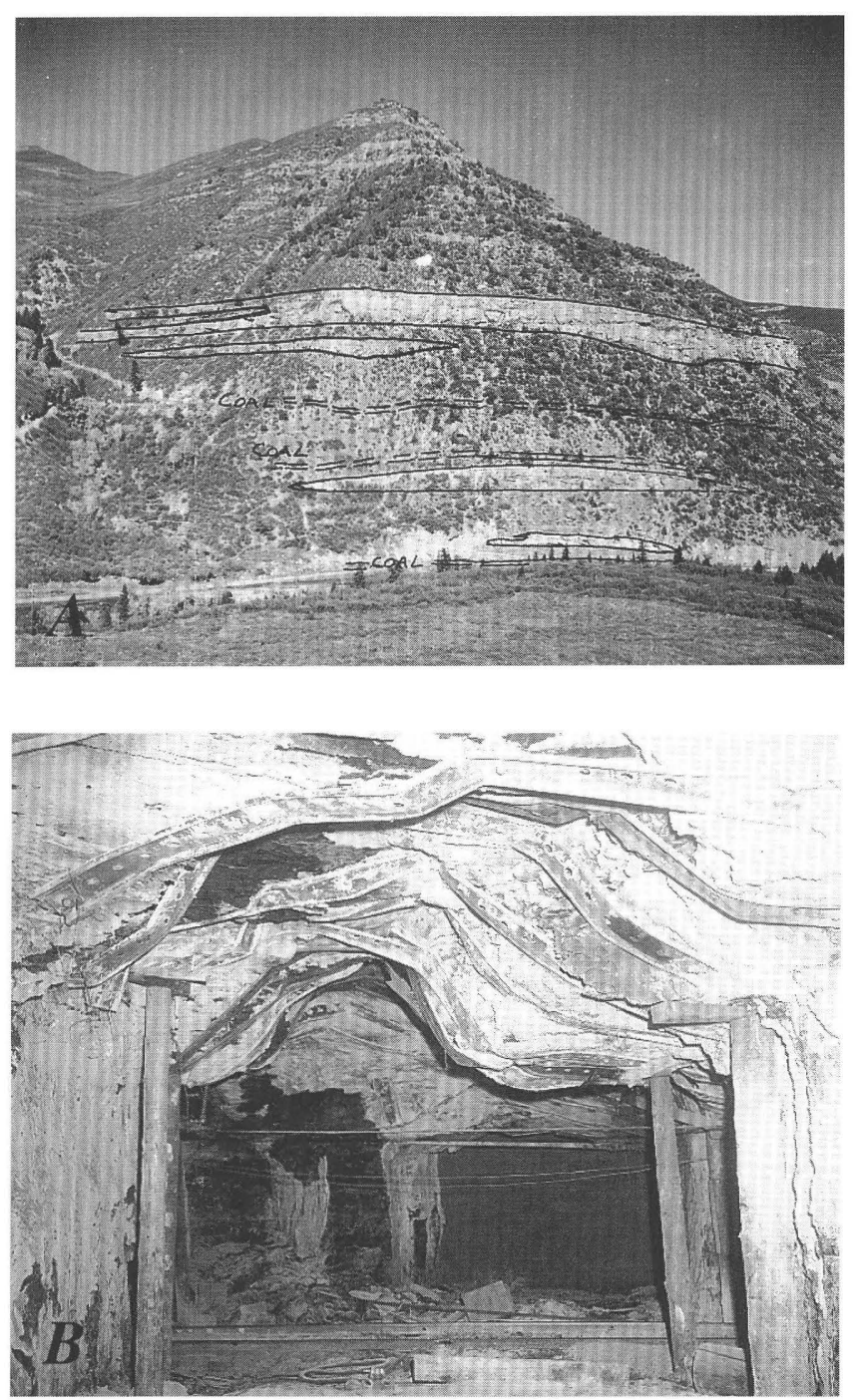

Figure 41 (above and facing page). Photographs and cross sections showing some causes and effects of mining hazards in the Somerset, Colo., area. A, Sandstone lenses (outlined in black) that thicken and thin in short distances, which cause pressure points and rolls in coal beds. B, Failure in the roof of the Bear (" $C$ ") coal bed near a sandstone body, which locally increases in thickness in short distances. From Dunrud (1976, p. 17, 31). C, D, Cross sections through mine openings in the " $C$ " coal bed showing $(C)$ slickensided protrusion, which forced miners to abandon the area, and $(D)$ the site of a massive roof fall before failure, which occurred suddenly and without warning along a slickensided channel above the roof bolt anchors, and killed four people. Scale is similar for $C$ and $D$. 


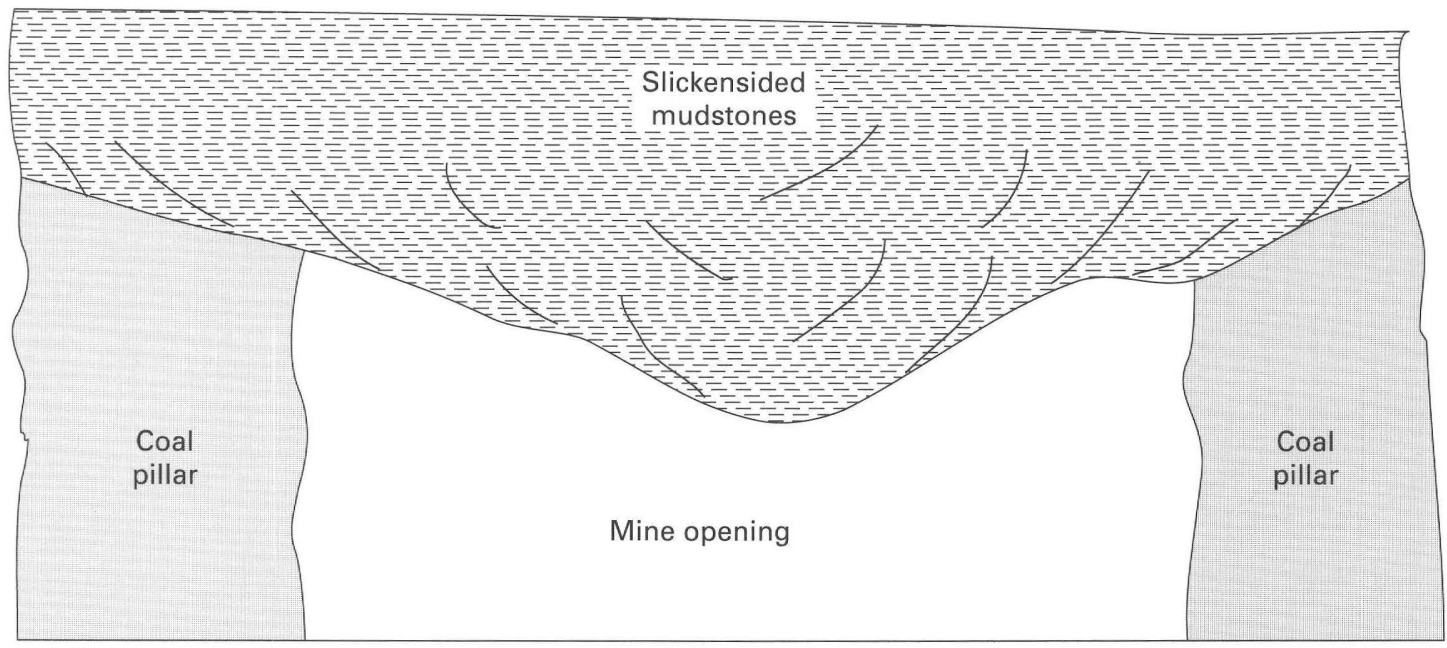

C

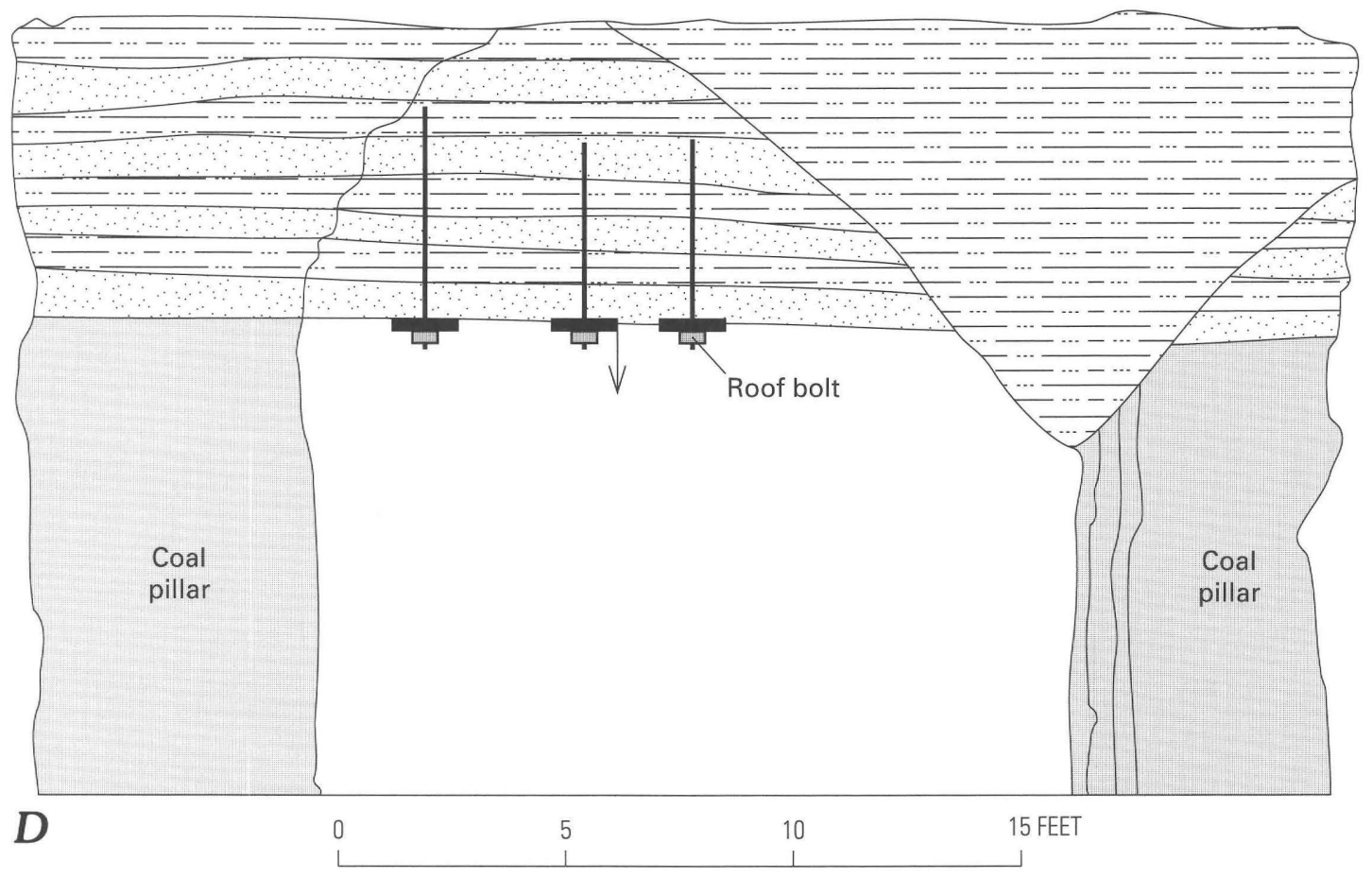

indicate bump conditions) or by detecting the rate and location of seismic emissions

1. Bumps were more common during periods of increased seismic activity in the Sunnyside, Utah, area, particularly when large-magnitude tremors increased (Osterwald and Dunrud, 1965; Dunrud and Osterwald, 1965; Osterwald and Dunrud, 1966; Dunrud and others, 1972)

2. Bumps also may be more common when there is a sudden increase, then decrease, of seismic events in a given area (Peng, 1978, p. 362)

E. Rock bursts and bumps commonly occur:

1. Near pillar lines or longwalls where high abutment loads occur due to incomplete caving of the goaf

2. In barrier pillars between mining panels or pillars within room-and-pillar panels where pillar width or mining sequence was not designed to support stress conditions, or in larger pillars surrounded by smaller pillars 

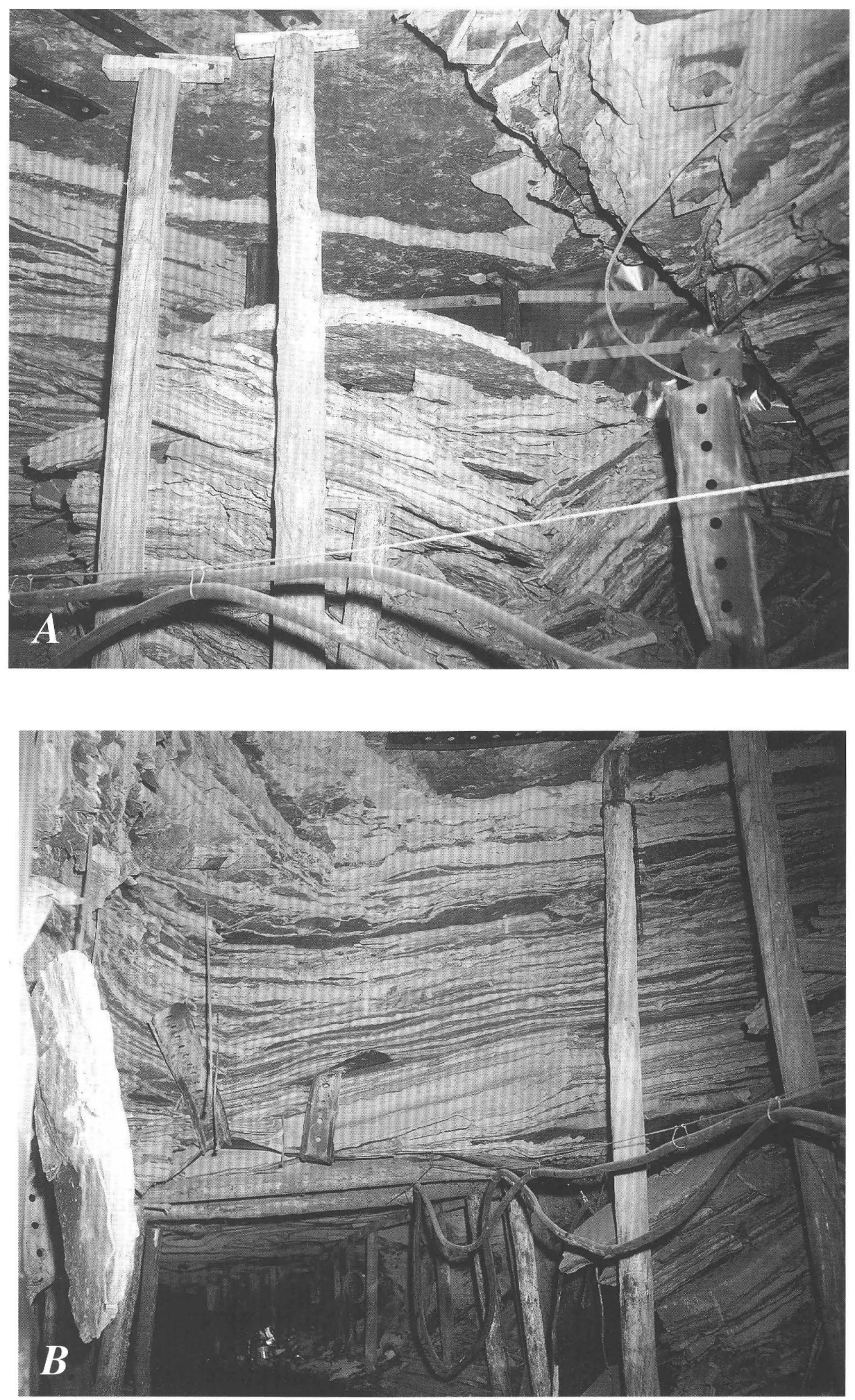

Figure 42 (above and facing page). Structural features that caused severe roof-fall hazards in the Sunnyside coal bed, Emery County, Utah, during the 1960's. $A$ and $B$, Photographs looking upward $(A)$ and obliquely $(B)$ at a roof fall, which occurred in thinly layered sandstones and siltstones along two prominent joint sets. $C$, Massive failure of roof in wedges along branches of a major normal fault and slabbing failure due to air slaking in shale and mudstone with a low slake-durability index. $D$, Roof fall along planes of cross stratification above the rock bolts. 

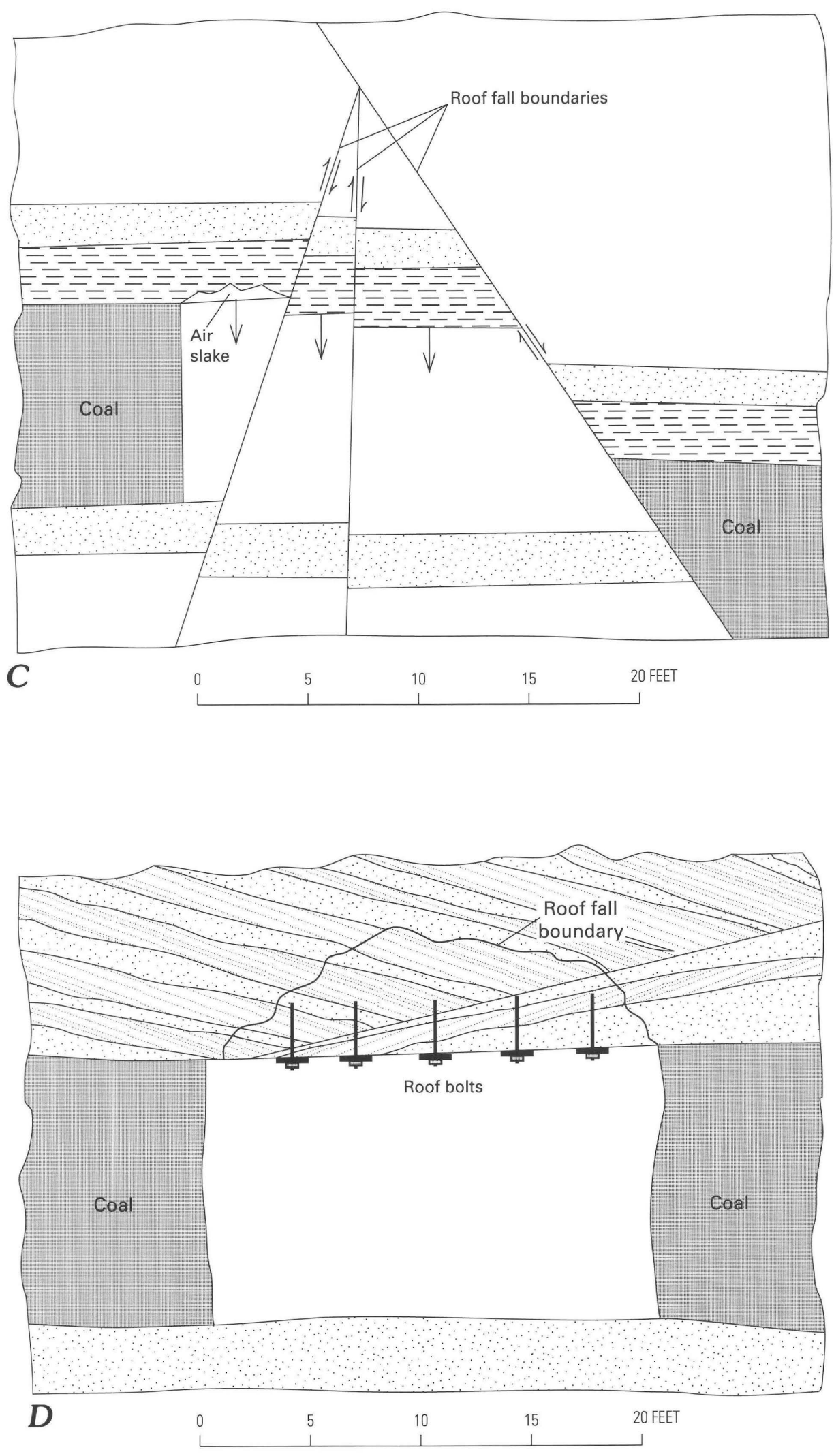

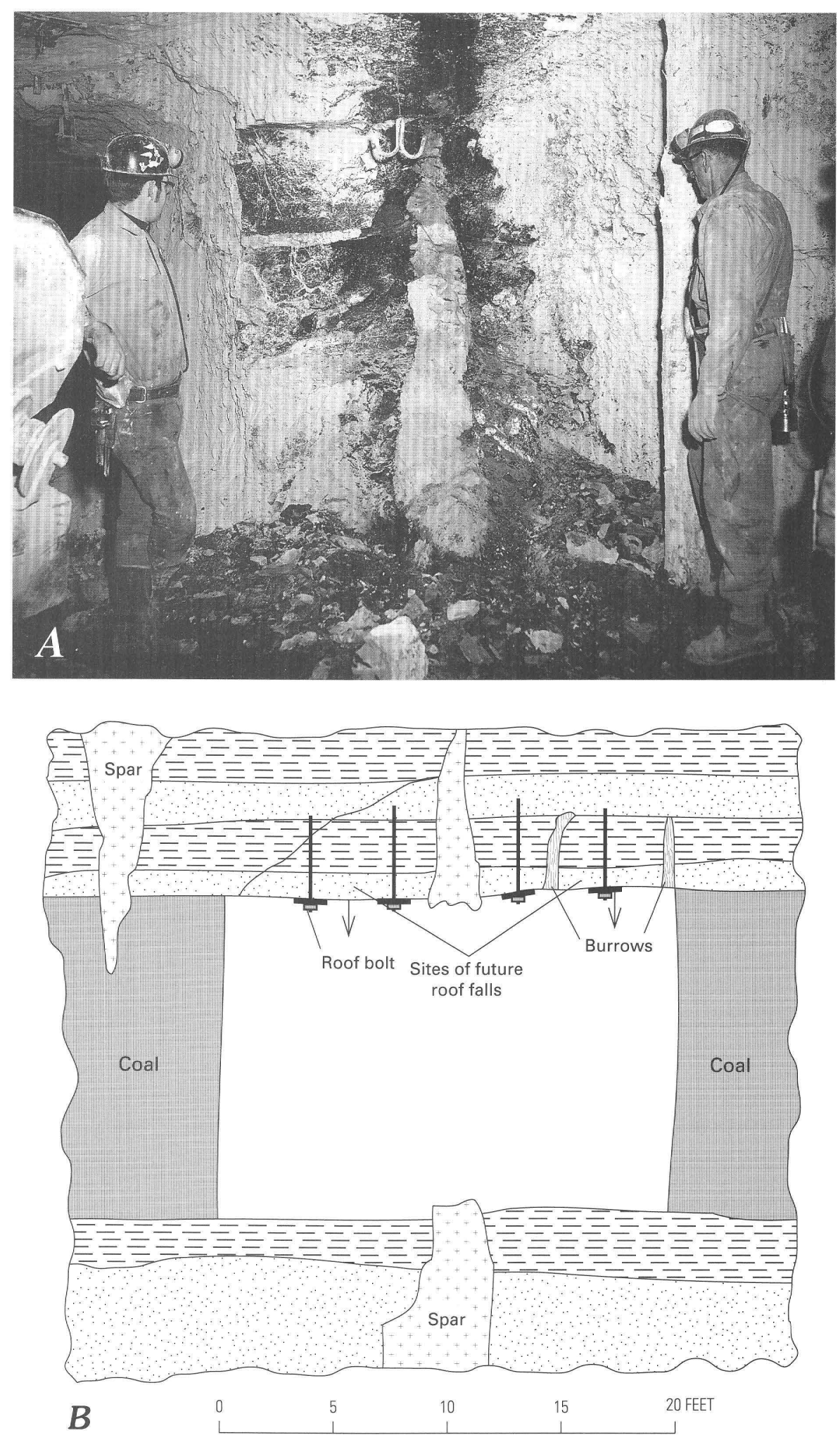

Figure 43. Effects of rock "spars" in the "B" coal bed in the Somerset, Colo., area. A, Photograph showing a rock spar (hard, fine-grained sandstone with carbonate cement) which intrudes the coal bed from below. $B$, Diagrammatic cross section showing rock spars intruding the coal from above and below, and animal burrows. Roof falls are more common near sites of discontinuities in the roof such as spars and burrows, because structural integrity of the rock is markedly decreased. 

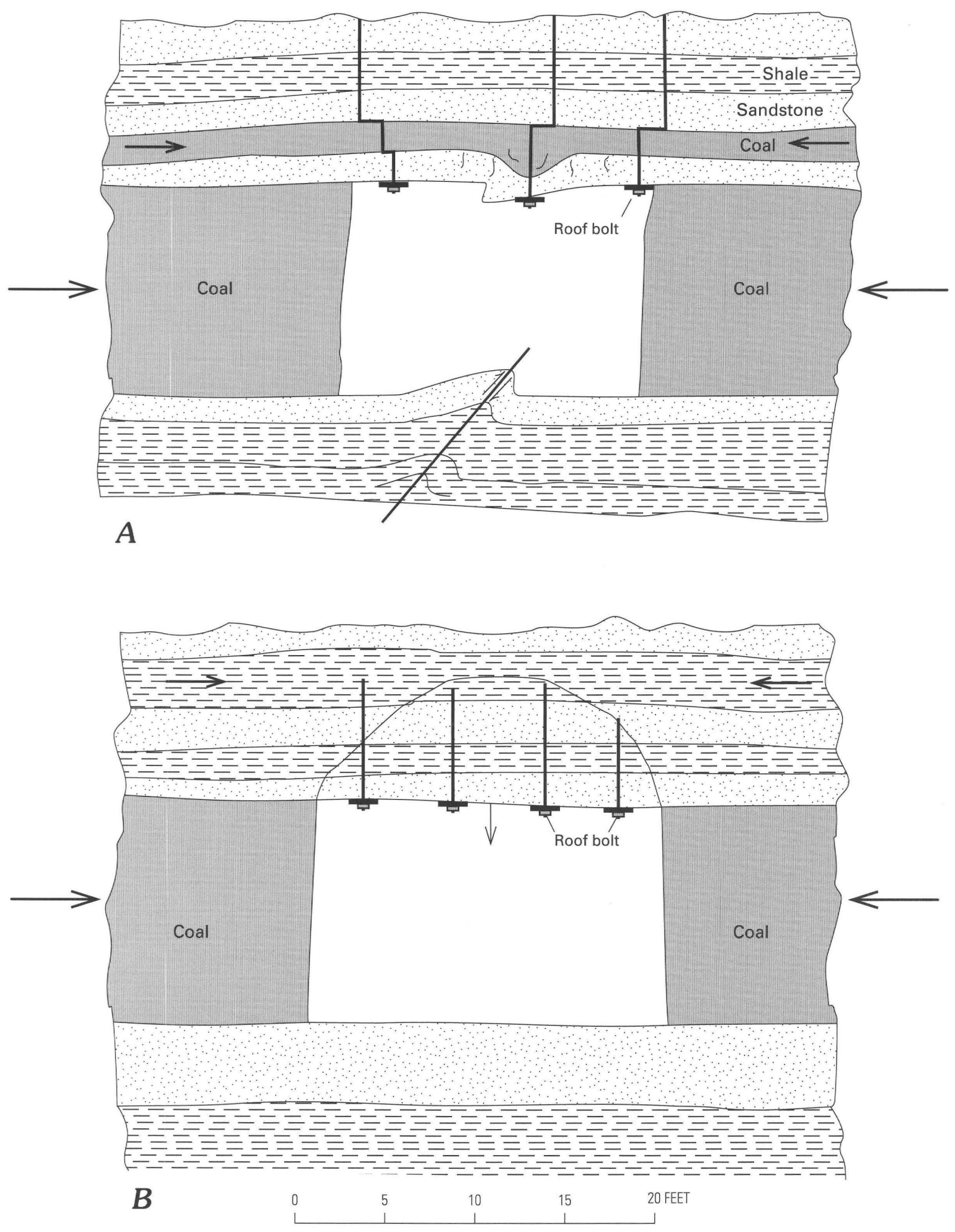

Figure 44 (above and overleaf). Unstable mine openings caused by lateral tectonic and mine-induced stresses. $A, B$, Buckled roof and floor (shown as fault in floor) $(A)$ and arching failure $(B)$ in the Sunnyside, Utah, area caused by high horizontal stresses (arrows), which were caused primarily by high abutment stresses in a room-and-pillar retreat section in the 1960's (the high stresses were caused by uneven pillar lines and leaving unmined pillars in the goaf, which in turn prevented as complete a stress transfer to the goaf as would have occurred if pillar lines were even and all pillars removed). $C$, Unstable rib (behind miners) caused by high vertical stresses in the "B" bed in the Somerset, Colo., area. The highly stressed area is located beneath a barrier pillar in a mine $60 \mathrm{ft}$ above the " $\mathrm{B}$ " bed. 


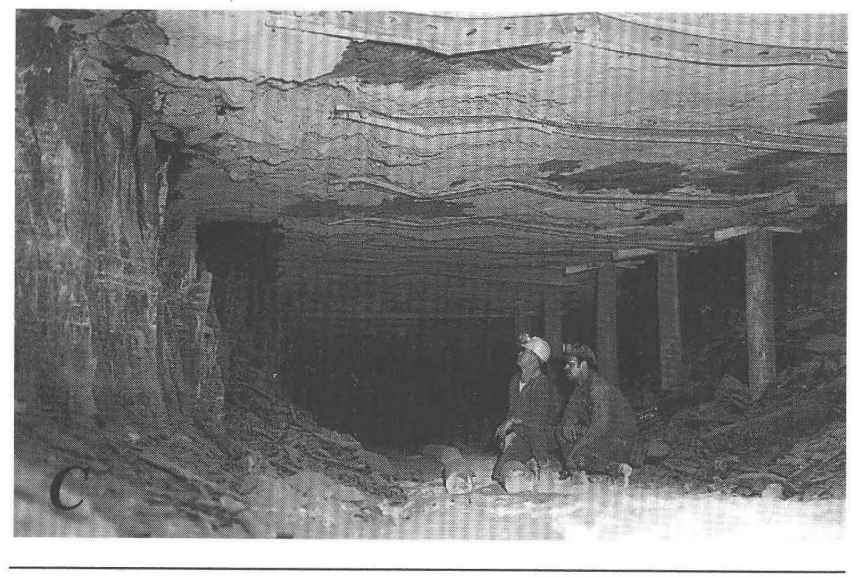

a. In the Somerset mining area, Gunnison County, Colo., at least 25 bumps were observed or heard in the mine roof and floor by the writer in one 2-hour period during 1976. These occurred adjacent to a large pillar about $200 \mathrm{ft}$ wide by $300 \mathrm{ft}$ long, which was surrounded by pillars $80 \mathrm{ft}$ square

3. In rocks above or beneath the mine workings, particularly near faults or extensive joint sets where stress increases (due to abutment loading above or beneath the boundaries of mining areas or to unloading above or beneath mining areas) exceed the strength of the weakest areas of the rock mass (figs. 46-48)

F. Rock bursts above mine workings and bumps resulting from the burst in Utah, which were mapped by the author in the late 1960's and early 1970 's, caused as much as 10,000 tons of coal to be thrown into mine openings from the ribs of coal pillars (figs. 46, 47); cause and effects were believed to be as follows:

1. Mining-induced tremors occurred $3,000-6,000 \mathrm{ft}$ below active mining area (fig. 46); these occurred due to major stress transfers to abutment areas across faults that transect the mine and rocks below the mine

2. Rock bursts in mine were triggered in unstable rock mass above active mining area by mining-induced tremors (figs. 46, 47)

3. Bumps in pillars in active mine area caused explosive failure and sloughing within the active mining area (fig. 47)

G. Bump hazards may be reduced or perhaps eliminated in room-and-pillar extraction panels by (1) driving and extracting rooms on the retreat, (2) maintaining straight pillar lines using uniform pillar sizes and dimensions that are oriented properly for the in-situ state of stress, (3) mining all pillars in a similar pattern (leave no isolated pillars in the goaf, blast them if necessary), and
(4) laying out the mine workings so that rooms are not driven nor pillars split in the abutment zones of a pillar line (Peng, 1978, p. 349)

1. Rock bursts and bumps have been reduced in the Zenica mine in Bosnia-Hertzegovina, [former] Yugoslavia (1) by changing from the room-and-pillar method to longwall mining using powered supports, (2) by triggering bumps in highly stressed areas .by drilling ahead of mining faces and blasting the coal (weakening it so that it would crush more easily), and (3) by using flexible, circular steel arches in the main entries (M. Osmanagić, written commun., 1984)

\section{Gas Outbursts}

- The sudden release of gas $\left(\mathrm{CH}_{4}\right.$ and (or) $\left.\mathrm{CO}_{2}\right)$ and fine coal from mining faces, where the coal is under high stress and contains large amounts of gas under high pressure

A. Gas outbursts may occur in three stages (Peng, 1978, p. 362-363):

1. A rapid, sequential fracturing of coal and release of gas from cleat and fractures in areas where the coal and gas are under high stress and are exposed in mining faces (fig. 49)

2. The gas in coal microfractures (free gas) explosively throws coal fragments into the mine openings, causing additional breakage

3. The amount of gas desorbed from the pores within the coal fragments (adsorbed gas) increases as the coal is ejected into the mine openings and is further pulverized; the free gas and adsorbed gas cause the pulverized coal and gas mixture to move as a fluid-phase wave

B. Gas outburst hazards include (1) possibility of death to miners by suffocation or crushing as the coal comes out like a water wave, (2) damage to mine support and mining equipment, and (3) lost time and money in cleaning up and resupporting the area

C. Gas outbursts or sudden inflows of gas are more common where natural stresses are localized and increased by such features or aspects as:

1. Channel deposits, which produce sudden changes in coal thickness or dip

2. Intrusive bodies and faults where local stresses cause the coal to be highly fractured at closely spaced intervals (perhaps less than $1 \mathrm{~mm}$ ), and cause the coal to lose some volatiles in the form of methane which are then stored in the fractures (fig. 49)

3. Increasing methane content; methane content reportedly increases with depth and with increasing thickness of coal beds (M. Osmanagić, written commun., 1984) 

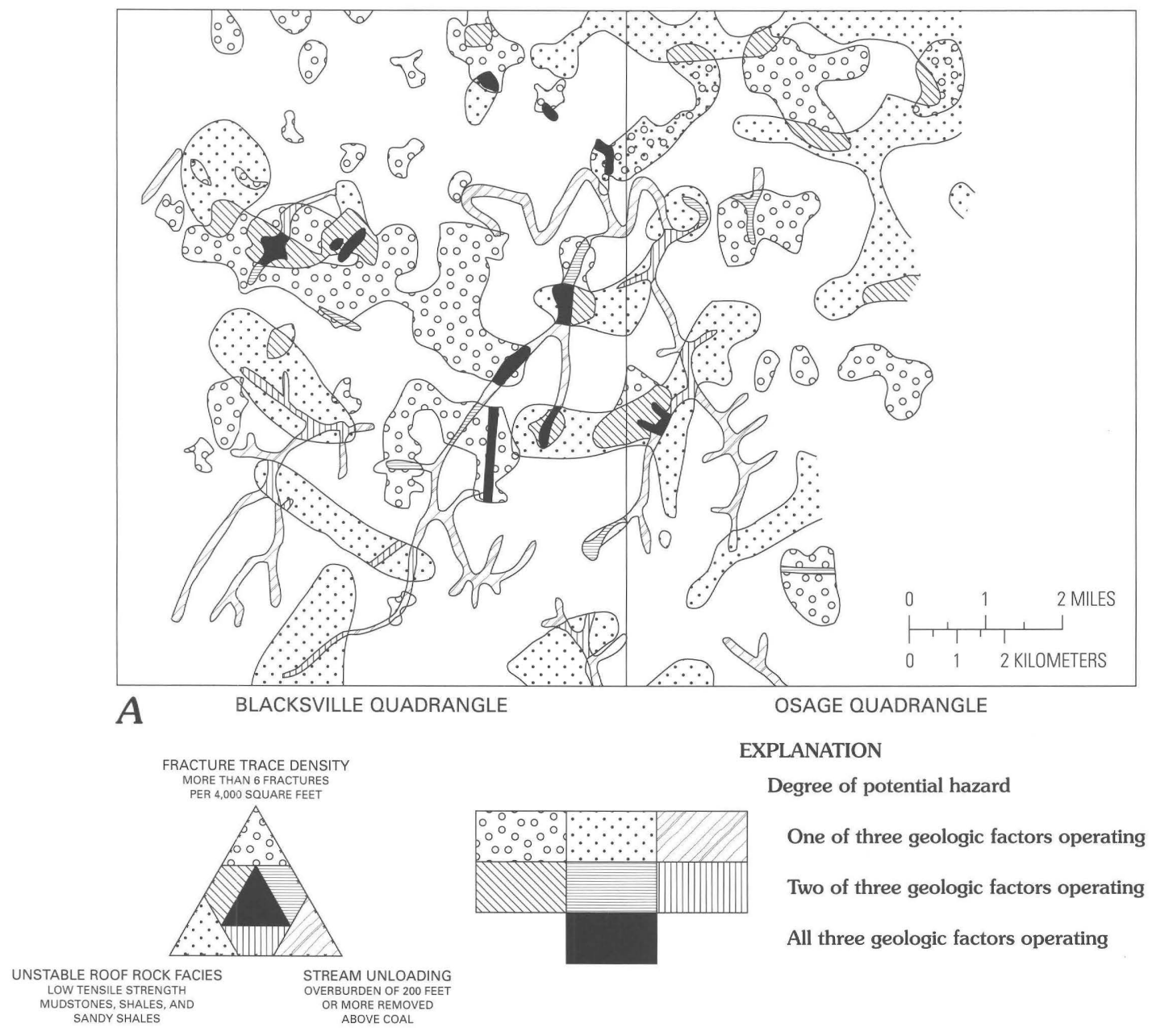

One of three geologic factors operating

Two of three geologic factors operating

All three geologic factors operating
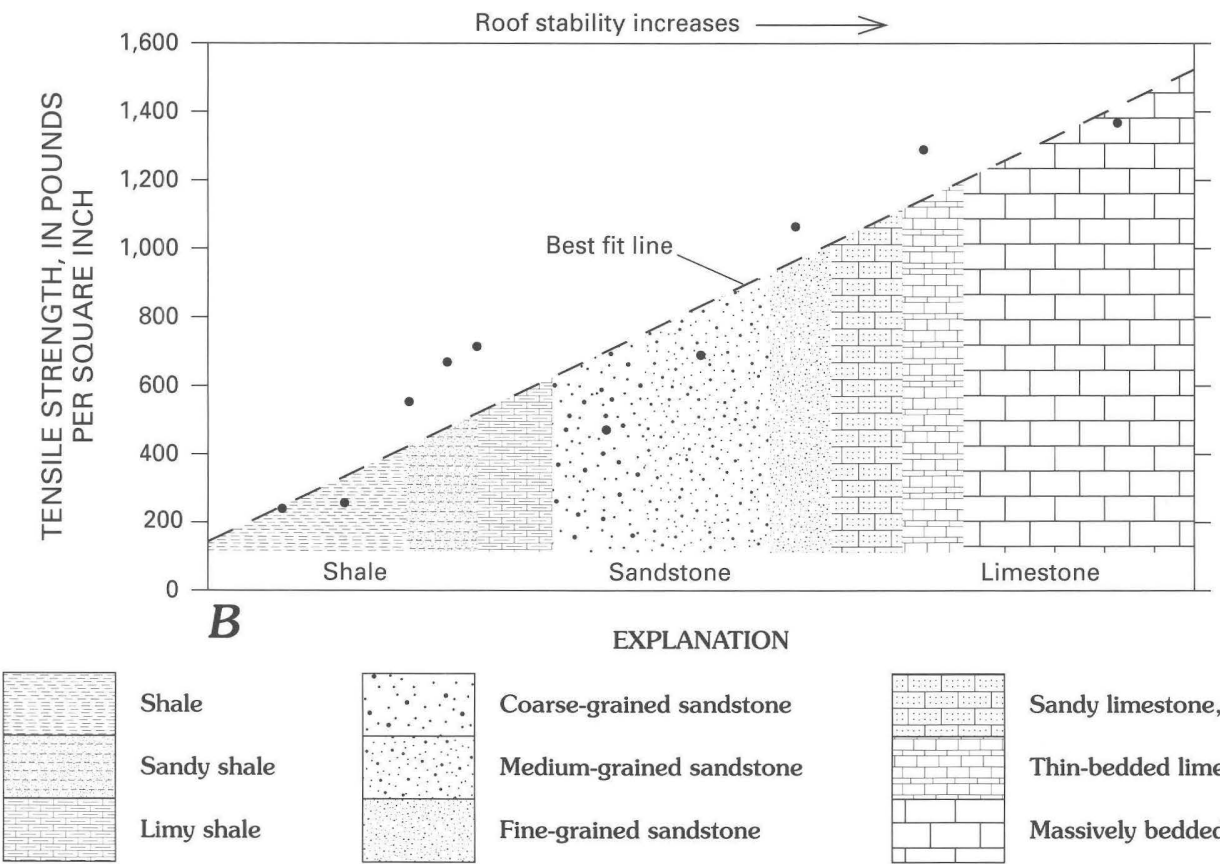

Coarse-grained sandstone

Medium-grained sandstone

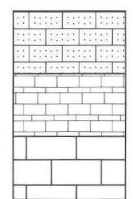

Sandy limestone, thin-bedded

Thin-bedded limestone

Fine-grained sandstone

Massively bedded limestone

Figure 45. Map and graph showing potential hazards from unstable roofs in southwestern Pennsylvania and northern West Virginia. $A$, Potential-hazard map showing location, type, and degree of hazard. $B$, Relation between rock type, tensile strength, and roof stability; tensile strength is based on Brazilian tests done on $2 \times 1$-in. disks. Dots are data points. Modified from Overbey and others (1973, p. 6, 13). 

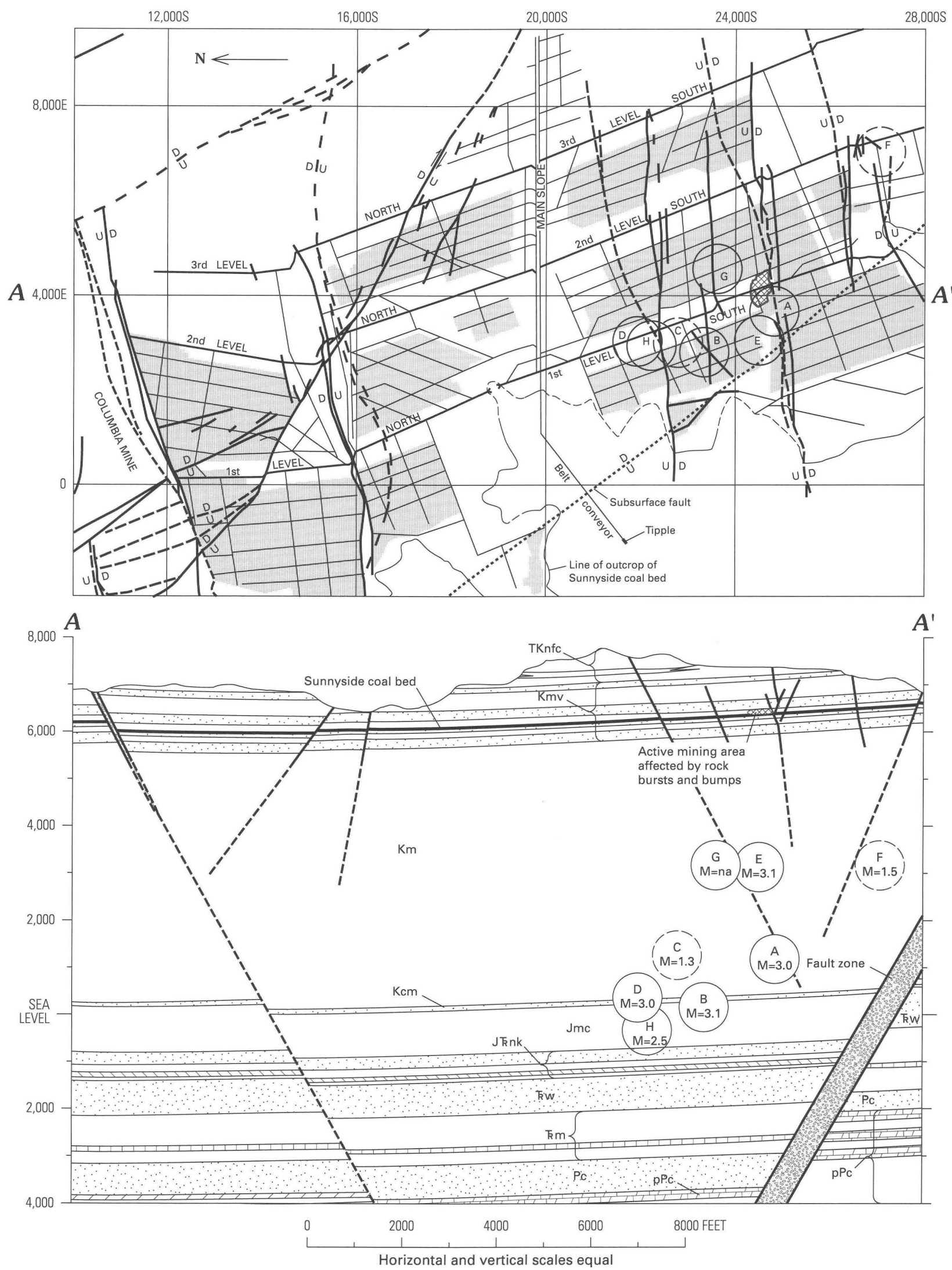
Figure 46 (facing page). Map and cross section showing conditions caused by rock bursts and bumps in the Geneva mine area, Emery County, Utah. Geologic, mining, and seismic setting of rock bursts and bumps that occurred in the Geneva mine area (mined area indicated by shade), Emery County, Utah, on Oct. 25, 1967. Two rock bursts in the active mining area (cross-hatched area), an hour apart, and tremors, which were located along or near faults 3,000-7,000 ft below the mine workings, apparently were caused by mine-induced stresses (circles indicate estimated limit of location error). The tremors, which ranged from 1.3 to 3.1 in Richter magnitude (M; na, not obtainable), and occurred over a 17-hour period, began about 45 minutes before the first rock burst in the mine. Rock units in cross section, from youngest to oldest, are TKnfc, Eocene and Paleocene Colton Formation and Flagstaff Member of the Green River Formation and Paleocene and Upper Cretaceous North Horn Formation; Kmv, Upper Cretaceous Mesaverde Group; Km, Upper Cretaceous Mancos Shale; Kcm, Lower Cretaceous Cedar Mountain Formation; Jmc, Upper Jurassic Morrison Formation to Middle Jurassic Carmel Formation; J knk, Jurassic and Triassic(?) rocks including Navajo Sandstone and Upper Triassic(?) Kayenta Formation; Kw, Upper Triassic Wingate Sandstone; Km, Middle(?) and Lower Triassic Moenkopi Formation and younger rocks; Pc, Lower Permian Coconino Sandstone; pPc, pre-Coconino rocks. Cross section elevations in feet.

\section{Rock Flow (Squeezes, Floor Heave)}

- Slow to moderately rapid closure of mine openings by flowage of pillar ribs, floors, and sometimes roofs into the mine openings where stresses exceed the strength of the coal, rock, and other mine support, but where failure is more of the plastic type than the elastic type (where bursts or bumps occur). Rock bursts and bumps may also be common in mine areas undergoing a squeeze where local conditions of confinement can cause sudden releases of strain energy (fig. 50)

A. Rock flow commonly occurs in the weakest material near the mine openings (mostly floors and pillar ribs as in fig. 50) where stresses exceed the strength of the weakest material; lateral movement commonly is greatest where frictional resistance to movement is lowest (for example, lateral movement near slick shale floor is much greater than it is near rough sandstone roof in fig. 50C)

1. Floor heave can occur where floors are softer than the coal or roof rocks, and stresses exceed the strength of the rocks in the floor (Jeremić, 1981a, p. 41; 1981b, p. 707)

2. Ductile and brittle failure can occur in the pillars where the roof and floor rocks are stronger than the coal pillars and stresses exceed the strength of the pillars
3. Pillar yield, roof failure, and floor heave commonly occur where stresses exceed rock strength and where coal, roof, and floor rocks have about the same strength (fig. 44A; Jeremić, 1981a, p. 42-43)

4. Differential extrusion of ribs into mine openings is described by Jeremić (1981b, p. 706) where stresses exceed the strength; the amount of extrusion increases with decreasing material strength and shearing resistance between layers

5. In Western Canada, the most severe roof falls, floor heave, and extrusion of coal ribs were reported by Jeremić, (1981b, p. 708) to occur in mine openings oriented perpendicular to the tectonic-stress direction

V. Sudden, Violent Inflows of Water and Methane and (or) Carbon Dioxide

- The sudden, sometimes explosive emission of large volumes of water or gas from mine roofs, ribs, or floors under high pressure

A. Inflows can be a serious hazard to life and mining equipment where water or gas sources under high pressure are encountered

1. Where subsidence fractures intersect surface water and (or) underground aquifers, the working area can be flooded very rapidly. This situation killed many miners in the Eastern United States in the early 1900's (for example, Young and Stoek, 1916, p. 31-42)

2. Less violent inflows of water and (or) methane can occur where subsidence fractures intersect lower volume water or lower pressure gas-bearing zones (fig. $51 A, B, D$ ) (Kratzsch, 1983, p. 400-401)

B. Water in coal mines can be a problem in areas where precipitation is high and permeable

Figure 47 (following pages). Damage caused by rock bursts and bumps, Geneva mine area, Emery County, Utah, Oct. 25, 1967. A, Map and cross section showing location of explosive failure on pillar ribs (X's) and rib slough (barbs) where about 10,000 tons of coal and rock were thrown into the mine openings. Solid lines, faults; $U$, upthrown side; D, downthrown side. Strike and dip of joints and slickensided fractures (S) in coal shown by symbol where measured; curved, slickensided fractures (C), which steepen downward, are indicated by dip range (ex. 45-65). Dip amount and direction of faults indicated by number near arrow. Explosive failure occurred near upthrown side of normal fault when pillar extraction began. Cross section elevation in feet. $B, C$, Photographs showing damage to $B$, mine openings, and $C$, ribs and roofs, caused by lateral and vertical explosive releases of strain energy. 

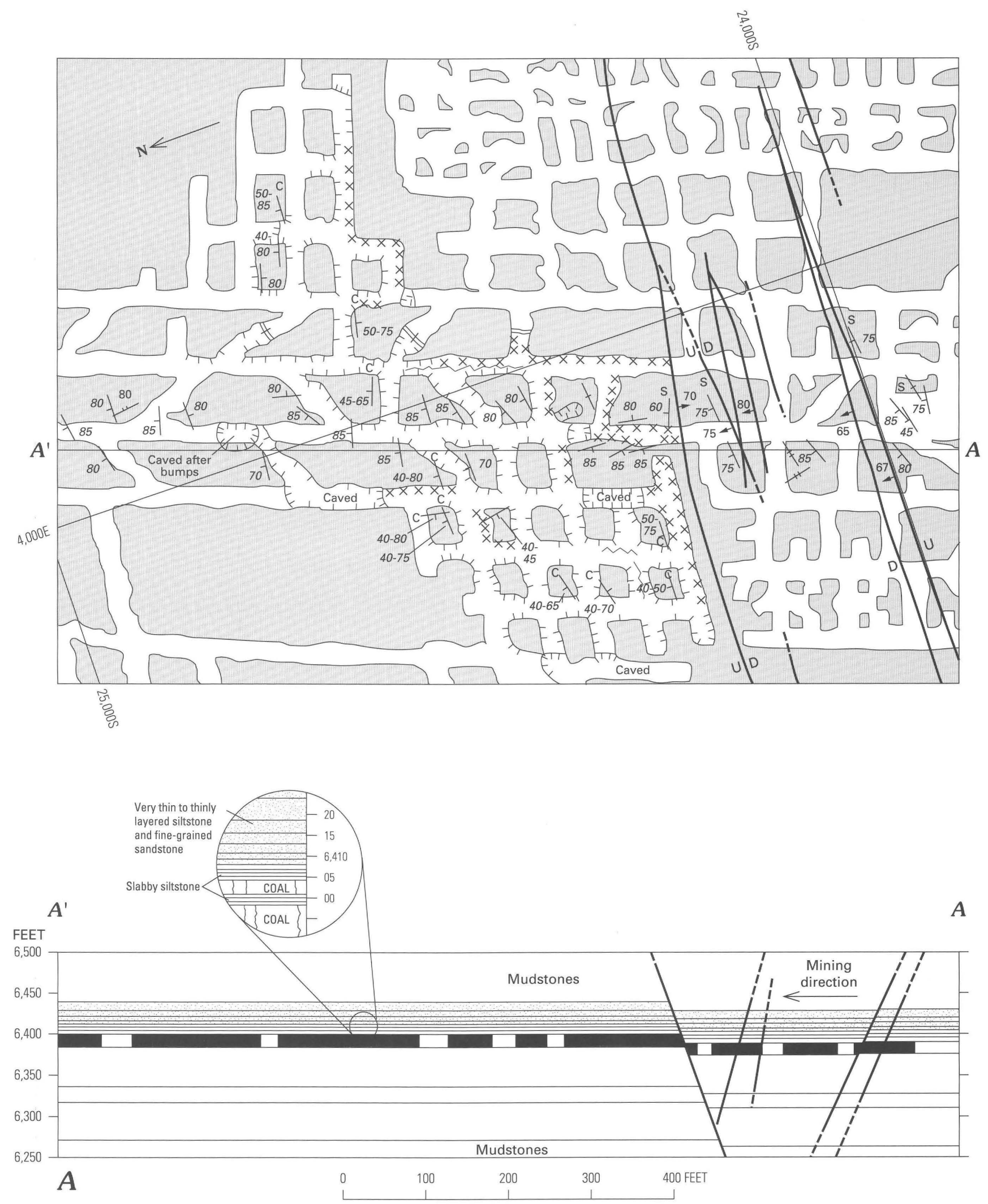

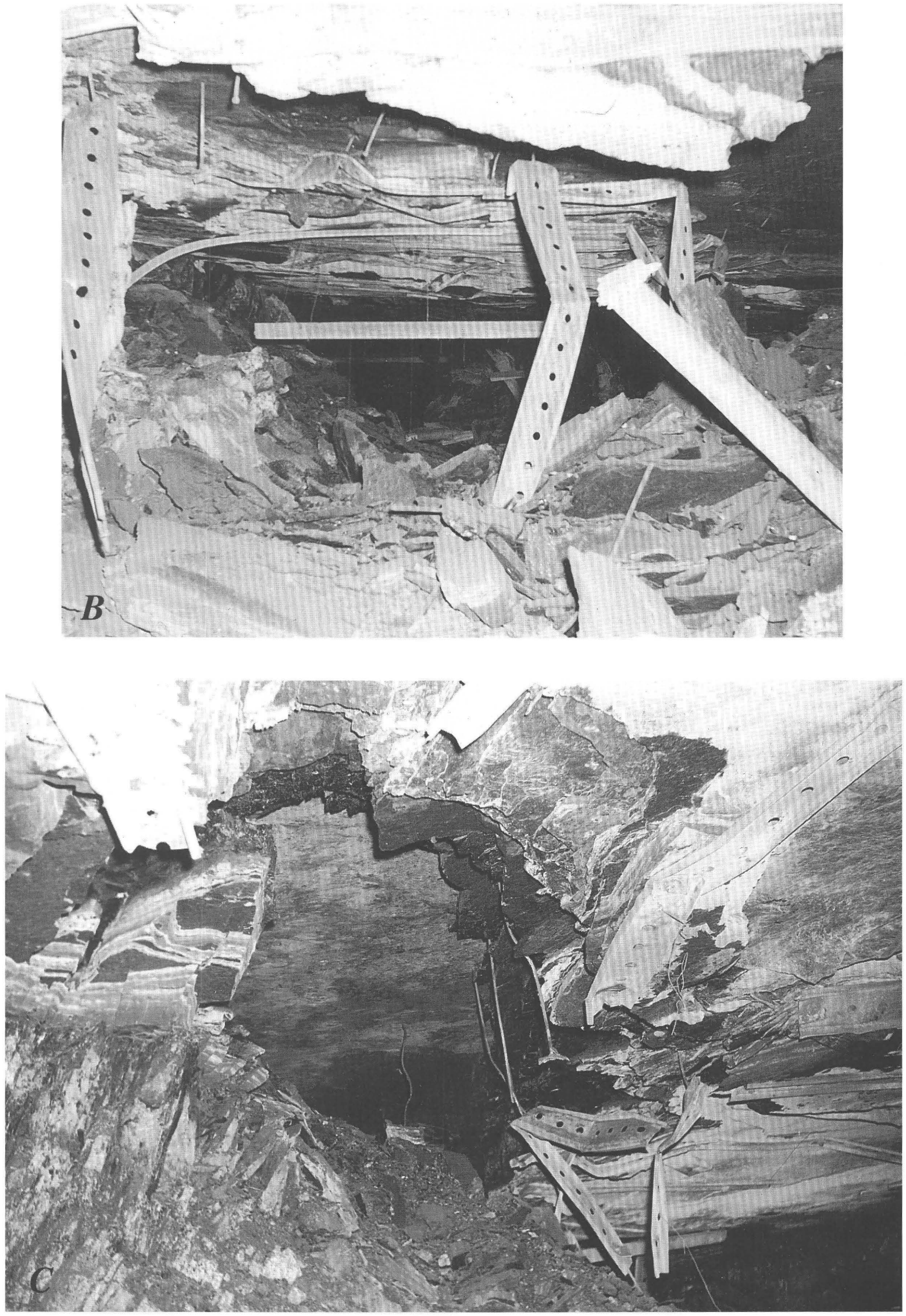


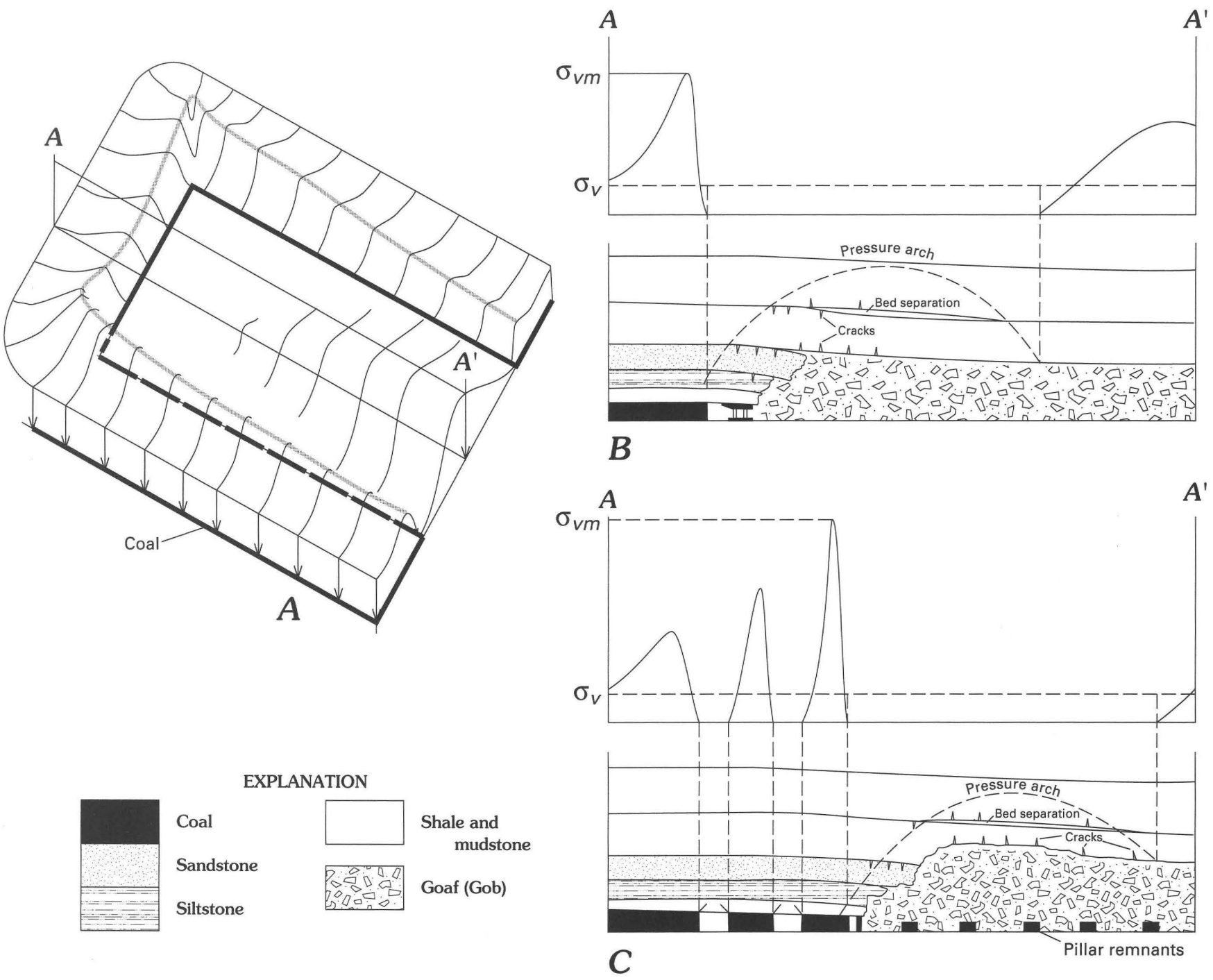

Figure 48. Conceptual diagrams showing general relation of vertical stress to unmined coal and goaf areas in longwall and room-and-pillar extraction panels. $A$, Three-dimensional diagram showing general vertical stresses around an extraction panel (mining direction is from right to left). Stresses at a given point at the mine boundary decrease as mining progresses from right to left, because stresses are transferred to goaf. $B, C$, General stress conditions near the face and caved areas of $B$, a longwall panel, and $C$, a room-and-pillar extraction panel. Note that maximum vertical stresses $\left(\sigma_{v m}\right)$ are higher on pillar line $(C)$ than near longwall face, because vertical stresses before mining $\left(\sigma_{v}\right)$ must be borne by the coal adjacent to mining area and by the goaf from stress-balance considerations. Figures based on general stress and stressbalance concepts by Whittaker and Pye (1977), Olson and Tandanand (1977, p. 13); Peng (1978, p. 214-232), and Wilson (1982, p. 85-95).

sandstones or karstic carbonates occur near the coal beds; for example:

1. In [former] Yugoslavia, dewatering must be done before mining in order to reduce damaging and sometimes hazardous inflows of water under high pressure from porous marlstones or sandstones above or beneath the coal (M. Osmanagić, oral commun., 1986)

2. In [former] Yugoslavia, potentially dangerous inflows of water under very high pressure commonly are prevented or reduced from flowing into the mine from underlying, highly porous carbonates by thick clay layers located below the coal-bearing rocks and above the carbonates; the clay appears to be residual clay produced by weathering of the limestone prior to further deposition

- The lakes in Slovenia, [former] Yugoslavia, which reportedly are as much as $140 \mathrm{ft}$ deep, were formed by subsidence above multilift, longwall-mining panels with sublevel-caving in a lignite coal bed of Pliocene age, which is as much as 420 $\mathrm{ft}$ thick (fig. 51E) 


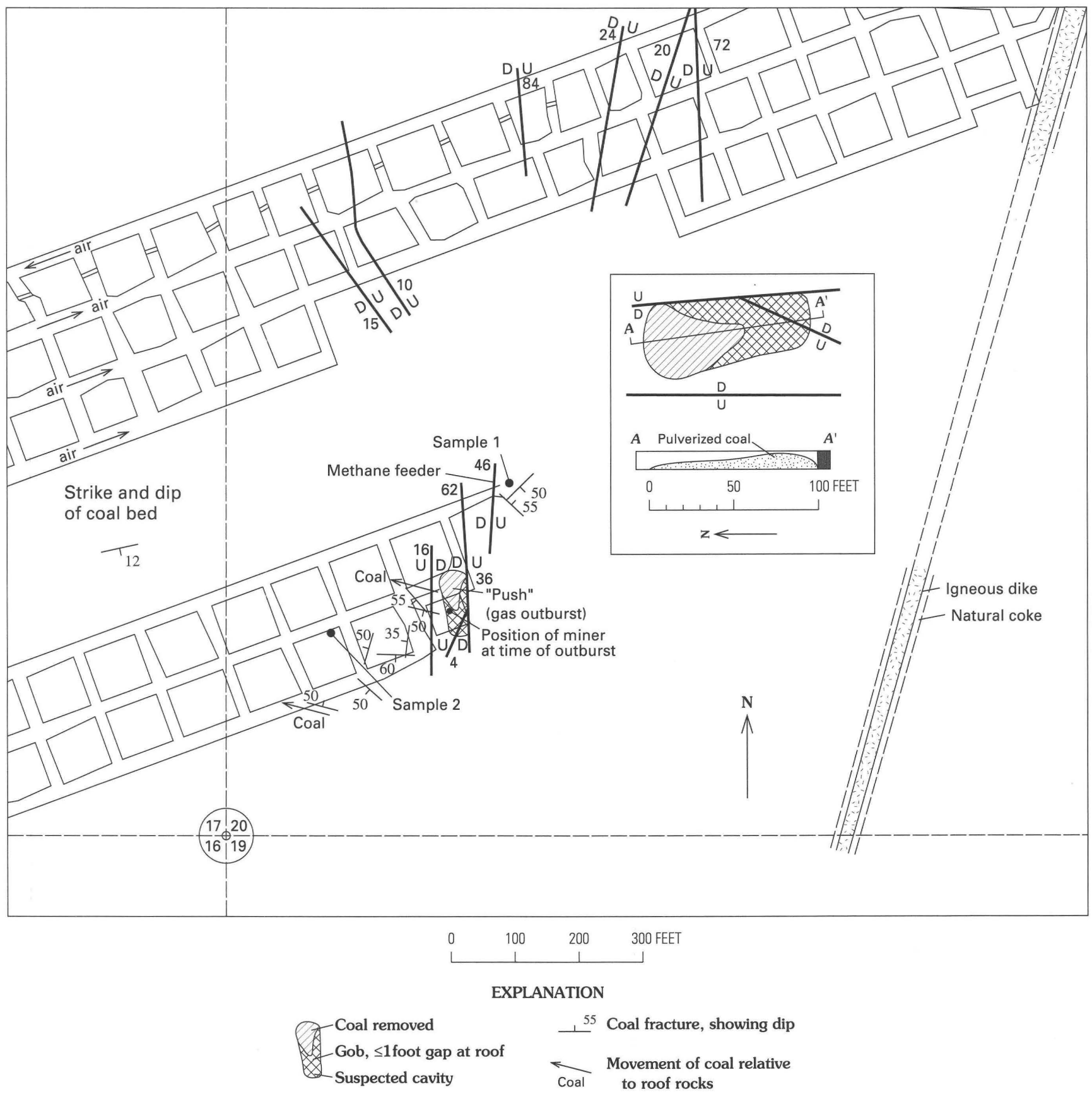

Figure 49. Map location of an outburst in the Redstone area, Pitkin County, Colo., in 1969. High stresses and large accumulations of methane were located near faults in this map locality. Numbers beside upthrown (U) and downthrown (D) sides of faults are in inches. Inset shows enlarged area of outburst.

3. Inflows of water from lakes above mines at Valenje, Slovenia, [former] Yugoslavia, are prevented or reduced by thick clay beds above the coal, which deform plastically and self-seal the overlying flows (W. Lutzens, U.S. Bureau of Mines, oral commun., 1985)

C. Inflows of water and methane can be a hazard to life and property in semiarid to temperate climates, where high-pressure aquifers and methane pockets are encountered

1. Large volumes of water and methane flowed into a coal mine in western Colorado in the early 1950 's, forcing closure of the mine (Dunrud, 1976, p. 30-34)

2. Large inflows of methane caused a severe explosion and fire hazard to miners in the 

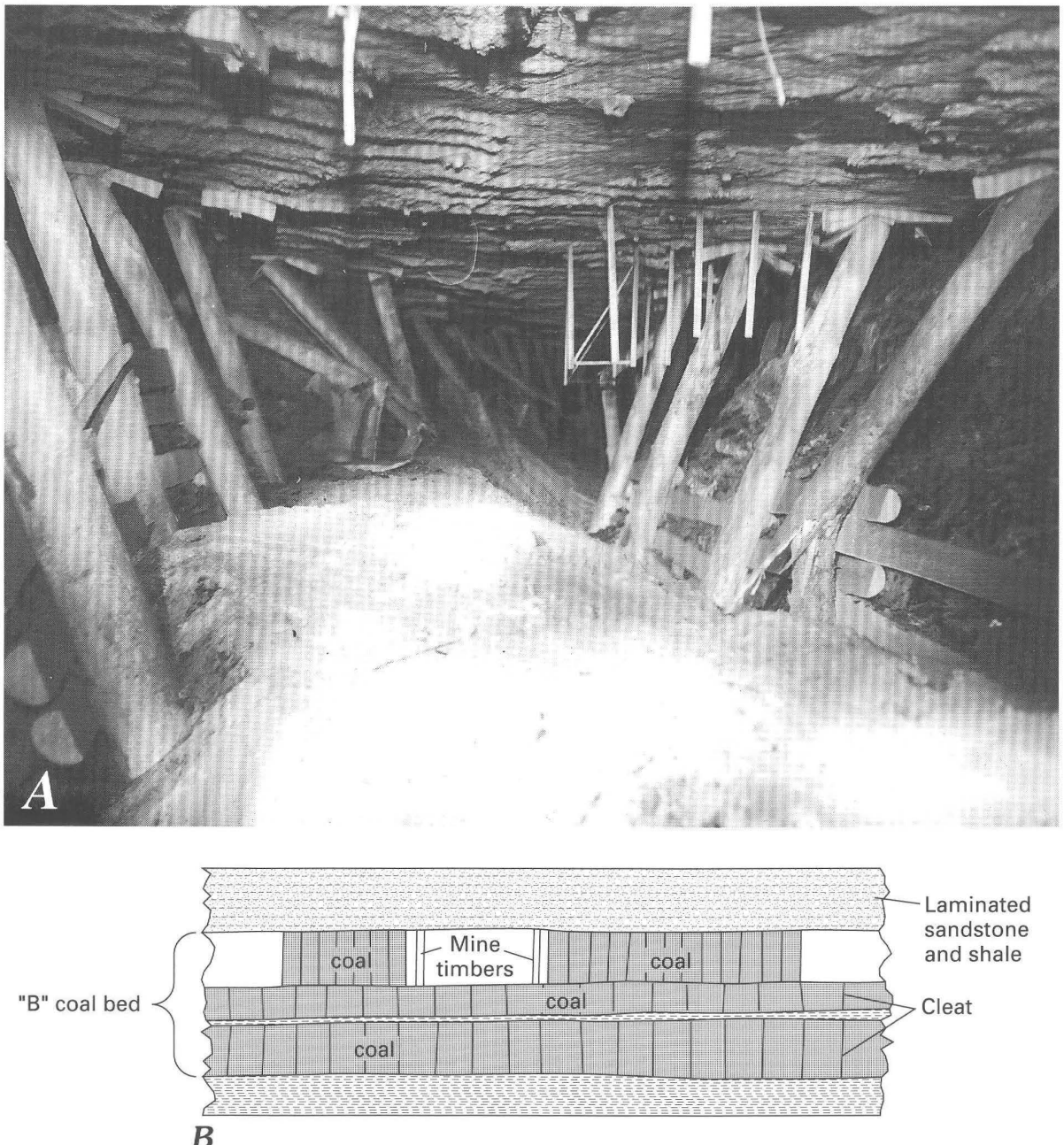

Figure 50. Effects of a squeeze, Somerset, Colo., area. A, Photograph showing a squeeze; $B, C$, Cross sections showing $B$, conditions before, and $C$, conditions after a squeeze. From Dunrud (1976, p. 36).

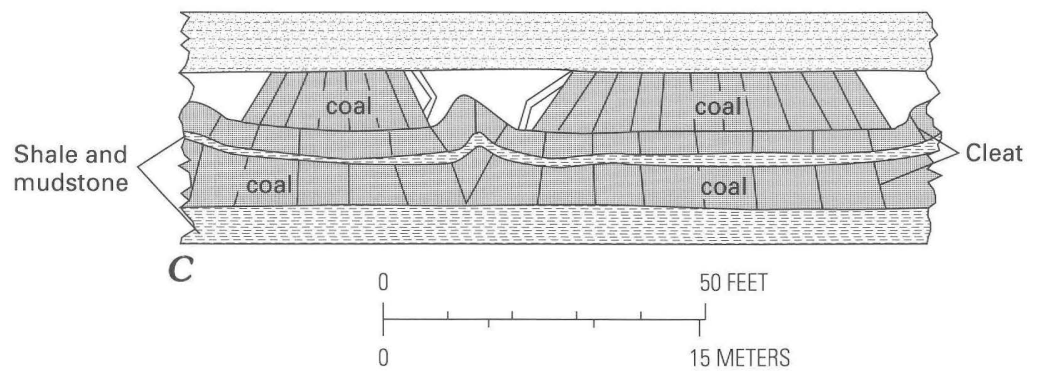

Sunnyside area, Carbon County, Utah, in the early 1970's, when a large roof fall exposed a channel sandstone which contained a large volume of methane

D. Water and methane can be removed by advance drilling in selected sites above ground and underground to reduce potential hazards

1. Both water and methane can be considered a resource or a hazard, depending on whether or not they are extracted before or after mining, whether they can be accumulated and used, and whether or not the resource can be obtained profitably
2. Water can be removed or water pressure reduced by drilling from the surface and within the mine to intersect water-filled zones in advance of mining, as is done locally in Bosnia-Hertzegovina, [former] Yugoslavia (L. Ćekić, oral commun., 1984, 1985)

3. Methane can also be removed before mining by drilling ahead of mining faces and draining the methane (for example, Perry and others, 1978)

a. Faults, joints, and cleat provide avenues of increased methane flow; large flows can occur along faults and extensive joints; flow often is 


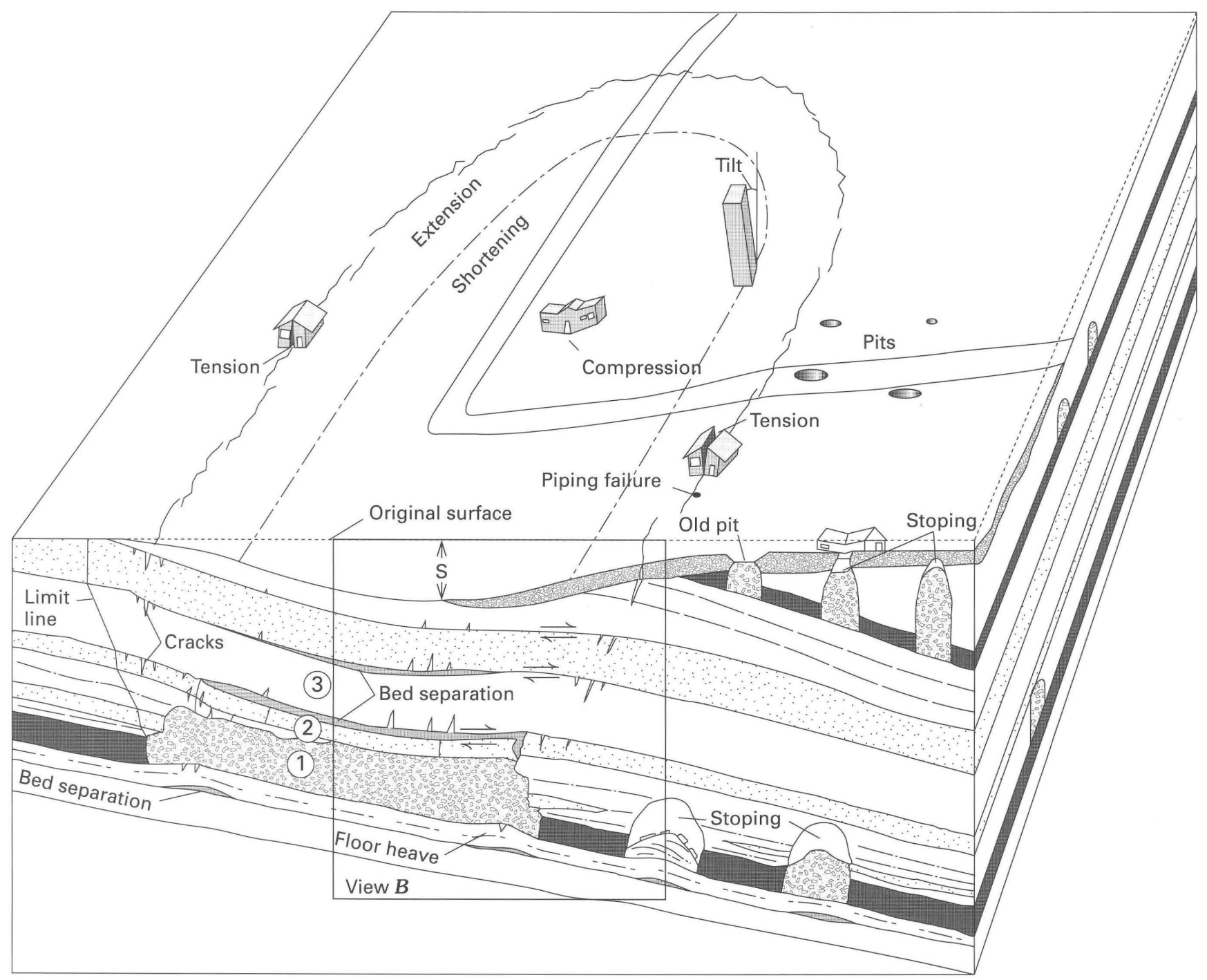

A

Figure 51 (above and following pages). Diagrams and photographs showing processes of coal mine deformation and subsidence. $A$, Conceptual block diagram showing processes of deformation around mine workings and subsidence. Bed separation characteristics: 1 , Caving, rotation of fragments, bulking; 2, breaking and some rotation of fragments; 3, S, subsidence (downwarping, local separation along bedding and stratifications, and vertical cracking in tension zones).

greater from the more well developed and more extensive face cleat than it is from the butt cleat; this can cause the drainage zone to be elliptical in plan view (see, for example, Diamond, 1982; Diamond and others, 1976, p. 2)

b. Methane has been removed from the caved zones (goaves) behind longwall faces and piped to the surface in some mining areas (Schatzel and others, 1982)

\section{COAL MINE SUBSIDENCE}

- The local lowering of the rocks and surficial material above coal mine openings; subsidence processes consist of
(1) downwarping, (2) stoping, (3) block movement, and (4) mine shaft failure. (For further details see Kratzsch, 1983; National Coal Board (NCB), 1975; Shadbolt, 1975, 1978; Peng, 1978, p. 281-342; Karmis and others, 1982; Braüner, 1973a, b; Bell, 1978; Berry, 1978; Hood and others, 1981; Jones and Bellamy, 1973; Salamon, 1978; Peng and Chyan, 1981; Piggot and Eynon, 1978; Briggs, 1929; Voight and Pariseau, 1970; Pöttgens, 1979; Allgaier, 1982; Mohr, 1956; Lee and Abel, 1983; Down and Stocks, 1978, p. 311-335; Dunrud, 1984)

\section{Downwarping}

A. Consists of the gradual, differential lowering of the overburden and ground surface to form depressions (troughs, sags) where the coal 


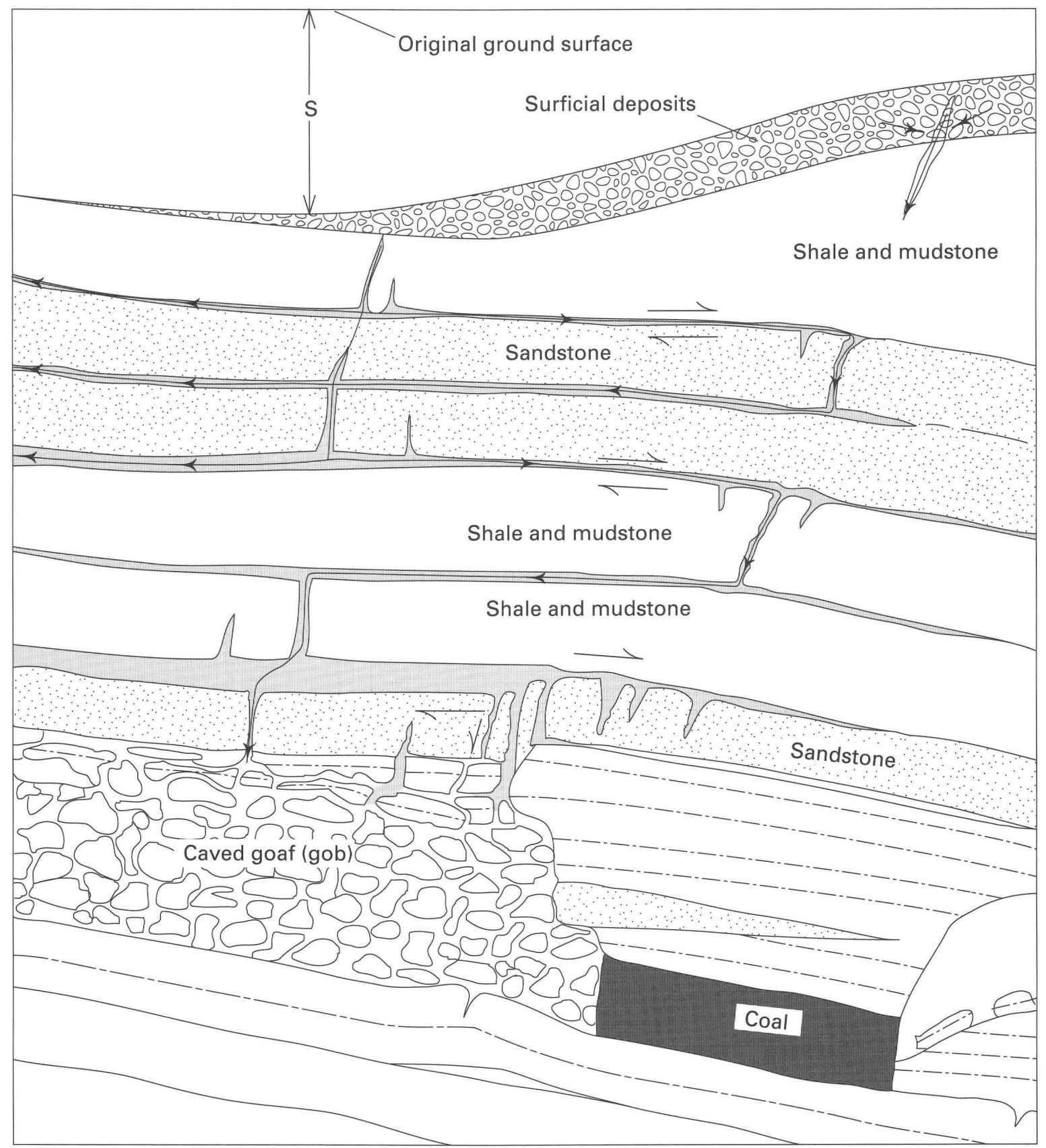

$B$

Figure 51-Continued. Processes of coal mine deformation and subsidence. $B$, Enlarged view of rectangular section marked in $A$, showing potential fracture patterns that may provide avenues for the flow of water and methane (arrows) to the mine workings. Light shade, cavity resulting from vertical lowering of rock units. $\mathrm{S}$, subsidence. 

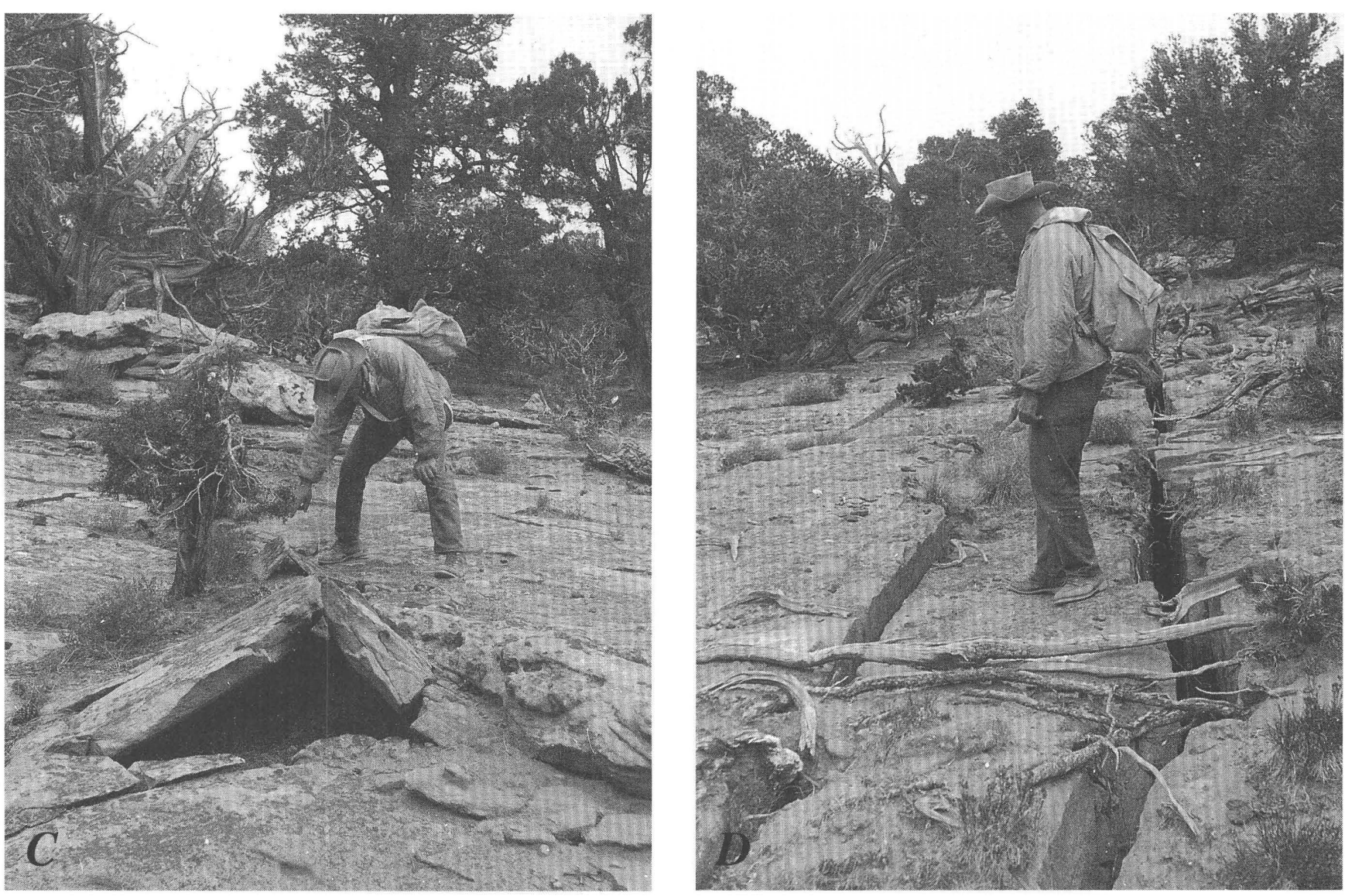

Figure 51-Continued. Processes of coal mine deformation and subsidence. $C$ and $D$, Photographs showing $C$, compression anticlines, and $D$, tension cracks in areas of shortening and extension above Geneva mine area, Emery County, Utah.

remaining after mining cannot support the weight of the overburden (fig. 51A)

1. Downwarping also can occur where extensive dewatering is done before mining; the lowering of the ground surface commonly is a function of the amount of lowering of the water table and of the porosity and lithology of the overburden material involved

a. In the Tuzla area of Bosnia-Hertzegovina, [former] Yugoslavia, for example, the ground reportedly has been lowered as much as $3.3 \mathrm{ft}(1 \mathrm{~m})$ due to dewatering (L. Ćekić, oral commun., 1984)

B. There commonly are four zones of deformation in the rocks above longwall or room-and-pillar extraction panels; this deformation, a potential hazard to miners and mine property, commonly occurs in sequence with the movement of roof supports in longwall mining panels, but may occur during and after mining in room-and-pillar mining panels (fig. 51A, $B$; for example, Ropski and Lama, 1973; Kanlybayeva, 1964)

1. A zone of caving, breaking, collapse, and rotation of the broken fragments for a few mining heights (two to three) into the roof (fig. 52A, $B$ )

2. A zone of fracturing with little or no rotation of fragments and separation of rock layers for another several mining heights (5-15) into the roof (fig. 51A, B)

3. A zone of continuous deformation comprising downwarping and flexure of rock units with local bed separation, differential shear along rock unit boundaries, and local discontinuous fracturing from zone 2 to the ground surface (fig. 51 $A, B$ )

4. A near-surface zone consisting of weathered bedrock, surficial material, and soil which may stretch without breaking over cracks in underlying, unweathered bedrock 


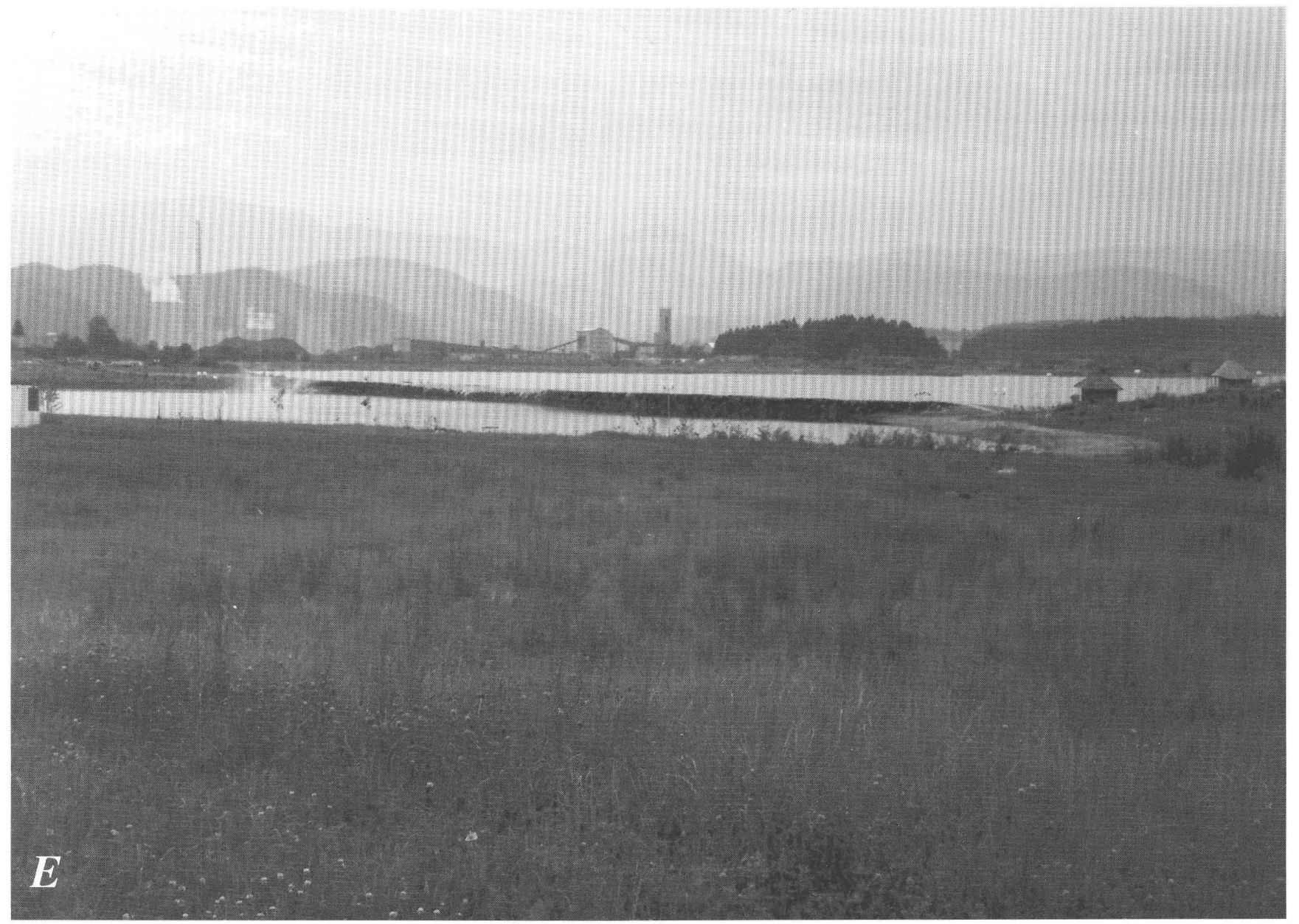

Figure 51-Continued. Processes of coal mine deformation and subsidence. $E$, Lake as much as $140 \mathrm{ft}$ deep in subsided area above Valenje mine, Slovenia, [former] Yugoslavia. Photograph by Bill Lutzens, U.S. Bureau of Mines, 1984.

C. Vertical displacement of the ground surface commonly ranges from about 0.45 (45 percent) to 0.98 (98 percent) of the mining thickness for critical or super-critical extraction panels (where the width of the mining panel $(W)$ is greater than 1.0 to 1.4 times the overburden thickness $(d)$ ) (fig. 53); vertical displacement commonly is:

1. Independent of overburden thickness

2. Not greater than the thickness of coal mined

3. Less where the overburden consists of strong, thick sandstone and limestone that contain little water than where the overburden consists of weak sandstone, mudstone, and claystone that contain large amounts of water (for example, Dunrud, 1984, p. 172-174)

a. Subsidence amounts to as much as 98 percent of the mining thickness in a mine near the town of Mostar in Bosnia-Hertzegovina, [former] Yugoslavia, where the coal was mined by a double-lift, longwall method; caving is the only goaf treatment used, and the overburden consists of as much as 670 $\mathrm{ft}$ of saturated shale and marlstone

b. Subsidence of as much as about $140 \mathrm{ft}$ (70 percent of mining thickness) has been reported above multilift, sublevelcaving, longwall mines in the Valenje area, Slovenia, [former] Yugoslavia, where about $200 \mathrm{ft}$ of a lignite bed as much as $400 \mathrm{ft}$ thick was being mined by a multilift, longwall method with sublevel caving

1- Extensive lakes occupy the subsidence depressions above the mine area (fig. 51E)

4. Reduced to 0.45 of mining thickness where the goaf is mechanically backfilled (fig. 53)

5. Reduced to 0.15 of mining thickness where the goaf is hydraulically backfilled 

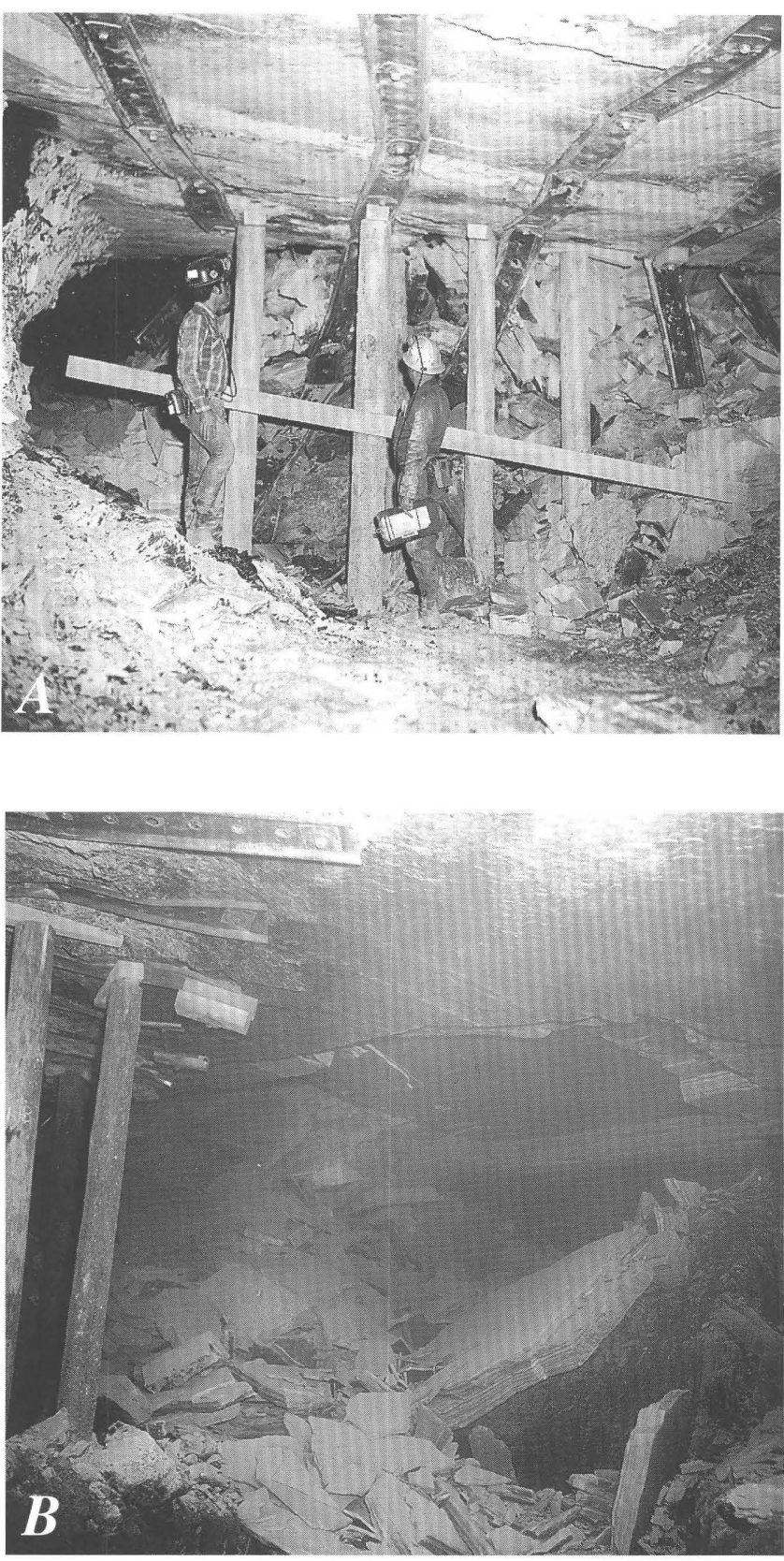

Figure 52. Photographs showing caving characteristics at the extraction limits in two room-and-pillar extraction panels. Equidimensional $(A)$ and slabby $(B)$ caved rock fragments behind breaker timbers at pillar lines in the "B" coal bed, Somerset area, Gunnison County, Colo. Size of fragments primarily a function of lithology and structure such as bedding, stratification, jointing.

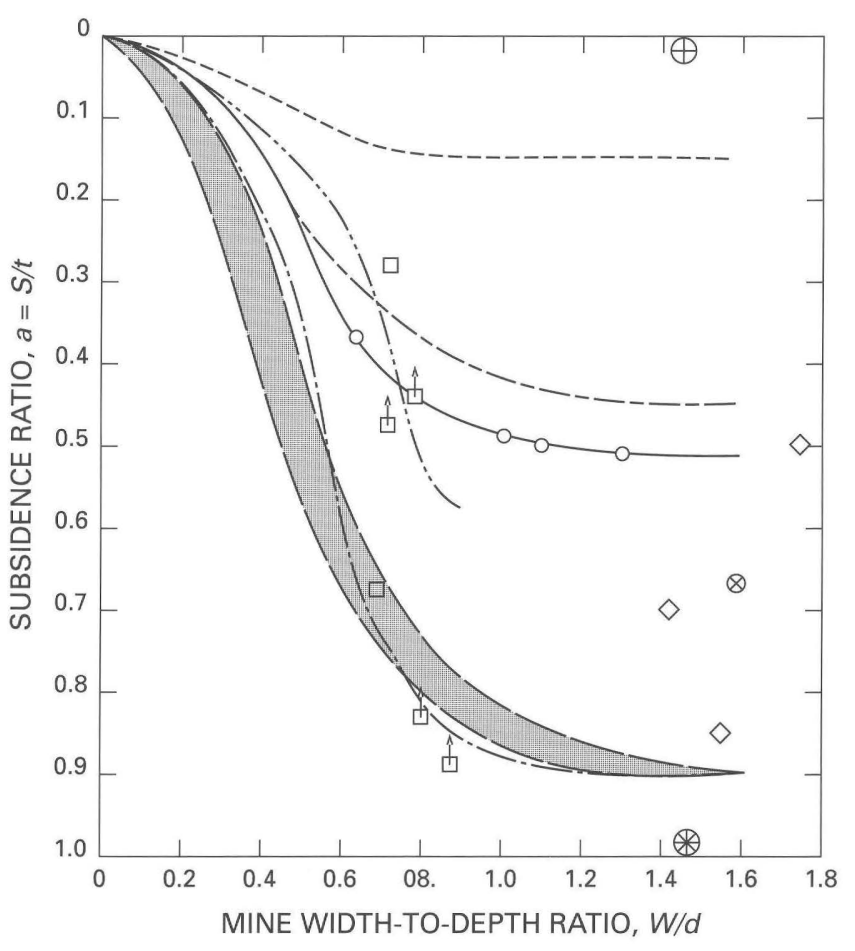

Figure 53. Graph showing maximum subsidence ratio $(a=S / t)$ for Western United States and the United Kingdom. Graph shows the relation between the ratio of maximum vertical displacement to thickness of coal mined $(S / t)$ versus the ratio of the width of coal extraction panels to overburden thickness $(W / d)$ for the Somerset, Colo., area (circles), the Salina, Utah, area (squares), the York Canyon, N. Mex., area (diamonds; upper point is in draw, middle point is on ridge, lower point is maximum for area; Gentry and Abel, 1978, p. 191-220), and the Huntington, Utah, area (circled $\times)$. Circled cross and asterisk are maximum subsidence ratios for hydraulically backfilled, room-and-pillar workings (0.02) and caved, double-lift longwall mine workings $(0.98)$ that were measured near the town of Mostar, Bosnia-Hertzegovina, [former] Yugoslavia (M. Osmanagić, written commun., 1984). Patterned area represents typical curves for longwall extraction in the United Kingdom; long-and-short-dashed curve is average subsidence above mechanically backfilled mines; short-dashed curve is average for hydraulically backfilled mines (modified from NCB, 1975, p. 9; Wardell, 1971, p. 207). Curve with long dash and single dot is from measurements in overburden composed of interbedded shales, mudstones, and lenticular sandstones in the Salina, Utah, area; curve with dash and two dots is from measurements above a massive sandstone about $150 \mathrm{ft}$ thick in the same area near Salina, which overlies the interbedded shales, mudstones, and lenticular sandstones. Uplift (arrows on squares show amount of uplift) may be caused by expansion of swelling clays, buoyant effects of water in caved zone, and (or) downwarping of overburden into adjacent extraction panels. Modified from NCB (1975, p. 9, replotted format), Shadbolt (1978, p. 729), Dunrud (1987, p. 27), and Wardell (1971, p. 206). 

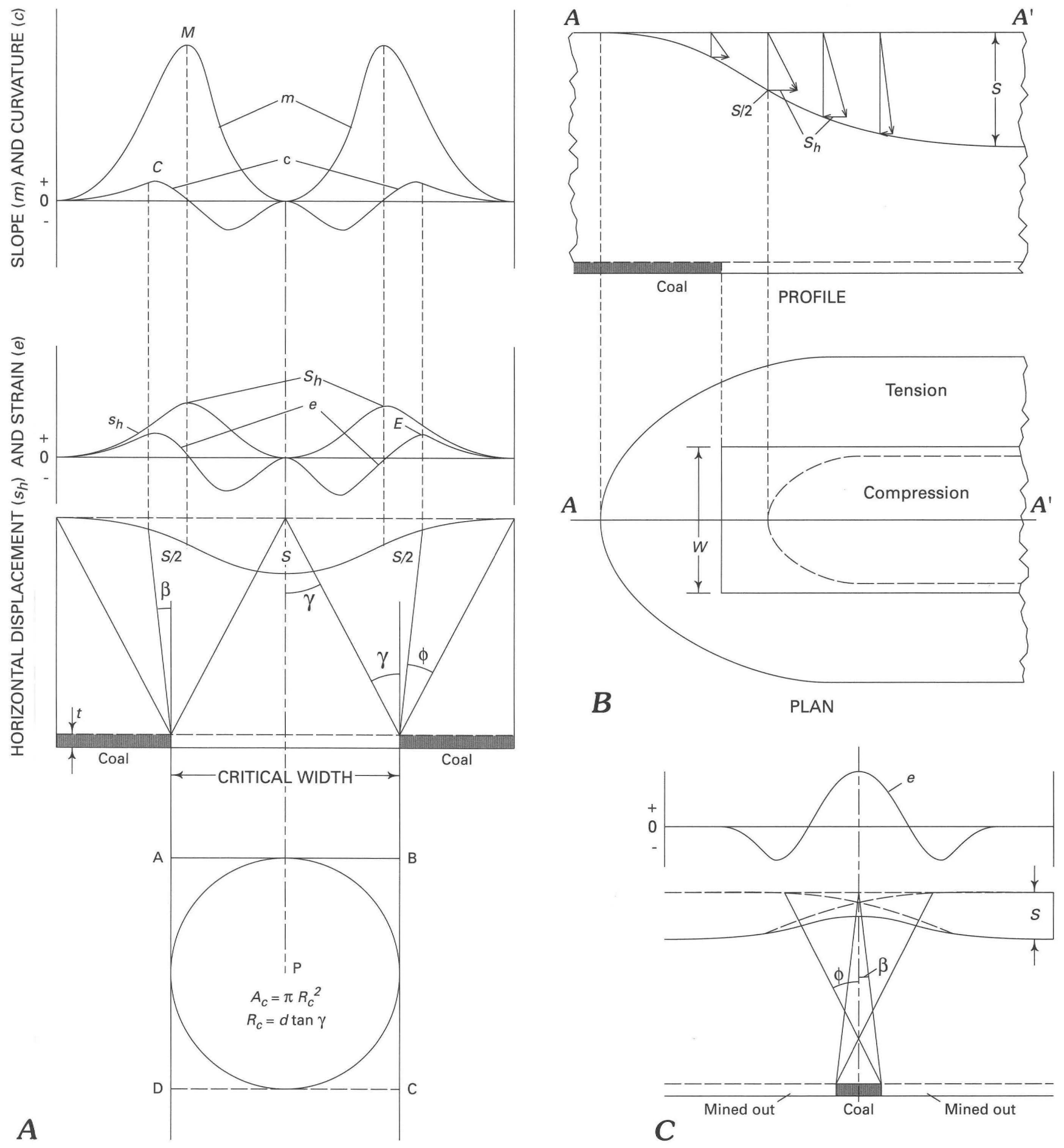

Figure 54. Conceptual subsidence maps and profiles. A, Subsidence profile, horizontal displacement, tilt, and strain above an extraction panel of critical width; $t$, thickness of coal mined (mining thickness); $S$, maximum vertical displacement; $S_{h}$, maximum horizontal displacement; $M$, maximum tilt; $C$, maximum curvature; $E$, maximum horizontal strain. Values less than maximum are shown in lower case. $\beta$, break angle; $\gamma$, critical extraction angle; $\phi$, limit angle (angle of draw). $A c, R c$, critical extraction area and radius, respectively, for maximum surface subsidence to occur. $B$, Map and profile of a subsidence depression (trough) showing vertical and horizontal displacement and zone of tension and compression above an extraction panel of width $W$. Compare figure 51. C, Profile showing how horizontal displacement and strain are increased above a barrier pillar by superposition of subsidence profiles above panels on either side of the barrier; $e$, horizontal strain; $S$, maximum horizontal displacement. From Dunrud (1984, p. 162). 
a. Subsidence is reduced to only about 2 percent of the mining thickness near Mostar, Bosnia-Hertzegovina, [former] Yugoslavia, where modified room-andpillar mining areas are hydraulically backfilled in sequence with extraction (fig. 53)

6. Less beneath draws than beneath ridges in rugged topography of the Western United States (Gentry and Abel, 1978)
D. Downwarping causes rock units under lateral confining stress to behave like laterally constrained plates, which in turn produces (1) vertical displacement, (2) horizontal displacement, (3) tilt, (4) curvature, and (5) strain (figs. 54, 55; for example, O'Rourke, 1982; Lee and Shen, 1969)

1. Vertical displacement increases inward from the margins of depressions; it reaches onehalf maximum subsidence at the point of

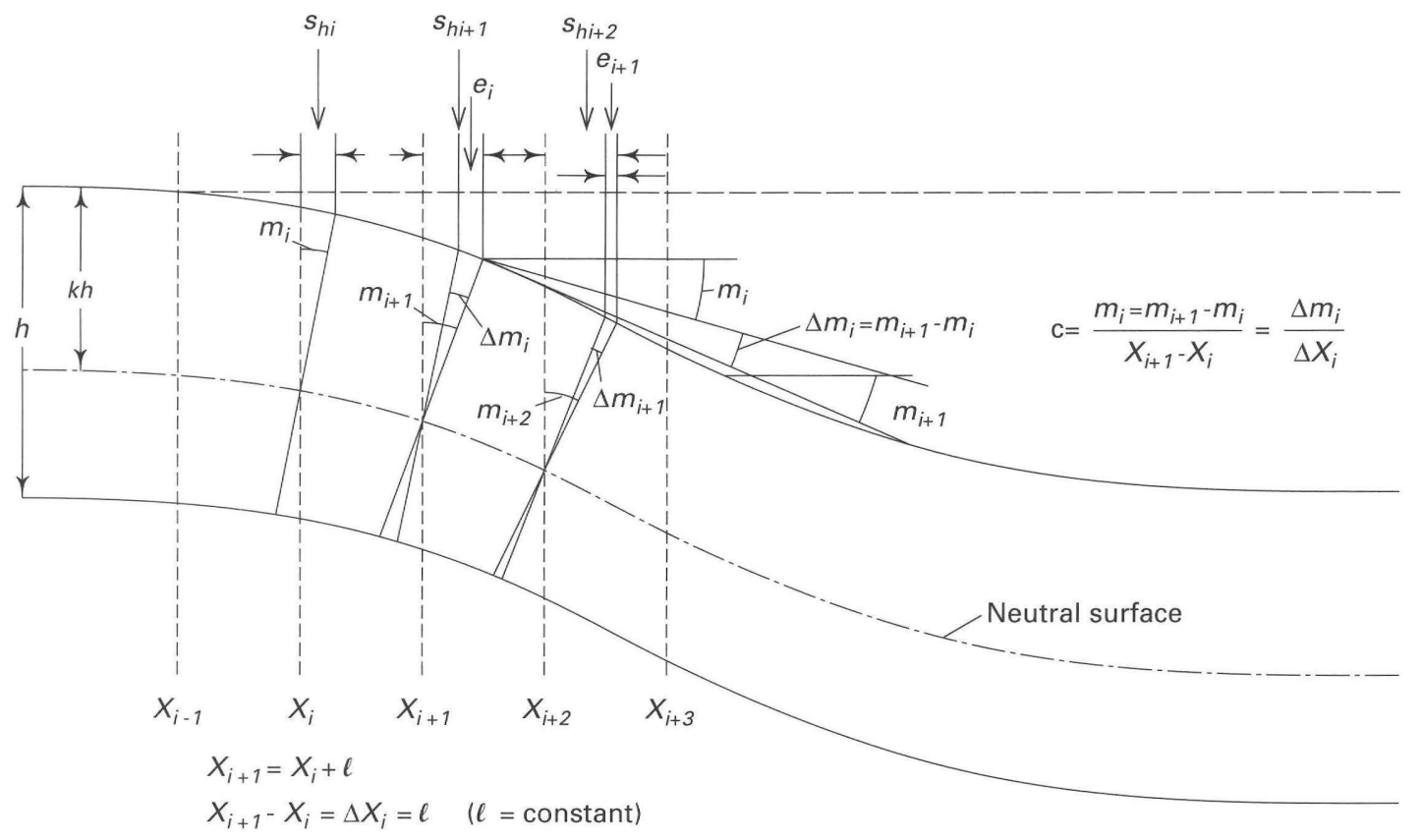

\begin{tabular}{llll}
\hline$X$ & $s$ & $\Delta s$ & $\Delta^{2} s$ \\
\hline$X_{i}$ & $s_{i}$ & $\Delta s_{i}$ & \\
$X_{i+1}$ & $s_{i+1}$ & $\Delta s_{i+1}$ & $\Delta^{2} s_{i}$ \\
$X_{i+2}$ & $s_{i+2}$ & $\Delta s_{i+2}$ & $\Delta^{2} s_{i+1}$ \\
$X_{i+3}$ & $s_{i+3}$ & $\cdot$ & $\cdot$ \\
$\cdot$ & $\cdot$ & $\cdot$ & $\cdot$ \\
$X_{i+n}$ & $\cdot$ & $\cdot$ & $\Delta^{2} s_{i+n-2}$ \\
& $s_{i+n}$ & &
\end{tabular}

$$
\begin{aligned}
& m_{i}=\frac{s_{i+1}-s_{i}}{\ell} \\
& c_{i}=\frac{s_{i+2}-2 s_{i+1}+s_{i}}{\ell^{2}} \\
& s_{h i}=k h m_{i}=\frac{k h\left(s_{i+1}-s_{i}\right)}{\ell} \\
& e_{i}=k h c_{i}=\frac{k h\left(s_{i+2}-2 s_{i+1}+s_{i}\right)}{\ell^{2}}
\end{aligned}
$$

$\Delta s_{i}=s_{i+1}-s_{i}$

$\Delta^{2} s_{i}=\Delta s_{i+1}-\Delta s_{i}=\left(s_{i+2}-s_{i+1}\right)-\left(s_{i+1}-s_{i}\right)=s_{i+2}-2 s_{i+1}+s_{i}$

Figure 55. Profile showing laterally constrained plate undergoing downwarping. Deflection causes vertical and horizontal displacement, tilt, curvature (caused by flexure), and horizontal strain, where the ratio of beam lengthto-thickness is greater than about 5 ; $s_{h i}$, horizontal displacement, $m_{i}$, tilt, $c$, curvature, $e$, horizontal strain; $h$ is plate thickness; $k$ is constant for a given lithology; neutral surface is surface that is neither in tension nor compression. Equations for incremental values of tilt $\left(m_{i}\right)$, curvature $\left(c_{i}\right)$, horizontal displacement $\left(s_{h i}\right)$, and horizontal strain $\left(e_{i}\right)$ are derived by the descending finite-difference table; $i$ subscript means finite incremental (" $i$ "th) value in finite-difference table. Modified from Dunrud (1987, p. 27). 

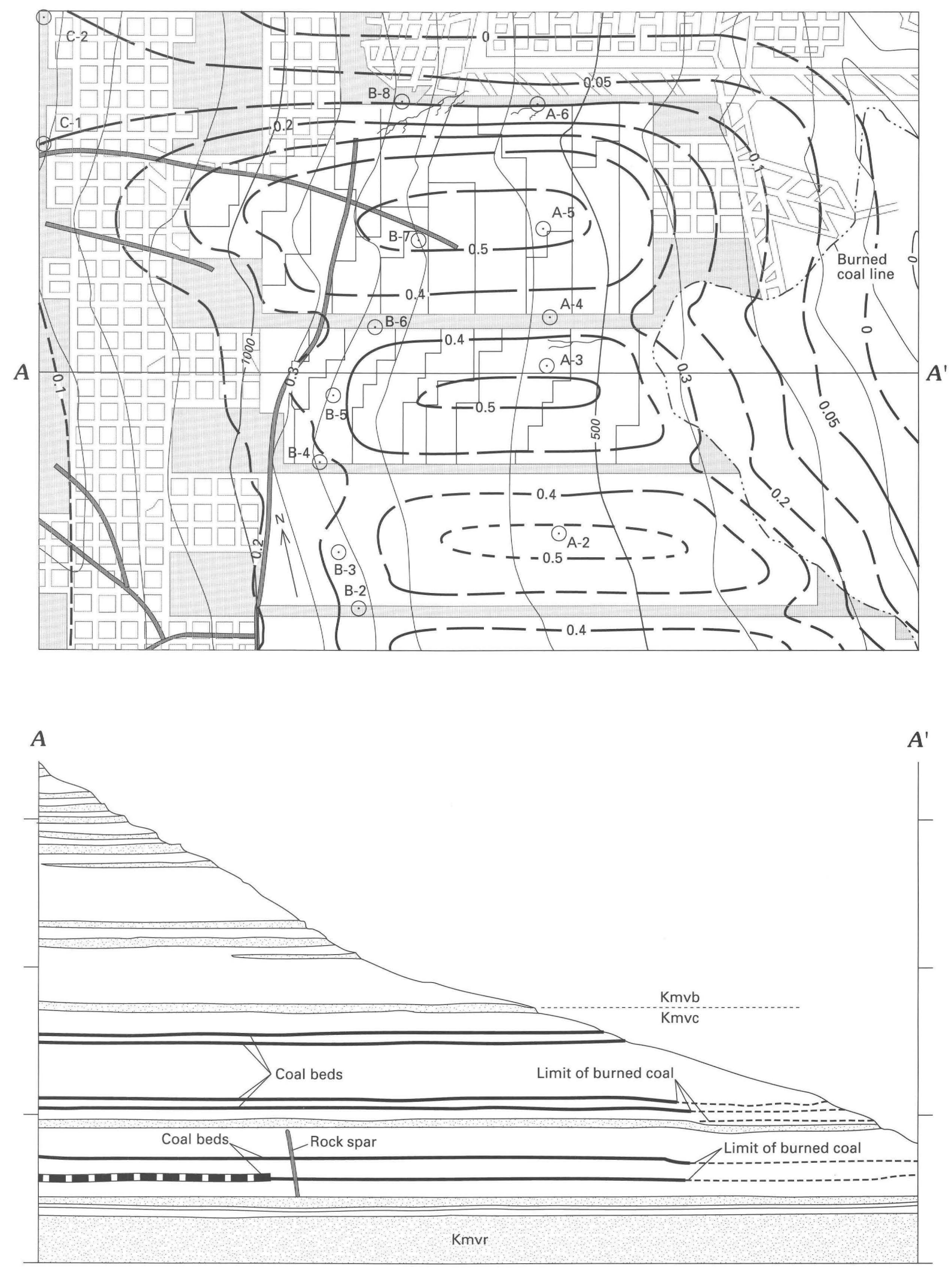
Figure 56 (facing page). Coal mining and subsidence map and geologic cross section, Somerset area, Colorado. Map shows roomand-pillar extraction panels (unpatterned), barrier pillars (gray), overburden thickness contours in feet (light solid lines), tension cracks (solid, short, irregular lines), rock spars (patterned lines), and contours of the ratio of vertical displacement of the ground surface to mining thickness ( $S / t$; heavy lines that are long dashed where approximately located, short dashed where inferred). Circled dot, subsidence monument. Geologic section $A-A^{\prime}$ shows Upper Cretaceous rocks of part of the Mesaverde Formation: Kmvb, barren member; Kmvc, coal-bearing member; Kmvr, Rollins Sandstone Member.

inflection and attains a maximum value in the middle of the depression above subcritical or critical mining areas or above the flat parts of the depression in supercritical mining areas (fig. 54A, B)

2. Horizontal displacement and tilt increase inward from depression margins to a maximum at the point of inflection and decrease again to zero at the point of maximum vertical displacement

3. Convex curvature and horizontal tensile strain above critical or supercritical panel extraction areas increase inward from the limit of the subsidence depression to a maximum about midway between the limit of subsidence and the inflection point, and decrease to zero at the inflection point; concave curvature and compressive horizontal strain increase inward from the inflection point to a maximum about midway between the inflection point and the point of maximum subsidence, and decrease to zero again at the point of maximum subsidence

a. Tension cracks are most common and widest at points of maximum tensile strain (fig. 51A, $B, D$ ); the cracks above mining panels may close again after the coal has been mined out, but cracks above barrier pillars or mine boundaries commonly remain open until erosion, weathering, mass wasting, and deposition obliterate them

1- For example, cracks were observed to close partially or completely in the Salina, Utah, area after mining was complete beneath the area (DeGraff and Romesburg, 1981), but remained open above barrier pillars and at the mine boundary

b. Buckling and bulging are most common at points of maximum compressive strain (shortening), particularly where the nearsurface material consists of brittle, nonyielding rocks like sandstone or limestone

4. The presence of barrier pillars between extraction panels can have a significant effect on subsidence; curvature and strain above barrier pillars between two adjacent mining panels can be about twice the amount expected above a single panel because the subsidence profiles overlap above the barrier (fig. 54C)

a. Curvature and strain above barrier pillars, $45 \mathrm{ft}$ wide, which were left between adjacent room-and-pillar extraction panels in the Somerset, Colo., area for protection against methane and water buildup and intrusion, produced subsidence profiles similar to those shown in figure $54 C$; this is because the barriers did not yield completely to the weight of the overburden (fig. 56)

b. Curvature and strain above small chain pillars in double-entry longwall systems, such as in the Huntington, Utah, area, are small to nonexistent because the pillars yielded and were crushed so that little or no hump (local positive curvature) remains in the profile (fig. 57)

Figure 57 (following pages). Coal mining and subsidence map and profiles in the Huntington, Utah, area. A, Map showing extent of mining; $5 \mathrm{E}$ through $8 \mathrm{E}$ are longwall (LW) panels, $9 \mathrm{E}$ is a roomand-pillar (R\&P) extraction panel. Overburden thickness contours (dashed lines) are in feet; solid lines of $0,0.025,0.05,0.1,0.2,0.3$, $0.4,0.5$ are the ratios of vertical displacement of ground surface to mining thickness $(S / t)$; measurements by U.S. Bureau of Mines as of June 1982; dots show location of subsidence monuments; also identified in profiles. Faults marked by $U$, upthrown side; $D$, downthrown side; number is amount of displacement, in feet. $B$, Longitudinal (east-west) cross section through 7E LW panel at the monument locations ( $A$, dots) showing rocks of the Upper Cretaceous Mesaverde Group: Kpr, Price River Formation; Kc, Castlegate Sandstone; Kb, Blackhawk Formation; Ksp, Star Point Sandstone. Modified from Ellis and Frank (1981) and Allgaier (1982, p. 7-11). Barbs on fault show relative displacement. C, Transverse (north-south) subsidence profiles (shown by dash-dot lines) across panels $5 \mathrm{E}$ through $9 \mathrm{E}$, at line of monuments (dots) on $A$, when the coal was mined in $5 \mathrm{E}, 6 \mathrm{E}$, and $7 \mathrm{E}$ to point of June 1982 , and for August 1983, when the coal was mined as shown. Dots on profiles are subsidence monument measuring stations. $D$, Longitudinal (east-west) profile for June 1982 and August 1983 through center of $7 \mathrm{E}$ at monuments ( $A$, dots). 


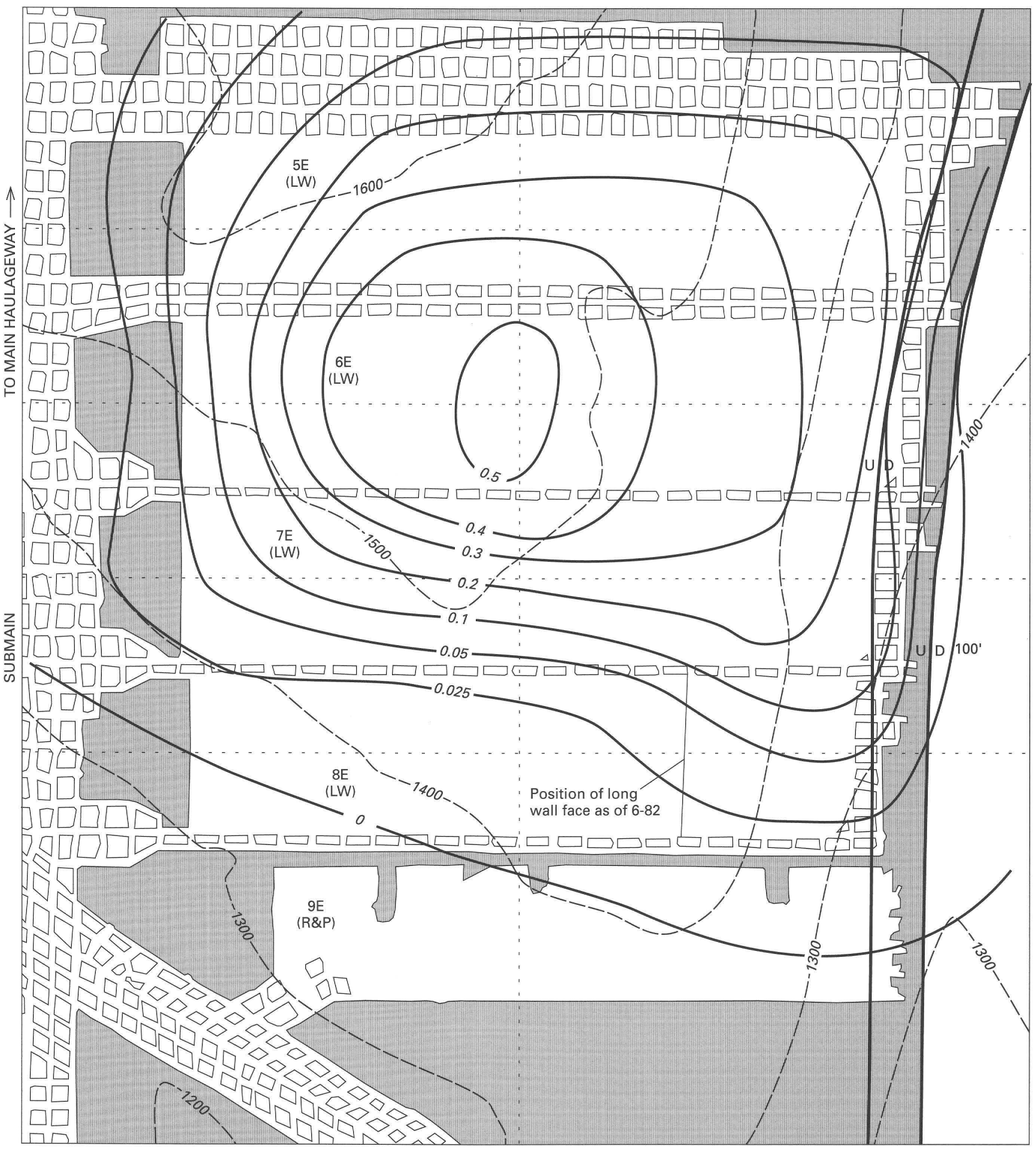

A

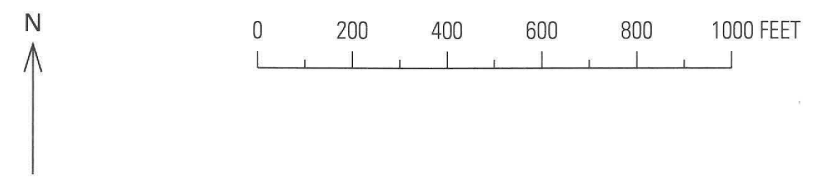


WEST
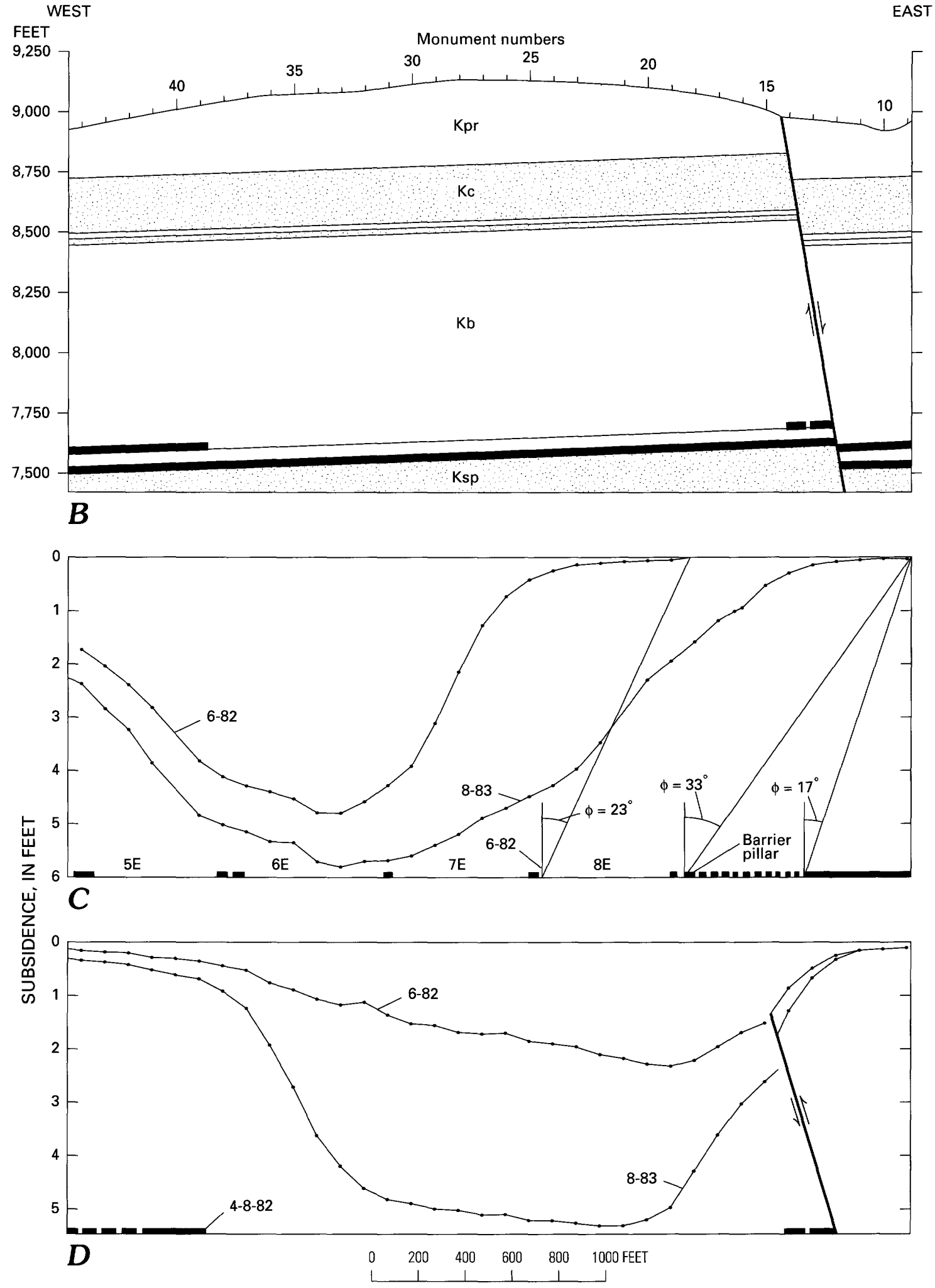
5. Tilt and horizontal strain commonly increase in direct proportion to increasing thickness of coal mined or to decreasing overburden thickness for similar mining and geologic conditions (fig. 58A, C; Wardell, 1971, p. 209)

a. For example, tilt and horizontal strain commonly increase by a factor of 10 as the coal thickness increases or the overburden thickness decreases by the same factor of 10

E. Subsidence parameters, including tilt, curvature, horizontal displacement, and horizontal strain, can be determined from the vertical displacements $\left(s_{i}, s_{i+1}, s_{i+2}, \ldots\right)$ at their respective points $\left(X_{i}, X_{i+1}, X_{i+2}, \ldots\right)$ using finite-difference methods (for example, Kunz, 1957, p. 125-166) and deflection of laterally constrained plates, or laterally constrained beams in two dimensions (fig. 55) as follows:

1. Tilt $\left(m_{i}\right): \quad m_{i}=\frac{s_{i+1}-s_{i}}{l}$

2. Curvature $\left(c_{i}\right): \quad c_{i}=\frac{s_{i+2}-2 s_{i+1}+\mathrm{s}_{i}}{l^{2}}$

3. Horizontal displacement $\left(s_{h i}\right)$ :

$$
s_{h i}=k h \frac{\left(s_{i+1}-s_{i}\right)}{l}
$$

4. Horizontal strain $\left(e_{i}\right)$ :

$$
e_{i}=k h \frac{\left(s_{i+2}-2 s_{i+1}+s_{i}\right)}{l^{2}}
$$

5. Tilt and curvature can be determined from vertical displacement measurements without knowing plate thickness

6. Horizontal displacement and horizontal strain can be determined in terms of vertical displacement of survey monuments provided that the thickness of major lithologic (rock) unit $(h)$, near the surface, behaves as a homogeneous plate and its thickness is known

7. Construction and use of finite-difference tables from surveyed data, showing vertical displacement, tilt, curvature, horizontal displacement, and horizontal strain, are facilitated by the use of digital computers

F. Subsidence parameters, such as vertical displacement, tilt, curvature, and horizontal strain, may also be estimated by mathematically fitting functions to representative subsidence profiles, from areas that have been measured and analyzed, in the following way:

1. Estimate the subsidence factor $(a=S / t)$, from fig. 53, for local conditions
2. Fit a profile function to subsidence profiles, such as the widely used hyperbolic tangent equation, of the form:

$s=S k[\tan h(A X)+1]$,

or, because $S=$ at (from fig. 53),

$s=\operatorname{kat}[\tanh (A X)+1]$

where:

a. $s$ is the vertical displacement at $X$ (where $X=X_{r} / d$ ) (fig. 58A), which is positive and increases below the point of zero subsidence like the parameter graph in figure $58 \mathrm{~A}$

b. $k$ commonly equals 0.5

c. $d$ is the overburden thickness

d. $S$ is the maximum subsidence (maximum vertical displacement)

e. $A$ is a constant, which appears to be a function of the thickness and strength of the overburden rocks

3. The values of the constant $A$ in the hyperbolic tangent equation can be determined iteratively by calculating $s / S$ for various values of $X / d$ on the subsidence parameter graph (fig. 58A) and letting $A$ equal various values until a best fit is attained

a. Calculations are facilitated with the use of a digital computer

b. A computer program can be compiled to (1) compute the $Y(s / S)$ values for various values of $X\left(X_{r} / d\right)$ in increments of 0.1 , (2) solve for the difference of the absolute value of $Y$ and the data point $(B)$, and (3) print the values of $A, X_{r}-C(C=$ the ratio of the horizontal distance from panel ribs (ribside) to the point of inflection divided by overburden thickness $(d)), X, Y, B$, and $D$ (the differences between $B$ and $Y$ ) when the values of $D$ reach a minimum; the same procedure is done for the curve beyond the point of inflection

c. The listings below are the values and largest differences in the absolute values between calculated and measured values of $Y(s / S)$ for typical profiles above mines in gently dipping coal beds in the United Kingdom and in two active mining areas and one abandoned mining area of the Western United States, above (A) and beyond (B) the inflection point (fig. 58A): 
1- $A=4.2,0.003(\mathrm{~A})$ and $A=5.8,0.003$ (B) for the United Kingdom (NCB, 1975, p. 12-14) (active)

2- $A=4.4,0.03$ (A) and $A=5.6,0.01$ (B) for the Paonia, Colo., area (active)

3- $A=9.5,0.04$ (A), $A=12.8,0.02$ (B) for the Salina, Utah, area (active)

4- $A=5.2,0.02$ (A) and $A=7.1,0.01$ (B) for the Huntington, Utah, area (active)

5- $A=13.8,0.08$ (A), $A=6.8,0.05$ (B) for the Sheridan, Wyo., area (abandoned)

d. Differences between calculated and measured values of $Y$ are greater in abandoned mining areas than they are in the active mining areas, because the profiles in active mining areas were measured during or shortly after mining, when they are smoother and more mathematically definable than they are after the mine area has been abandoned, when continued adjustments in the overburden and erosion, mass wasting, and deposition may affect the shapes of the profiles

4. Horizontal strain $(e)$ may also be estimated, using the empirical relation between horizontal strain and curvature $(c)$ proposed by the National Coal Board (NCB) of the United Kingdom (1975, p. 37):

$$
e=0.16 c^{1 / 2}
$$

G. Damage to structures; values calculated using equation (6) commonly are low in the Western United States compared to measured value, however:

1. Displacement, tilt, curvature, and horizontal strain commonly cause damage to structures such as buildings, railroad tracks, roads and bridges, cables and pipes, canals, locks, and sewers, and may involve litigation and mitigation on the part of mining companies (for example, Kratzsch, 1983; Stephenson and Augenbaugh, 1978; Thorburn and Reid, 1978; Young and Stoek, 1916); for example:

a. Areas near water bodies or with high water tables can be inundated by local lowering of the ground surface (fig. 51E)

b. Stream gradients can be changed or locally reversed and thus affect surface drainage

c. The taller the building, the more vulnerable it is to toppling failure due to tilt d. The greater the surface area of the building, the more it can be damaged by horizontal strain; a building can be slightly to very severely damaged by undergoing extension or shortening; the degree of damage, for a given type of construction and material used, is a function of the amount of extension or shortening in relation to the length and width of the structure; for example, according to the NCB (fig. 59), a building with a maximum length of $100 \mathrm{~m}(330 \mathrm{ft})$ will undergo a change in length of:

l- 3-6 cm (7.5-15 in.) where a horizontal strain of about $0.0003-0.0006$ occurs, causing slight damage

2- $12-18 \mathrm{~cm} \mathrm{(30-45} \mathrm{in.)} \mathrm{where} \mathrm{a} \mathrm{hori-}$ zontal strain of about $0.0012-0.0018$ occurs, causing severe damage

2. In [the former] Yugoslavia, in Poland, and in countries of the former Soviet Union, maximum allowable deformations are classified into groups on the basis of structural sensitivity, as shown in table 1 (see p. 100) (Osman Pehlić, written commun., 1985)

3. Subsidence damage can be reduced by:

a. Designing partial extraction techniques, such as longwall or room-and-pillar extraction panels of subcritical width that are bounded by barrier pillars capable of supporting the overburden, or by room-and-pillar mining without extracting the pillars (for example, Kaneshige, 1971; NCB, 1975, p. 98-99)

b. Backfilling the mined-out areas (Colaizzi and others, 1981)

c. Not building structures above or near the mined-out areas, taking into account the angle of draw

d. Building subsidence-resistant structures (for examples, see Kratzsch, 1983, p. 441-497; Geddes, 1978a, b, p. 579-596, 949-974)

H. The area affected by downwarping is usually greater than the mining area

1. The limit angle (angle of draw) commonly ranges from a few degrees to about $45^{\circ}$

a. The limit angle commonly is less (measured from a vertical reference) in overburden consisting of thick, strong sandstones and limestones than it is for weak shales and mudstones (Abel and Lee, 1980)

b. The affected area therefore is less if the overburden consists of thicker, stronger 


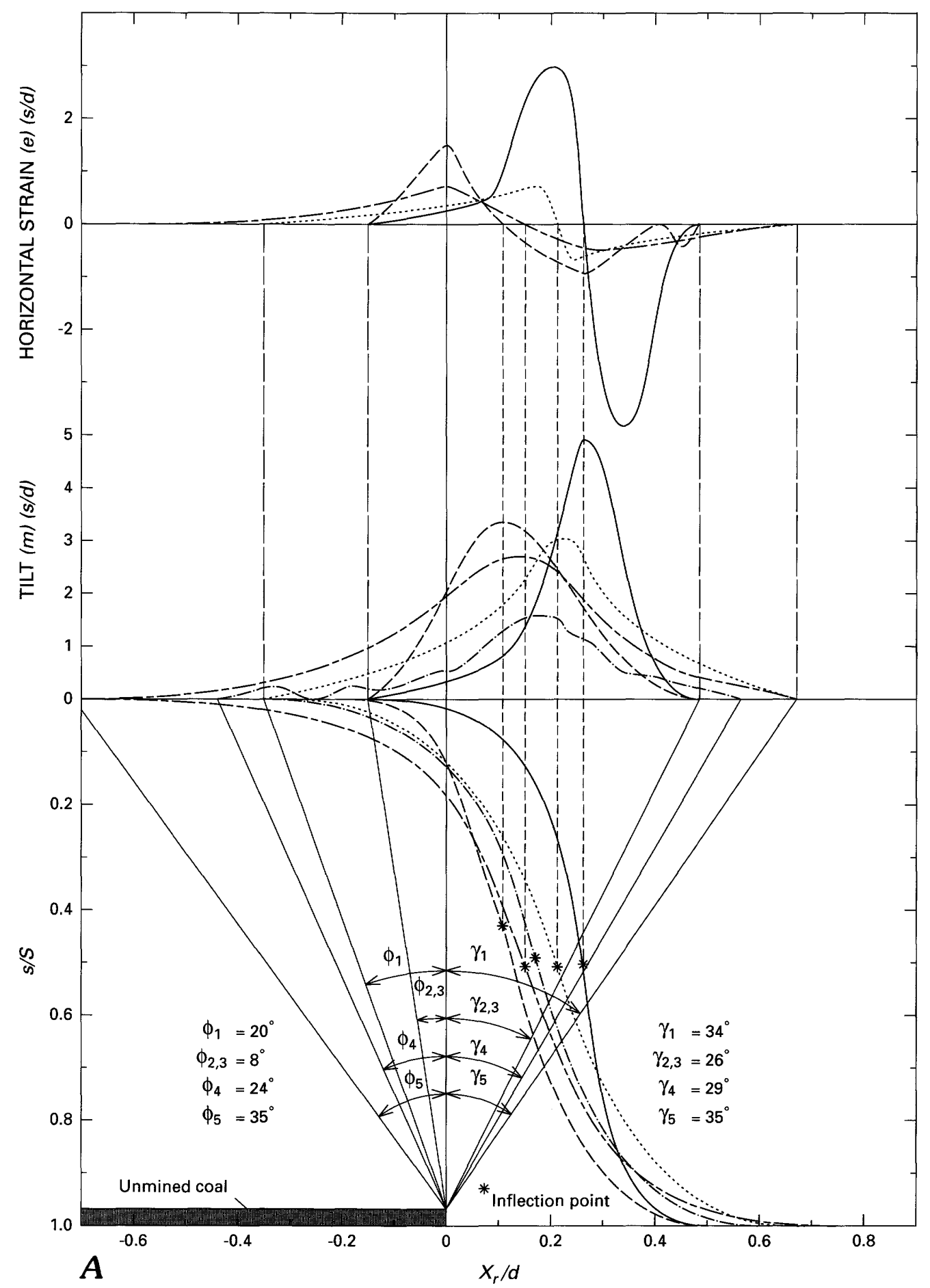

rocks than it is if the overburden consists of weaker rocks

2. The area increases with increasing overburden thickness in proportion to the limit angle (figs. $51 ; 58 A, B$ ); however, the area commonly increases at a lesser rate where the overburden consists of thick, strong rocks

3. The area affected by subsidence in relation to the mining area commonly is located differently in steeply dipping rocks than in gently dipping rocks; for example:

a. In the United Kingdom and in the Zenica coal field, Bosnia-Hertzegovina, [former] Yugoslavia, where overburden rocks are quite often saturated, the subsidence depression commonly is offset downdip relative to the mine area where the rocks dip more than about 
Figure 58 (facing page and facing column). Subsidence graphs and map for predicting limit angle, displacement, tilt, and horizontal strain. All overburden thicknesses are average. Strain curve for Huntington, Utah, area not plottable at this scale. $A$, Subsidence parameter graph showing $s / S$ (ratio of vertical displacement at point of measurement to maximum vertical displacement), tilt $(m)$, and horizontal strain $(e)$, limit angle $(\phi)$, and critical extraction angle $(\gamma)$ based on measurements above active coal mines in areas near Paonia, Colo. (dotted line; overburden $580 \mathrm{ft}$ thick, rocks are of medium ( 25 percent), low (70 percent), and very low ( 5 percent) strength); Salina, Utah (solid line; overburden $875 \mathrm{ft}$, rocks are of medium (35-45 percent), low (60-50 percent), and very low ( 5 percent) strength); Sheridan, Wyo. (short dash; overburden $100 \mathrm{ft}$ thick, rocks are of low (10 percent) and very low (90 percent) strength); Huntington, Utah (dash and dot; overburden 1,425 ft thick, rocks are of medium ( 45 percent), low ( 50 percent), and very low ( 5 percent) strength); and the United Kingdom (long and short dash) versus $\mathrm{Xr} /$ $d$ (ratio of horizontal distance between mining face or pillar line and points of measurement to overburden thickness). Modified from Dunrud (1984, p. 166, 168) and Dunrud (1987, p. 28). B, Conceptual map showing contours of the ratio of $s / S$ for a rectangular extraction panel, based on curve of subsidence graph for the Salina, Utah, area (in view $A$ ). Dashed lines are predicted tensile horizontal strain; long-dash and dot lines are predicted compressive horizontal strain. $C$, Maximum tilt $(M)$ and maximum horizontal strain $(E)$ caused by subsidence in the Western United States and the United Kingdom (solid lines); circle, square, $x$, and triangle are maximum tilt calculated from subsidence profiles near Paonia, Colo., Salina, Utah, Huntington, Utah, and Sheridan, Wyo., respectively; circled circle, square, and triangle are maximum horizontal strain calculated from curvature of the profiles from Paonia, Salina, and Sheridan areas. Diamonds are compressive and tensile strain measured in the York Canyon, N. Mex., area by Gentry and Abel (1978, p. 216); curves are dashed where they extend beyond NCB data.

$15^{\circ}$ (NCB, 1975, p. 18; Osman Pehlić, written commun., 1985)

b. Model studies by Kanishege (1971, p. 173-176) to simulate steeply dipping rocks indicate that the point of maximum subsidence is offset updip from the center of the mining area where the rock sequences in the overburden are predominantly thick, but is offset downdip from the center of the mining area where the rock sequences in the overburden are predominantly thin

4. Faults can change the area affected by subsidence and also can localize displacement, particularly where lateral stresses are low and attendant frictional resistance along the faults is less than shear stresses generated by subsidence (fig. 60)

a. The area may be reduced where the faults dip more steeply than the angle of draw (fig. 60A)
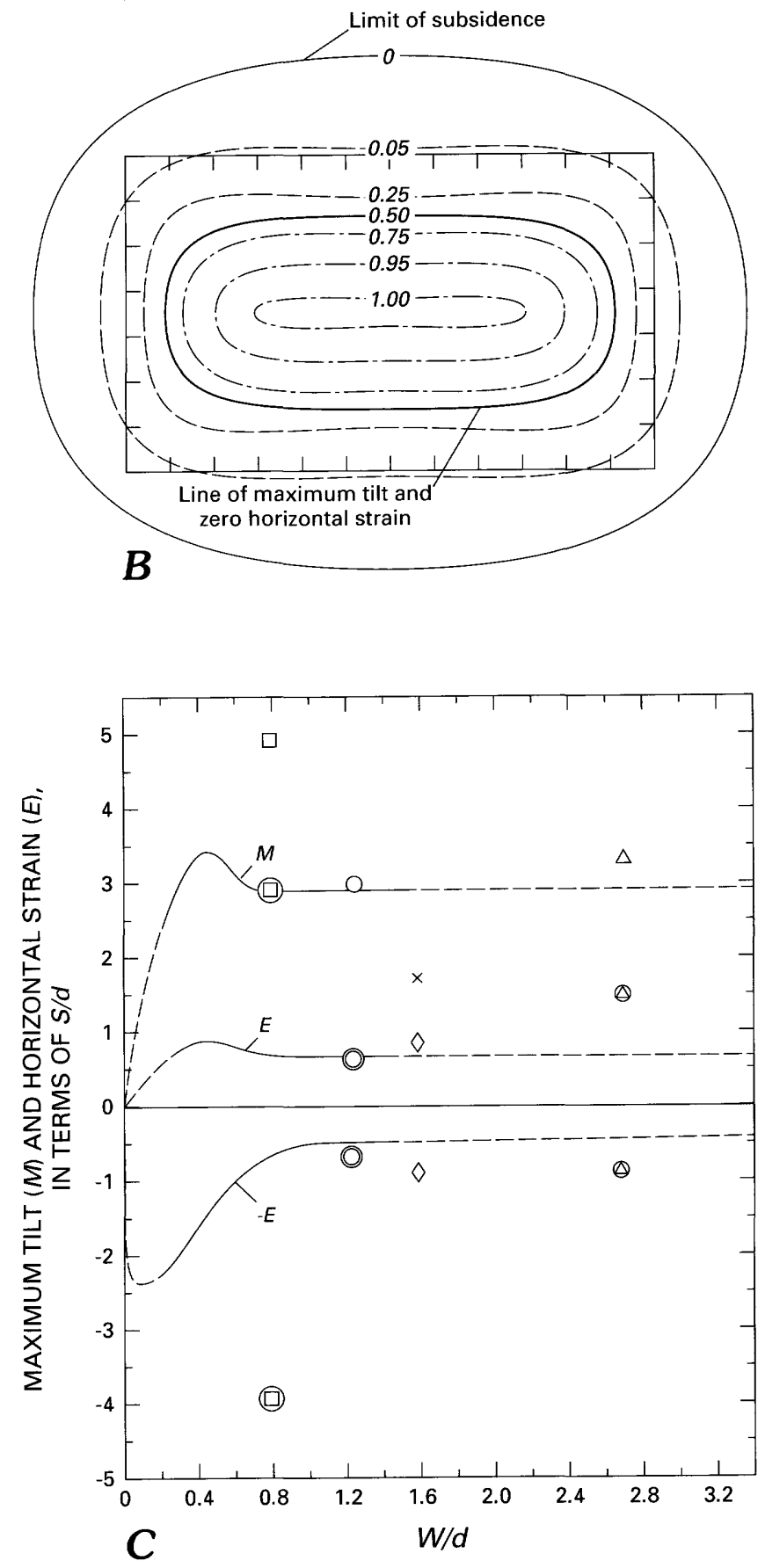

b. The area may be increased where faults dip less steeply than the angle of draw (fig. 60B)

c. Renewed offset can occur along faults that transect the area affected by subsidence (fig. 60C)

d. Faults affected subsidence area and subsidence profiles in only minor ways in the gently dipping rocks of the Huntington, Utah, area (fig. 57D); however, renewed offset occurred in dramatic 
Table 1. Maximum allowable subsidence deformations for various group classes of structures in [the former] Yugoslavia, in Poland, and countries of the former Soviet Union

[From Osman Pehlić, written commun., 1985; leaders (---), no data]

\begin{tabular}{|c|c|c|c|}
\hline \multirow[b]{2}{*}{$\begin{array}{l}\text { Structural } \\
\text { group }\end{array}$} & \multicolumn{3}{|c|}{ Maximum Allowable Deformations } \\
\hline & $\begin{array}{c}\text { Tilt } \\
(\mathrm{mm} / \mathrm{m})\end{array}$ & $\begin{array}{l}\text { Horizontal strain } \\
\qquad(\mathrm{mm} / \mathrm{m})\end{array}$ & $\begin{array}{c}\text { Curvature } \\
C\left(\times 10^{-5} \mathrm{~m}^{-1}\right)\end{array}$ \\
\hline \multicolumn{4}{|c|}{ [Former] Yugoslavia: } \\
\hline I & 2.5 & 2.4 & 2.9 \\
\hline II & 10.0 & 4.0 & 5.0 \\
\hline III & 15.0 & 8.0 & 8.3 \\
\hline IV & 20.0 & 12.0 & 16.6 \\
\hline \multicolumn{4}{|l|}{ Poland: } \\
\hline I & $1-4$ & $0.5-2$ & --- \\
\hline II & $4-7$ & $2-4$ & -- \\
\hline III & $7-10$ & $6-8$ & --- \\
\hline IV & 13 & 9 & -- \\
\hline \multicolumn{4}{|c|}{ Former Soviet Union: } \\
\hline I & 4 & 2 & -- \\
\hline II & 8 & 4 & --- \\
\hline III & 12 & 6 & --- \\
\hline IV & 20 & 8 & $\cdots$ \\
\hline
\end{tabular}

GROUP CLASSES ACCORDING TO SENSITIVITY TO SUBSIDENCE IN [FORMER] YUGOSLAVIA (also includes some major structural features in Poland and countries of the former Soviet Union):

I - Very sensitive structures: includes main access mine shafts, large industrial structures such as power plants, major paved highways, dams, large bridges, residential buildings more than two stories high; natural features in this category include navigable rivers and large lakes.

II - Structures of medium sensitivity: includes mine ventilation shafts, industrial structures of secondary importance such as main railway station, substations, distribution systems, and buildings with two stories or less; natural features in this category include rivers, small lakes, and very important agricultural land.

III - Structures of low sensitivity such as cableways, unpaved roads and temporary roads, temporary wooden structures, prefabricated metal structures or other temporary houses, underground mine workings, and single-story residences.

IV - Structures of minor importance and of low value that are not included in groups I, II, III; agricultural land and forests are also included in this category.

proportions in the same area along faults near canyons, where lateral confining stresses were low, as the underlying coal was mined (fig. $68 \mathrm{C}$ )

I. Subsidence duration - the time required for subsidence to be completed-appears to depend primarily on mining procedures (longwall, roomand-pillar), on thickness, strength, and dip of the overburden, and on the regional stresses and stress history of a region

1. Subsidence at a point above critical or supercritical longwall panels or room-and-pillar extraction panels commonly can be predicted to be complete to within 5-10 percent of the total value when all the coal is extracted within the critical area beneath the point (fig. $61 A, B$; for example, Wardell, 1954)

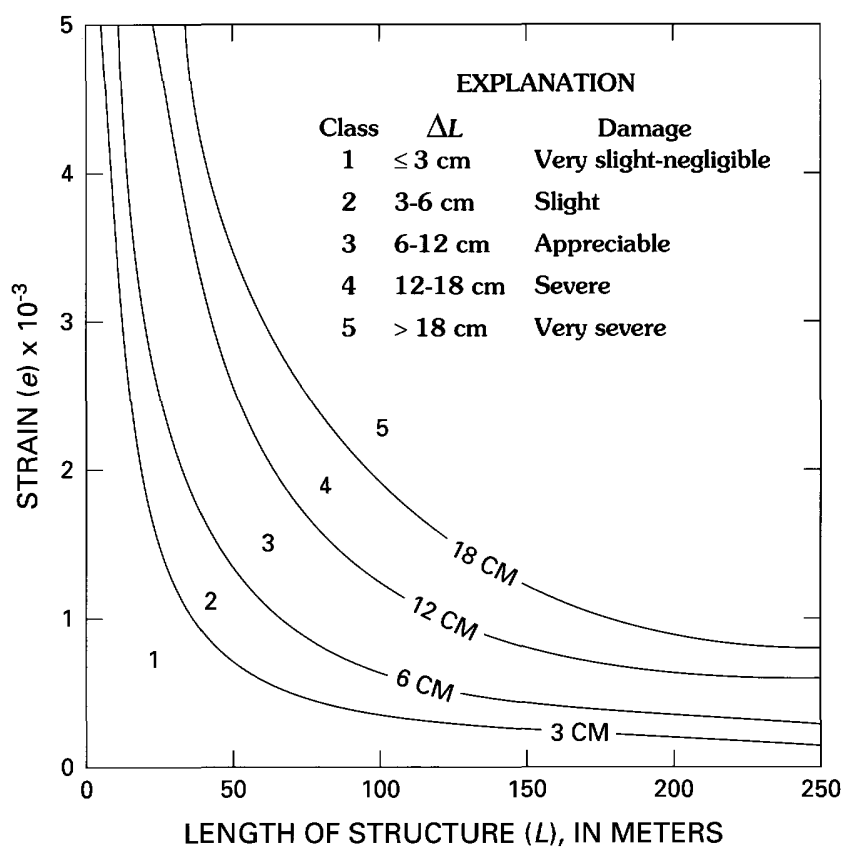

Figure 59. Structural damage in relation to horizontal strain and length of structure. Damage classification is as follows: (1) very slight to negligible-local hairline cracks inside building; (2) slight-several hairline cracks inside building; windows and doors may stick slightly; (3) appreciable-local, small fractures can be seen on building exterior; doors and windows are hard to open or close; utility pipes (water, sewer, gas lines) are locally fractured, split, or pulled apart; (4) severe-many utility pipes broken; open fractures in building that require repair; window and door frames are distorted; floors and walls bulging and out of alignment; support is locally lost on beams, columns, and joists; (5) very severe-same problems as (4) except damage is more extensive; partial or complete rebuilding is required; support beams, columns, and joists are loose; windows are broken; floors and ceilings are tilted; walls are bulged and buckled noticeably. Modified from NCB (1975, p. 49).

2. After mining is complete, subsidence may continue in the critical area beneath a point of measurement, where the panel width is subcritical and the barrier pillars cannot support the weight of the overburden over the long term (see the curve identified by triangles in fig. $61 B$ )

a. Van Besien and Rockaway (1987) found that the mean delay time between mining and downwarping (sag subsidence) in 42 different abandoned room-andpillar mine areas, primarily in the Eastern United States, was 37 years

3. Subsidence can be delayed or prolonged for many years or even decades where the mining areas are located in steeply dipping rocks, compared to subsidence in mines located in gently dipping rocks; for example: 


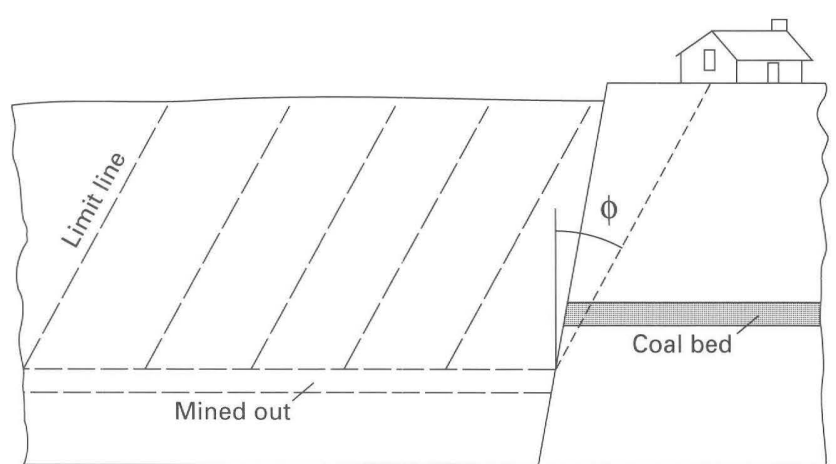

A

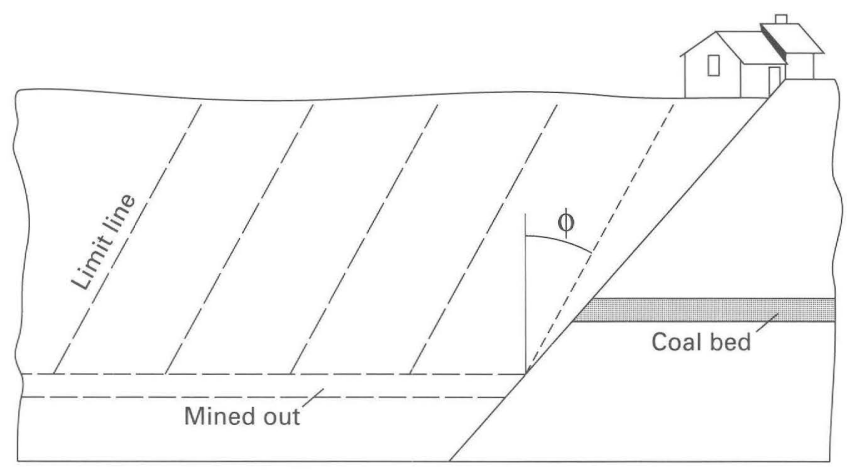

B a. In the Newcastle-Issaquah area, King County, Wash., the writer observed that downwarping has been delayed for decades in rocks dipping from $30^{\circ}$ to $45^{\circ}$ (fig. 62B); this is thought to be because:

1- The components of gravitational force oriented normal to $\left(F_{n}\right)$ and parallel to $\left(F_{p}\right)$ the mine roof (and dip of bedrock), are reduced by:

$$
\begin{aligned}
& F_{n}=F_{g} \cos (\theta) \\
& F_{p}=F_{g} \sin (\theta)
\end{aligned}
$$

where $F_{g}$ is the gravitational force and $(\theta)$ is the dip of bedrock

2- Joints dipping normal to bedding are much more stable in steeply dipping rocks than in gently dipping rocks,

Figure 60 (left and below). Cross sections and photograph showing how faults can control subsidence area. A, Building protected from subsidence because fault dips more steeply than limit line (as defined by limit angle, $\phi$ ). $B$, House damaged even though it is located outside normal limit of subsidence, because fault dips less steeply than limit line. Modified from Briggs (1929, p. 22). C, Renewed offset (of as much as $1.2 \mathrm{ft}$ ) along a fault that transects a subsidence area near Salina, Utah.

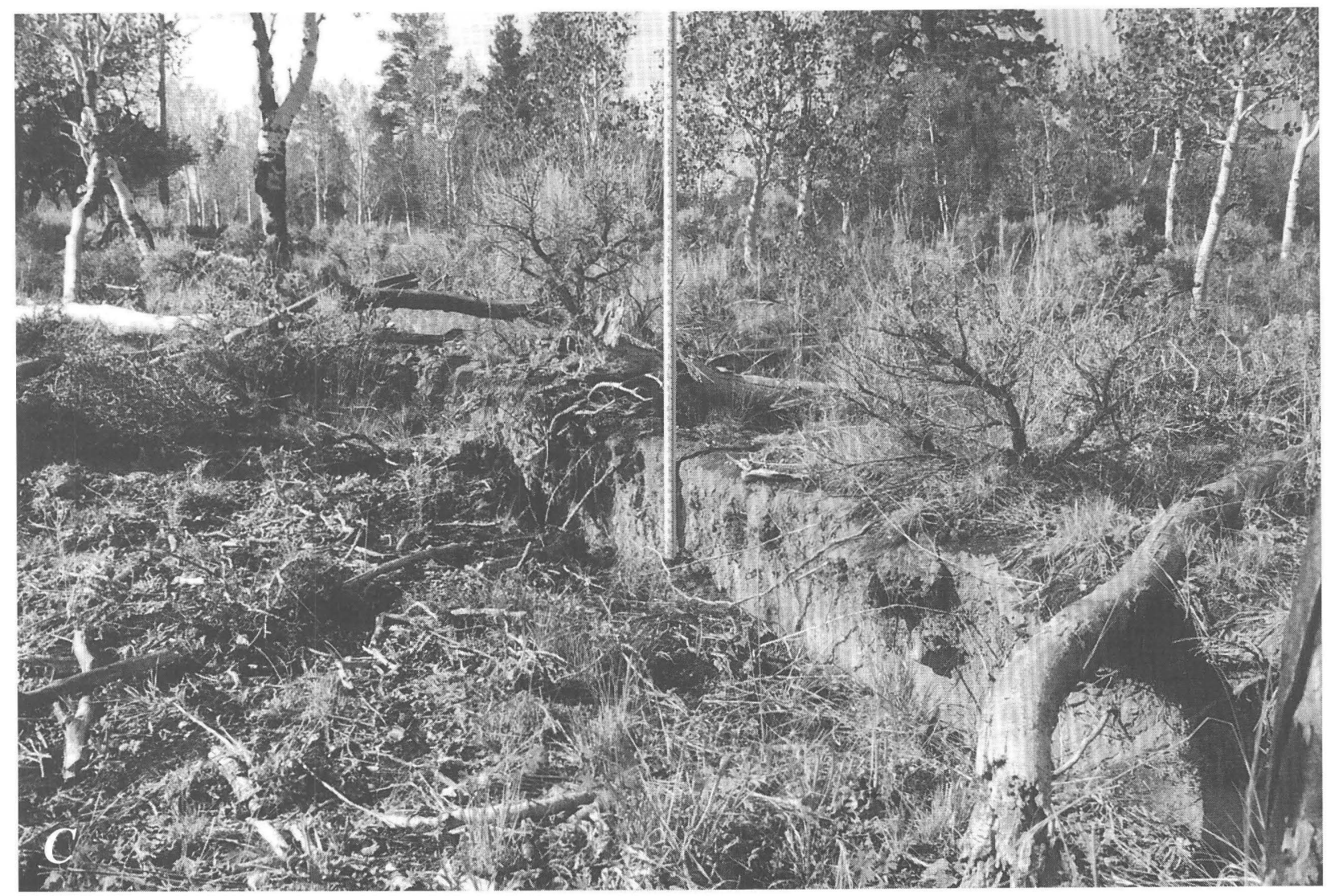


because they are constrained by the component of gravitational force parallel to bedding and the mine roof $\left(F_{p}\right)$ (fig. 62B), and the joint planes also are inclined by the dip angle to the maximum gravitational force $\left(F_{g}\right)$

4. Subsidence may continue for many years or even decades above room-and-pillar areas where the pillars were only partially removed, or where the pillars or rocks above or below them eventually yield to overburden stress where the strength of the coal and roof and floor rocks decreases with fluctuating ground-water levels and (or) with time

II. Stoping

A. Consists of successive caving of the roofs above individual mine openings (haulageways, aircourses, adits, rooms, and crosscuts) where the tensile, compressive, or shear strength of the rock is exceeded; the strength of the rock can be reduced by wetting and drying associated with fluctuating water tables, by reduction in confining stress (stress relief), or by time-dependent deformation such as creep and strain softening of rocks at or near the free-air interface

B. Stoping occurs where:

1. Layered rocks undergo large vertical deflections in short lateral distances (large bending moments) over short to long time intervals (figs. 51A, 63A, 64A-C)

2. Sudden en-masse failure of thickly layered rocks or of thinly layered rocks that have been bolted occurs by failure along fractures, slickensided surfaces (fig. $41 B$ ), and by arching failure (figs. $41 D, 44 B, 51,63 B$ )

3. Tensile failure also may occur where rocks are cantilevered into the mine openings and where the stresses produced exceed the strength of the rock beam element
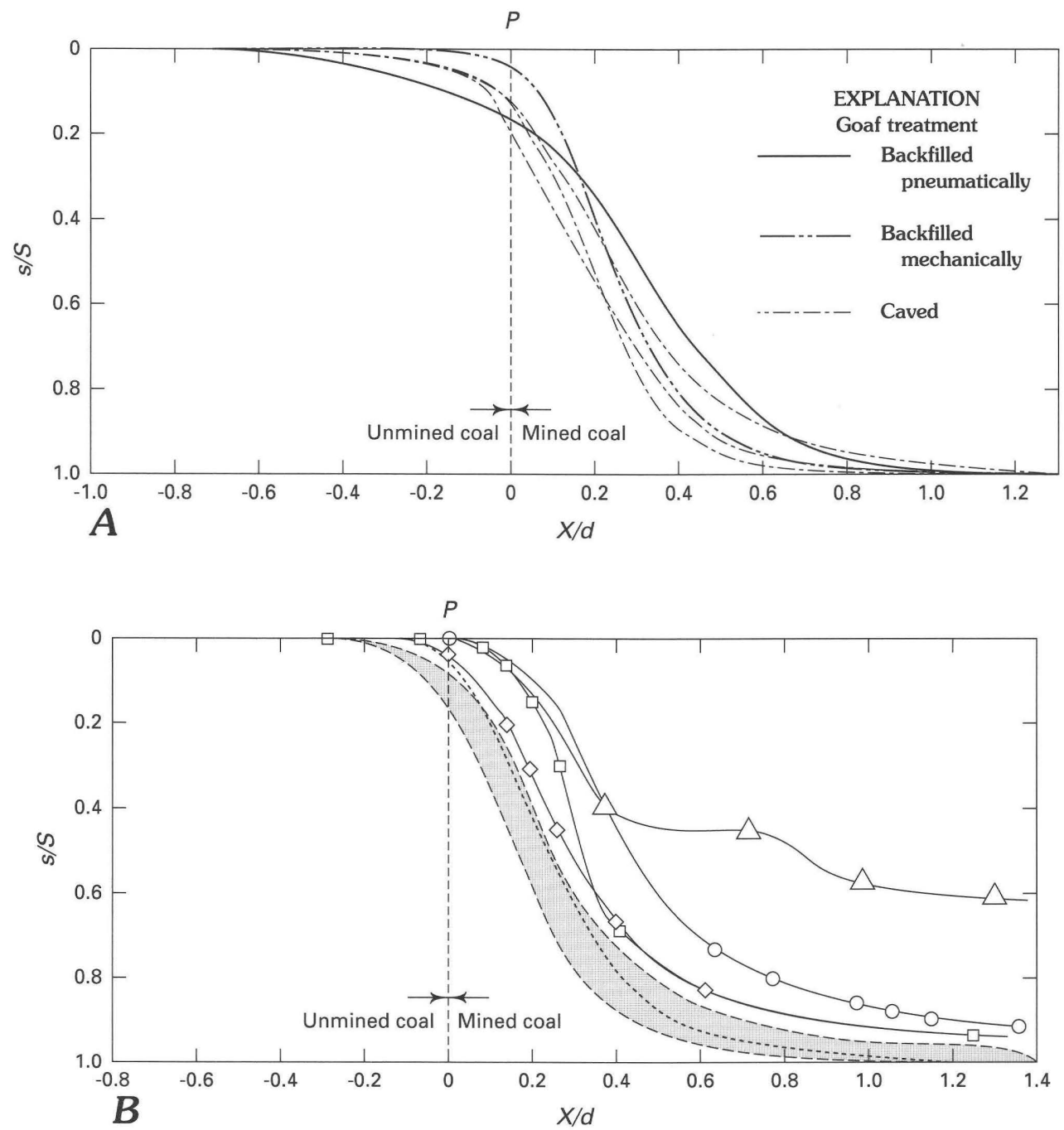

Figure 61. Subsidence development curves for longwall and room-and-pillar extraction panels in Western United States and the United Kingdom. A, Graph of $s / S$ (ratio of vertical displacement at point of measurement to maximum vertical displacement) versus $X / d$ (ratio of horizontal distance between mining face and point of measurement at ground surface $(\mathrm{P})$ ) in the United Kingdom for caved and backfilled longwall panels. $B$, Graph of $s / S$ versus $X / d$ in western Colorado (circles and triangles), central Utah (squares and diamonds), and northern New Mexico (dotted line); patterned envelope contains subsidence development curves for caved and mechanically backfilled longwall mines in the United Kingdom. From Dunrud (1984, p. 164). 


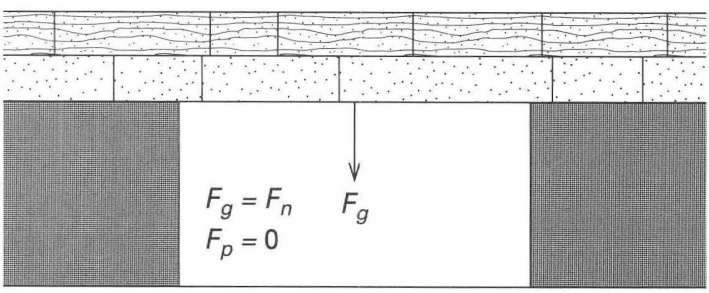

A

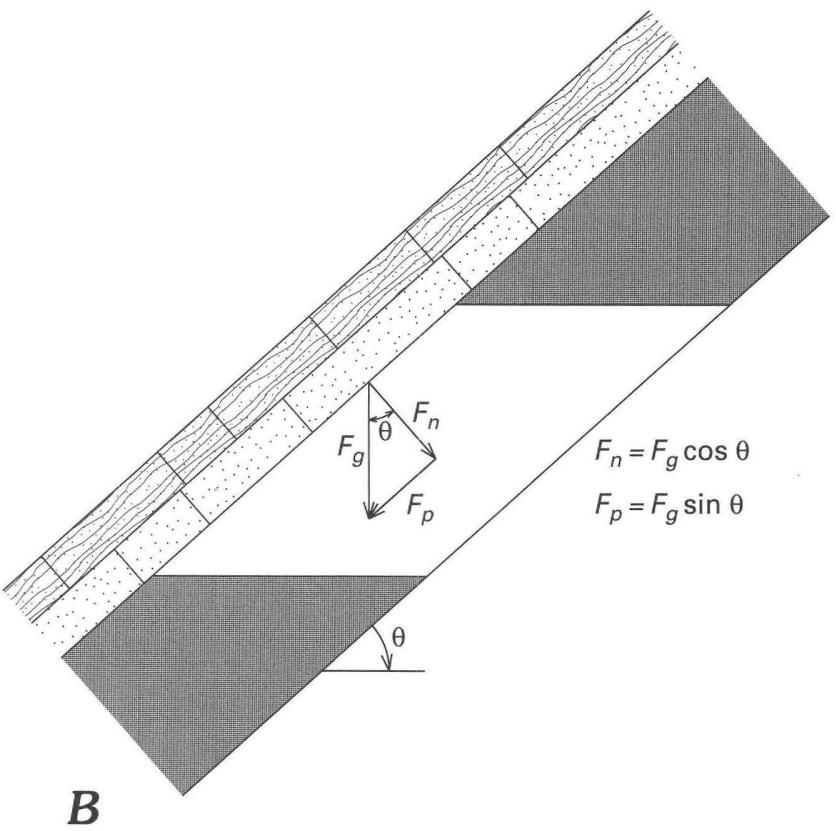

Figure 62. Cross sections of coal mine openings showing changes in stability with dip of a jointed roof. $A$, Cross section of mine opening with jointed roof in rocks with horizontal attitude. $B$, Cross section of mining opening with jointed roof similar to $A$, but in steeply dipping rocks of the Newcastle-Issaquah area, King County, Wash; $F_{g}$, gravitational force; $F_{n}$, component of gravitational force normal (perpendicular) to bedding (dip of bedrock, $\theta$ ); $F_{p}$, component of gravitational force parallel to bedding.

C. The mine openings begin to move upward beneath an increasingly higher arch as the roof rocks break and fall to the mine floor (figs. 51, $64,65)$

1. The volume of the openings commonly decreases as they move upward because the fragments occupy more space than the equivalent mass of rock in place (bulking) (fig. 66A)

a. The bulking factor of small caved fragments of shale, for example (fig. 66B), commonly is less than it is for large blocks of jointed sandstone and siltstone (fig. 66C)

2. Stoping continues intermittently until the cavities become filled with caved rock fragments, or until a strong rock unit (sandstone, limestone) is reached and the caving process is halted, or until the ground surface is reached and a pit (also called sinkhole, cave hole) occurs (fig. 67)

a. In profile, the stoped cavities tend to widen where soft, saturated material is encountered (for example, Karmis and others, 1982, p. 118) and become narrower where hard rocks (sandstone, limestone) occur (fig. 64C)

3. The maximum stoping height depends on the height of the mine opening, the bulking factor, and the geometric shape of the caved opening, but commonly is less than about 10-15 times the thickness of coal mined (fig. 66)

a. The height of caving for an average bulking factor of 0.25 (that is, the bulked fragments occupy a volume 25
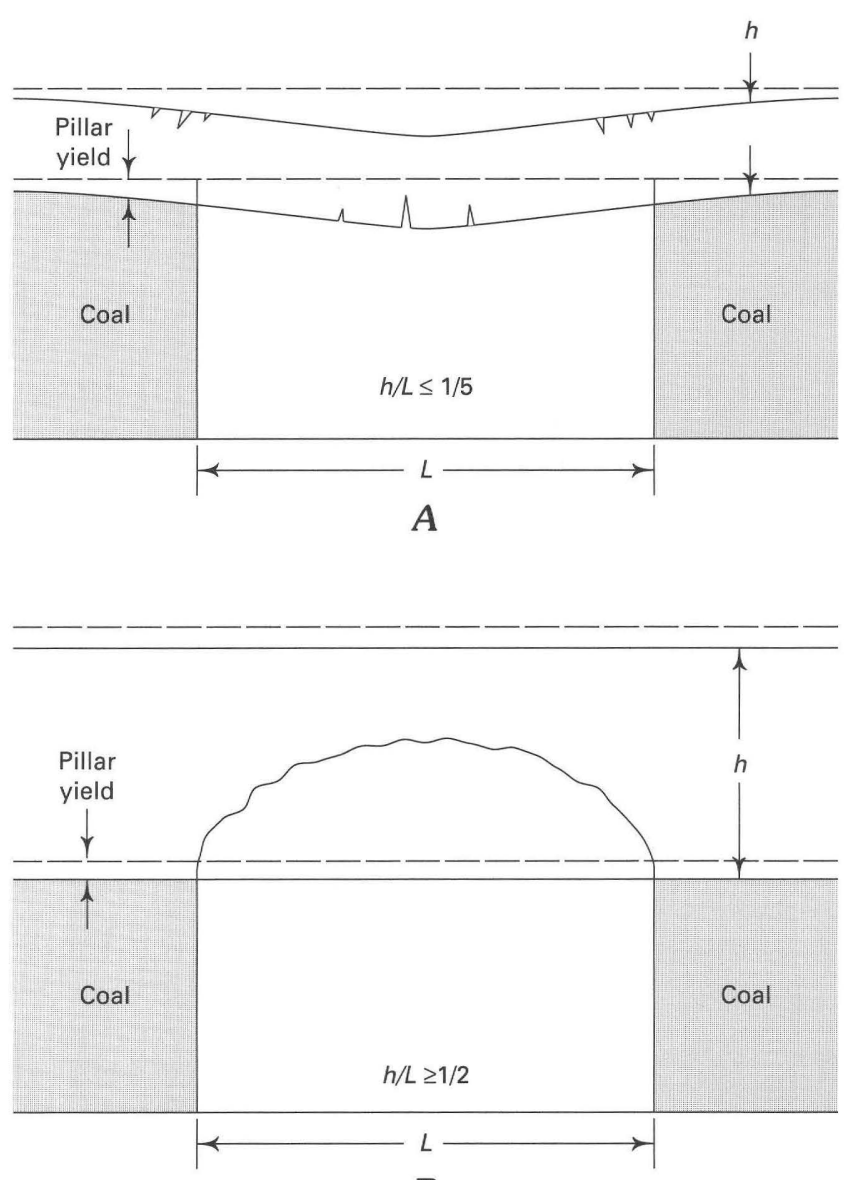

B

Figure 63. Initial stages of stoping in thinly and thickly layered rocks. Initial caving is occurring where: $A, h / L$ is less than or equal to $1 / 5 ; B, h / L$ is greater than or equal to $1 / 2 ; h$, thickness of roof rock behaving as a unit, $L$, unsupported distance (width of mine opening). 


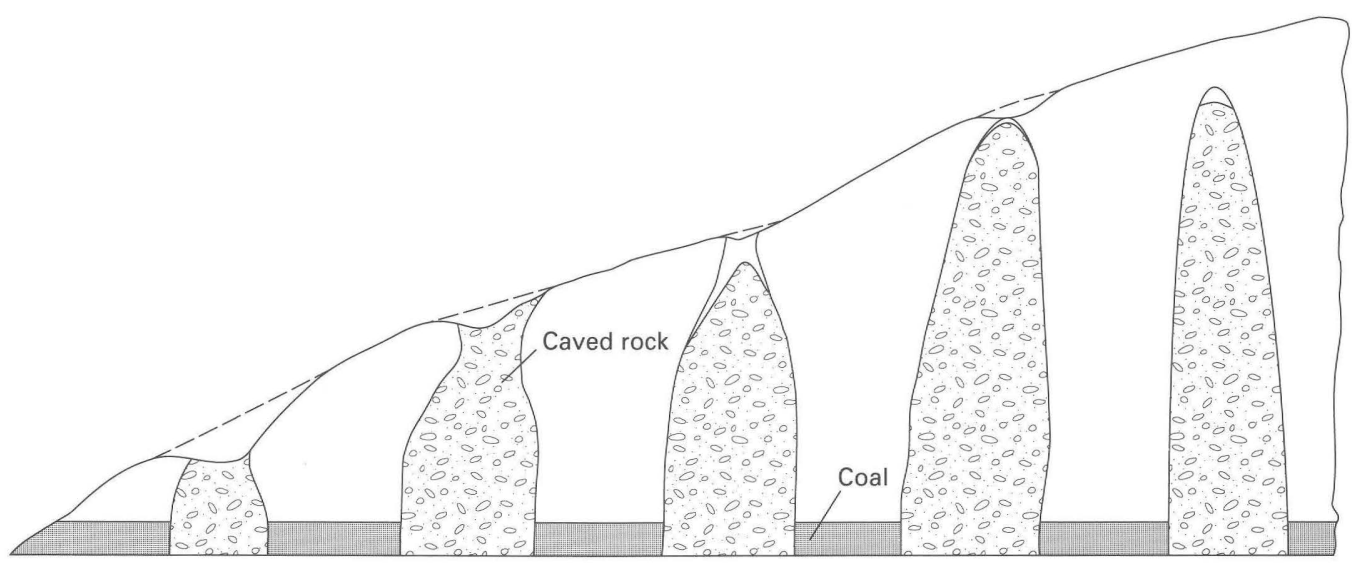

A
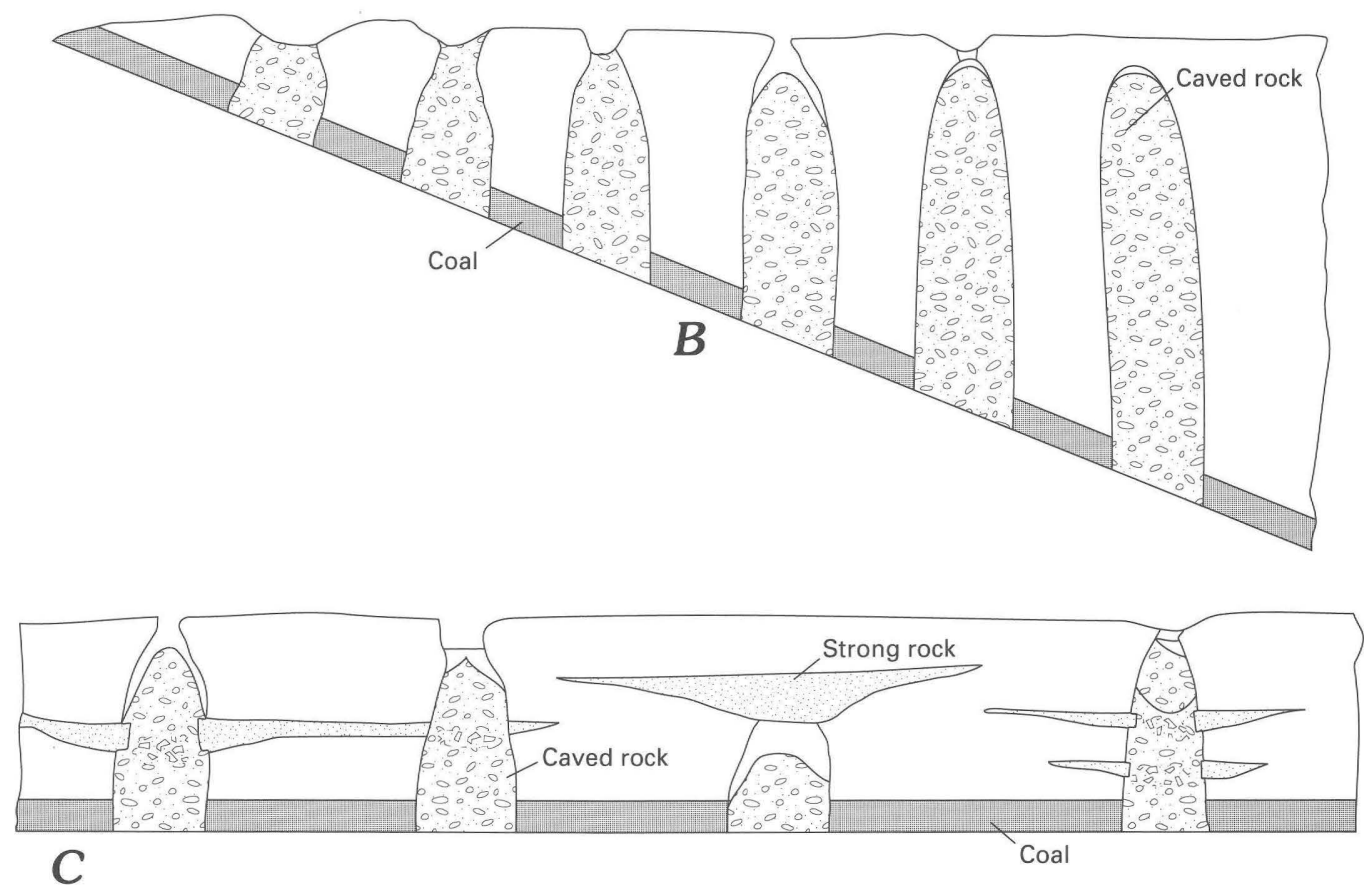

Figure 64. Stoping limits controlled by $A$, topography; $B$, structure (dip of coal); $C$, lithology (local presence of strong rocks). From Dunrud (1984, p. 169).

percent greater on the average than the in-place rock) for the various caving geometries (fig. 66A) is approximately:

1 - $4 t$ for a rectangular prism $(t=$ thickness of coal mined)

2- $6 t$ for an ellipsoid

3- $8 t$ for a wedge

4- $12 t$ for a cone

b. The actual bulking factor varies from least (most dense packing framework) to greatest (least dense packing framework) from the base of caved rubble upwards due to self-loading and compaction

4. Stoping can occur above mine openings where the adjacent pillars are stable

D. The pits may be deeper than the thickness of coal mined (in contrast to downwarped areas where subsidence is less than the mining thickness) where the stoped material can move laterally into mine openings adjacent to the stoping areas, especially at or near intersections of mine openings or where mine openings are parallel to steeply dipping coal beds below the water table 


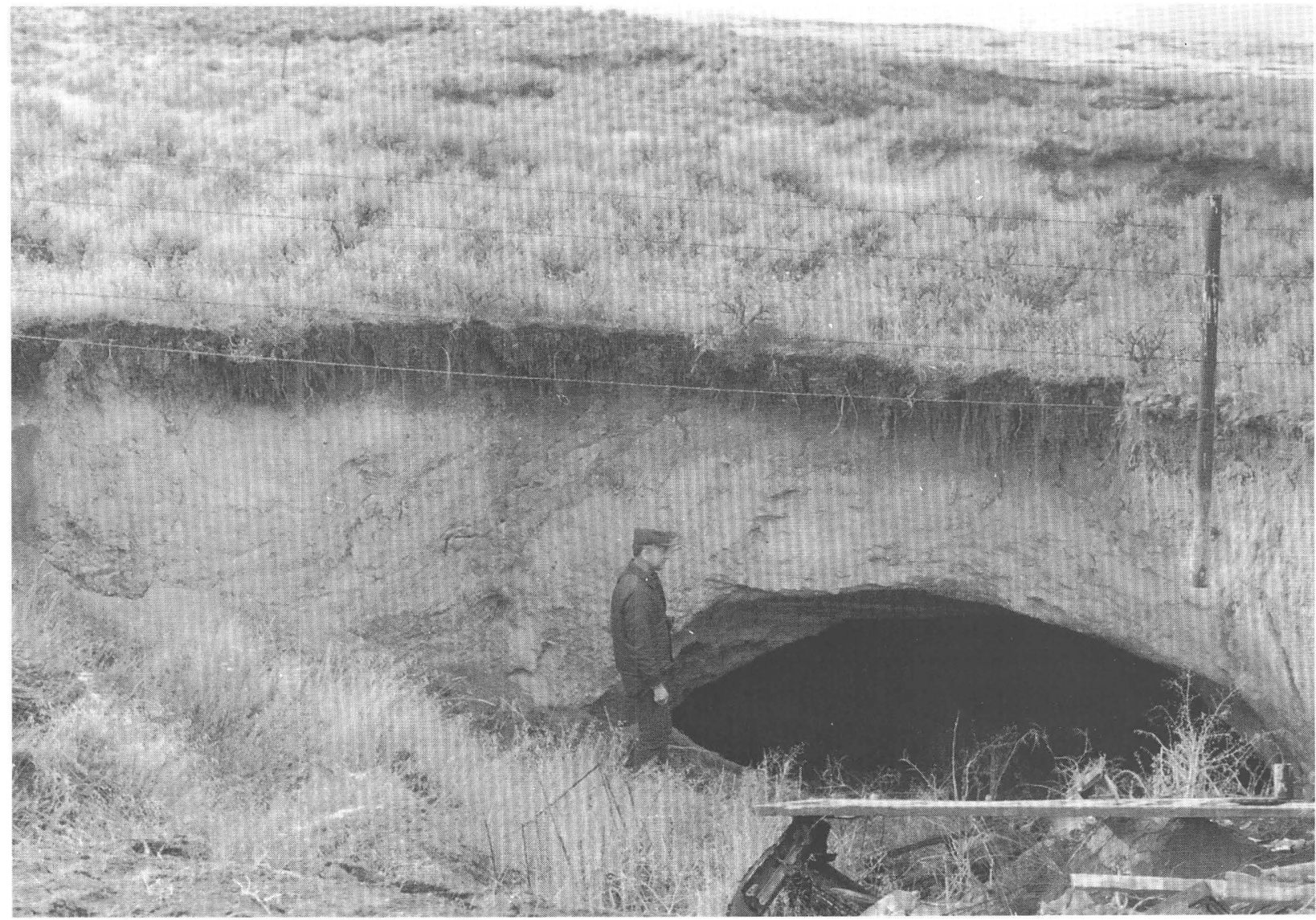

Figure 65. Photograph showing stoping process in the Sheridan, Wyo., area. Underground cavity, right foreground, is connected with a reclaimed subsidence pit in access road (immediate left foreground); cavity has moved upward to within 5-6 ft of the surface. Overburden is about five times the thickness of coal mined. From Dunrud and Osterwald (1980, p. 21).

E. The area affected by the initial subsidence pits, which may eventually form where the overburden thickness is less than the stoping height, is less than, or about equal to, the area of the mine opening that caused them (fig. 64)

F. The time required for pit development varies greatly because stoping is dependent on roof support, strength of rocks, ratio of strong to weak material in overburden, dip of bedrock, thickness of the overburden, and confining stress

1. The time can vary from a few decades to many decades, or even centuries in the United Kingdom, according to Littlejohn (1979, p. 22)

2. The stoping rate commonly is much slower through strong, hard limestone or sandstone that contains a strong siliceous or carbonate cement or matrix than the rate through soft, weak mudstone or shale
3. Van Besien and Rockaway (1987) found that the mean duration (time delay between mining and the beginning of subsidence) in 45 areas above abandoned coal mines, primarily in the Eastern United States, was 57.2 years

4. Matheson (1987) concluded, for 85 abandoned mines in the Boulder-Denver-Colorado Springs area, Colorado, beneath weak overburden, that:

a. A period of major subsidence (including downwarping and stoping) commonly occurs for 20-30 years

b. Subsidence continues to occur at a relatively low rate after the 20-30 year period

c. Numerous underground voids can remain after the major subsidence is complete (thus total subsidence may still not be complete) 


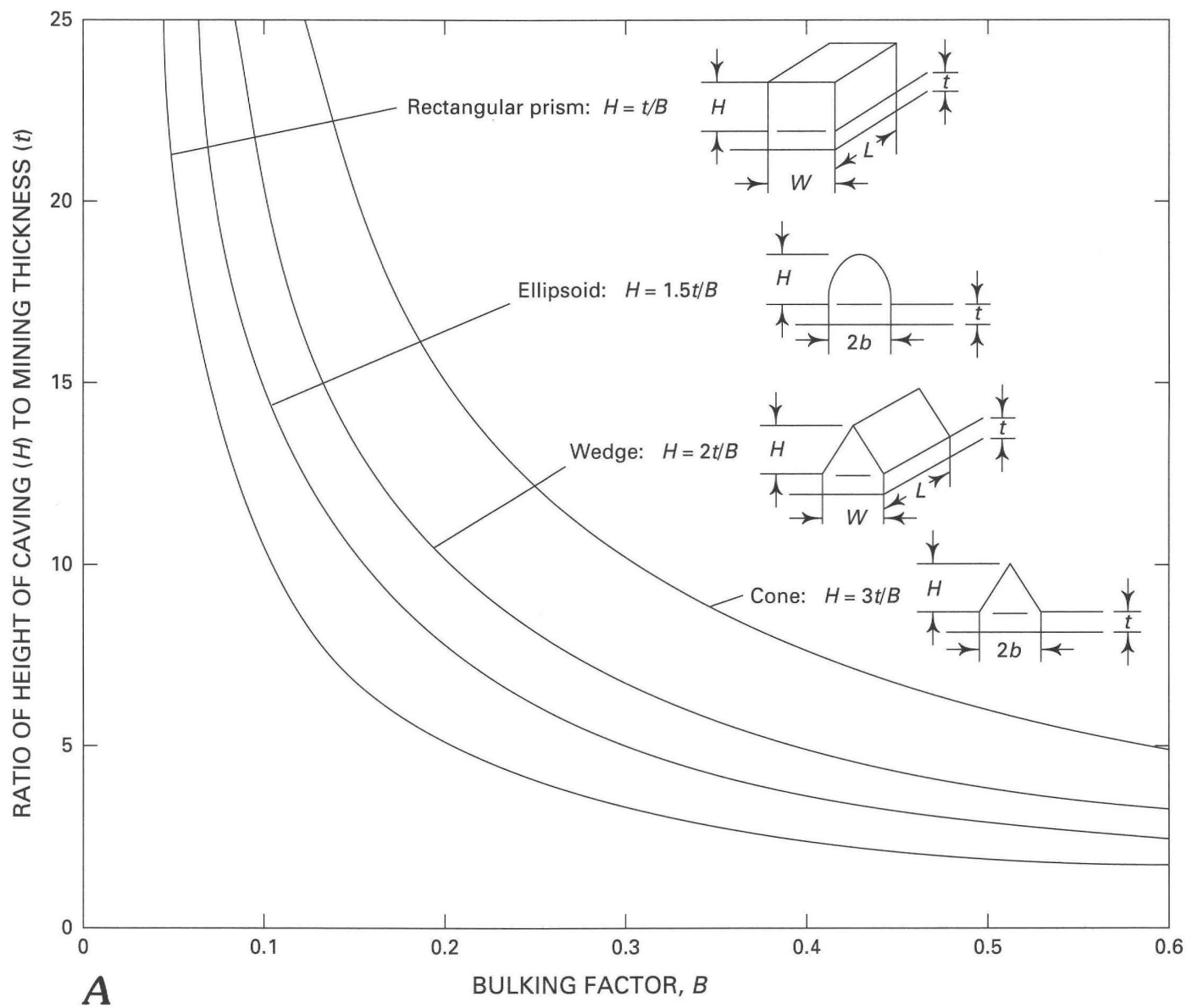

$$
B=\frac{V_{C}-V_{O}}{V_{O}} \quad \begin{aligned}
& V_{O}=\text { Volume of rock before caving } \\
& V_{C}=\text { Volume of rock after caving }
\end{aligned}
$$

SAMPLE CALCULATION:

ELLIPSE: $B=\underline{\left[(4 / 3)(1 / 2) \pi H b^{2}+\pi b^{2} t\right]-(4 / 3)(1 / 2) \pi H b^{2}}$

$(4 / 3)(1 / 2) \pi H b^{2}$

$$
B=\frac{\pi b^{2} t}{2 / 3 \pi H b^{2}}=\frac{t}{2 / 3 H}, \quad H=3 / 2 t / B=1.5 t / B
$$

Figure 66 (above and facing page). Geometric and lithologic aspects of the stoping process. A, Maximum height of stoping due to caving, bulking of caved material, and caving geometry. $H$, maximum height of stoping; $t$, thickness of coal mined; $W$, width of mine opening (prism and wedge); $b$, radius of mine opening (ellipsoid and cone). From Dunrud (1984, p. 160). B, Cavity filled with caved debris consisting of shale and siltstone; height of cavity is about three to four times the thickness of coal mined (width of view about $8 \mathrm{ft}$ ). $C$, Caved opening above mine entry (width of view about $12 \mathrm{ft}$ ). Caved fragments, which consist of well-cemented siltstone and finegrained sandstone, are larger and more blocky than caved material in B. Mine workings driven 50-70 years prior to date of photographs (1979). From Dunrud and Osterwald (1980, p. 25). 

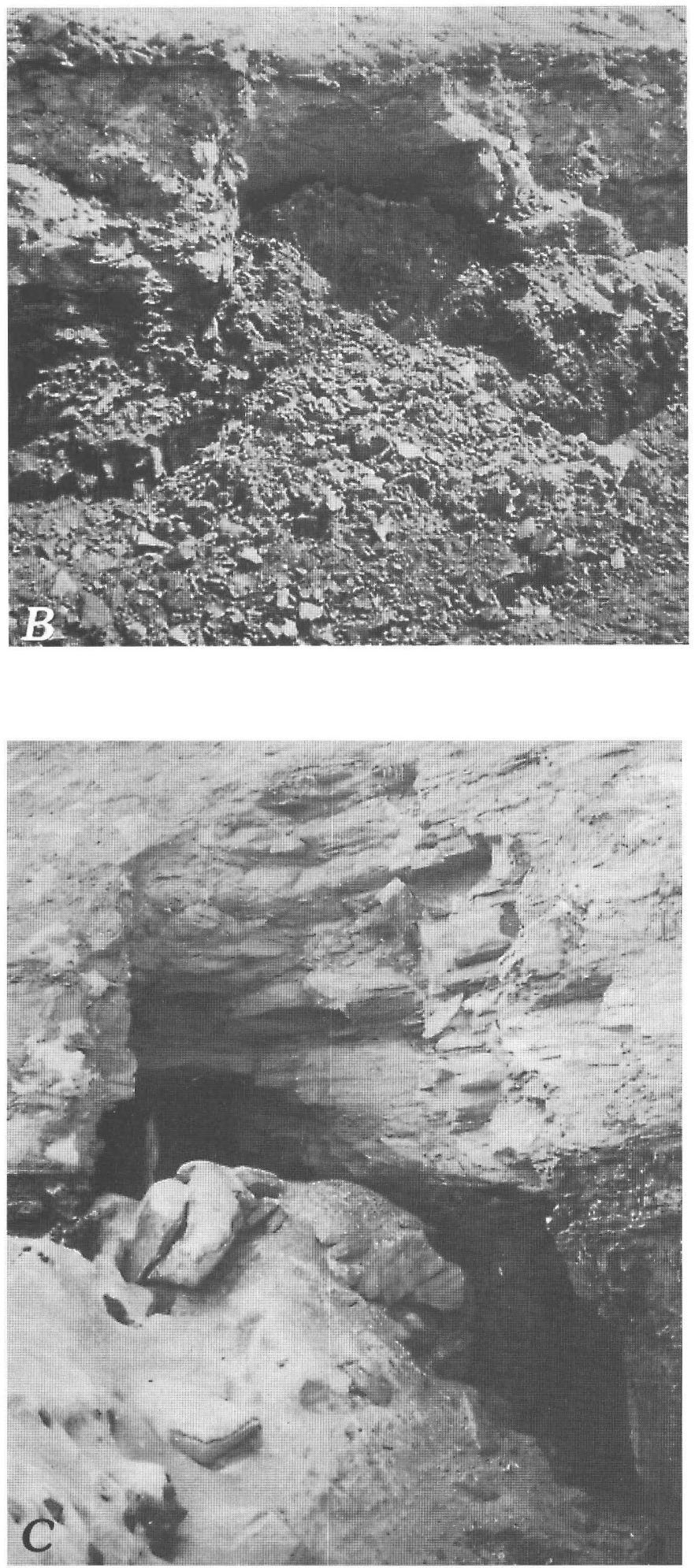

5. The stoping rate can be much slower for steeply dipping rocks than for gently dipping rocks (fig. 62) because:

a. The gravitational component normal to bedding $\left(F_{n}\right)$ decreases, and the component parallel to bedding $\left(F_{p}\right)$ increases as the dip increases

b. Joints oriented normal to bedding become more stable because of increases in the lateral constraint $\left(F_{p}\right)$ and because the joint planes are inclined to the gravitational force $\left(F_{g}\right)$

6. The stoping rate can increase greatly, for overburden of a given strength, where the overlying surface is subjected to vibrations from heavy vehicles, machinery, blasting, and seismic activity

a. In the Sheridan, Wyo., area, for example, mine openings had been stable for about 40 years at a depth of about $60 \mathrm{ft}$, but stoping occurred to the surface in a mine haul road after only 6 months of traffic by heavy vehicles and road grading machinery

b. In this same area, vibrations caused by the stoping process appeared to increase the stoping rate and rate of pit formation above nearby mine openings

G. Pits can form suddenly and without warning by en-masse failure (sometimes called chimney failure) of near-surface material where the cavities have moved upward to within a few feet of the surface and the rocks or surficial materials are softened by water and (or) heat and steam from underground coal fires (fig. 67)

1. In areas where there are no fires to soften the overburden by heat and steam, pits would be most likely to develop after periods of high precipitation (for example, Bruhn and others, 1978)

2. This type of failure is a severe hazard to life and property, particularly where methane accumulations or noxious or toxic gases from underlying coal fires are suddenly emitted through the newly formed pits (fig. 67)

H. Downwarping and stoping can both occur where the overburden thickness is less than the maximum height of stoping (thickness less than 10-15 times the thickness of coal mined), where 



Figure 67. Potentially hazardous, sudden pit development. Pits have occurred without warning in this area where stoping height is less than overburden thickness. $A$, Initial stage of pit development above a coal mine fire in the Sheridan, Wyo., area; pit, which is only a few days old, is about $12 \mathrm{ft}$ deep and has overhanging rims; any person or animal that falls into pit cannot escape without assistance. $B$, Later stage of pit development; pit, a few months old, is about $12 \mathrm{ft}$ deep, has vertical rims. Pit in foreground is interconnected by tunnel with another pit like $A$ (background). Bedrock and surficial material were softened by heat and steam from the fire, and by precipitation. Toxic chemicals (carbon sulfides and carbon monoxide) were monitored in a nearby coal mine fire area (Dunrud and Osterwald, 1980, p. 31-32). 
the unmined pillars do not support the weight of the overburden, and where stoping can extend to the surface above the cavities that are present after pillar yield

III. Block Movement

A. Consists of vertical displacement and (or) rotation of large blocks of overburden in areas where lateral constraint and vertical support are reduced (fig. 68A-C)

1. Vertical displacement can occur along faults or extensive joints near cliffs or steep slopes where coal pillars left at the outcrop do not have sufficient strength to support the overburden

2. Both rotation and vertical displacement can occur where coal barrier pillars are strong enough to support the overburden, but where coal pillars left at outcrops near cliffs or steep canyon walls do not have sufficient strength to support the overburden (fig. 68A-C)

B. Cracks formed by block movement commonly are wider and more continuous than cracks formed by downwarping; cracks formed by block movement often are continuous from the mine to the surface (figs. $51 D, 68 D$ ), whereas the cracks formed by downwarping commonly occur in zones of maximum extension and may only extend to the neutral surfaces of the rock units that deform as plates (figs. 51, 55)

1. Surface and ground water can readily be transmitted and intermixed with other aquifers and to the mine through cracks caused by block movement

2. Mine ventilation may also be disrupted by the cracks

IV. Mine Shaft Failure (see, for example, Taylor, 1975, p. 131-133; Littlejohn, 1979; and Down and Stocks, 1978, p. 238-240)

A. Subsidence pits have caused severe hazards above or near shafts that were not filled, were not adequately designed, and where:

1. Shaft caps, which are located at ground level, fail by mass wasting, or erosion, or are damaged by vehicles or vandals

2. Shaft plugs, which are located below ground level, fail by rotting (if made of wood) or by spalling or breaking where human activities, wetting, mass-wasting, and (or) erosion increase vulnerability

3. The shaft walls or linings below the caps or plugs fail by rotting, cracking, and breaking

B. Current designs to prevent eventual hazards of shaft failure include the following systems:

1. Completely fill the shafts with inert, nontoxic material and cap the fill with a reinforcedconcrete slab (system probably stable unless ground-water flow eventually causes underground erosion of the fill material) (see, for example, Down and Stocks, 1978, p. 239)

2. Cap open shafts below ground level with circular or pentagonal, reinforced-concrete slabs with a minimum dimension of twice the diameter of the shafts and 2-3ft thick; ensure that the shaft lining below is stable; construct a vent pipe in the cap to prevent gas buildup; backfill the slab above ground level, and erect a permanent marker with a hazard sign (system probably stable for about a century)

3. Use other procedures, such as inserting a metal cone with a maximum dimension of about 1.5-2 times the shaft diameter filled with concrete, installed below ground level, and marked as in 2 above (system was used by the Office of Surface Mining (OSM) in the Pittsburg-Nortonville area, Calif., in the early 1980 's to plug a deep, abandoned coal mine shaft)

4. All shafts should be located on county, State, and (or) Federal maps for future land-use planning

C. The geologic and geotechnical properties of the rocks in which the shafts are located play an important role in the overall shaft stability; for example:

1. Shafts driven in strong, hard rocks which bear little or no water and are not subject to slaking from damp mine air, such as sandstones cemented with carbonates, limestones, and hard, durable shales, and capped with reinforced concrete caps or concrete cone plugs, are likely to be stable for centuries

2. Shafts driven in weak, soft rocks and rocks that transmit large volumes of water, such as mudstones and soft marlstones and shales alternating with poorly cemented, permeable sandstones, are likely to become unstable in perhaps a decade, unless completely filled with nontoxic material that will not deteriorate in time when saturated; failure could occur in the lining and cap or cone plug, particularly near the contacts between waterbearing sandstones and weak rocks

\section{COAL MINE FIRES AND EXPLOSIONS}

I. Ignition of Fine Coal Dust and (or) Methane

- Caused primarily by sparks or by spontaneous combustion of coal dust in active or abandoned mines (for example, Hertzberg and others, 1979) 


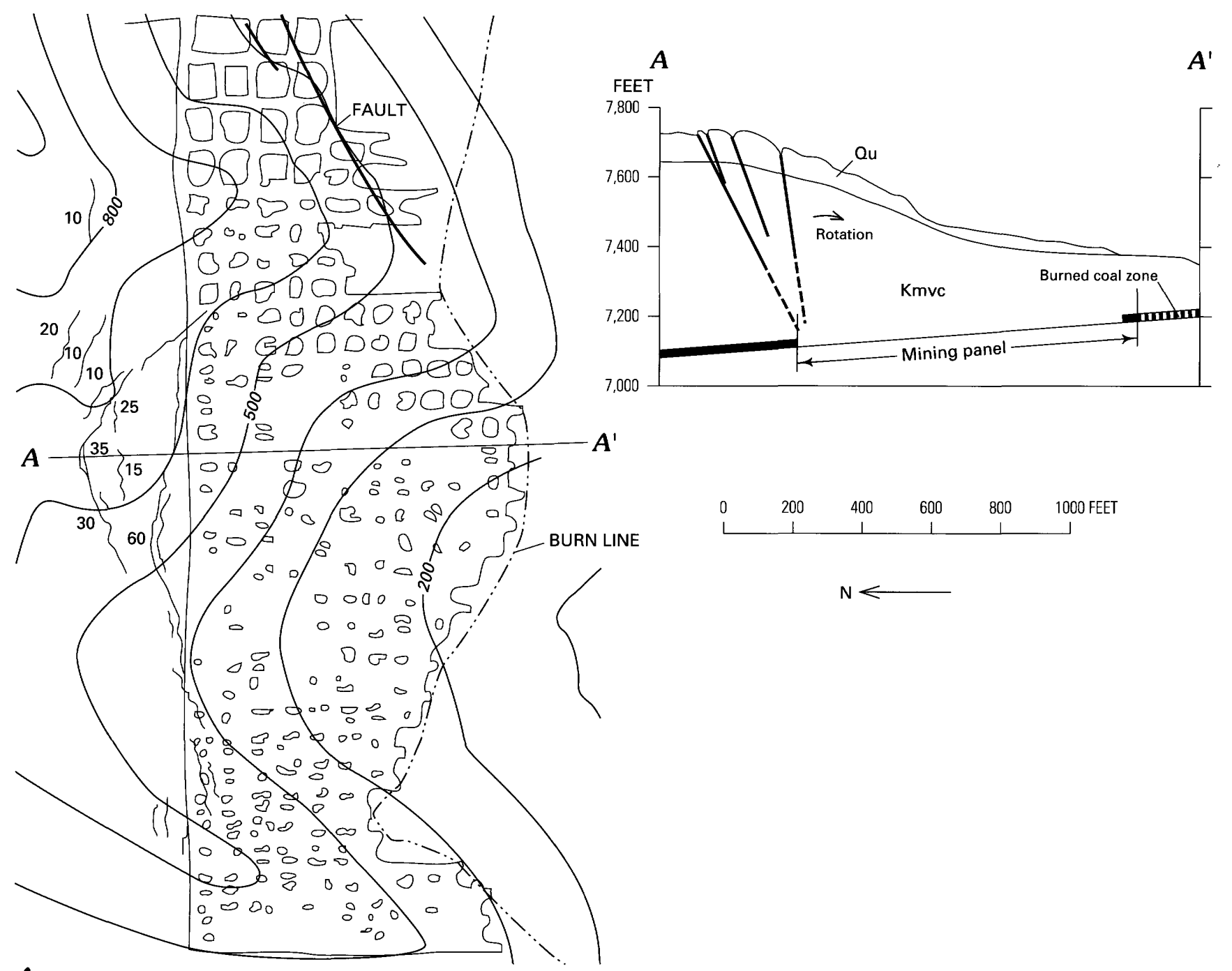

A

Figure 68 (above and following pages). Block movement above underground coal mines in Colorado and Utah. A, Map and cross section in the Paonia, Colo., area showing the relation between a room-and-pillar extraction panel and tension cracks (solid wavy lines) which developed in the overburden (overburden thickness contour interval=100 ft); numbers by cracks indicate maximum width in centimeters; $K$ mvc, coal-bearing member of the Mesaverde Formation; Qu, unconsolidated deposits consisting primarily of clay and basalt boulders. B, Map and cross section showing rotation and vertical movement above a mine near Huntington, Utah. Base map prepared by author by photogrammetric methods (1983). Qc, Quaternary colluvium; QI, Quaternary landslide; Kpr, Upper Cretaceous Price River Formation; Kc, Castlegate Sandstone; Kb, Blackhawk Formation; Ksp, Star Point Sandstone.

A. Fire and explosion potential increases with increasing methane content and increased fracturing of the coal, which increases the permeability and allows the gas to be released rapidly into mine workings

1. In the mining areas of Bosnia-Hertzegovina, [former] Yugoslavia, methane content in the coal increases with depth and with increasing thickness of the coal bed or zone

2. In the Paonia and Redstone, Colo., areas, the methane content in the coal commonly is greater in areas where high stresses have caused microfracturing and macrofracturing of the coal, such as:

a. Near igneous bodies that have intruded into the coal and associated rocks

b. Near channel sandstone deposits

3. In the United States, the former Yugoslavia, and Brazil, for example, methane is often concentrated to a higher degree than in other areas near or along extensive faults, fault intersections, and joints 


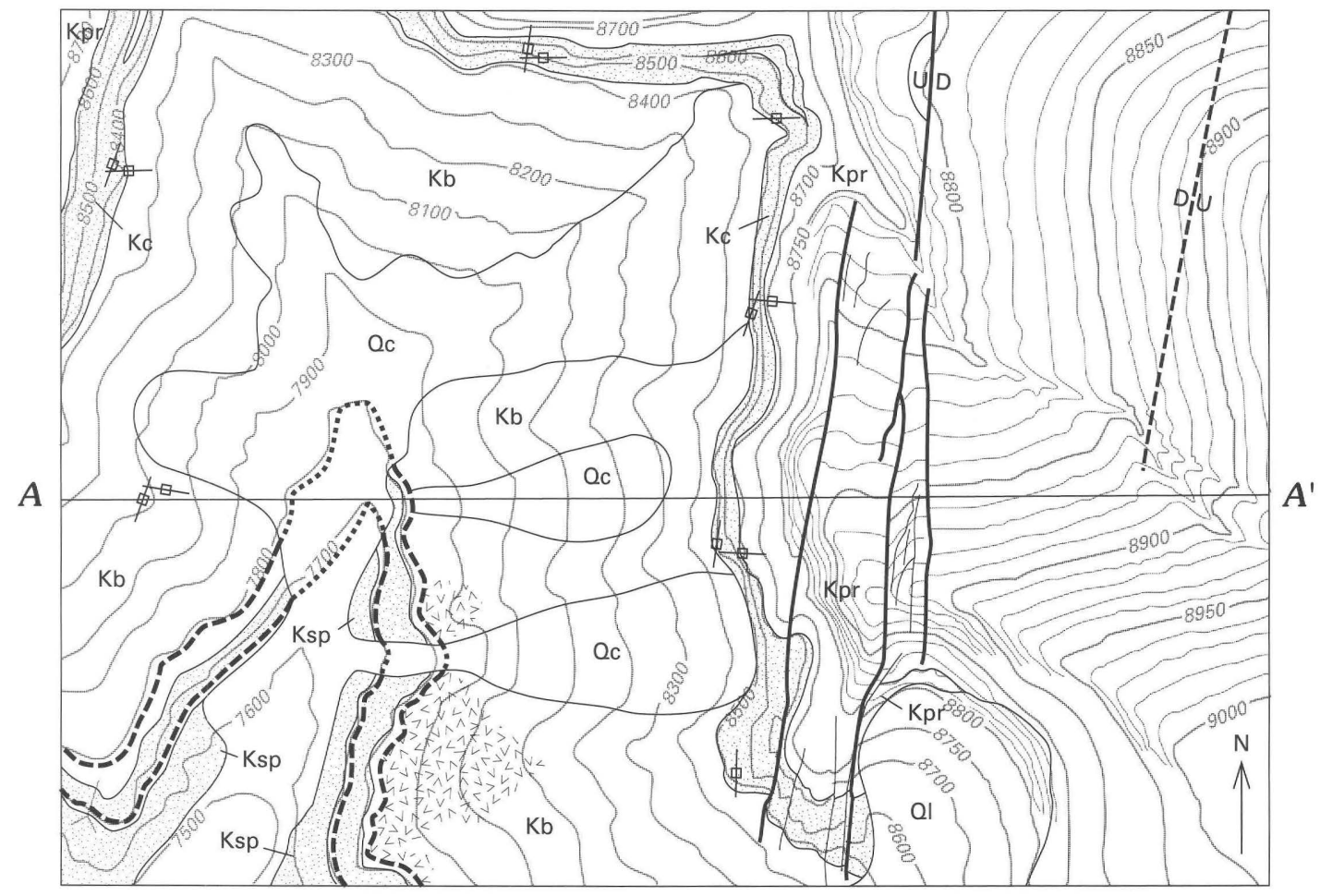

\section{A}

$A^{\prime}$

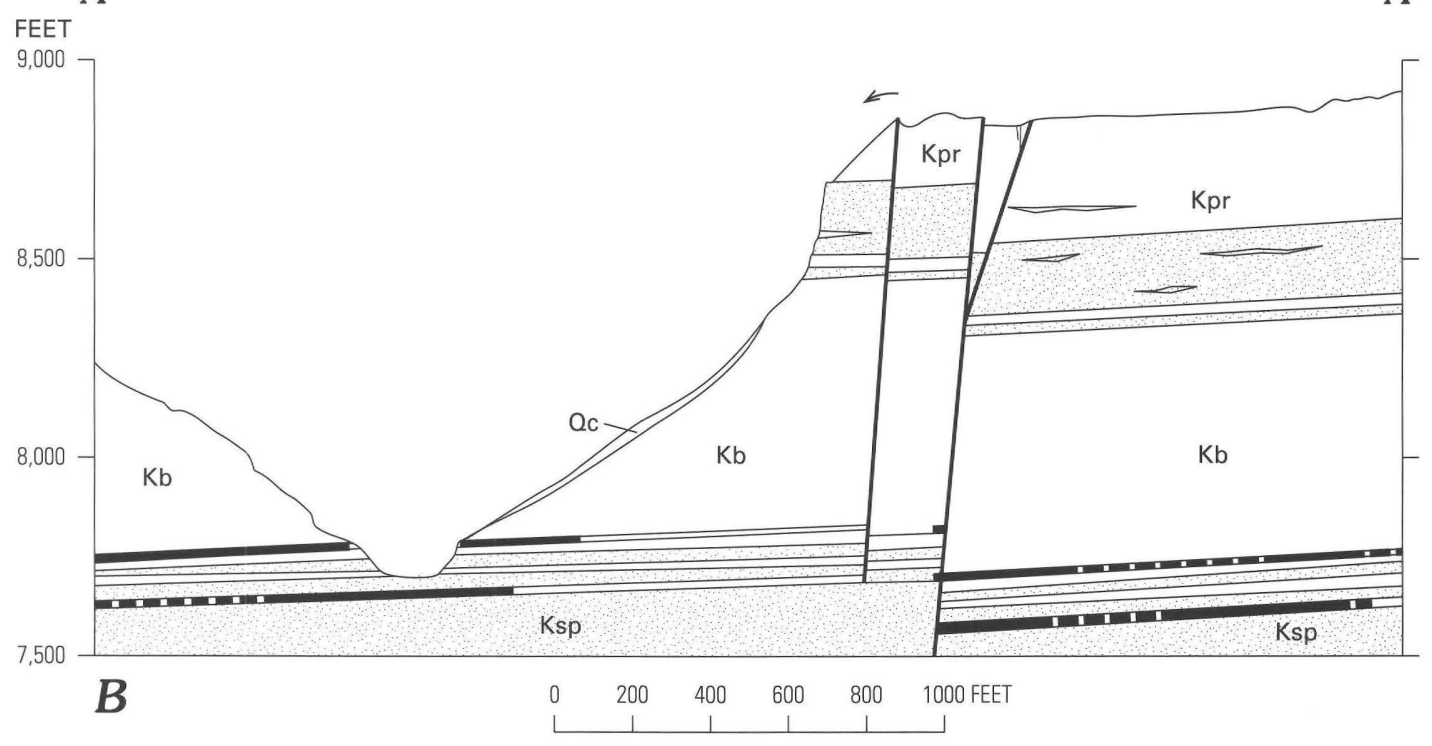

EXPLANATION

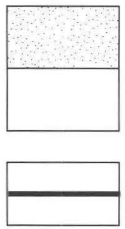

\section{Sandstone}

Mudstone and siltstone with lenticular sandstones

Coal bed on map-Dashed where uncertain, dotted where concealed

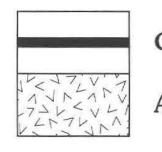

Coal bed in cross section

Area of burned coal beds

\section{Contact}

Fault-Dashed where uncertain;

$\mathrm{U}$, upthrown side;

$D$, downthrown side $\square \quad$ Vertically dipping joints

Extension and locally offset cracks caused by rotation and vertical displacement of overburden rocks

Mine portal 


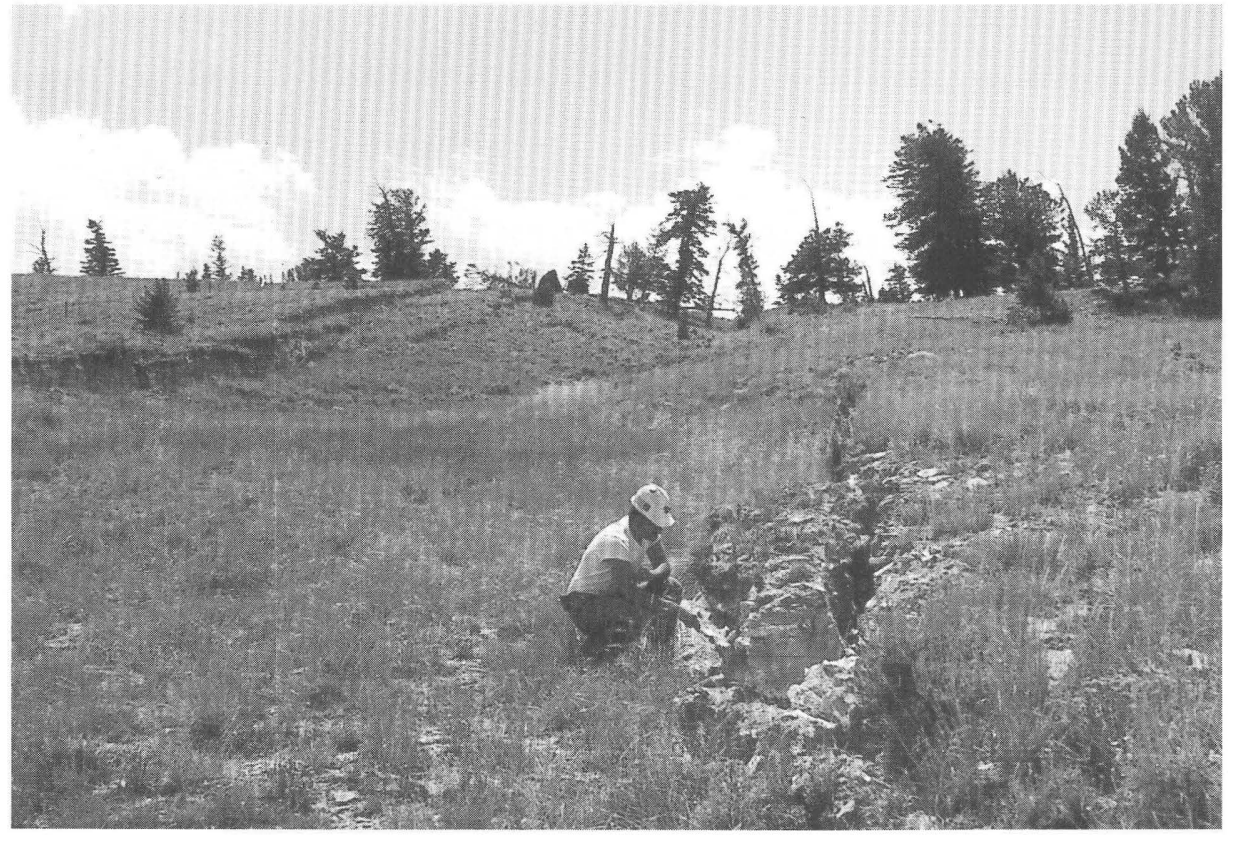

Figure 68-Continued. Block movement above underground mines. $C$, Photographs showing open and locally offset cracks in the Huntington, Utah, area.

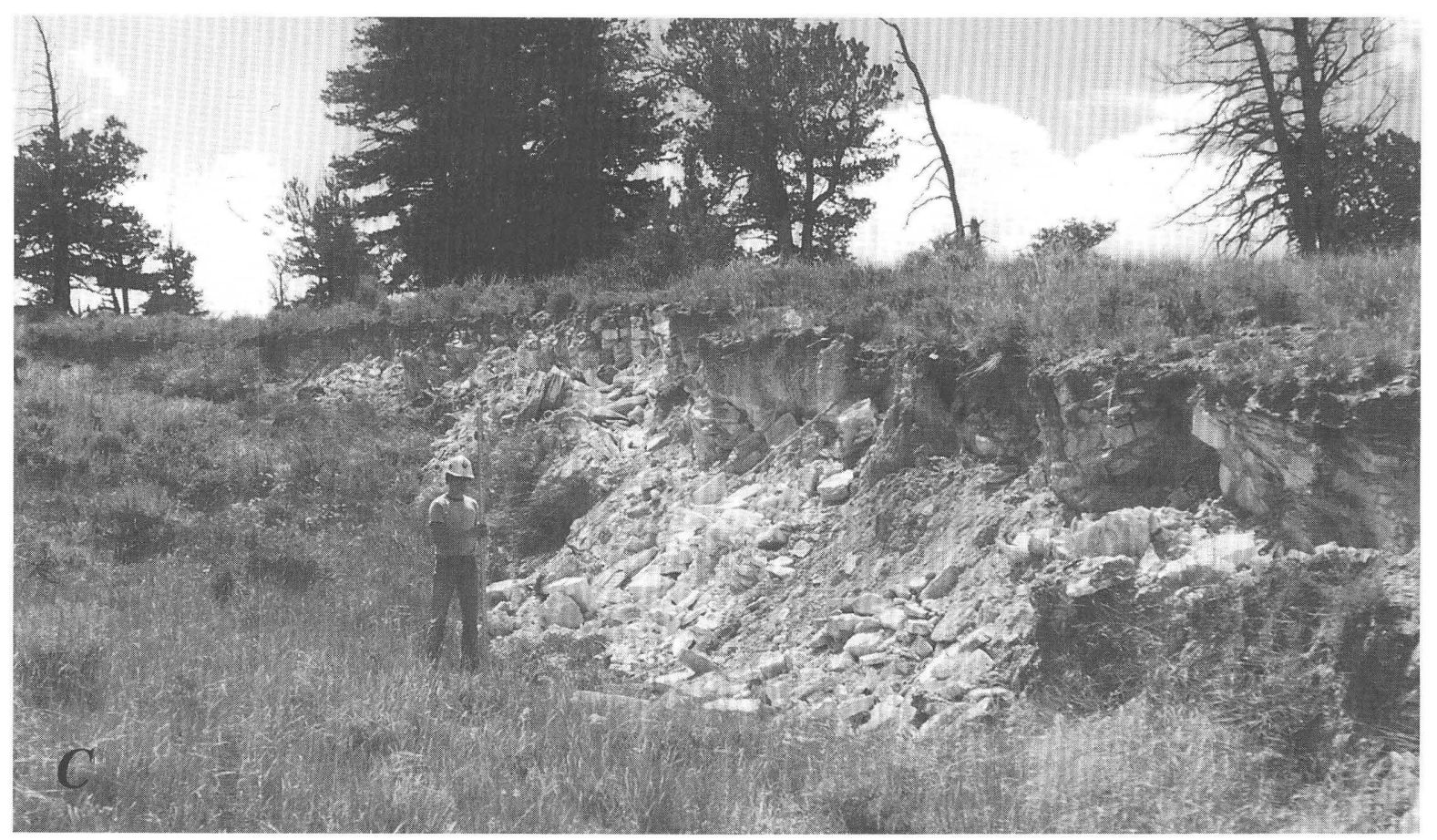

II. Causes and Locations of Explosions in Active Mines

- Caused by sparks or flames from electrical systems (such as trolley wires, electrical switches), welding, drilling, longwall cutters, smoking (Richmond and others, 1983), and overheating of bearings in equipment, such as conveyor belts

A. In many cases, ignition occurs where methane is mixed with fine coal dust floating in the air, such as near continuous mining machines and longwall cutters
B. In some cases, such as in a gassy mine in Pitkin County, Colo., explosions have occurred from ignition of methane and coal-dust mixtures that were the direct result of bumps and outbursts; the methane and coal dust were dispersed over large areas by the bumps and outbursts; in the Pitkin County mine, the resulting explosions caused the deaths of 9 miners on Dec. 31, 1965, and 15 men on Apr. 15, 1981 (Richmond and others, 1983, p. 14-15; fig. 69A) 
C. Many explosions have occurred in mine workings near faults or fault intersections; for example:

1. On Mar. 14, 1970, 50 miners were killed and 39 were injured by a fire and explosion in a double-lift longwall section of a coal mine near Breza, Bosnia-Hertzegovina, [former] Yugoslavia (M. Osmanagić, written commun., 1984) (fig. 69B)

a. The explosion occurred in an entry that was driven up to a fault near the intersection with another fault

b. The ventilation had been shut off for 8 hours, causing an accumulation of 150 $\mathrm{m}^{3}$ of explosive methane-air mixture in a blind entry

c. Miners were sent to the longwall without first checking for methane; within 30 seconds after the ventilator fans were turned on, a spark, static charge, or some electrical defect ignited the explosive mixture

d. Men near the explosion were killed by the blast, heat, and toxic gases (mostly carbon monoxide), but miners many hundreds of feet away from the explosion site were killed by the toxic gases produced by the explosion

2. On Sept. 11, 1984, 34 miners were killed by the first explosion in the history of coal mining in Brazil; the explosion occurred in an underground mine near the town of Criciuma, Santa Catarina, Brazil

a. The explosion occurred in workings near a fault after the ventilation had been shut off for a number of hours

b. About $100 \mathrm{~kg}$ of dynamite, which was stored in the mine area, also was set off by the explosion, causing severe damage to the mining machinery

c. The miners were killed instantly by toxic gases (mainly carbon monoxide) and by the blast and heat as they walked toward the mine area

D. In some cases, explosions have been caused by ignition of fine coal dust, which was dispersed near the face, by sparks from continuous mining machines and longwall cutting devices

III. Two Principal Hazards of Explosions to Miners

A. The shock wave, flying objects, and heat can cause injury or death (for example, Nagy and Mitchell, 1963)
B. Death can occur (within seconds or minutes) from carbon monoxide ( $\mathrm{CO}$ ) poisoning or from an inadequate oxygen supply

1. Carbon monoxide is the main product of incomplete combustion and is nearly always present after an underground explosion

2. Oxygen levels also often are reduced by the combustion process

IV. Reduction of Explosion Hazards in the United States in the Last 50 Years

- There were 1,674 fatalities from 1936 through 1958 , but only 335 fatalities from 1959 through 1981; explosion hazards have been reduced primarily because:

A. Greater volumes of fresh air are now circulated near mining faces, where most explosions originate

B. A transition from $\mathrm{DC}$ power to $\mathrm{AC}$ power has occurred, along with the use of safer electrical equipment

C. Better methane-detection methods now exist in the United States and in other countries

1. In the Breza mine in [former] Yugoslavia, for example, methanometer monitoring systems, which continuously monitor the gases in the mining sections from the surface, will automatically shut off all electrical power when the methane content exceeds 1 percent; these systems have reduced explosion hazards in active mining areas (M. Osmanagić, oral commun., 1985)

2. Such a system prevented a possible serious explosion on Sept. 30, 1982, when a large pocket of methane was released into the Breza mine by a large roof fall, causing a highly explosive mixture to build up quickly on the longwall

a. The volume of methane was so large that it took 10 days to ventilate the section from an explosive level of 9.2 percent methane and 4.1 percent $\mathrm{CO}_{2}$ to a safe level of 1 percent methane, even with ventilation rates doubled (M. Osmanagić, oral commun., 1985)

D. Methane drainage procedures have been used locally to remove methane before mining begins (for example, Perry and others, 1978; Elder and Deul, 1974); drainage methods can involve:

1. Drilling vertical holes from the surface ahead of mining faces

2. Drilling horizontal holes within the mine ahead of mining faces 


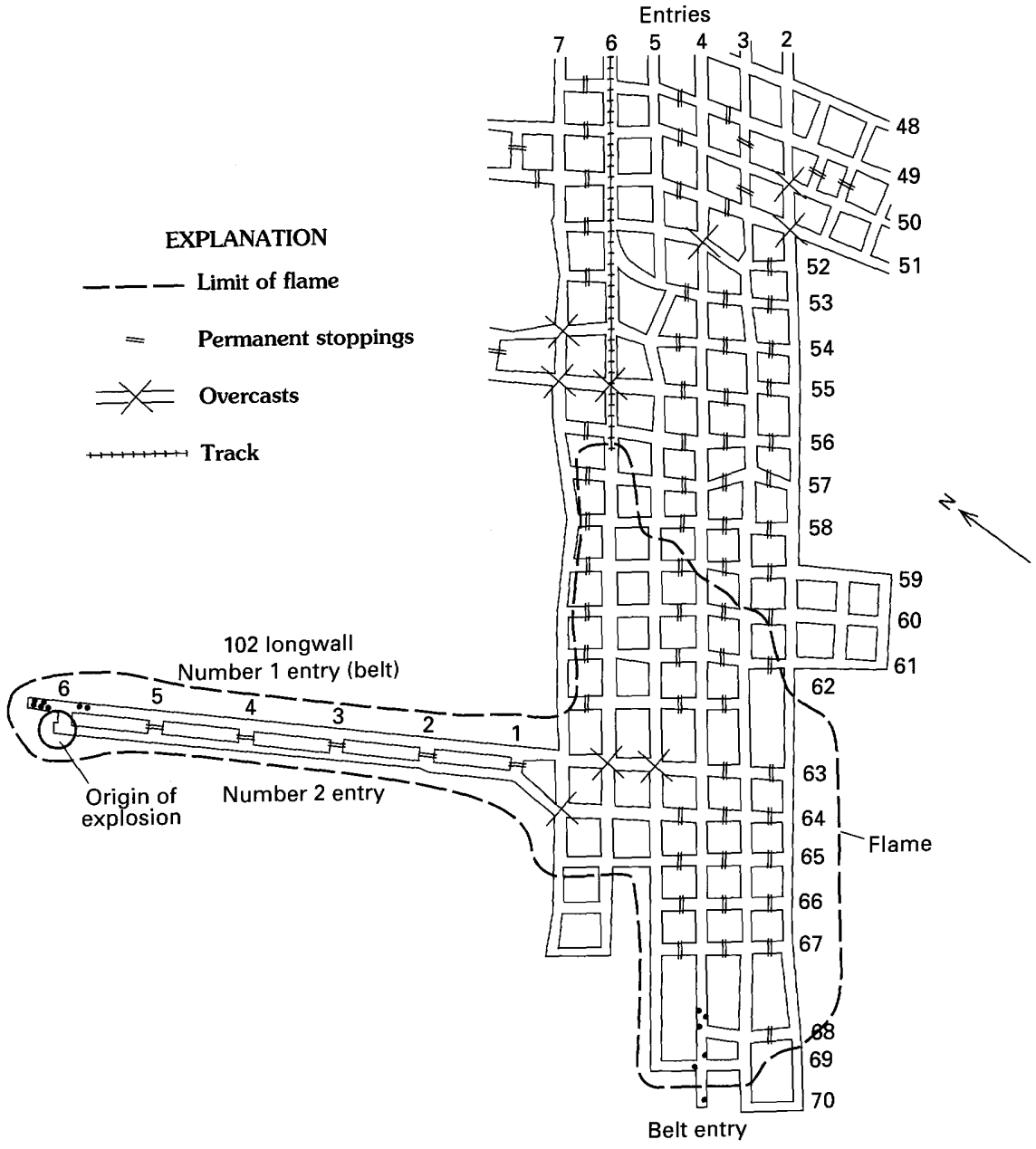

A

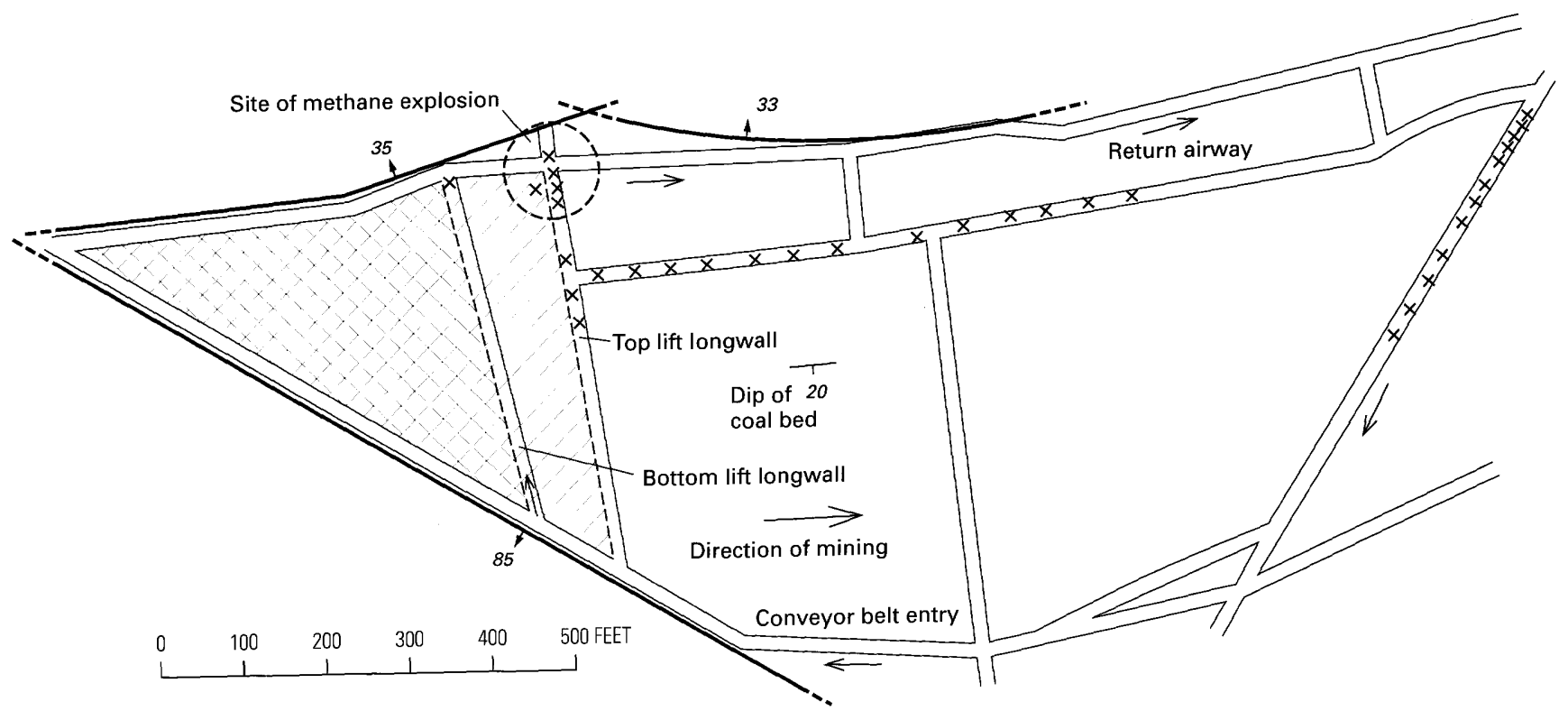


Figure 69 (facing page). Maps showing sites of coal mine explosions in Colorado and [former] Yugoslavia. A, Location of a coal mine methane explosion in Pitkin County, Colo., on April 15, 1981. Modified from Richmond and others (1983, p. 14). No scale given. Dot, location of one or more fatalities. $B$, Site of methane explosion in a double-lift longwall mine near Breza, Bosnia-Hertzegovina, [former] Yugoslavia, which killed 50 miners $(\times$, one or more fatalities) and injured 39 on March 14, 1970. The explosion occurred near the intersection of two low-angle faults (heavy lines, faults, showing dip) (M. Osmanagić, written commun., 1984).

3. The saving, rather than loss, of significant amounts of methane that can help conserve energy resources

V. Fires and Explosions in Abandoned Underground Coal Mines

A. Ignition may be spontaneous where coal dust, moisture, and oxygen occur in combustible proportions (for example, Kim, 1977)

B. Explosions can occur where hot areas or flames, resulting from spontaneous heating and combustion, come in contact with methane and (or) coal dust

1. Flames and smoke emitted from subsidence pits in the Sheridan, Wyo., area in 1979 were a severe hazard to people and animals until brought under control (Dunrud and Osterwald, 1980, p. 30-44)

C. The oxygen needed to sustain combustion comes through poorly sealed portals or shafts, or through subsidence cracks and pits (Dunrud, 1984, p. 181-182)

D. Once ignition occurs, combustion is sustained and accelerated by ventilating through poorly sealed portals or shafts or through subsidence cracks or pits

E. Voids produced in the burning coal and the softened roof rocks (softening caused by the heat and steam) produce more subsidence, which, in turn, accelerates the burning process by promoting the circulation of more fresh air

1. The burning process often is sporadic because caving above the fire area can temporarily reduce ventilation

F. Noxious and toxic chemicals, steam, and smoke are introduced into the atmosphere

1. In the Sheridan, Wyo., area, for example, traces of carbon disulfide, carbon oxysulfide, carbon monoxide, methane, and organic sulfur compounds were detected in gas samples (Dunrud and Osterwald, 1980, p. 31-32)

G. Although the procedure is often very difficult, fires have been contained, controlled, or extinguished by such procedures as the following (for example, Johnson and Miller, 1979):

1. Constructing trenches around the fire and filling them with incombustible material (isolation trenches)

2. Covering the fire with a thick blanket of incombustible material (smothering)

3. Flooding and permanently submerging the fire area (flooding)

\section{MINE SITE SELECTION, DESIGN, AND OPERATION}

- Experience has shown that the time and money spent in obtaining the necessary geologic and geotechnical information needed to plan, design, and operate underground coal mines before mining will pay large dividends; the investment will result in safer, more efficient, and more productive mines

- For example, the following geologic, geotechnical, and mining factors are considered in designing underground coal mines in [former] Yugoslavia (M. Osmanagić, written commun., 1984):

I. Depth, thickness, and dip of the coal bed or coal beds (and thickness of rocks between beds)

II. Structural, geologic, and geotechnical properties of the rocks above and below the coal bed(s)

III. Methane and water content of the coal and associated rocks and tendency of the coal to ignite spontaneously

IV. Amount of allowable surface subsidence, planned extraction ratio, and type of mining equipment to be used

V. Projected productivity of the labor force and health and safety factors of the miners

VI. Price of coal and cost of extracting the coal (profit ratio). This factor controls whether or not the coal will be mined and, therefore, controls the other five factors

- In addition to these factors, other factors should be considered in the United States, such as:

VII. Coal quality (rank, chemistry, ash content, and combustion characteristics)

VIII. Planned mining methods (in view of subsidence limitations, air emission standards and environmental restoration)

IX. Stress history of the proposed mining site (based on geologic evaluations of orogenic history and type of faulting, and perhaps in-situ stress measurements) 


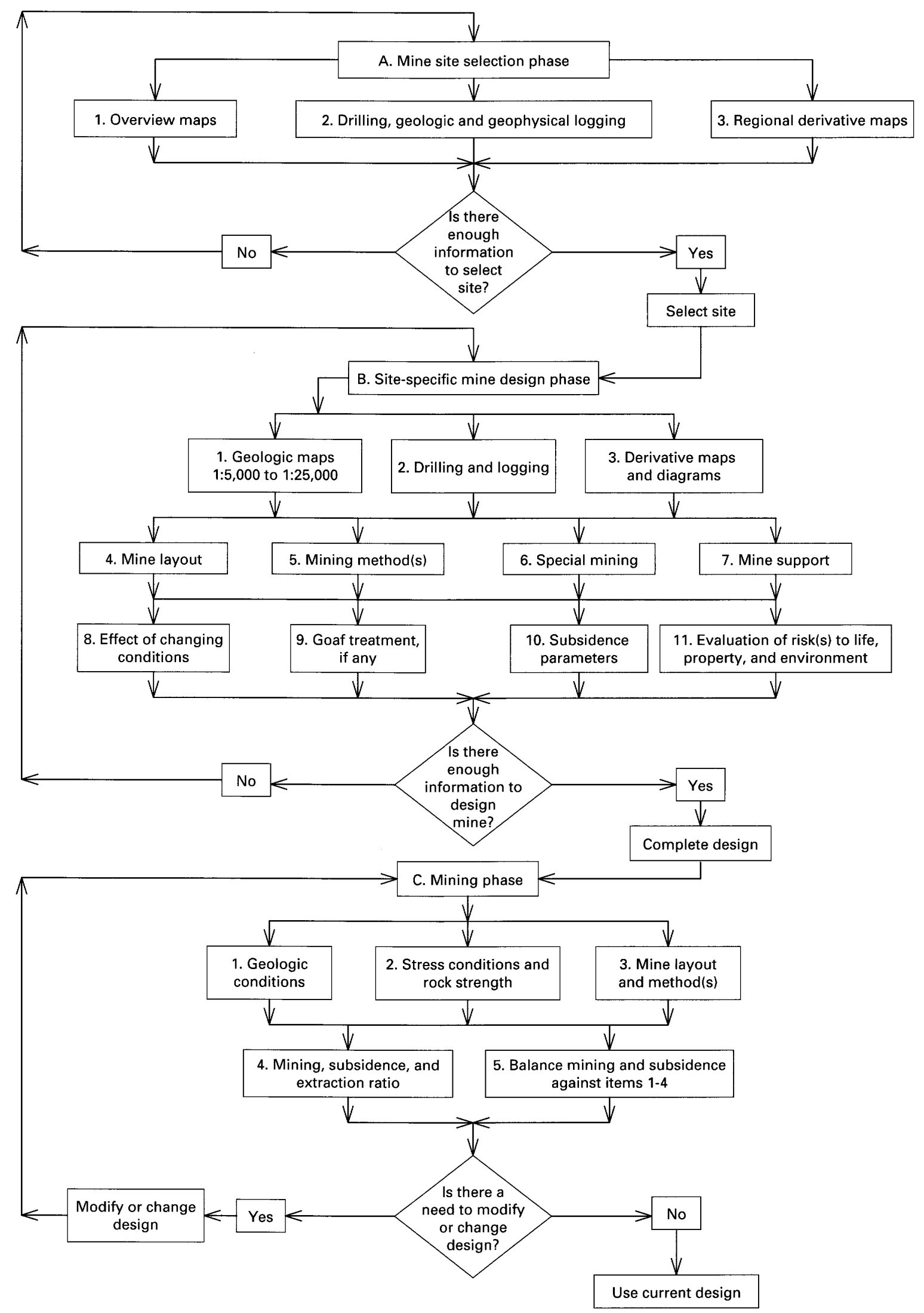


Figure 70 (facing page). Flow diagram showing possible steps in mine site selection, mine design, and operation of underground coal mines. Modified from Dunrud (1984, p. 189).

\section{MINE SITE SELECTION PHASE}

- Commonly involves the following steps (fig. 70) (for example, McCulloch, 1977; Vaninetti and others, 1980; Vaninetti and others, 1982; Stephenson and Allison, 1982; Bunnell, 1982)

I. Compile Regional Overview Maps (there may be more than one or several potential mining sites)

A. Use a scale of $1: 50,000$ to $1: 250,000$; include available geologic information, land ownership data, information from remote sensing imagery, and field studies

B. Show bedrock, coal zones, structure contours on key horizons, and surficial deposits

II. Drill and Log Coal-bearing Rocks; Obtain Regional Data, such as:

A. Geologic information (coal thickness, cleat, permeability, depth, and structure), by logging drill core and interpreting the petrophysical logs made in core and rotary drill holes

B. Geotechnical properties (physical properties, engineering properties, compressive and tensile strength, and slake durability) of the core from field and laboratory tests on the core and analysis of petrophysical logs (for example, Daniels and Scott, 1982)

C. Economic factors (overall economics based on mining depth and method, haulage, markets for the coal in view of coal quality, energy content, and chemistry)

III. Construct Regional Derivative Maps, Graphs, and Tables Showing:

A. Coal thickness (figs. 17, 71A), coal quality, coal structure (cleat, bedding), and overburden thickness (fig. $71 B$ ) in enough detail for selecting the best mine site(s) in the region of interest

1. Various state-of-the-art computer systems with mapping, profiling, and block diagramming programs can greatly facilitate construction of derivative maps (for example, McCulloch, 1976; Kork and Miesch, 1984)

2. Geostatistical analyses, such as point and block Kriging, can facilitate analyses of coal thickness, structure, quality, and strength of rocks above and beneath the coal beds

B. Stratigraphic sections showing coal correlations, thickness trends, and stratigraphic framework of the coal-bearing rocks (for example, fig. 2)
C. Fence diagrams that show stratigraphic framework in three dimensions may help determine the general depositional environment (fig. 72)

D. Coal-resource estimates using maps or tables (fig. 19) by section and (or) township

E. Faults, joints, and lineaments

1. Coal-cleat orientations can often be estimated from orientations of these structural features (see, for example, fig. 4) and by cleat trend studies of coal cores

F. Areas previously mined

G. Land ownership

\section{Expansion and Reiteration of the Process}

- The preceding steps are repeated, with additional mapping, drilling and logging, and remote-sensing work, until mine planners have enough information to select the best site (fig. 70)

A. Select the best mine site or sites, acquire land, and go to the mine-design phase when the decision to mine is made

\section{MINE DESIGN PHASE}

- Steps of this site-specific phase may include the following:

\section{Compile Site-Specific Geologic Maps}

- Use a scale ranging from about 1:5,000 to 1:25,000; show lithology, structure, and surficial deposits in the mine area; maps are similar to those made in the site-selection phase but are more detailed

A. Obtain site-specific information from studies at the outcrops, drilling and geologic and geotechnical logging, and by using low-altitude aerial photographs with the stereoscope and (or) precision stereoplotters

\section{Do Site-Specific Core Drilling and Rotary Drilling}

- Obtain data for geologic, geotechnical, and petrophysical logs, similar to those used in the site-selection phase but spaced more closely as needed

A. Spacing of drill holes commonly is governed by depositional environment, in addition to common distance considerations, for reliable classification of coal resources (figs. 2, 14); for example:

1. Drill hole spacing of about $1 / 4 \mathrm{mi}$ to $1 \mathrm{mi}$ may be adequate to obtain the necessary information for the " $B$ " and " $C$ " beds near the top of the Rollins Sandstone Member in the Somerset, Colo., area

2. Spacing of about $1 / 8 \mathrm{mi}$ to $1 / 2 \mathrm{mi}$ commonly is needed to obtain enough information in the " $D$ " and "E" zones located 200-400 ft above the Rollins Sandstone Member, where the beds thicken and thin in short distances 

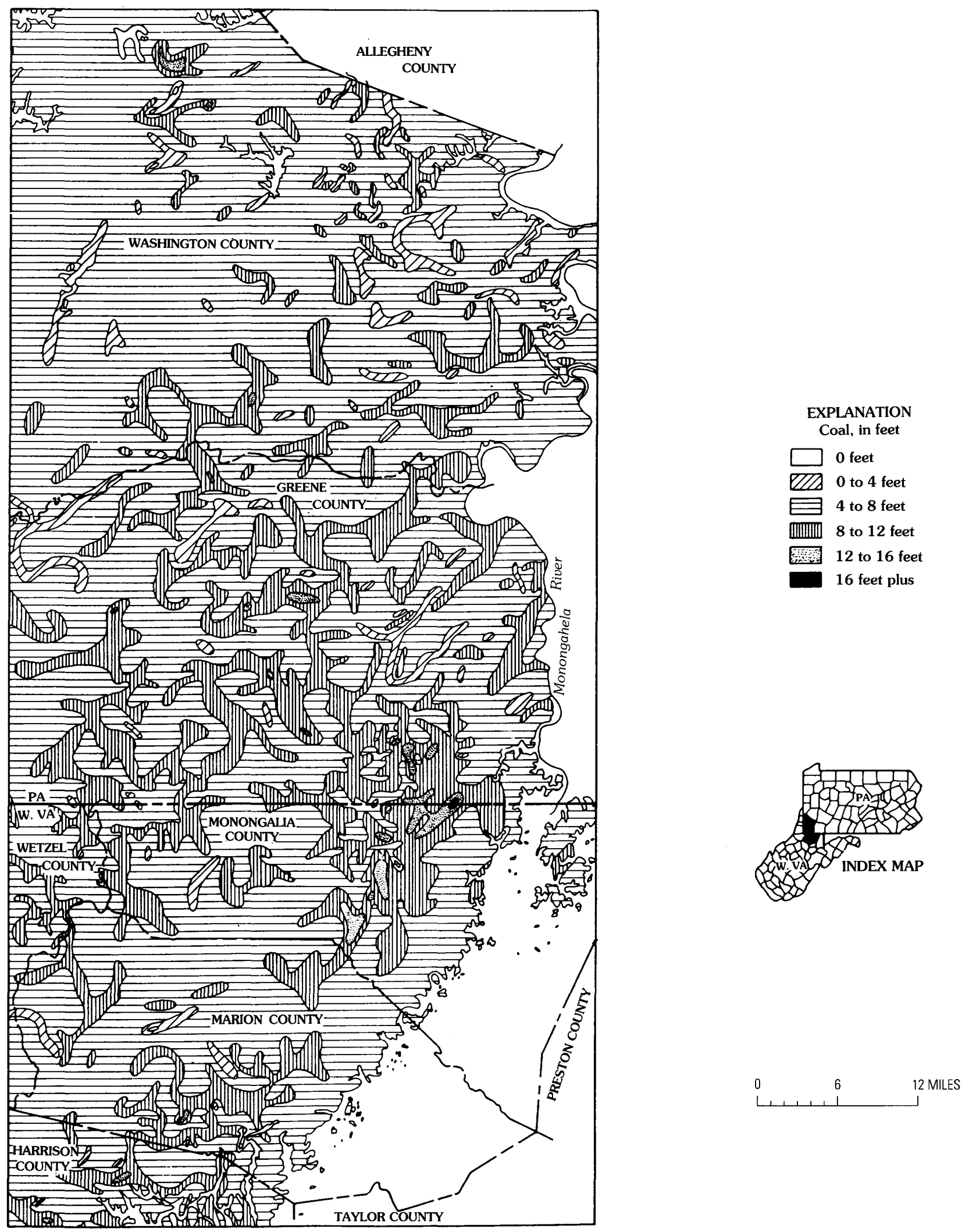

A

Figure 71 (above and facing page). Maps showing $A$, thickness of the Pittsburgh coal bed and $B$, overburden thickness relative to the Pittsburgh coal bed in southwestern Pennsylvania and northern West Virginia. From McCulloch and others (1975, p. 7, 10). 


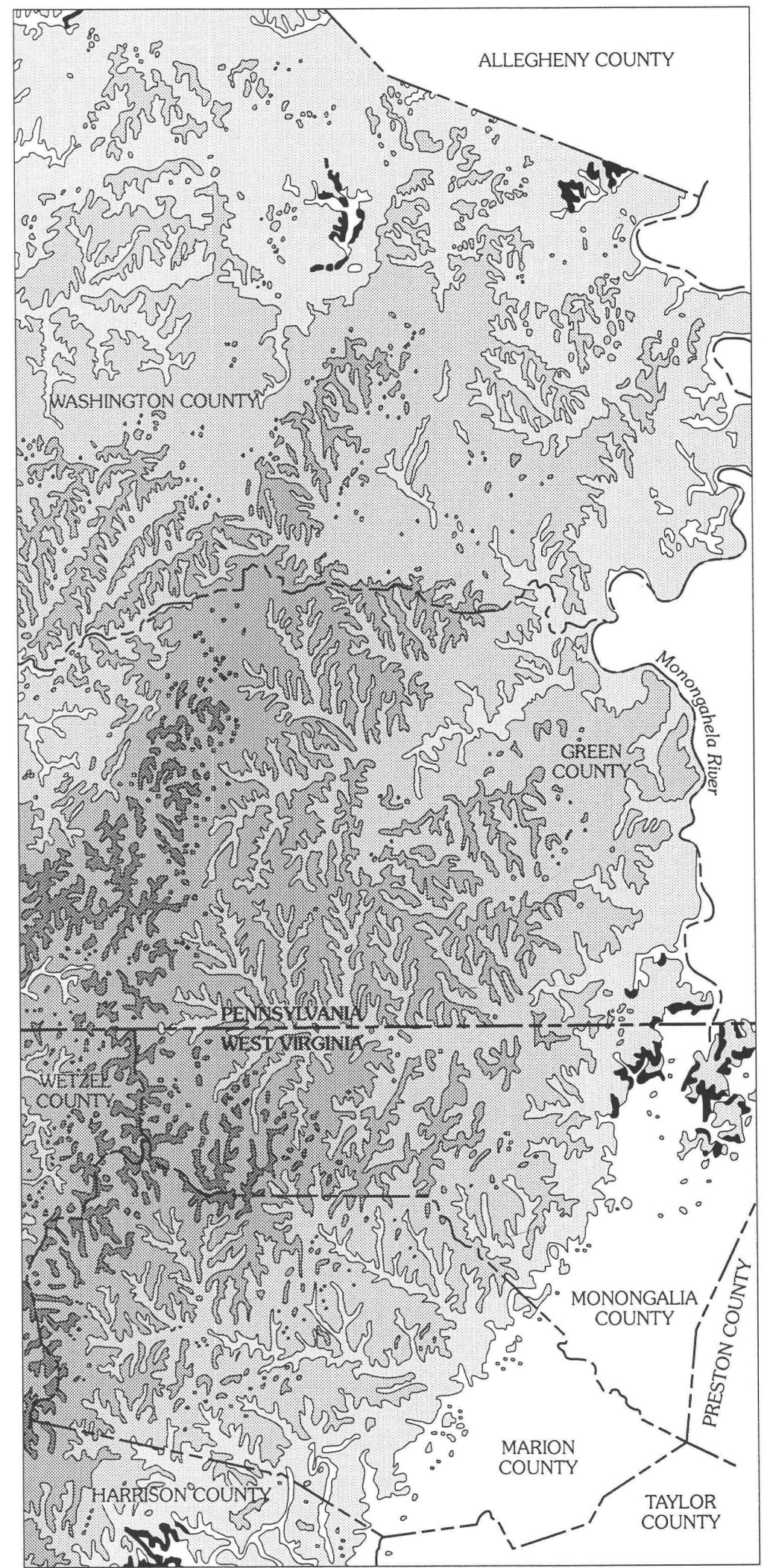

EXPLANATION

Overburden, in feet

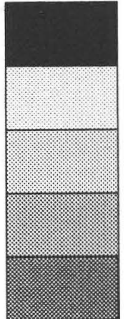

Strip mine

0 to 400 feet

400 to 800 feet

800 to 1,200 feet

1,200 feet plus
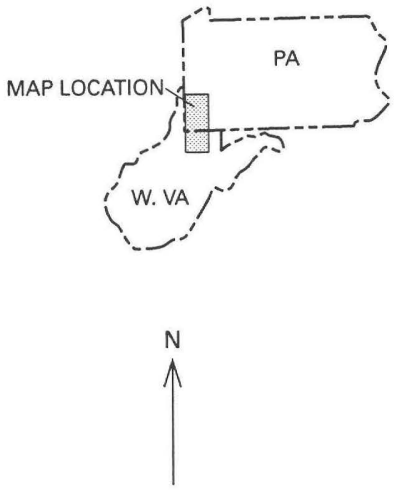

5 10 MILES 


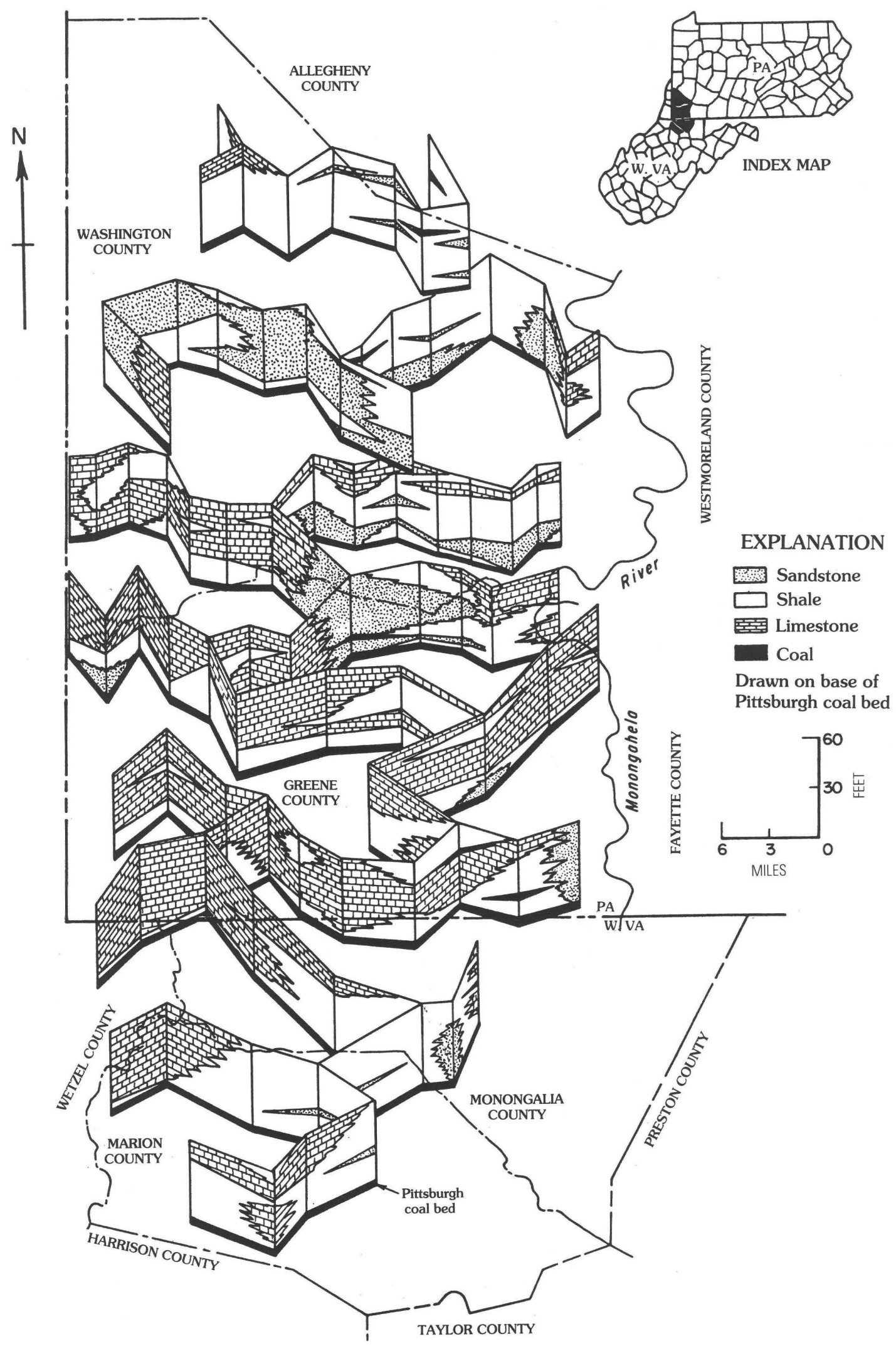

Figure 72. Fence diagram of the Pittsburgh coal bed and overlying rocks, southwestern Pennsylvania and northern West Virginia. From McCulloch and others (1975, p. 15). 
B. High-resolution seismic surveys may help determine the continuity of coal beds between drill holes and also may help locate faults, channel sandstones, and other deposits near coal beds (for example, Fry and Orange, 1982)

III. Construct Site-Specific Derivative Maps, Graphs, Fence Diagrams, Cross Sections and (or) Tables (see fig. 70)

A. Geologic characteristics

1. Thickness contours of coal bed(s) (geostatistical analyses are useful to determine coal thickness, structure, and quality)

2. Coal quality (sulfur, ash, Btu, trace elements, moisture)

3. Structure contours on top and (or) base of coal bed(s)

4. Overburden thickness, and thickness between coal beds, if more than one minable bed is present

5. Coal stratigraphic framework (using cross sections and fence diagrams of the coalbearing rocks)

6. Lithology of the mine roof(s) and floor(s)

a. Knowledge of the depositional environment can help to predict lithology and structure in advance of mining

7. Location and orientation of faults, lineaments, joints, and cleat

B. Geotechnical characteristics of the rocks above and below the coal bed(s) using geologic maps and drilling and logging information

1. Strength (point load, uniaxial compressive, tensile, shear)

2. General stress conditions (principal directions and magnitudes) based on overburden thickness, regional tectonic conditions in the area, and style of folding, faulting, and jointing (see section "Geotechnical Studies" for details)

C. Locate and delineate previously mined areas; the most reliable existing mine maps of the area should be adjusted to the derivative map scale and composited (or overlaid) to mine plan maps

1. Areas of abandoned underground mines, for which no mine maps are available, might be detected by down-hole and surface geophysical methods (for example, Howell, 1975) or by drilling in critical areas

IV. Lay Out Mine Workings

- Use a composite or overlay composite maps of the geologic, geotechnical, and previous mining derivative maps and data; include the following:

A. Optimize the orientation of mine openings
1. Where dip of coal bed(s) ranges from about $5^{\circ}$ to $15^{\circ}$, for haulage efficiency within the mining areas (fig. 73)

a. Orient mainline entries and panel entries roughly parallel to structure contours

b. Orient submains, such as raises and slopes, roughly perpendicular to structure contours

c. Minimize the number of panel entries to reduce roof falls, floor heave, pillar failure, and bumps, and to increase extraction efficiency

1- For example, the two-entry system commonly is used in longwall panels in the Western United States because roof falls, bumps, and floor heave commonly are minimized (Poad and others, 1977, p. 6)

2- In the two-entry system, however, escapeways are limited in case of a fire or explosion; attempt to strike a balance (between fewer entries for minimizing mine stability problems and more entries for ventilation and escapeways) where the fire and explosion potential is significant

2. Where coal beds dip less than (or equal to) about $5^{\circ}$

a. Mains, submains, and panels may be oriented at an angle of about $30^{\circ}$ to the dominant joint sets and lineaments in order to reduce roof control problems in roomand-pillar mining areas (for example, Kent, 1974)

b. Longwall faces may be oriented nearly parallel to a dominant set of joints to facilitate caving of the roof, where caving is practiced

B. Width, spacing, and length of mining panels

1. Panel width may be a function of limitations on allowable surface subsidence amount, area, slope, and strain (subsidence can also be controlled by mining method and goaf treatment, which are discussed later)

a. Where subsidence is to be limited, extraction panels (longwall, room-andpillar, shortwall) can be designed to be of subcritical width to reduce the subsidence (fig. 53); for example:

1- In the Somerset, Colo., area, subsidence was reduced from $0.5 t$ to 0.35 $t$ (where $t$ equals the average coal thickness mined) by reducing the 

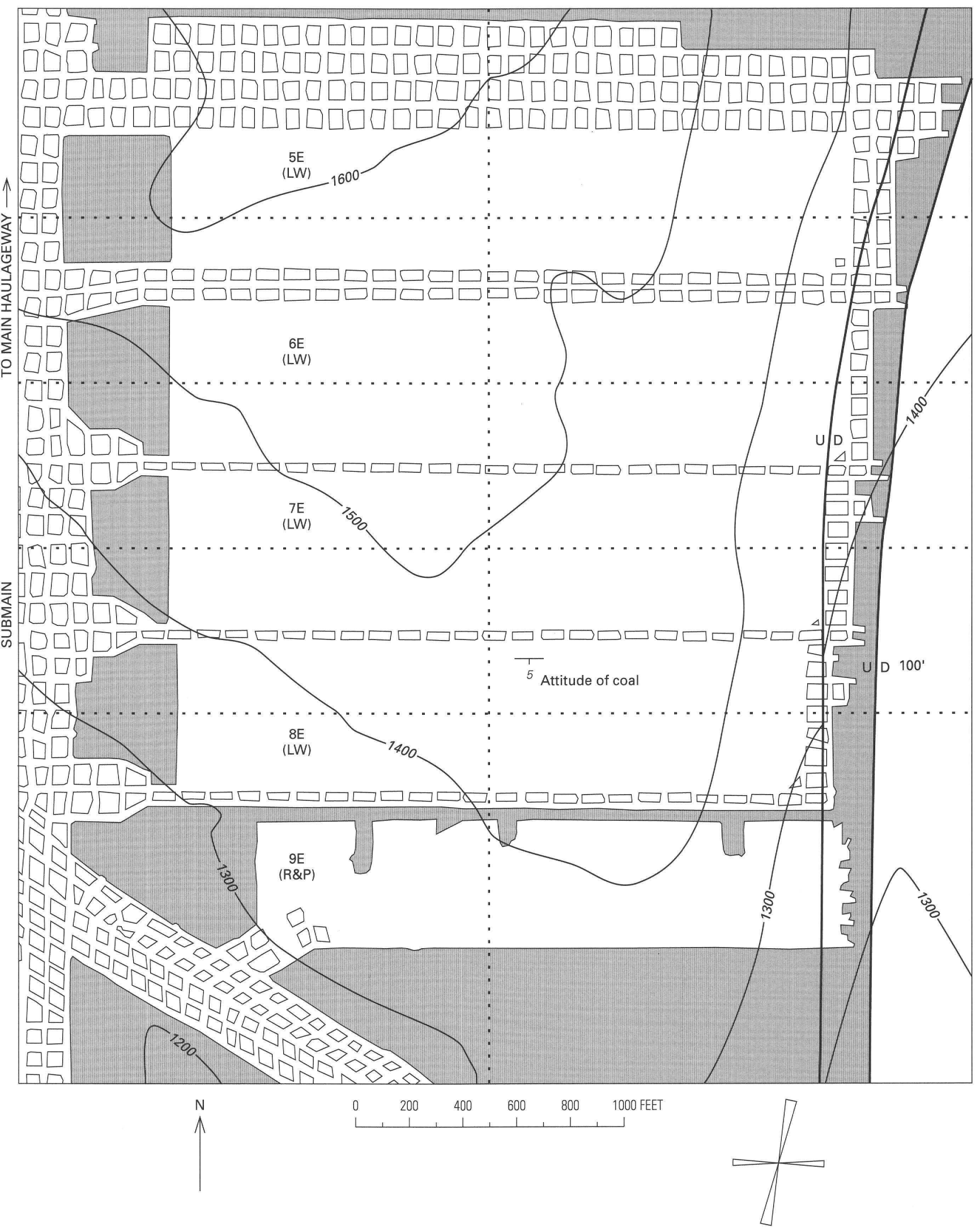
Figure 73 (facing page). Mine map showing room-and-pillar extraction (R\&P) and longwall (LW) mine panels in the Huntington area, Utah. Mine workings, bounded by a normal fault on the east (right; $U$, upthrown side; $\mathrm{D}$, downthrown side; 100, displacement in feet), occur at depths of about 1,200 to more than $1,600 \mathrm{ft}$ (overburden contour interval $100 \mathrm{ft}$ ). Note regular, uniform geometry of the longwall panels, which are separated by single or double sets of chain pillars; whereas the room-and-pillar areas have a less regular, less uniform geometry and consist of three to five entries. Diagram at base of map shows predominant trends of the two most extensive joint sets; compiled with a photogrammetric plotter by author.

width of the room-and-pillar extraction panels from about $1.4 d$ to $0.7 d$ (where $d$ equals the overburden thickness)

2- In the Salina, Utah, area, subsidence was reduced from about $0.9 t$ to 0.35 $t$ by reducing the width of room-andpillar extraction panels from about $1.0 d$ to $0.5 d$ where the overburden consists of predominantly shale and thin sandstone, or from about $0.6 t$ to $0.15 t$ by reducing the extraction panel width from $1.0 d$ to $0.5 d$ where the overburden consists of shale and thick sandstone (fig. 53)

2. Panel spacing is controlled primarily by the width of barrier pillars needed for stability

a. Barrier pillars of sufficient width to support the overburden may be needed, where subsidence is to be reduced by designing extraction panels of subcritical width (see, for example, NCB, 1975, p. 90-98, for details on designing subcritical longwall panels and barrier pillars to reduce subsidence displacement, slope, and strain to acceptable values)

b. Barrier pillars $40-50 \mathrm{ft}$ wide also are commonly used in the Western United States to isolate mined-out extraction panels from active panels where methane and (or) water are present in sufficient quantities to cause mining hazards 1- These barrier pillars commonly cause increased surface strain because horizontal displacement and strain from adjacent mining panels are additive by superposition (figs. $54 C, 56)$

c. Chain pillars (single or double) with no adjacent barriers sometimes are left between extraction panels where panel isolation is not required (fig. 73)
1- These pillars did not cause significant increased surface strain in the Huntington, Utah, area (fig. 57)

d. Where multiple coal bed mining is to be done in vertically superimposed coal beds, barrier pillars and chain pillars should be designed so that stresses are not concentrated in other coal beds above or below the mining areas

1- Large pillars must be vertically superimposed (columnized)

2- Pillars may be designed to yield and disperse stresses

a- The single chain pillars in a double-entry system may crush out and cause few or no problems in other beds

$b$ - The subsidence contour map in the Huntington, Utah, area, for example, indicates that stresses are not significantly concentrated in the other beds above or below the chain pillars between longwall panels (fig. 57), whereas the map for the Somerset, Colo., area indicates that stresses may be concentrated in other beds above and below the barrier pillars between extraction panels (fig. 56)

3. Panel length commonly is governed by such factors as the limitations of efficient haulage distance, ventilation, property boundaries, and faults

\section{Mining Methods}

- See sections "Coal Mining Methods and Mine Support Procedures" and "Coal Mine Deformation" for more details (fig. 70)

A. The standard longwall system with powered shield supports (figs. 33, 39) may be most efficient where:

1. The coal thickness is uniform enough to mine by longwall, the coal bed is extensive enough to warrant the cost of longwall mining equipment (cost may be $4-5$ times that of equipment for the room-and-pillar method), and the coal thickness ranges from about 5 to $12 \mathrm{ft}$

2. The overburden thickness is greater than about 1,600 ft where room-and-pillar mining becomes more risky (for example, Peng, 1978, p. 208)

3. The dip of beds ranges from about $0^{\circ}$ to $30^{\circ}$ 
4. The roof rocks are weak, of variable lithology, and (or) locally slake readily

5. High extraction ratio, productivity, and yield are required or planned (for economic, environmental, and (or) geologic reasons)

6. Surface subsidence will not be a significant problem to natural or man-made structures or features

a. Where subsidence may be a significant problem, longwall panels may be designed to be of subcritical width, and bounded by barrier pillars of adequate dimensions to support the overburden

B. The room-and-pillar method, with pillar extraction, may be most efficient where (fig. $41 A-C$ ):

1. The coal is less than about $15 \mathrm{ft}$ thick and of such limited extent, or of variable thickness, that longwall mining would not be economical

2. The roof rocks are too strong to break readily, as required by the longwall method to minimize roof stresses

3. The mine area is cut by numerous faults or channel deposits, that cut out parts of the coal beds

4. The dip is less than about $15^{\circ}$ for mechanized mines (coal beds dipping nearly vertically, however, were mined by hand using a modified room-and-pillar method (chuteand-pillar, breast-and-pillar) in the old days)

5. The overburden is less than about $1,500 \mathrm{ft}$ thick

6. The roof rocks are strong enough to be safely supported by bolting

C. The room-and-pillar method, where only rooms are driven (fig. $31 D$ ), may be used where limited subsidence is necessary and the coal is of variable thickness and of limited lateral extent (see, for example, NCB, 1975, p. 98-99, for details on pillar design for various subsidence factors)

1. However, subsidence and spontaneous combustion may be a problem decades or many decades later because of pillar deterioration and heating due to such causes as mine dewatering

D. The shortwall mining method has been used locally in the Eastern United States where:

1. The mine roofs are soft and fractured

2. The overburden thickness is greater than about 1,500 $\mathrm{ft}($ ?) (the standard longwall method probably is less expensive than shortwall, and thus appears to be replacing the shortwall method)

VI. Special Mining Methods for Thick Beds or Multiple Coal Beds
A. These methods apply in areas where the coal is thicker than about $10 \mathrm{ft}$ or where the coal is separated by rocks ranging from a few feet to about $30 \mathrm{ft}$ thick

B. Coal beds more than about $12 \mathrm{ft}$ thick should be mined by these methods if conservation of resources is to be seriously considered and if mining regulations allow these methods to be used

1. The coal remaining in a bed thicker than 15 $\mathrm{ft}$ probably cannot be mined later unless mining operations and extraction sequences are very carefully planned, because the remaining coal will be of irregular thickness and there may be local high stress concentrations where pillars are left

2. The coal left in the ground for subsequent mining may ignite spontaneously, burn coal reserves, and cause serious environmental problems, as discussed in the "Coal Mine Fires and Explosions" section

C. Thick or multiple-bed mining methods currently being used in the United States and in other countries include the following:

1. The high-face longwall method, with powered-chock shield supports, now is being used with greater frequency in the United States and in other countries in areas where:

a. A uniform coal bed $10-15 \mathrm{ft}$ thick is extensive enough and of good enough quality to warrant the increased mining cost

b. The other previously mentioned factors favoring the longwall method generally apply

2. The double-lift longwall method is being used in other countries, such as the former Yugoslavia (fig. 35), where:

a. A laterally continuous coal bed $15-25 \mathrm{ft}$ thick or two closely spaced beds 6-10 ft thick are to be extracted

b. Single-entry systems can be used (it commonly is not feasible to use more than one haulage and ventilation entry with the double-lift mining method)

3. The multilift longwall, with sublevel caving, currently is being used in [former] Yugoslavia (fig. 36) in areas where:

a. The coal beds are extensive and are $40-400 \mathrm{ft}$ thick

b. Single entries commonly are used in the panels (one entry provides incoming air to each panel; one entry provides haulage and return air from each panel) 
4. A modified room-and-pillar method, with sequential hydraulic backfilling, has been used in [former] Yugoslavia (near Mostar, Bosnia-Hertzegovina) to mine coal beds as thick as $65 \mathrm{ft}$, which are located beneath villages and towns, where subsidence must be minimized (fig. 37)

a. The only equipment needed is a drill, rock bolter, and conveyor (M. Osmanagić, written commun., 1984)

b. Subsidence was reduced to about $0.02 t$ ( 2 percent of the mining thickness) by using this method

c. The extraction ratio, however, was reduced to about 50 percent, compared to about 80 percent with the multilift longwall method

5. Hydraulic mining reportedly is used in other countries where:

a. Coal beds are 6-50 ft thick and friable enough to be easily mined with water jets

b. The roof and floor rocks are not adversely affected by water

c. Faults, rolls, and undulations in the coal bed are absent or at a minimum

d. The overburden thickness is less than about 2,000 ft and supply of water and electric power is adequate

VII. Mine Roof Support Procedures in Entries and Rooms (fig. 70)

A. Various combinations of the following may be needed to adequately support mine roofs during mining, where lithology and structure of the mine roofs and floors are highly variable (figs. $74,75)$

1. Roof bolts

a. Expansive shell (point anchor)—used where the roof is moderately strong to strong and not prone to slake or lose anchorage

b. Epoxy resin (full column grouted)-used where the roof is weak, of variable lithology, and prone to slake and lose anchorage

2. Props-partial support-commonly used in openings, such as airways and near pillar lines

3. Cribs-primary support-commonly used in highly stressed, non-haulage openings

4. Arches-primary support—commonly used in highly stressed haulageways and some airways

VIII. Possible Necessity for More Than One Mining Method (fig. 70)
- Varying geologic and geotechnical conditions and overburden thickness in a mine area may dictate more than one mining method; for example:

A. Thick-bed mining techniques may be used in thicker parts of beds (fig. 2), but standard longwall or room-and-pillar methods might be better where beds thin to about $10 \mathrm{ft}$; multilift longwall mining may be best where thick beds split into two or more beds

B. Longwall mining methods are better than the room-and-pillar methods where the coal beds are laterally continuous, where the overburden thickness increases to more than $1,500 \mathrm{ft}$, where roof and floor rock lithologies are variable, and where faults and channel deposits are not prevalent (fig. 2)

\section{Goaf (Gob, Caved Area) Treatment}

- Commonly involves caving, mechanical backfilling (stowing), and hydraulic backfilling of the mined-out areas (fig. 70)

A. Caving often is used where subsidence is to be expedited and maximum subsidence is permissible

B. Mechanical backfilling may be used where subsidence above critical to supercritical extraction panels is to be limited to about $0.4 t$ (where $t=$ coal bed thickness, fig. 53) and where the extraction ratio is to be maximized

1. Costs to backfill mine refuse, in sequence with mining, in Poland and England are about 5 and 11.5 percent of coal production costs, respectively (Cochran, 1971)

C. Hydraulic backfilling may be used where extraction ratio is to be maximized, subsidence above critical to supercritical extraction panels is to be limited to $0.15 t$ or less, and the backfilled water will not cause additional problems (fig. 53)

D. In [former] Yugoslavia, for example, subsidence above critical to supercritical double-lift extraction panels can amount to only $0.02 t$ or as much as $0.98 t$, depending on whether the mine openings are hydraulically backfilled or allowed to cave (fig. 53)

\section{Subsidence Parameters}

- Where downwarping is the dominant process, maximum vertical displacement $(S)$, horizontal displacement $(S h)$, tilt $(M)$, curvature $(C)$, horizontal strain $(E)$, and duration (all subsidence parameters are maximum) can be estimated using the procedures outlined in the section, "Panel-Pillar Mine Geometry," assuming that the procedures outlined in "Coal Mine Subsidence" are valid in the proposed mining area; the following can then be estimated:

A. Maximum vertical displacement from figure 53 


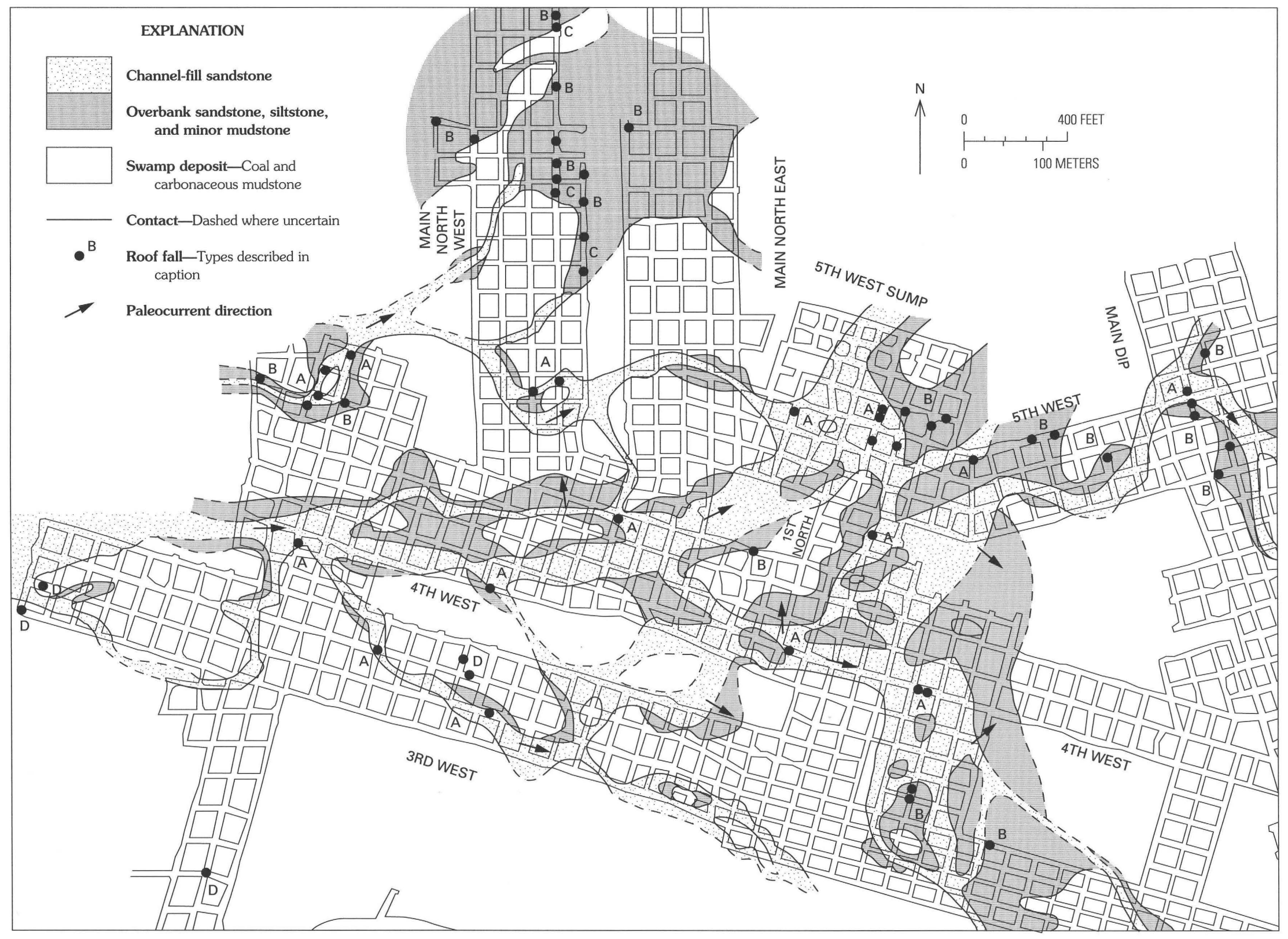

Figure 74. Composite map showing mine workings and complex mine roof rocks northwest of Helper, Utah. Type A roof falls occur beneath channel-fill sandstones (minor hazard); type B occur beneath thinly bedded, overbank sandstones (greatest hazard); type $\mathrm{C}$ occur beneath overbank siltstones (intermediate hazard, often a forerunner of type A and B falls); type D probably occur in relation to mine-induced stresses, rather than depositional environment. Modified from Bunnell (1982, p. 123). 

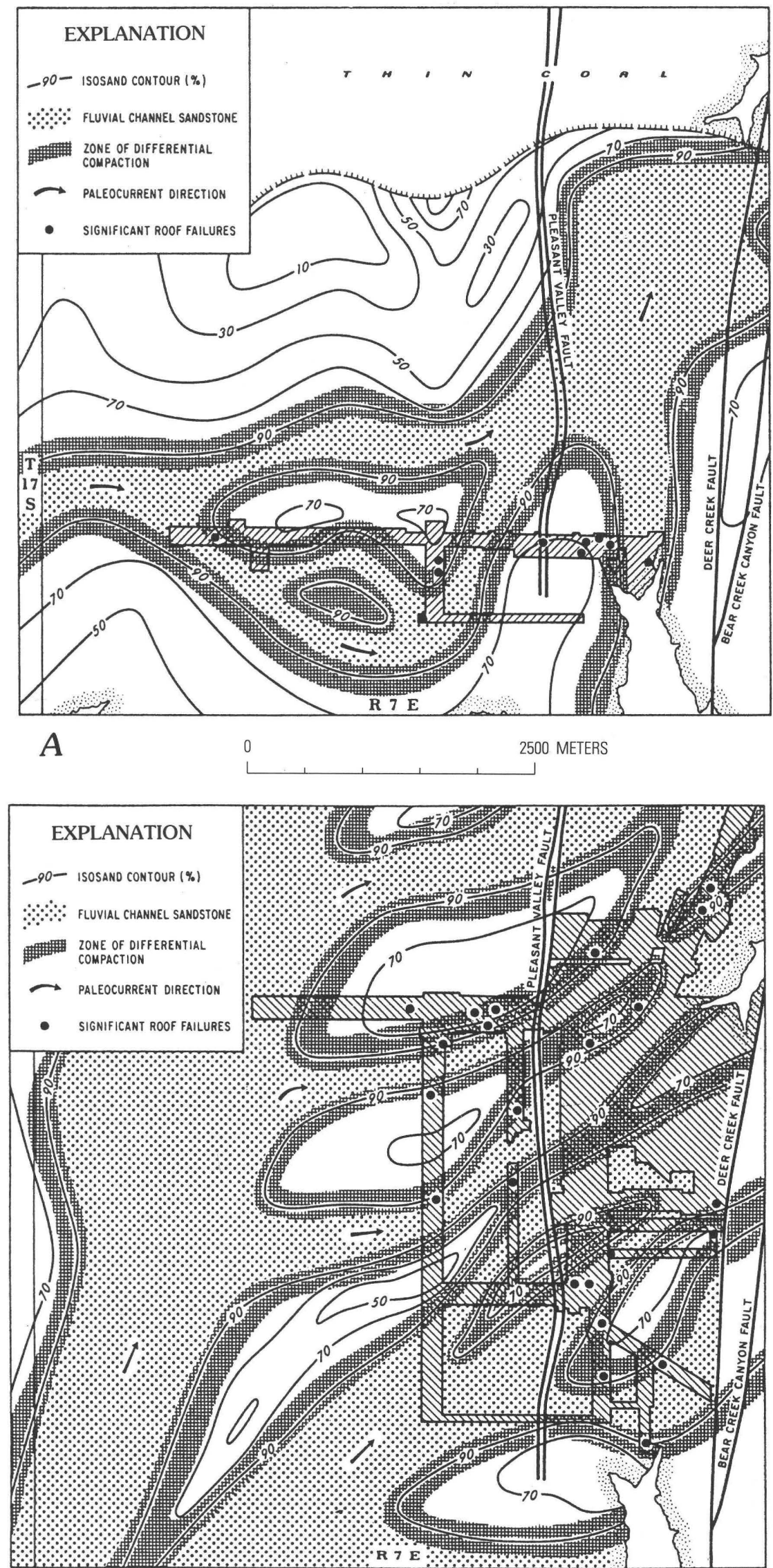

Figure 75. Maps showing contours of equal percentage of sand in the roofs of two mines in $A$, a lower and $B$, an upper coal bed in the Huntington, Utah, area. Coal beds are about $100 \mathrm{ft}$ apart stratigraphically. From Vaninetti and others (1980, p. 25-26). 
B. Maximum horizontal displacement, tilt, and horizontal strain from figures $54-58$

1. Maximum allowable tilt and strain on structures of different lengths may be estimated from figure 59

C. Maximum area affected by subsidence (fig. $58 A, B)$

1. Check to see if faults will change subsidence area (fig. 60)

D. Duration of subsidence using subsidence development curves (fig. 61)

E. Factors controlling subsidence processes or parameters including:

1. Thickness of coal mined ( $t$ in equation $a=S /$ $t$, in fig. 53)

2. Lithology of roof and floor rocks and overburden

3. Structure (dip, faults, lineaments, joints)

4. Hydrology (surface water, ground water)

5. Geotechnical properties (strength, behavioral properties, slake durability; see section, "Geotechnical Studies" for details)

6. Topography and slope angle

XI. Evaluate Risk to Life, Property, or the Environment (fig. 70) as a Result of the Following:

A. Deformation within nearby mine workings (if applicable and possible), such as:

1. Roof falls, and whether caused by geologic or mining factors

2. Bumps, methane releases, outbursts, sudden water-inflow potential, outbursts, fires or explosions, and their probable cause

B. Subsidence caused by stoping or block movement

C. Extraction ratio: Is it too low or too high?

XII. Review the Mining Design Phase

- Preceding questions should be answered to the satisfaction of appropriate regulatory authorities and those involved in designing the mining operation

\section{MINING PHASE}

- Continue to refine the steps taken in the preceding design phase using information acquired during mining; continually check, correct, and supplement information obtained in the design phase; this can be done in much more detail than is possible before mining begins

I. Evaluate Geologic Conditions, such as Coal Thickness, Quality, and Structure as it is Obtained

A. The depositional environment can be checked in detail during the mining and roof-bolting phase and interpretations corrected (figs. 74, 75)
B. Structural features, such as faults and joints, that are encountered during mining, may dictate changes in panel orientation (for example, Kent, 1974, p. 1, 16), width and length, and even changes in mining method(s) and roof support procedures

II. Evaluate Rock and Coal Strength, Stress Conditions, and Behavior of the Mine Roof and Floor

- Estimates made before mining can now be verified by mapping the orientation(s) and type(s) of roof fracturing; design modifications or changes may be required (for example, Parker, 1973)

\section{Evaluate Mine Layout and Mining Method(s)}

- Use knowledge obtained about geologic, geotechnical, and topographic conditions

IV. Evaluate Mining Method, Subsidence, and Extraction Ratio

- Use data obtained during the mining phase regarding geologic and geotechnical conditions and potential risks to life, property, and the environment

V. Balance and Modify:

A. Mining methods and subsidence parameters against items I through IV, and use current design, modify the design, or change the design

B. Mine layout and mining method, where another mining plan or method may result in a safer and more efficient operation (figs. 74, 75)

1. For example, roof control problems were reduced and a higher percentage of the coal reserve was extracted when the room-andpillar retreat mining method was changed to the longwall retreat mining method in the Huntington, Utah, area (fig. 73)

\section{REFERENCES CITED}

Abel, J.F., Jr., and Lee, F.T., 1980, Lithologic controls on subsidence: Society of Mining Engineers Preprint 80-314, p. 1-16.

Abrams, M.J., and Siegal, B.S., 1980, Lithologic mapping, in Siegal, B.S., and Gillespie, A.R., Remote sensing in geology: New York, John Wiley, p. 381-418.

Aggson, J.R., 1979, Stress-induced failure in mine roof: U.S. Bureau of Mines Report of Investigations 8338, $16 \mathrm{p}$.

Allen, J.R.L., 1970, Sediments of the modern Niger delta-A summary and review, in Morgan, J.P., and Shaver, R.H., eds., Deltaic sedimentation, modern and ancient: Society of Economic Paleontologists and Mineralogists, Special Publication 15, p. 138-151.

Allgaier, F.K., 1982, Surface subsidence over longwall panels in the western United States: U.S. Bureau of Mines Information Circular 8896, $24 \mathrm{p}$. 
Asquith, G.B., 1982, Basic well $\log$ analysis for geologists with Charles C. Gibson: American Association of Petroleum Geologists, $216 \mathrm{p}$.

Babcock, C., Morgan, T., and Haramy, K., 1981, Review of pillar design equations including the effects of constraint, in Peng, S.S., ed., Conference on ground control in mining, West Virginia University, 1981: Proceedings, Department of Mining Engineering, Morgantown, W. Va., p. 23-34.

Barry, A.J., and Nair, O.B., 1970, In situ tests of bearing capacity of roof and floor in selected bituminous coal mines: U.S. Bureau of Mines Report of Investigations 7406, 20 p.

Beeson, D.C., 1980, Igneous intrusion of steeply dipping Eocene coals near Ashford, Pierce County, Washington, in Carter, L.M.H., ed., Proceedings of the Fourth Symposium on the Geology of Rocky Mountain Coal: Colorado Geological Survey Resource Series 10, p. 88-94.

Bell, F.G., 1975, The character of the coal measures, in Bell, F.G., ed., Site investigations in areas of mining subsidence: London, Butterworth \& Co., Ltd., p. 1-39.

Bell, S.E., 1978, Successful design for mining subsidence, in Geddes, J.D., ed., Large ground movements and structures, Conference at the University of Wales Institute of Science and Technology, Cardiff, 1977, Proceedings: New York, John Wiley, p. 562-596.

Bieniawski, Z.T., 1975, The point load test in geotechnical practice: Engineering Geology, v. 9, p. 1-11.

1981, Improved design of coal pillars for U.S. mining conditions, in Peng, S.S., ed., Conference on ground control in mining, West Virginia University, 1981, Proceedings: Department of Mining Engineering, Morgantown, W. Va., p. 13-22.

Blodget, H.W., and Brown, G.F., 1982, Geological mapping by use of computer-enhanced imagery in western Saudia Arabia: U.S. Geological Survey Professional Paper 1153, 10 p.

Bortels, J.R., and Pappas, D.M., 1985, Comparative laboratory evaluation of resin-grouted roof bolt elements: U.S. Bureau of Mines Report of Investigations 8924, 20 p.

Brauner, Gerhard, 1973a, Subsidence due to underground mining, Part 1 of Theory and practices in predicting surface deformation: U.S. Bureau of Mines Information Circular 8571, $56 \mathrm{p}$.

-1973b, Ground movements and mining damage, Part 2 of Theory and practices in predicting surface deformation: U.S. Bureau of Mines Information Circular 8572, $53 \mathrm{p}$.

Briggs, Henry, 1929, Mining subsidence: London, Edward Arnold and Co., 153 p.

Broch, E., and Franklin, J.A., 1972, The point-load strength test: International Journal of Rock Mechanics and Mining Sciences, v. 9, no. 6, p. 669-693.

Bruhn, R.W., Magnuson, M.O., and Gray, R.E., 1978, Subsidence over the mined-out Pittsburg coal, in Coal mine subsidence session, American Society of Civil Engineers Convention, Pittsburgh: American Society of Civil Engineers preprint, p. 26-55.

Bunnell, M.D., 1982, Roof geology and stability of an underground coal mine in Carbon County, Utah, in Gurgel, K.D., ed., Proceedings, Fifth Symposium on the Geology of Rocky Mountain coal: Utah Geological and Mineral Survey Bulletin 118, p. 121-128.

Capper, P.L., and Cassie, W.F., 1963, The mechanics of engineering soils: London, E. \& F.N. Spon, 298 p.
Clark, Isobel, 1979, Practical geostatistics: London, Applied Science Publishers, Ltd., 129 p.

Cochran, William, 1971, Mine subsidence-Extent and cost of control in a selected area: U.S. Bureau of Mines Information Circular $8507,32 \mathrm{p}$.

Colaizzi, G.J., Whaite, R.H., and Donner, D.L., 1981, Pumpedslurry backfilling of abandoned coal mine workings for subsidence control at Rock Springs, Wyo., with an appendix on Hydraulic model studies for backfilling mine cavities, by E. J. Carlson: U.S. Bureau of Mines Information Circular 8846, 56 p., appendix, $40 \mathrm{p}$.

Colwell, R.N., editor-in-chief, Manual of remote sensing: The Sheridan Press, Second Edition, v. I and II, 2440 p.

Cook, N.G.W., and Hood, M., 1978, Stability of underground coal mine workings, in Brawner, C.O., and Dorling, I.P.F., eds., Stability in coal mining, Proceedings, First International Symposium on Stability in Coal Mining, Vancouver, B.C., Canada: San Francisco, Miller Freeman Publications, p. 135-147.

Cooley, W.C., 1975, Survey of underground hydraulic coal mining technology: U.S. Bureau of Mines Contract Report (Contract HO242031), 129 p.

Corlett, A.V., and Emery, C.L., 1959, Prestress and stress redistribution around a mine opening: Canadian Mining and Metallurgical Bulletin, June, p. 372-384.

Cumming, J.D., and Wicklund, A.P., 1975, Diamond drill handbook: J. K. Smit and Sons Diamond Products, Ltd. [3d ed.], $547 \mathrm{p}$.

Curth, E.A., 1974a, Coal mining techniques in the Federal Republic of Germany-1971: U.S. Bureau of Mines Information Circular $8645,52 \mathrm{p}$.

1974b, Roof support problems in longwall mining-A study in the United States and Germany in 1971: U.S. Bureau of Mines Information Circular 8630, p. 101-114.

D'Andrea, D.V., Fischer, R.L., and Fogelson, D.E., 1965, Prediction of compressive strength from other rock properties: U.S. Bureau of Mines Report of Investigations No. 6702, 23 p.

Daniels, J.J., and Scott, J.H., 1982, Automated lithologic interpretation from geophysical well logs in a coal depositional environment, Carbon County, Wyoming, in Gurgel, K.D., ed., Proceedings, Fifth Symposium on the Geology of Rocky Mountain Coal: Utah Geological and Mineral Survey Bulletin 118 , p. 220-232.

DeGraff, J.V., and Romesburg, H.C., 1981, Subsidence crack closure; rate, magnitude, and sequence: International Association of Engineering Geology Bulletin 23, p. 123-127.

Delfiner, P.C., 1984, Automatic determination of lithology from well logs: Society of Petroleum Geologists of AIME: 59th Annual Technical Conference and Exhibition, Houston, Texas, Sept. 16-19, 1984, p. 1-5.

Diamond, W.P., 1982, Site-specific and regional geologic considerations for coalbed gas drainage: U.S. Bureau of Mines Information Circular 8898, 24 p.

Diamond, W.P., McCulloch, C.M., and Bench, B.M., 1976, Use of surface joint and photolinear data for predicting subsurface coal cleat orientation: U.S. Bureau of Mines Report of Investigations $8120,13 \mathrm{p}$.

Dickinson, K.A., Berryhill, H.L., Jr., and Holmes, C.W., 1972, Criteria for recognizing ancient barrier coastlines, in Rigby, J.K., and Hamblin, W.K., eds., Recognition of ancient sedimentary 
environments: Society of Economic Paleontologists and Mineralogists Special Publication 16, p. 192-214.

Donaldson, A.C., Martin, R.H., and Kanes, W.H., 1970, Holocene Guadalupe delta of Texas Gulf Coast, in Morgan, J.P., and Shaver, R.H., eds., Deltaic sedimentation, modern and ancient: Society of Economic Paleontologists and Mineralogists Special Publication 15, p. 107-137.

Dott, R.L., 1964, Wacke, greywacke and matrix-What approach to immature sandstone classification?: Journal of Sedimentary Petrology, v. 34, p. 625-632.

Down, C.G., and Stocks, J., 1978, Environmental impact of mining: London, Applied Science Publishers, Ltd., 371 p.

Dunrud, C.R., 1976, Some engineering geologic factors controlling coal mine subsidence in Utah and Colorado: U.S. Geological Survey Professional Paper 969, 39 p.

1984, Coal mine subsidence-Western United States, in Holzer, T.L., ed., Man-induced land subsidence: Geological Society of America, Reviews in Engineering Geology, v. VI, p. 151-194.

1987, Subsidence-An important aspect of land use planning above abandoned underground mines, in Building over underground mines-Subsidence considerations: Association of Engineering Geology Symposium Series, No. 4; p. 3-36.

-1989a, Geologic map and coal stratigraphic framework of the Paonia area, Delta and Gunnison Counties, Colorado: U.S. Geological Survey Coal Investigations Map C-115.

-1989b, Geologic map and coal stratigraphic framework of the Cedaredge area, Delta County, Colorado: U.S. Geological Survey Coal Investigations Map C-116.

Dunrud, C.R., and Barnes, B.K., 1972, Engineering geologic map of the Geneva mine area, Carbon and Emery Counties, Utah: U.S. Geological Survey Miscellaneous Investigations Map I-704, 2 sheets.

Dunrud, C.R., and Osterwald, F.W., 1965, Seismic study of coal mine bumps, Carbon and Emery Counties, Utah: Society of Mining Engineers Transactions, v. 232, p. 174-182.

1980, Effects of coal mine subsidence in the Sheridan, Wyoming, area: U.S. Geological Survey Professional Paper $1164,49 \mathrm{p}$.

Dunrud, C.R., Osterwald, F.W., and Hernandez, Jerome, 1972, Summary of the seismic activity and its relation to geology and to mining in the Sunnyside mining district, Carbon and Emery Counties, Utah, during 1967 through 1970: U.S. Geological Survey Open-file report, $62 \mathrm{p}$.

Eager, G.P., 1978, Geophysical logs of coal test drill holes in the Grand Mesa coal field, Delta and Mesa Counties, Colorado: U.S. Geological Survey Open-File Report 78-540, 97 p.

1979, Geophysical logs of coal test drill holes in the Grand Mesa coal field, Delta County, Colorado: U.S. Geological Survey Open-File Report 79-327, 21 p.

Elder, C.H., and Deul, Maurice, 1974, Degasification of the Mary Lee coal bed near Oak Grove, Jefferson County, Ala., by vertical borehole in advance of mining: U.S. Bureau of Mines Report of Investigations 7968, 21 p.

Ellis, E.G., and Frank, J.R., 1981, Geologic map and coal sections of the Red Point quadrangle, Emery County, Utah: U.S. Geological Survey Open-File Report 81-1356.

Evans, W.H., 1941, The strength of undermined strata: Institution of Mining and Metallurgy Transactions, 1940-41, p. 475-500.
Fairbridge, R.W., and Burgeois, Joanne, eds., 1978, The encyclopedia of sedimentology: Stroudsburg, Pa., Dowden, Hutchinson and Ross, Inc., 901 p.

Flores, R.M., 1980, Comparison of depositional models of Tertiary and Upper Cretaceous coal-bearing rocks in some western interior basins of the United States, in Carter, L.M.H., ed., Proceedings of the Fourth Symposium on the Geology of Rocky Mountain Coal: Colorado Geological Survey Resource Series 10, p. 17-20.

Flores, R.M., Marley, W.E., Sanchez, J.D., Blanchard, L.F., and Muldoon, W.J., 1982, Coal correlations and depositional environments of Cretaceous Blackhawk Formation and Star Point Sandstone, Wasatch Plateau, Utah, in Gurgel, K.D., ed., Proceedings, Fifth Symposium on the Geology of Rocky Mountain Coal: Utah Geological and Mineral Survey Bulletin 118, p. 70-75.

Franklin, J.A., and Chandra, R., 1972, The slake-durability test: International Journal of Rock Mechanics and Mining Sciences, v. 9 , no. 3 , p. 325-338.

Freden, S.C., and Gordon, Frederick, Jr., 1983, Landsat satellites, in Colwell, R.N., editor-in-chief, Manual of remote sensing [2d edition]: The Sheridan Press, v. 1, p. 517-570.

Friedman, G.M., and Sanders, J.E., 1978, Principles of sedimentology: New York, John Wiley, 792 p.

Fry, R.C., and Orange, A.S., 1982, High-resolution seismic: A practical approach to coal exploration, in Gurgel, K.D., ed., Proceedings, Fifth Symposium on the Geology of Rocky Mountain Coal: Utah Geological and Mineral Survey Bulletin 118, p. 211-218.

Gardner, N.K., and Carter, M.D., 1986, Geologic application of the Interactive Surface Model program (ISM): U.S. Geological Survey Open-File Report 86-87, 60 p.

Geddes, J.D., 1978, The behavior of a CLASP-system school subjected to mining movements, in Geddes, J.D., ed., Large ground movements and structures, Conference at the University of Wales Institute of Science and Technology, Cardiff, 1977, Proceedings: New York, John Wiley, p. 579-596.

Gentry, D.W., and Abel, J.F., Jr., 1978, Surface response to longwall coal mining in mountainous terrain: Association of Engineering Geologists Bulletin, v. 15, no. 2, p. 191-220.

Gill, J.R., and Hail, W.J., Jr., 1975, Stratigraphic section across Upper Cretaceous Mancos Shale-Mesaverde Group boundary, eastern Utah and western Colorado: U.S. Geological Survey Oil and Gas Investigations Chart OC-68.

Gillespie, A.R., 1980, Digital techniques of image enhancement, in Siegal, B.S., and Gillespie, A.R., eds., Remote sensing in geology: New York, John Wiley, p. 139-226.

Graf, J.S., 1980, Bogging around: Science, May/June, p. 103-104.

Green, W.B., 1983, Digital image processing: Van Nostrand Rheinhold, $192 \mathrm{p}$.

Hantzschel, Walter, 1975, Treatise on invertebrate paleontology, trace fossils and problematica, in Teichert, C., dir. and ed.: Geological Society of America and University of Kansas, Part W, Miscellanea, $269 \mathrm{p}$.

Hassani, F.P., Scoble, M.J., and Whittaker, B.N., 1980, Application of the point load index test to strength determination of rock and proposals for a new size-correction chart, in Summers, D.A., compiler, The state-of-the-art in rock mechanics: Proceedings, U.S. Symposium on Rock Mechanics, 21st, Rolla, Mo., p. 543-565. 
Hayes, P.T., and Sanchez, J.D., 1979, Geologic map and coal resources of the Mery West quadrangle, Emery and Sevier Counties, Utah: U.S. Geological Survey Coal Investigations Map C-82.

Heim, A., 1912, Zur Frage der Gebirgs und Gesteinsfestigkeit: Schweisz. Bauztg., v. 50.

Hertzberg, Martin, Cashdollar, K.L., and Opferman, J.J., 1979, The flamability of coal dust-air mixtures: U.S. Bureau of Mines Report of Investigations 8360, $70 \mathrm{p}$.

Hoek, E., and Brown, E.T., 1980, Underground excavations in rock: London, Institution of Mining and Metallurgy, $527 \mathrm{p}$.

Hood, Michael, Ewy, R.T., and Riddle, L.R., 1981, Empirical methods of subsidence prediction-A case study, in Peng, S.S., and Harthill, Michalann, eds., Proceedings, Workshop on surface subsidence due to underground mining: Morgantown, W.Va., West Virginia University, p. 100-123.

Horne, J.C., Howell, D.J., Baganz, B.P., and Ferm, J.C., 1977, Splay deposits as an economic factor in coal mining, in Hodgson, H.E., ed., Proceedings of the Second Symposium of the Geology of Rocky Mountain Coal: Colorado Geological Survey Resource Series 4, p. 89-100.

Howard, J.D., 1972, Trace fossils as criteria for recognizing shorelines in stratigraphic record, in Rigby, J.K., and Hamblin, W.K., eds., Recognition of ancient sedimentary environments: Society of Economic Paleontologists and Mineralogists Special Publication 16, p. 215-225.

Howell, M., 1975, Improved geophysical techniques for survey of disturbed ground, in Bell, F.G., ed., Site investigations in areas of mining subsidence: London, Butterworth \& Co., Ltd., p. 103-108.

Iannancchione, A.T., and Puglio, D.G., 1979, Geology of the Lower Kittanning coal bed and related mining and methane emission problems in Cambria County, Pa.: U.S. Bureau of Mines Report of Investigations 8354, $31 \mathrm{p}$.

Jaeger, J.C., and Cook, N.G.W., 1979, Fundamentals of rock mechanics (3rd edition): London, Chapman and Hall, v. 18, $593 \mathrm{p}$.

Jeremić, M.L., 1981a, Effect of sub-coal strata on coal pillar stability: Coal Miner, v. 6, no. 1, p. 39-46.

1981b, Coal mine roadway stability in relation to lateral tectonic stress; western Canada: Mining Engineering, v. 33, no. 6, p. 704-709.

Johnson, R.C., and May, Fred, 1980, A study of the CretaceousTertiary unconformity in the Piceance Creek Basin, Colorado: The underlying Ohio Creek Formation (Upper Cretaceous) redefined as a member of the Hunter Canyon or Mesaverde Formation: U.S. Geological Survey Bulletin 1482-B, 27 p.

Johnson, Wilton, and Miller, G.C., 1979, Abandoned coal mine lands-Nature, extent, and cost of reclamation: U.S. Bureau of Mines, $29 \mathrm{p}$.

Jones, C.J.F.P., and Bellamy, J.B., 1973, Computer prediction of ground movements due to mining subsidence: Geotechnique, v. 23 , no. 4 , p. $515-530$.

Kaneshige, Osamu, 1971, The underground excavation to avoid subsidence damage to existing structures in Japan, in Symposium [on] geological and geographical problems of areas of high population density, Washington, D.C., 1970, Proceedings: Association of Engineering Geologists, p. 169-199.

Kanlybayeva, Z.M., 1964, Dynamics of displacement of a stratum under the influence of working gently dipping coal seams, based on geophysical data; Fourth International Conference on Strata Control and Rock Mechanics [translated from Russian by H. Frisch]: Canada Department of Energy Mines and Resources, 18 p., 1965.

Karmis, N., Chen, C.Y., Jones, D.E., and Triplett, T., 1982, Some aspects of mining subsidence and its control in the U.S. coal fields, in Brown, C.G., ed., Minerals and the environment: v. 4, no. 4, p. 116-130.

Katell, Sidney, Hemingway, E.L., and Berkshire, L.H., 1976, Basic estimated capital investment and operating costs for underground bituminous coal mines: U.S. Bureau of Mines Information Circular 8682-A, 41 p.

Kauffman, P.W., Hawkins, S.A., and Thompson, R.R., 1981, Room and pillar retreat mining: U.S. Bureau of Mines Information Circular 8849, $228 \mathrm{p}$.

Kent, B.H., 1974, Geologic causes and possible preventions of roof fall in room-and-pillar coal mines: Commonwealth of Pennsylvania Information Circular 75, $17 \mathrm{p}$.

Kent, B.H., and Arndt, H.H., 1980, Geology of the Carbondale coal mining area, Garfield and Pitkin Counties, Colorado, as related to subsurface hydraulic mining potential: U.S. Geological Survey Open-File Report 80-709, 94 p.

Kim, A.G., 1977, Laboratory studies on spontaneous heating of coal: U.S. Bureau of Mines Information Circular 8756, 13 p.

Klein, G.deV., 1977, Sandstone depositional models for exploration for fossil fuels: Continuing Education Publication Company, Inc., $110 \mathrm{p}$.

Kork, J.O., and Miesch, A.T., 1984, USGS STATPAC, spatial statistics, graphics, and digitizing programs of an IBM Personal Computer, in Peters, D.C., Urban, S.B., Dahm, J.N., Krajewshi, S.A., and Stewart, C.R., eds.: Geotech ' 84 , Sponsored by the American Institute of Professional Geologists and others, p. 25-28.

Kratzsch, Helmut, 1983, Mining subsidence engineering: Berlin, Heidelberg, New York, Springer-Verlag, 543 p.

Krausse, H.F., Damberger, H.H., Nelson, W.J., Hunt, S.R., Ledvina, C.T., Treworgy, C.G., and White, W.A., 1979, Roof strata of the Herrin [no. 6] coal member in mines of Illinois; their geology and stability: Illinois State Geological Survey, Illinois Minerals Note 72, $54 \mathrm{p}$.

Kunz, K.S., 1957, Numerical analysis: New York, McGraw-Hill, $381 \mathrm{p}$.

Kuti, Joseph, 1979, Longwall mining in America: Society of Mining Engineers Transactions, v. 266, p. 1593-1602.

Lahee, F.H., 1941, Field geology: New York, McGraw-Hill, 853 p.

Lang, H.R., Steven, L.A., Conel, J.E., McGuffie, B.A., Paylor, E.D., and Walker, R.E., 1987, Multispectral remote sensing as stratigraphic and structural tool, Wind River Basin and Big Horn Basin areas, Wyoming: American Association of Petroleum Geologists Bulletin, v. 71, no. 4, p. 389-402.

LeBlanc, R.J., 1975, Significant studies of modern and ancient deltaic sediments; deltas, models for exploration, in Broussard, M.L., ed.: Houston Geological Society, p. 13-85.

Lee, F.T., and Abel, J.F., Jr., 1983, Subsidence from underground mining-Environmental analysis and planning considerations: U.S. Geological Survey Circular 876, 28 p.

Lee, K.L., and Shen, C.K., 1969, Horizontal movements related to subsidence: American Society of Civil Engineers Proceedings, Journal of the Soil Mechanics and Foundations Division, v. 95, p. 139-166. 
Leeder, M.R., 1982, Sedimentology: London, George Allen and Unwin, $344 \mathrm{p}$.

Leonard-Mayer, P.J., 1984, A surface resistivity method for measuring hydrologic characteristics of joint formations: U.S. Bureau of Mines Report of Investigations 8901, 45 p.

Littlejohn, G.S., 1979, Surface stability in areas underlain by old coal workings: Ground Engineering, v. 12, no. 2, p. 22-30.

Matheson, G.M., 1987, Subsidence above abandoned underground coal mines-Weak rock overburden, in Building over underground mines-Subsidence considerations: Association of Engineering Geology Symposium series, No. 4, p. 63-81.

M'Gonigle, J.W., 1983, Use of aerial photography for geologic and coal-bed mapping in southwestern Wyoming, in Colwell, R.N., editor-in-chief, Manual of remote sensing ( $2 \mathrm{~d}$ edition, volume II): American Society of Photogrammetry, The Sheridan Press, p. 1805-1808.

McCulloch, C.M., 1976, Applying computer-drawn maps of geologic data to analysis of mining problems: U.S. Bureau of Mines Report of Investigations 8151, 26 p.

1977, The role of the geologist in coal mining, in Hodgson, H.E., ed., Proceedings of the Second Symposium of the Geology of Rocky Mountain Coal: Colorado Geological Survey Resource Series 4, p. 101-127.

McCulloch, C.M., Deul, Maurice, and Jeran, P.W., 1974, Cleat in bituminous coal beds: U.S. Bureau of Mines Report of Investigation 7910, $25 \mathrm{p}$.

McCulloch, C.M., Diamond, W.P., Bench, B.M., and Deul, Maurice, 1975, Selected geologic factors affecting mining of the Pittsburgh coal bed: U.S. Bureau of Mines Report of Investigations 8093, $72 \mathrm{p}$.

McCulloch, C.M., Lambert, S.W., and White, J.R., 1976, Determining cleat orientation of deeper coalbeds from overlying coals: U.S. Bureau of Mines Report of Investigations 8116,19 p.

Moebs, N.N., 1977, Roof rock structures and related roof support problems in the Pittsburgh coal bed of southwestern Pennsylvania: U.S. Bureau of Mines Report of Investigations $8230,30 \mathrm{p}$.

Moebs, N.N., and Ellenberger, J.L., 1982, Geologic structures in coal mine roof: U.S. Bureau of Mines Report of Investigations $8620,16 \mathrm{p}$.

Mohr, H.F., 1956, Influence of mining on strata: Mine and Quarry Engineering, v. 22, no. 4, p. 140-152.

Molnia, C.L., 1983, Use of the Kern PG-2 photogrammetric plotter in geologic and coal-bed mapping, Powder River Basin, northeastern Wyoming, in Colwell, R.N., editor-in-chief, Manual of remote sensing (2nd edition, volume II): American Society of Photogrammetry, The Sheridan Press, p. 1808-1812.

Moore, P.L., 1974, Drilling practice manual: Tulsa, Okla., Petroleum Publishing Co., 448 p.

Mousset-Jones, P.F., ed., 1980, Geostatistics: New York, McGraw-Hill, $168 \mathrm{p}$.

Nagy, John, and Mitchell, D.W., 1963, Experimental coal-dust and gas explosions: U.S. Bureau of Mines Report of Investigations $6344,27 \mathrm{p}$.

NCB (National Coal Board), 1975, Subsidence engineers' handbook: National Coal Board [United Kingdom], Mining Department, $111 \mathrm{p}$.
Nelson, J.W., 1983, Geologic disturbances in Illinois coal seams: Illinois Department of Energy and Natural Resources, State Geological Survey Division Circular 530, 47 p.

Oitto, R.H., 1979, Three potential longwall mining methods for thick coal seams in the western United States: U.S. Bureau of Mines Information Circular 8792, $34 \mathrm{p}$.

Olson, J.J., and Tandanand, Sathit, 1977, Mechanized longwall mining: U.S. Bureau of Mines Information Circular 8740 , $201 \mathrm{p}$.

O'Rourke, J.E., 1982, Monitoring subsidence in the west: problems and analysis, in Peng, S.S., and Harthill, Michalann, eds., Proceedings, Workshop on surface subsidence due to underground mining: Morgantown, W.Va., West Virginia University, p. 164-181.

Osen, Lars, Habberstad, J.L., Parsons, E.W., and Rodriguez, E.R., 1965, Load relations in preloaded rockbolt testing: U.S. Bureau of Mines Report of Investigations 6613, 24 p.

Osterwald, F.W., and Dunrud, C.R., 1965, Geology applied to the study of coal mine bumps at Sunnyside, Utah: Society of Mining Engineers Transactions, v. 232, no. 2, p. 168-174.

1966, Instrumentation study of coal mine bumps, Sunnyside district, Utah: Utah Geological and Mineralogical Survey Bulletin 80 , p. 97-110.

Overbey, W.K., Jr., Komar, C.A., and Pasini, J., III, 1973, Predicting probable roof fall areas in advance of mining by geological analysis: U.S. Bureau of Mines Health and Safety Research Technical Progress Report-70, $17 \mathrm{p}$.

Panek, L.A., 1974, Evaluation of roof stability from measurements of horizontal roof strain: U.S. Bureau of Mines Information Circular 8630, $138 \mathrm{p}$.

Pariseau, W.G., 1980, Inexpensive but technically sound mine pillar design analysis, in Summers, D.A., compiler, The stateof-the-art in rock mechanics: U.S. Symposium on Rock Mechanics, Rolla, Mo., p. 57-72.

Parker, Jack, 1973, Practical rock mechanics for the miner: Engineering and Mining Journals from August 1973 to 1974.

Parsons, E.W., and Osen, Lars, 1968, Transverse force produced by tensioned expansion-shell-type rock-bolt anchors: U.S. Bureau of Mines Report of Investigations 7087, $10 \mathrm{p}$.

Peng, S.S., 1978, Coal mine ground control: New York, John Wiley, $450 \mathrm{p}$.

1980, 3-D structural analysis of longwall panels, in Summers, D.A., compiler, The state-of-the-art of rock mechanics: U.S. Symposium on Rock Mechanics, 21st, Rolla, Mo., p. 44-66.

Peng, S.S., and Chyan, C.T., 1981, Surface subsidence, surface structural damages and subsidence predictions and modeling in the Northern Appalachian coal field, in Peng, S.S., and Harthill, Michalann, eds.: Proceedings, Workshop on surface subsidence due to underground mining: Morgantown, W.Va., West Virginia University, p. 73-84.

Perry, J.H., Aul, G.N., and Cervik, Joseph, 1978, Methane drainage study in the Sunnyside coalbed, Utah: U.S. Bureau of Mines Report of Investigations 8323, $11 \mathrm{p}$.

Pettijohn, F.J., Potter, P.E., and Siever, R., 1972, Sand and sandstone: New York, Springer.

Pettinger, L.R., 1982, Digital classification of Landsat data for vegetation and land-cover mapping in the Blackfoot River watershed, southeastern Idaho: U.S. Geological Survey Professional Paper 1219, 33 p. 
Pierce, F.W., Kent, B.H., and Grundy, W.D., 1982, Geostatistical analysis of a 113-billion-ton coal deposit, central part of the Powder River Basin, northeastern Wyoming, in Gurgel, K.D., ed., Proceedings, Fifth Symposium on the Geology of Rocky Mountain Coal: Utah Geological and Mineral Survey Bulletin 118 , p. 262-272.

Piggot, R.J., and Eynon, Peter, 1978, Ground movements arising from the presence of shallow abandoned mine workings, in Geddes, J.D., ed., Large ground movements and structures, Conference at the University of Wales Institute of Science and Technology, Cardiff, 1977, Proceedings: New York, John Wiley, p. 749-780.

Poad, M.E., Waddell, G.G., and Phillips, E.L., 1977, Single-entry development for longwall mining: U.S. Bureau of Mines Report of Investigations 8252, $29 \mathrm{p}$.

Pottgens, J.J.E., 1979, Ground movements by coal mining in the Netherlands, in Saxena, S.K., ed., Evaluation and prediction of subsidence, International Engineering Foundation Conferences, Pensacola Beach, 1978: American Society of Civil Engineers, p. 267-282.

Radcliffe, D.E., and Stateham, R.E., 1980, Stress distribution around resin-grouted bolts: U.S. Bureau of Mines Report of Investigations $8440,39 \mathrm{p}$.

Reichmuth, D.R., 1962, Correlation of force-displacement data with physical properties of rock for percussive drilling systems: Rock Mechanics, Proceedings, Fifth Symposium of Rock Mechanics, University of Minnesota, p. 44-52.

Rendu, Jean-Michel, 1982, Application of geostatistics to coal evaluation, in Gurgel, K.D., ed., Proceedings, Fifth Symposium on the Geology of Rocky Mountain Coal: Utah Geological and Mineral Survey Bulletin 118, p. 251-261.

Richmond, J.K., Price, G.C., Sapko, M.J., and Kawenski, E.M., 1983, Historical summary of coal mine explosions in the United States, 1959-1981: U.S. Bureau of Mines Information Circular $8909,51 \mathrm{p}$.

Rockaway, J.D., and Stephenson, R.W., 1982, Geotechnical evaluation of the support of coal pillars in underground coal mines: Association of Engineering Geologists Bulletin, v. 19, no. 1, p. 5-14.

Roehler, H.W., 1979, Geology and mineral resources of the Mud Springs Ranch quadrangle, Sweetwater county, Wyoming: U.S. Geological Survey Professional Paper 1065-C, 35 p.

Ropski, S., and Lama, R.D., 1973, Subsidence in the near-vicinity of a longwall face: International Journal of Rock Mechanics and Mining Sciences, v. 10, no. 2, p. 105-118.

Salamon, M.D.G., 1978, The role of linear models in the estimation of surface ground movements induced by mining tabular deposits, in Geddes, J.D., ed., Large ground movements and structures, Conference at the University of Wales Institute of Science and Technology, Cardiff, 1977, Proceedings: New York, John Wiley, p. 30-59.

Sanchez, J.D., and Hayes, P.T., 1979, Geologic map and coal resources of the Flagstaff Peak quadrangle, Emery, Sanpete, and Sevier Counties, Utah: U.S. Geological Survey Coal Investigations Map C-83.

Schatzel, S.J., Finfinger, G.L., and Cervik, Joseph, 1982, Underground gob gas drainage during longwall mining: U.S. Bureau of Mines Report of Investigations 8644, 14 p.
Shadbolt, C.H., 1975, Mining subsidence, in Bell, F.G., ed., Site investigations in areas of mining subsidence: London, Butterworth \& Co., Ltd,. p. 109-124.

1978, Mining subsidence-Historical review and state-ofthe-art, in Geddes, J.D., ed., Large ground movements and structures, Conference at the University of Wales Institute of Science and Technology, Cardiff, 1977, Proceedings: New York, John Wiley, p. 705-748.

Siegal, B.S., and Gillespie, A.R., 1980, Remote sensing in geology: New York, John Wiley, 702 p.

Stach, E., Mackowsky, M.T., Teichmuller, M., Teichmuller, R., Taylor, G.H., Chandra, D., 1975, Stach's textbook of coal petrology: Berlin, Stuttgart, $428 \mathrm{p}$.

Stephenson, H.G., and Allison, T.W., 1982, The coal geologist's role in underground coal mine safety, in Gurgel, K.D., ed., Proceedings, Fifth Symposium on the Geology of Rocky Mountain Coal: Utah Geological and Mineral Survey Bulletin 118, p. 137-142.

Stephenson, R.W., and Aughenbaugh, N.B., 1978, Analysis and prediction of ground subsidence due to coal mine entry collapse, in Geddes, J.D., ed., Large ground movements and structures, Conference at the University of Wales Institute of Science and Technology, Cardiff, 1977, Proceedings: New York, John Wiley, p. 100-118.

Stimpson, Brian, and Ross-Brown, D.M., 1979, Estimating the cohesive strength of randomly jointed rock masses: Mining Engineering, v. 31, no. 2, p. 182-188.

Sultan, Mohamed, Arvidson, R.E., Sturchio, N.C., and Guinness, E.A., 1987, Lithologic mapping in arid regions with Landsat thematic mapper data-Meatiq dome, Egypt: Geological Society of America Bulletin, v. 99, no. 6, p. 748-762.

Taylor, R.K., 1975, Characteristics of shallow coal-mine workings and their implications in urban redevelopment areas, in Bell, F.G., ed., Site investigations in areas of mining subsidence: London, Butterworth \& Co., Ltd., p. 125-148.

Thorburn, S., and Reid, W.M., 1978, Incipient failure and demolition of two- story dwellings due to large ground movements, in Geddes, J.D., ed., Large ground movements and structures, Conference at the University of Wales Institute of Science and Technology, Cardiff, 1977, Proceedings: New York, John Wiley, p. 87-99.

Van Besien, A.C., and Rockaway, J.D., 1987, Influence of overburden materials on the type and time required for subsidence development over room-and-pillar coal mines: Association of Engineering Geologists Symposium Series, No. 4, Building overunderground mines-Subsidence considerations, p. 51-62.

Vaninetti, G.E., Lloyd, Thomas, and Bonaquisto, Jack, 1980, Mine plan optimization through the use of geologic and fuel quality control programs, in Carter, L.M.H., ed., Proceedings of the Fourth Symposium on the Geology of Rocky Mountain Coal: Colorado Geological Survey Resource Series 10, p. 21-28.

Vaninetti, G.E., Gurr, K.D., and Dewey, R.S., 1982, Effect of geologic features on underground coal mine productivity, in Gurgel, K.D., ed., Proceedings, Fifth Symposium on the Geology of Rocky Mountain Coal: Utah Geological and Mineral Survey Bulletin 118, p. 129-142.

Varnes, D.J., 1978, Slope movement types and processes, in Schuster, R.L., and Krizek, R.J., eds., Landslides-Analysis and control: Transportation Research Board, Commission on 
Sociotechnical Systems, National Academy of Sciences, Special Report 176, p. 11-33.

Voight, Barry, and Pariseau, William, 1970, State of predictive art in subsidence engineering: Proceedings of the American Society of Civil Engineers, v. 96, Journal of the Soil Mechanics and Foundations Division, No. SM2, p. 721-750.

Wardell, K., 1954, Some observations on the relationship between time and mining subsidence: Transactions of the Institution of Mining Engineers, London, v. 113, p. 471-482.

1971, The effects of mineral and other underground excavations on the overlying ground surface, in Symposium [on] geological and geographical problems of areas of high population density, Washington, D.C., 1970, Proceedings: Association of Engineering Geologists, p. 201-217.

Whittaker, B.N., and Pye, J.H., 1977, Design and layout aspects of longwall methods of coal mining, in Design methods in rock mechanics, Proceedings, Sixteenth Symposium on Rock Mechanics: American Society of Civil Engineers, p. 303-314.

Widdicombe, R.E., Noon, P., and Best, D.L., 1984, Multiwell faciolog evaluation, Hartzog Draw field, Powder River Basin, Wyoming: SPWLA Twenty-Fifth Annual Logging Symposium, p. 1-19.
Wieczorek, G.F., 1984, Preparing a detailed landslide-inventory map of hazard evaluation and reduction: Association of Engineering Geologists Bulletin, v. XXI, no. 3, p. 337-342.

Williams, P.L., and Hackman, R.J., 1971, Geology, structure, and uranium deposits of the Salina quadrangle, Utah: U.S. Geological Survey Miscellaneous Investigations Map I-591, 2 sheets.

Williamson, D.A., 1984, Unified Rock Classification System: Association of Engineering Geologists Bulletin, v. 21, no. 3, p. 345-369.

Wilson, A.H., 1981, Stress and stability in coal ribsides and pillars: Proceedings of the First Annual Conference on Ground Control in Mining, West Virginia University, p. 1-12.

1982, Pillar stability in longwall mining, in Chugh, Y.P., and Karmis, Michael, eds., State-of-the-art of ground control in longwall mining and mining subsidence: Society of Mining Engineers of the American Institute of Mining, Metallurgical, and Petroleum Engineers, Inc., p. 85-105.

Wood, G.H., Jr., Kehn, T.M., Carter, M.D., and Culbertson, W.C., 1983, Coal resource classification system of the U.S. Geological Survey: U.S. Geological Survey Circular 891, 65 p.

Young, L.E., and Stoek, H.H., 1916, Subsidence resulting from mining: University of Illinois Bulletin 91, 205 p.

Published in the Central Region, Denver, Colorado Manuscript approved for publication July 25, 1995 Edited by Lorna Carter

Graphics by Bill Sowers and Springfield and Springfield Photocomposition by Joan G. Nadeau and Bill Sowers 
ISBN 0607-88571-8

(III) 